\title{
Sufismus und Futuwwa
}

\section{Männerbünde und ihre sozialen und religiösen Bezüge}

Die Untersuchungen von M. Gronke, Ch. Werner, E.S. Wolper und J. Pfeiffer machen übereinstimmend auf die politischen Instabilitäten im Städtedreieck zwischen Konya, Tabriz und Bagdad nach dem Einfall der Mongolen aufmerksam. Die breite Bevölkerung litt infolge der diffusen Machtverhältnisse ab der zweiten Hälfte des 13. Jh. unter vielfachen Unsicherheiten. Der Mongolensturm beschränkte sich aber nicht auf den Einfall von feindlichen Kriegern. Das Eindringen der Mongolen in den östlichen Teil der islamischen Welt löste vielmehr auch umfangreiche Migrationsbewegungen aus. Einerseits gelangten viele mongolischstämmige Turkvölker nach Iran und Ostanatolien. Die ortsansässigen Einwohner machten sich oft bereits auf die Flucht, bevor die Mongolen selbst in ihre frühere Heimat einfielen. In dieser gemeinhin als Khorasan bekannten Gegend lassen sich anderseits seit dem 12. und verstärkt dem 13. Jh. aber auch bedeutende religiöse Veränderungen beobachten. Davon ist in erster Linie die islamische Mystik (Sufismus) betroffen.

Es ist hier der inzwischen überholten Auffassung entgegenzutreten, dass es sich bei der islamischen Mystik (tașawwuf) um eine ausschliesslich auf das jenseitige Wohlergehen des Menschen ausgerichtete Erscheinung handle. Der Sufi wird zwar gern als weltabgewandter Eremit verstanden, der unbehelligt von den Entwicklungen und Umwälzungen in seinem Umfeld seine spirituellen Ziele zu realisieren versucht. Es soll auch nicht in Abrede gestellt werden, dass es im islamischen Kulturraum derartige weltabgewandte Mystiker tatsächlich gegeben hat. Allerdings deuten zahlreiche Beobachtungen darauf hin, dass Weltabgewandtheit zwar ein wichtiger Aspekt des SufiIdeals darstellt. ${ }^{1}$ Bereits ab dem 12. Jh. machen sich jedoch gerade im Osten der islamischen Welt Kräfte bemerkbar, die mystisches Erleben auch breiteren Kreisen der Bevölkerung zugänglich machen wollen und deren alltäglichen Sorgen Aufmerksamkeit schenken. In diesem Rahmen kommt es zur Bildung von mystischen Orden (țariqa, Pl. țuruq). ${ }^{2}$

In der frühen islamischen Mystik (bis etwa ins 12. Jh.) haben sich immer wieder Einzelpersonen durch ihren ausserordentlichen Charakter und ihre ganz individuelle Gotteserfahrung hervorgetan. Diese für die Anfänge der islamischen Mystik typische Situation soll hier nur im Vorbeigehen mit dem Hinweis auf einige zentrale Figuren verdeutlicht werden. Den weiteren Ausführungen sei die Bemerkung vorausgeschickt, dass der zur Bezeichnung der islamischen Mystik verwendete Begriff Sufismus gern mit dem Ausdruck șūf (Wolle) in Zusammenhang gebracht wird. Die Sufis wären demnach jene Männer und Frauen, die wollene Kleidung tragen und dadurch die für ihre Lebenshaltung charakteristische Armut (faqr) und Weltentsagung (zuhd) zum Ausdruck bringen. ${ }^{3}$

Die spätere Sufi-Literatur identifizierte im nachhinein bereits im unmittelbaren Umfeld des Propheten Muhammad verschiedene Persönlichkei-

1 Man beachte gerade auch die Praxis der vierzigtägigen Klausur (čilla); vgl. dazu unten Kapitel 3.4.2, nach Anm. 462.

2 Zum Prozess der Ordensbildung vgl. Trimingham Sufi orders 1-30, I. The formation of schools of mysticism; Knysh, Islamic mysticism v.a. 169-179 (Kapitel 8: The rise of the tarīqas). Zu einer modernen Definition der islamischen Mystik (tașawwuf) vgl. Green, Sufism u.a. 1-3.

3 Siehe dazu Knysh, Islamic mysticism 5, wo auch weitere Erklärungen des Ausdrucks Sufismus; Trimingham, Sufi orders 1. 
ten, die diesen Idealen nachlebten. ${ }^{4}$ Sie wären sozusagen als Sufis avant la lettre zu bezeichnen. Dazu zählen Abū Darr al-Ġifārī (gest. 32/652) Abu d-Dardā' (gest. 32/652) und seine Frau Umm ad-Dardā' ${ }^{3}$, Salmān al-Fārisī (gest. 35/655 oder $37 / 657)^{7}$, Hudayfa b. al-Yaman (gest. $\left.37 / 657\right)^{8}$ und 'Imrān b. al-Ḥusayn al-Hुuzāî̀ (gest. 53/672 oder $54 / 673)^{9}$.

Im frühen Sufismus (7.-9. Jh.) lässt sich ein auffälliges Nebeneinander von Gerichtsfurcht und Liebesmystik beobachten. In dieser ersten Entwicklungsphase nahm die asketische Haltung der Sufis einen zentralen Platz ein. Dies kommt u.a. im Leben Ḥasan al-Bașrīs (gest. 110/728) zum Ausdruck, der sich gerade durch seine negative Einstellung gegenüber dem Diesseits hervortat. ${ }^{10}$ Etwas später lebte Dū n-Nūn al-Mișrī (gest. 859 oder 245/86o). ${ }^{11}$ Erwähnung verdient sodann Ğunayd al-Bag̉dādī (gest. 298/910). ${ }^{12}$ Gern wird bei der Aufzählung wichtiger Vertreter der frühen Mystik mit Rābi'a al-'Adawiyya (ca. 95-185/714-801) auch auf eine Frau verwiesen. Für sie stellte die Liebe das zentrale Element in der Beziehung zwischen Gott und dem Menschen dar. ${ }^{13}$ Unter den frühen Frommen verdient überdies Abū Yazīd al-Basțāmī

4 Vgl. Knysh, loc. cit.

5 Afsaruddin, Abū Darr al-Ghifārī, in $E I^{3}$; Robson, Abū Dharr, in $E I^{2}$; Tayob, Abū Dharr al-Ghifārī, in The Oxford Encyclopedia of the Islamic World I, 23-24.

6 Vgl. Melchert, Abū l-Dardā', in $E I^{3}$; Jeffrey, Abu 'l-Dardā', in $E I^{2}$.

7 Levi Della Vida, Salmān al-Fārisī, in $E I^{2}$; Knysh, Islamic mysticism 5; Renard, Sufism 209f.; Schimmel, Mystische Dimensionen $5^{2} \mathrm{f}$.

8 Ḥudayfa b. al-Yaman zählt zu den Ahl aṣ-Ṣuffa; vgl. Tottoli, Ahl al-Ṣuffa, in $E I^{3}$.

9 Knysh, Islamic mysticism 5 f.

10 Ritter, Hasan al-Bașrī, in $E I^{2}$; Schimmel, Mystische Dimensionen $54-56$.

11 Vgl. Schimmel, Mystische Dimensionen 71-78, und ihr Index s.v. Dhu 'n-Nun; Mojaddedi, Dhū l-Nūn Abū l-Fayḍ al-Mișrī, in $E I^{3}$.

12 Vgl. Arberrry, Djunayd, in $E I^{2}$; Schimmel, Mystische Dimensionen 87-90, und ihr Index s. v.Junaid; Knysh, Islamic mysticism $5^{2-56 .}$

13 Zu ihr siehe Smith, Rābica; Knysh, Islamic mysticism 26 32.
(810-261/875) Erwähnung, ${ }^{14}$ auf den das Konzept des fan $\bar{a}$, des Entwerdens in Gott, zurückgehen dürfte. ${ }^{15}$ Dieses Bestreben erklärt sich aus monistischen Vorstellungen, kann neben Gott doch nichts anderes bestehen. Auch Manșūr al-Hallāğ war von Basțāmīs Auffassungen geprägt worden. ${ }^{16}$ Er hat für seine besondere Art der Annäherung an Gott einen hohen Preis bezahlt, ist ihm doch gerade wegen seines Ausrufs Anā l-haqq („Ich bin Gott.“) der Vorwurf der Ketzerei gemacht worden. Er wurde in Bagdad auf grausame Weise hingerichtet (309/922).

Obwohl Muhammad einen Kult um seine Person ablehnte, lässt sich doch bereits in dieser frühen Phase (ab dem 8. Jh.) die Entwicklung einer Muhammad-Mystik beobachten. ${ }^{17}$ In Muhammad hat sich das alles überstrahlende Licht Gottes manifestiert. Um die Person des Propheten entwickelte sich eine Lichtmystik, die um 900 voll ausgebildet war (nūr muhammadī). ${ }^{18}$ Aus dieser Verehrung des Propheten heraus - sie lässt sich auch in der breiten Bevölkerung beobachten - ging später das Konzept des vollkommenen Menschen (insān kāmil) hervor.

Während die spirituellen Erlebnisse individueller Gottsucher die Anfänge der islamischen Mystik prägen, lässt sich in einer zweiten Phase (ca. 10.-12. Jh.) eine Systematisierung dieser Erfahrungen beobachten. ${ }^{19}$ Die Verfasser von systematisch angelegten Werken sind darum bemüht, den zunehmend heftigeren Anfeindungen aus dem Umfeld des traditionalistisch orientierten Islams entgegenzutreten und Wesen und Zielsetzungen des Sufismus zu erklären. Zu diesem Schrifttum zählt Abū Ṭālib al-Makkīs (gest. 386/996) Qūt

14 Vgl. Mojaddedi, al-Bisțāmī, Abū Yazīd (Bāyazīd), in $E I^{3}$.

15 Vgl. Schimmel, Mystische Dimensionen, 207-213; Knysh, Islamic mysticism u. a. 69-72.

16 Vgl. Schimmel, Mystische Dimensionen, 100-120, und ihr Index s.v. Hallaj; Knysh, Islamic mysticism 72-82.

17 Schimmel, Mystische Dimensionen $305 \mathrm{f}$.

18 Vgl. Rubin, Nūr muhammadī, in $E I^{2}$; derselbe, Preexistence and light.

19 Siehe Ernst, Eternal garden 9-13 ( $\left.{ }^{2} 2004\right)$; Creming, Sufismus $144 \mathrm{f}$ 
al-qulūb. ${ }^{20}$ Ebenso hierhin gehört Abū Nașr asSarrāğs Kitāb al-luma ', das die Aussagen bedeutender Vertreter der islamischen Mystik zusammenstellt. ${ }^{21}$ Ähnliche Zielsetzungen verfolgen Sulamī (gest. 937/1021) in den aț-Ṭabaqāt aș-șūfiyya ${ }^{22}$ und Qušayrī (gest. 465/1072) in seiner berühmten Risāla. ${ }^{23}$ Huğwīì̄ (gest. ca. 465/1072) wiederum stellt in seinem persischen Kašf ul-mahğūb die Lehren und Biographien wichtiger Sufis zusammen. ${ }^{24}$ Ähnliche Feststellungen treffen auf 'Ațtāars (gest. ca. 618/1221) Tadkirat ul-awliyā' zu. ${ }^{25}$ 'Umar as-Suhrawardī (1145-1234) seinerseits hielt die Lehren und Übungen des Sufismus in einer konzisen Übersicht fest. ${ }^{26}$

Im Zusammenhang mit der Mystik sind in dieser zweiten Phase auch mehrere Autoren zu erwähnen, die zugleich als Philosophen tätig waren. Dazu zählt u.a. Ibn Sīnā (gest. 428/1037), der mehrere Schriften esoterischen Inhalts verfasst hatte. ${ }^{27}$ Hierhin gehört sodann Abū Hāmid al-Ġazzālī (gest. 505/1111). ${ }^{28}$ Er vertrat gemässigte Positionen und bemühte sich darum, die traditionalistisch orientierte Theologie und die islamische Mystik miteinander in Einklang zu bringen. Im Gegensatz zu andern Mystikern war Gazzālī unter den Seldschuken (431-59o/1040-1194) auch politisch aktiv. Sein Bruder Ahmad-i Ġazzālī (gest. 520/1126) wiederum war Mystiker im engeren Sinn, wie sich anhand seiner Aphorismensammlug Sawānih aufzeigen lässt. ${ }^{29}$ Auch Ibn 'Ara-

20 Ohlander, Abū Țālib al-Makkī, in $E I^{3}$; Knysh, Islamic mysticism 121 f.; al-Makkī, Die Nahrung der Herzen.

21 Lory, al-Sarrādj, in $E I^{2}$; Knysh, Islamic mysticism 118-120; Sarrāğ, Schlaglichter.

22 Böwering, al-Sulamī, in $E I^{2}$; vgl. Schimmel, Mystische Dimensionen 130-133; Knysh, Islamic mysticism 125-127.

23 Vgl. Halm, al-Kushayrī, in $E I^{2}$; Knysh, Islamic mysticism 130-132.

24 Hidayet und Massé, Hudjwīrī, in $E I^{2}$; Knysh, Islamic mysticism 132-135.

25 Vgl. Omid, 'Aț̣āar, Farīd al-Dīn, in $E I^{3}$; Ritter, Meer der Seele.

26 Knysh, Islamic mysticism $195^{-203}$ und 203-207.

27 Vgl. Mahdi et al., Avicenna, in EIr.

28 Böwering et al., Ḡazālī, Abū Hāmed Mohammad, in EIr.

29 Pourjavadi, Ḡazālī, Majd-al-Dīn Abu'l-Fotūḥ Aḥmad, in EIr. bīs (gest. 638/1240) Name darf in einer Aufzählung bedeutender Philosophen-Mystiker nicht fehlen. ${ }^{30}$

Die soeben angeführten Mystiker haben vor 1250 gelebt. Zwar gibt es selbstredend auch nach der Mitte des 13. Jh. immer wieder Einzelpersonen, deren Ruf auf ihrer ausserordentlichen Frömmigkeit beruht. Allerdings besteht die bedeutendste Entwicklung in der islamischen Mystik ab dem 13. Jh. doch darin, dass sie sich zunehmend für breitere Kreise der Bevölkerung öffnet. Damit ist auch eine grundlegende Veränderung ihrer Organisation und Strukturen verbunden. Es kommt ab dem 13. Jh. zur Ausbildung von Orden (tarìqa, Pl. turuq). Diese Entwicklung geht mit einer Systematisierung des mystischen Erlebens selbst einher. ${ }^{31}$

Diese Prozesse waren bereits im 12. Jh. - und ansatzweise im 11. Jh. - in Gang gekommen, setzten sich aber in indirekter Abhängigkeit vom Mongolensturm nach 1250 mit erhöhter Intensität fort. Sie führen auf dem Gebiet der islamischen Mystik zur Ausbildung von Derwischorden und weiteren damit wesensverwandten Vereinigungen. $\mathrm{Zu}$ diesen Vereinigungen gehören die FutuwwaBünde (13. Jh.), die Ahī-Bruderschaften (14. Jh.) und die Handwerksgilden (șinf; Pl. așnāf; 15.-16. Jh.). ${ }^{32}$ Diese Männerbünde lassen sich oft kaum voneinander unterscheiden. Die vorangehenden historischen Ausführungen haben auch verdeutlicht, dass derartige aus Männerbünden entstandene Gruppierungen in die machtpolitischen Entwicklungen eingriffen. Die weiteren Ausführungen befassen sich aber nicht mit diesen machtpolitischen Aspekten, sondern gehen in erster Linie den weltanschaulichen Auffassungen und Zielen dieser Gruppierungen nach.

H.J. Kissling hat sich wiederholt mit den Eigenheiten des Derwischtums befasst und den Verhältnissen in Anatolien besondere Beachtung

30 Chittick, Ebn al-'Arabī, in EIr; Knysh, Islamic mysticism 163-168.

31 Siehe Ernst, Eternal garden 14f. ( $\left.{ }^{2} 2004\right)$; Green, Sufism $81 \mathrm{f}$.

32 Diese Gruppierungen werden später eingehender vorgestellt; vgl. Kapitel 3.2. 
geschenkt. ${ }^{33}$ Er versteht Derwischorden grundsätzlich als Männerbünde. Wegen ihrer eindeutig religiösen Ausrichtung sind Derwischorden gerade im Westen mit dem Mönchtum verglichen worden. Eine derartige Angleichung ist allerdings allein schon daher unstatthaft, da im Islam ein gesellschaftliches Gegenstück zur christlichen Kirche fehlt. Die christlichen Mönchsorden zeichnen sich in religiösen Fragen durch eine grosse Linientreue aus. Sie stellen wichtige Knotenpunkte im übergeordneten Kirchengefüge dar. Das Fehlen kirchlicher Strukturen im Islam verbietet aber eine derartige Funktion von Derwischorden. Diese Bemerkungen zeigen auch auf, dass es sich bei den Derwischorden und weiteren Männerbünden nicht um eine Vorausabteilung eines traditionalistisch orientierten Islams handelt.

Die Derwischorden sind nicht aus der von den Gelehrten ('ulama $\bar{a}$ ) getragenen islamischen Orthodoxie heraus entstanden. Sie weisen vielmehr enge Bezüge zu den religiösen Auffassungen und hergebrachten Vorstellungen auf, wie sie aus der breiten Bevölkerung bekannt sind (Volksislam). In den Derwischorden lassen sich zahlreiche Auffassungen feststellen, die von grundlegenden Dogmen des Islams abweichen und eine grosse Nähe zu unter dem Oberbegriff Schia, gerade auch der Ġulät-Schia, bekannten religiösen Strömungen aufweisen. ${ }^{34}$

Die Schia entwickelte sich früh zu einer eigentlichen Anti-Bewegung. Diese Feststellung trifft sowohl in politischer als auch religiöser Hinsicht zu. Die Schia fungiert unter diesen Voraussetzungen als Sammelbecken unterschiedlichster Kreise mit heterodoxen Auffassungen und auch unter sich selbst verfeindeter Gruppierungen. Im Lauf dieser Entwicklungen fanden auch nichtislamische Vorstellungen, gerade solche neoplatonischer Natur, Eingang in die Schia. Dies war mit der Ausbildung eigentlicher Häresien verbunden.

33 Kissling, Derwischorden; derselbe, Dervish orders in the Ottoman Empire.

34 Kissling, Derwischorden $2 \mathrm{f}$.
Die Spannweite der in der einstigen Partei 'Alīs (š̌́at 'Alī) vertretenen Auffassungen vergrösserte sich in kurzer Zeit. Sie umfasste die der Orthodoxie eng verbundene Fünfer-Schia (Zaydiyya). Die Siebner-Schia, auch als Ismā îliyya bekannt, spielte während der Kreuzzugszeit eine wichtige Rolle. Die Mongolen hatten dieser im Westen auch als Assassinen bekannten Gruppierung mit der Einnahme ihrer Festung Alamut (1256) einen herben Rückschlag versetzt. Zum grossen Gebilde der Schia gehört ebenso die Zwölfer-Schia, auch als Imāmiyya bekannt, die im Jahr 1501 in Iran zur Staatsreligion proklamiert wurde. Zur Schia zählen sodann unterschiedliche extremistisch ausgerichtete Gruppierungen ( $\dot{G} u$ lät-Schia). Ihr Extremismus äussert sich primär darin, dass sie in Imam 'Alī eine Verkörperung Gottes erkennen. ${ }^{35}$

Die vielfältigen Überbleibsel vorislamischer religiöser Vorstellungen fanden gerade unter dem Deckmantel der 'Alī-Verehrung eine neue Heimat. ${ }^{36}$ In diesen oft auch politisch motivierten Gruppierungen konnten neoplatonische Ideen und indisches Gedankengut ebenso gedeihen wie mystisch-pantheistische Auffassungen. Überdies gelangten im Gefolge des Mongolensturms religiöse Vorstellungen aus Zentralasien (z.B. Schamanismus) nach Westen. ${ }^{37}$ All diesen Strömungen gemeinsam ist, dass sie oft nur oberflächlich ein islamisches Gepräge angenommen hatten. Zugleich machen sich in diesen Entwicklungen aus dem Sufismus bekannte Ideen bemerkbar. Einzelne Gruppierungen aus dem Umfeld der Schia und aus jenem des Sufitums näherten sich

35 Moosa, Extremist Shiites Ix: „Members of these [Ghulāt] sects $[. .$.$] share common religious beliefs, the most fun-$ damental being that the Imam Ali [...] is God." Auch den weiteren schiitischen Imamen werden gern gottähnliche Züge zugeschrieben. Zur Gulāt-Schia vgl. bereits Kapitel 2, vor Anm. 147 und bei Anm. 224-225; auch Kapitel 3.1.3, bei Anm. 115-118.

36 Kissling, Derwischorden 3.

37 Vgl. zu den Einflüssen aus dem Schamanismus oben Kapitel 2, bei Anm. 22-23 und Anm. 99; siehe auch einen Hinweis bei Eliade, Shamanism 402 f., auf Barāq Bābā. Man beachte überdies Köprülüzade, Influence du chamanisme 14-19. 
einander an, da sie in der 'Alī-Verehrung und im Imam- bzw. Mahdī-Kult wesentliche Gemeinsamkeiten zu erkennen glaubten. Zahlreiche Derwischorden weisen eine grosse Nähe zu 'alidischschiitischen Auffassungen auf. Dies kommt auch darin zum Ausdruck, dass ihre silsila häufig auf 'Alī b. Abī Ṭālib zurückgeht. ${ }^{38}$ Dies ist selbst dann der Fall, wenn der betreffende Orden eigentlich zur Sunna gehört. Allerdings ist hier doch anzumerken, dass diese silsilas einer historischkritischen Überprüfung zumeist nicht standhalten. ${ }^{39}$ Sie bringen jedoch die in diesen Gruppierungen herrschenden Grundhaltungen gut zum Ausdruck. Die älteren Glieder in dieser silsila sind den meisten Orden gemeinsam und werden als klassischer isnād bezeichnet.

H.J. Kissling charakterisiert dieses Nebeneinander von religiösen Vorstellungen unter der breiten Bevölkerung in der islamischen Welt, vornehmlich ausserhalb Arabiens, als „organisierte Mystik“. Der Begriff „organisierte Vorhofreligion“ charakterisiert das Wesen der Derwischbünde am besten. Die in diesem Umfeld vertretenen Auffassungen bilden den ideologischen Nährboden, auf dem die Derwischorden ab dem 12. und 13. Jh. gedeihen können. In Anatolien finden diese Orden erst im 14. und 15. Jh. ihre definitive Ausbildung. ${ }^{40}$

Die Ursprünge dieser Volksbewegung verlieren sich im Dunkeln. Man bringt ihren Aufstieg zumeist mit den grossen Migrationsströmen in Verbindung, die durch das Vordringen der Mongolen nach Westen ausgelöst worden sind. Dies führte zu einer Masseninvasion von Wanderderwischen aus Zentralasien und Khorasan (NordostIran) nach Anatolien und letztlich bis nach Rumelien. ${ }^{41}$

38 Eine gewichtige Ausnahme ist die Naqšbandiyya, die auf Abū Bakr zurückgeht; zur Naqšbandiyya vgl. Knysh, Islamic mysticism 221-234, und sein Index s.v. „Naqshbandiyya" (345); Öztürk, The eye of the heart 107-109.

39 A. Kasrawī hat dies für die Șafawiyya exemplarisch aufgezeigt; vgl. Kapitel 2, Anm. 154.

40 Kissling, Derwischorden 4.

41 Loc. cit.
Auch H. Sohrweide macht darauf aufmerksam, ${ }^{42}$ dass im Verlauf dieser Invasionen, zuerst jener der Seldschuken, dann jener der Mongolen, zahlreiche türkische Scheiche (türkisch: $b \bar{a} b \bar{a}$, dede) nach Westen gekommen seien. Im 13. Jh. habe es sich bei ihnen häufig um Qalandarund Yasawiyya-Derwische gehandelt. Sie seien v.a. unter den türkischen und mongolischen Nomadenstämmen aktiv gewesen. Man konnte ihnen jedoch auch in den Städten und an den Fürstenhöfen begegnen. Sie hätten einen mystisch geprägten Islam mit 'alidischem Hintergrund vertreten. Unter den Stämmen sei das althergebrachte Brauchtum aus Zentralasien leicht islamisiert weitergepflegt worden. Die Städter hätten in den Angehörigen dieser Nomadenstämme und ihren Scheichen jedoch Häretiker gesehen.

Bereits die Ausführungen zu den historischen Entwicklungen enthielten Hinweise auf den Aufbau von Derwischorden, wobei die Șafawiyya in Ardabil im Vordergrund stand. ${ }^{43}$ Es ist dennoch angezeigt, hier nochmals auf allgemeine Merkmale dieser Gruppierungen hinzuweisen. ${ }^{44}$ Bei der kleinsten Einheit, die sich noch als Bundesgebilde bezeichnen lässt, handelt es sich um die zāwiya (arabisch), den ḩānaqāh (persisch) bzw. die tekke (türkisch). Der Begriff wird gern mit „Derwischkloster“ übersetzt, wobei der Ausdruck „Konvent“ unverfänglicher ist. Hier lebt eine kleine Zahl von Ordensbrüdern zusammen. Die Quellen bezeichnen bereits Zentren mit 25-30 Derwischen als gross. Diese Derwische sind einem Vorsteher (arabisch: šayh; persisch: pīr; türkisch: bābā, dede) unterstellt und ihm zu bedingungslosem Gehorsam verpflichtet. Die Ordensbrüder nehmen in ihrem Konvent bestimmte Aufgaben wahr. Es soll hier besonders auf die als murìd bekannten Novizen hingewiesen werden. Sie werden nach einer mehrjährigen Ausbildung als Vollmitglieder in den Orden aufgenommen, was ihnen in einer iğăza

42 Sohrweide, Safaviden $101 \mathrm{f}$.

43 Vgl. oben Kapitel 2.4.

44 Kissling, Derwischorden 4 f. 
(Befähigungszeugnis) bestätigt wird.$^{45}$ Diese Konvente bieten übrigens Fremden ohne Rücksicht auf ihre Glaubensauffassungen gastliche Aufnahme an und unterstützen die Bedürftigen.

Ein Orden verfügt häufig über mehrere Nebenkonvente, deren Beziehungen zum Stammkonvent unterschiedlich stark ausgebildet sind. In straff organisierten Gruppierungen bleiben auch die Tochterkonvente eng mit dem Hauptzentrum des Ordens verbunden. Die Mawlawiyya mit ihrem Zentrum in Konya stellt ein gutes Beispiel für einen straff organisierten Orden dar. Weniger deutlich entwickelt sind die Bindungen im Fall der Bektāšiyya, deren Stammhaus im heute nach dem Ordensgründer Ḥācı Bektaş benannten Ort liegt. ${ }^{46}$ Im Fall der Halwatiyya lassen sich derartige Abhängigkeiten kaum noch feststellen. Sie stellt ein Konglomerat von Einzelzweigen dar, die je einen eigenen Namen haben und sich oft $\mathrm{zu}$ einem eigenständigen Orden entwickelt haben.

Die Zahl der tatsächlich in den Konventen lebenden Angehörigen eines Ordens ist verhältnismässig gering. Allerdings lässt sich um diesen innern Kreis der Ordensbrüder ein deutlich zahlreicherer äusserer Kreis feststellen. ${ }^{47}$ Diese Mitglieder führen weiterhin ein weltliches und privates Leben, nehmen jedoch regelmässig an religiösen Übungen im lokalen Ordenszentrum teil. Ausserdem lässt sich um diese dem Orden enger verbundenen Mitglieder herum eine sehr grosse Zahl von Sympathisanten beobachten. Sie dominieren oft ganze Landstriche, wie sich dies im Fall der Bektāšiyya in späterer Zeit in Albanien beobachten lässt. In solchen Konstellationen kann aber nicht mehr von Männerbünden die Rede sein; es handelt sich vielmehr um Kongregationen oder sogar sektenähnliche Gebilde.

Die Entstehung dieser Derwischorden ist im einzelnen nicht geklärt. Es ist aber typisch, dass sie sich um einen heiligmässigen Vorsteher herum

45 Für eine solche iğāza aus der Rifāiyya vgl. Staatsbibliothek Berlin, Ms. or. fol. 1622.

46 Hāà Bektaş zwischen Ankara und Kayseri.

47 Kissling, Derwischorden 5. ausbilden, der sich durch sein persönliches Charisma auszeichnet. ${ }^{48}$ Die Forschung hat wiederholt darauf hingewiesen, dass sich diese Entwicklungen anfänglich v.a. in Zentralasien, besonders in Khorasan, feststellen lassen. ${ }^{49}$ Im Zentrum des Ordens steht dessen Stifter, wobei bei der Feststellung der eigentlichen historischen Verhältnisse grösste Vorsicht angebracht ist, haben diese Männerbünde doch die Tendenz, sich ein möglichst hohes Alter zuzuschreiben.

Die Angehörigen und Sympathisanten dieser Männerbünde stammen oft aus proletarischen Umfeldern und unterscheiden sich dadurch von den Religionsgelehrten des Hochislams ('ula$\left.m \bar{a}^{\jmath}\right) .{ }^{50}$ Die Aufnahme in einen Derwischorden ist aber nicht an eine bestimmte gesellschaftliche Stellung oder intellektuelle Bildung gebunden. Häufig wird die Vermutung geäussert, dass "gelehrte Typen in den Derwischorden nicht einmal besonders erwünscht waren“ (H.J. Kissling). Zwar lassen sich auch weibliche Derwische nachweisen. Sie stellen allerdings eher eine Begleiterscheinung dar, handelt es sich bei den Derwischorden von ihrer Natur her doch um Männerbünde.

Die traditionalistisch ausgerichtete islamische Theologie nahm an den in Derwischkreisen gepflegten religiösen Auffassungen und Bräuchen Anstoss, da sie ihr aus unterschiedlichen Gründen suspekt erschienen. Die oft übersteigerte Verehrung 'Alīs war nicht einmal der hauptsächlichste Kritikpunkt, denn auch in sunnitischen Kreisen wurde und wird 'Alī grosse Wertschätzung ent-

48 Die Bezeichnung „heiligmässige Männer“ wurde von H.J. Kissling geprägt; vgl. z.B. seinen Aufsatz Die islamischen Derwischorden 10. B.S. Amoretti nennt dieselben Personen Häresiarchen und rückt damit eine weitere, ebenso bedeutende Facette ihres Wirkens in den Vordergrund (Religion in the Timurid an Safavid Periods, in $\mathrm{CHI}$ VI, 611).

49 Vgl. Knysh, Islamic mysticism 169-244, Kapitel 8: Unity and diversity in Sufism: The rise of the tarīqas; beachte v.a. die Beispiele der Naqšbandiyya (218-234) und der Kubrāwiyya (234-239).

$5^{\circ}$ Kissling, Derwischorden $6 \mathrm{f}$. 
gegengebracht. ${ }^{51}$ Problematischer waren die oft kaum verhüllten pantheistischen Neigungen dieser Gruppierungen. Auch ist dem Umstand Beachtung zu schenken, dass in den Derwischorden das alte Glaubensgut und Brauchtum der erst frisch und nur oberflächlich zum Islam konvertierten, oft aus Zentralasien eingewanderten Stämme weitergepflegt wurde. Dies führte zur Ausbildung eines von synkretistischen Elementen geprägten Islams.

In ihrer ekstatischen Verfassung verfügen die Derwische über ausserordentliche Fähigkeiten. Sie sind in der Lage, Krankheiten zu heilen, können aber auch weitere Wunder wirken. Die Vorsteher der Derwischorden verfügen über diese Fähigkeiten in besonderer Weise. Das Volk schreibt ihnen deshalb heiligmässige Eigenschaften zu und verehrt sie wegen ihrer Segenskraft (baraka). Es liegt in der Natur der Sache, dass sich diese ausserordentlichen Fähigkeiten der Derwisch-Šayhs einer wissenschaftlichen Analyse stricto sensu entziehen. Jedenfalls rücken die Berichte über derartige Wunder die Derwische in bedrohliche Nähe zu den Zauberern (sāḥir), den Medizinmännern bei Naturvölkern oder medial veranlagten Personen, wie sie aus der Moderne bekannt sind. Gewiss ist auch, dass jeder Derwisch-Vorsteher von einem gewissen Format darauf bedacht war, seine Gottesnähe (walāya $)^{52}$ durch solche Huldwunder (karāma) unter Beweis zu stellen.

An diesem Punkt geht das Derwischtum in die Heiligenverehrung und ins Pilgerfahrtswesen über, die von traditionalistisch orientierten Theologen beide mit ebenso grossem Argwohn beobachtet wurden wie die Zauberei $($ sihr $) .{ }^{53}$ Die Kritik der Orthodoxie erklärt sich damit, dass sie den Heiligenkult in seinem Kern als Polytheismus (širk) versteht. Allerdings war die Heiligenverehrung im

51 'Alī b. Abī Ṭālib ist zwar der erste Imam der Schiiten. Er ist aber zugleich der vierte rechtgeleitete Kalif der Sunniten. Die 'Ali-Verehrung war unter Sunniten im Nachgang des Mongolensturms gerade im 14. Jh. weit verbreitet (siehe dazu Kapitel 3.3).

52 Zur wilāyat vgl. Walker, Wilāya, 2. In Shicism, in $E I^{2}$.

53 Man vergleiche dazu u. a. Ibn Taymiyyas Angriffe auf den Heiligenkult: Olesen, Culte des saints.
Volk derart tief verwurzelt, dass der Schulislam sie stillschweigend dulden und einen modus vivendi damit finden musste. Gerade die Bektāšiyya liess sich an jenen Stätten nieder, wo bereits vor der Islamisierung Heilige, zumeist christliche Heilige, verehrt worden sind. Dieses Phänomen ist unter dem Begriff der „utraquistischen Heiligen“ bekannt. ${ }^{54}$ Diese Voraussetzungen haben synkretistische Entwicklungen selbstredend begünstigt.

Entscheidend ist nun, dass sich in der islamischen Welt auch immer wieder lebendige Heilige nachweisen liessen. Bei ihnen handelt es sich zumeist um Derwische, gerade um DerwischŠayhs. Wenn den von Derwischen gewirkten Wundern auch viel Lug und Trug zugrunde liegen mag, beeindruckten die entsprechenden Fähigkeiten doch gerade das breite Volk. Diese ausserordentlichen Fähigkeiten erklären auch, dass die Derwischorden derart grosse Bedeutung erlangen konnten.

H.J. Kissling macht darauf aufmerksam, dass die Heiligen im Islam gemäss ihren Fähigkeiten in unterschiedliche Kategorien eingeteilt werden. ${ }^{55}$ Jedenfalls müssen die an den Heiligen gerichteten Gebete erhört werden. Der wahre Heilige muss mustağ $\bar{a} b$ ad-du' $\bar{a}^{3}$ sein. ${ }^{56}$ Diese Heiligen sind in der Lage, durch ihre Fürbitte (šafāa) individuelle und kollektive Sorgen und Ängste zu beheben. Sie heilen Krankheiten oder verhindern Seuchen und Naturkatastrophen (z.B. Dürren, Überschwemmungen). Bedeutendere Heilige verfügen über die Fähigkeit der firāsa und können somit die Gedanken ihres Gegenübers lesen. Auch ist ihnen Kunde des Verborgenen ( $\dot{g} a y b)$ zuteil geworden. Ganz besondere Verehrung geniesst, wer sich durch Ubiquität (tațawwur) auszeichnet, also

54 Zum Phänomen der utraquistischen Heiligen siehe Kissling, Derwischorden 9.

55 Kissling, Derwischorden 9 f.; vgl. Arnakis, Futuwwa traditions 243 (mit Anm. 67).

56 Der Ausdruck du'áa mustağāb lässt sich auf verschiedenen Dokumenten in Rollenform nachweisen; vgl. dazu Kapitel 4.1 (Anm. 40: Yā muğ̄̌b ad-da'wāt); Kapitel 4.8, bei Anm. 303-348. Zum Begriff mustağāb ad-du'ấ' selbst vgl. Kissling, Derwischorden 9. 
an mehreren Orten gleichzeitig auftreten kann. ${ }^{57}$ Auch gibt es Heilige, die Tote wieder zum Leben erwecken können.

Die Derwischorden und mit ihnen eng verwandte weitere Gruppierungen vermittelten den breiten Massen der Bevölkerung in den Zeiten grosser Not nach dem Einfall der Mongolen spirituellen Halt. Ihre unbestrittenen Erfolge erklären sich auch damit, dass dem Hochislam eine Seelsorge im weitesten Sinn des Wortes fehlt. Indem die traditionalistisch ausgerichteten Theologen die Ratsuchenden in ihrer Not mit Koransprüchen abspeisen, werden sie ihnen in keiner Weise gerecht. Die Derwischorden, gerade ihre charismatischen Vorsteher, füllen diese Lücke mit Erfolg.

Dem Derwischwesen sind aber auch schwerwiegende Gefahren inhärent. ${ }^{58}$ Dazu zählt der unbedingte Gehorsam, zu dem der Novize gegenüber seinem Šayh verpflichtet ist. Solange der Ordensvorsteher seinen Aufgaben moralisch-ethisch gewachsen ist, stellt dies zwar kein Problem dar. Andernfalls kann der vom murìd geforderte Kadavergehorsam zur moralischen Anarchie führen. In diesem Zusammenhang verdient auch Erwähnung, dass sich gewisse Derwische aufgrund ihres heiligmässigen Charakters nicht mehr zum Einhalten der šarîa-rechtlichen Bestimmungen verpflichtet fühlten. Sie lebten $b \bar{c}$-šar (gesetzlos) und unterschieden sich damit von jenen Ordensangehörigen, die šarīa-rechtliche Bestimmungen respektierten, und somit $b \bar{a}$-šar ${ }^{c}$ lebten. ${ }^{59}$

Gerade aus dem 14. Jh. sind Derwische in grösserer Zahl bekannt, die dem Einhalten der šarīa einen geringen Stellenwert zuweisen. Dazu gehören einerseits Einzelpersonen, z.B. Barāq Bābā $\left(655^{-707 / 1257-1307)^{60}}\right.$ oder Șarı Șalțūq Dede (13. Jh.). ${ }^{61}$ Anderseits gibt es Orden, deren Angehörige sich keinen Deut um das Einhalten der šarî̃a-

57 Loc. cit.

$5^{8}$ Kissling, Derwischorden 10.

59 Vgl. dazu Kissling, Zejnîje-Orden 323 (Anm. 41).

6o Vgl. zu ihm Algar, Barāq Bābā, in EIr; Karamustafa, Baraq Baba, in $E I^{3}$; ders., God's unruly friends $1 \mathrm{f}$. und $62 \mathrm{f}$.

61 Vgl. zu ihm Leiser, Sarı Saltūk Dede, in $E I^{2}$; Karamustafa, God's unruly friends 62 . rechtlichen Bestimmungen scherten. Dazu zählen die Qalandariyya ${ }^{62}$ und Malāmatiyya ${ }^{63}$. Die in ihrem Kern häufig so oder so lockere Einstellung gegenüber šarīa-rechtlichen Regeln im Umfeld von Derwischorden kommt auch darin zum Ausdruck, dass es durchaus üblich geworden war, die ekstatischen Zustände durch unterschiedliche Stimulanzien herbeizuführen. ${ }^{64}$ So wurde der Alkoholgenuss in gewissen Orden toleriert. Ausserdem ist der Gebrauch von Haschisch und weiteren Drogen belegt. In späterer Zeit waren Angehörige der Bektāšiyya als Schnapssäufer verschrieen. Im 17.Jh. breiteten sich Kaffee und Tabak im Osmanischen Reich gerade im Umfeld der Derwischbruderschaften aus.

Da die Aktivitäten der Derwischorden häufig politisch motiviert waren, sahen sie sich genötigt, im Untergrund zu agieren. Die Furcht der Angehörigen von Derwischorden und ihrer Sympathisanten vor Verfolgungen durch rechtgläubige Kreise waren durchaus berechtigt. Es kann auf das Schicksal Badr ad-Dīn b. Qāḍi Samāwnās hingewiesen werden. Er organisierte 1416 einen gewaltigen Derwischaufstand und wurde dafür hingerichtet. ${ }^{65}$ Dieser Aufstand stellte eine tiefgreifende Krise im alten Osmanischen Reich dar und konnte nur mit einem massiven Truppenaufgebot niedergeworfen werden.

Ähnliche Verfolgungen sind auch aus späterer Zeit bekannt. Angesichts dieser unablässigen Bedrohungen nahmen die Angehörigen von Derwischorden Zuflucht zum Mittel des kitmān (persisch; arabisch:taqiyya). ${ }^{66}$ Es gestattete ihnen, ihre eigentlichen Überzeugungen $\mathrm{zu}$ verbergen und sich so nicht in Lebensgefahr zu bringen. Diese

62 Zur Qalandariyya siehe Knysh, Islamic mysticism 272274; Karamustafa, God's unruly friends 52-63.

63 Zur Malāmatiyya siehe Knysh, Islamic mysticism 9499 und 274-277; Karamustafa, God's unruly friends 3of.; Imber, al-Malāmatiyya, in $E I^{2}$; Toussulis, Sufism and the way of blame.

64 Kissling, Derwischorden 10.

65 Kissling, Das Menāqybnāme Scheich Bedr ed-Dīn's; siehe ausserdem Kissling, Derwischorden 15.

66 Strothmann und Djebli, Takiyya, in $E I^{2}$; Kissling, Derwischorden 16. 
Einstellung ist auch aus der Schia und von $\dot{G} u l a \bar{t}-$ Gruppierungen, z.B. den Alawiten (Nuṣayriern), bekannt.

Es darf allerdings nicht übersehen werden, dass es Derwischbewegungen wiederholt gelang, erfolgreich auf dem machtpolitischen Parkett mitzuspielen, wie dies gerade auf die Șafawiyya zutrifft. Im Osmanischen Reich präsentieren sich die Verhältnisse unter etwas andern Vorzeichen. ${ }^{67}$ Vordergründig agierte der osmanische Sultan hier als Autokrat. Allerdings lässt sich nicht übersehen, dass auch er nicht im luftleeren Raum schalten und walten konnte, sondern immer wieder - oft auch unbewusst - von andern Kreisen abhängig war. N. Clayer zeigte auf, dass die osmanischen Sultane im 16. und 17. Jh. gerade auf dem Balkan gern auf den Derwischorden der Halwatiyya zurückgriffen, um ihre Machtansprüche durchzusetzen. ${ }^{68}$

\subsection{Hinweise auf ausgewählte Derwischorden}

Die weiteren Ausführungen kommen auf die Wanderbewegungen der Turkvölker aus den Steppen Zentralasiens in Richtung Westen zurück. ${ }^{69}$ Diese Turkvölker hatten sich im 10. und 11. Jh. in Transoxanien und Turkestan zumindest oberflächlich zum Islam bekehrt. Auch stiessen die turkstämmigen Oghusen unter der Führung des Seldschuken Alp Arslan damals nach Anatolien vor. Die Seldschuken entschieden den Kampf gegen Byzanz $1071 \mathrm{zu}$ ihren Gunsten (Schlacht von Manzikert). Mit diesem Sieg setzte die Türkisierung und Islamisierung Anatoliens ein. ${ }^{70}$

67 Kissling, Derwischorden 12.

68 Vgl. Clayer, Mystiques, état et société 90-111 und passim. N. Clayer hält fest (106): „De tous temps, les sultans ottomans ont été proches des tarikat, ou les ont utilisées selon leur propre penchant ou leur propre intérêt. $\mathrm{Au}$ cours des siècles, cet intérêt a naturellement évolué, de même qu'a varié la préférence pour telle ou telle confrérie. Or, à partir du règne du sultan Bayezid II, la préférence des sultans semble être allée très souvent vers des şeyhs halvetis."

69 Mélikoff, Hadji Bektach: Un mythe et ses avatars if.

70 Vgl. dazu bereits oben Kapitel 2, bei Anm. 9-11, 46-48 und
Bei diesen Wanderungsbewegungen - v.a. auch während der zweiten Phase, also während des Mongolensturms - zogen zusammen mit den Volksmassen ebenso Vorsteher religiöser Gruppierungen nach Westen. Diese heiligmässigen Männer werden in den Hagiographien (Menākib-nāme, Vilāyet-nāme) als Hurāsān erenleri bezeichnet und genossen im Volk breiten Rückhalt. Sie haben bei der Entwicklung des Sufismus im 12. und 13. Jh. eine wichtige Rolle gespielt. Aus ihrer Bezeichnung geht hervor, dass sie einen unmittelbaren Bezug zu Khorasan aufweisen. Besser bekannt sind unter ihnen Bābā Ilyās Hurāsānī (gest. 638/1240) ${ }^{71}$ und Hāḡğḡī Bektāš (gest. ca. 669/1271). ${ }^{72}$ Hierhin gehört im weitesten Sinn aber auch Ğalāl ad-Dīn Rūmī (gest. 672/1273). ${ }^{73}$

Der Begriff Hurāsān erenleri verallgemeinerte sich mit der Zeit und diente als Ehrentitel für einen Vorsteher einer im Volk verankerten mystischen Gruppierung. Der Ausdruck eren bezeichnet einen initiierten Adepten, wobei die Präzisierung Hurāsān erenleri die geographische Herkunft der Angehörigen dieser Bewegungen unterstreicht. ${ }^{74}$ Es gab aber auch die Turkistān erenleri. Es handelt sich um die Anhänger Ahmmad Yasawīs, die aus der Gegend von Samarkand stammen. ${ }^{75}$ Eine dritte Gruppe ist als Rūm erenleri bekannt. Es sind jene Mystiker, die bereits fest in Anatolien (Rūm) niedergelassen waren und sich gegen die neu eindringenden Hurāsān erenleri zur Wehr setzten. Die weiteren Ausführungen machen auf bedeutende Gruppierungen aufmerksam, die sich um diese heiligmässigen Männer aus Khorasan ausgebildet hatten.

Anm. 63. Für eine ausführlichere Darstellung siehe auch Mélikoff, Hadji Bektach: Un mythe et ses avatars 25-29.

71 Vgl. zu ihm Ocak, Baba İlyas-i Horasani, in $E I^{3}$; Algar, Bektāš, Hāj̄ì, in EIr (5. Abschnitt); Knysh, Islamic mysticism, 277; Renard, Sufism 43.

72 Vgl. dazu auch Cahen, Baba Ishaq, Baba Ilyas, Hadjdji Bektash et quelques autres. Zu Ḥāğğī Bektāš vgl. unten Kapitel 3.1.3.

73 Zu Ğalāl ad-Dīn Rūmī vgl. unten Kapitel 3.1.2.

74 Mélikoff, Hadji Bektach: Un mythe et ses avatars if.

75 Vgl. dazu unten Kapitel 3.1.1. 


\subsubsection{Aḥmad Yasawi und die Yasawiyya}

Aḥmad Yasawī ist ein turkstämmiger Sufi und war in Zentralasien aktiv. Um sein Leben ranken sich zahllose Legenden. ${ }^{76}$ Er soll als Sohn eines Šayh Ibrāhīm in der zweiten Hälfte des 11. Jh. in Sayrām (Isfiğāb) in Turkestan geboren worden sein. Nach dem Tod des Vaters liess sich die Familie in Yasi nieder. Der Sohn war damals etwa sieben Jahre alt. Er soll seine Ausbildung bei Arslan Bābā in Yasi begonnen und später in Buhārā bei Šayh Yūsuf Hamadān̄̄ $\overline{l n}^{77}$ fortgesetzt haben. Yasawī wurde 534/1140 dessen Nachfolger und blieb danach bis zu seinem Tod im Jahr $562 / 1166$ in Yasi ansässig. Hamad̄ānīs Traditionskette ging auf Haraqānī und Bāyazid-i Basțāmī zurück. Er gilt als wichtiges Glied in der Überlieferungskette (silsila) der Yasawiyya und Bektāšiyya. ${ }^{78}$

Die Yasawiyya war hauptsächlich in Transoxanien und Turkestan aktiv und kann als Beispiel eines türkischen Ordens par excellence angeführt werden. ${ }^{79}$ Yasawī ist der angebliche Verfasser einer Sammlung von Gedichten in umgangssprachlichem Türkisch; sie ist unter dem Namen Dīwān$i$ Hikmet bekannt. ${ }^{80}$ Die Yasawīs sangen Passagen aus diesen Gedichten bei ihren religiösen Zusammenkünften. Sie führten dazu oft wilde Tänze auf und gerieten in Ekstase. ${ }^{81}$ Ahmmad Yasawīs Schüler

76 Siehe für die folgende Darstellung İz, Ahmmad Yasawī, in $E I^{2}$; siehe ausserdem Knysh, Islamic mysticism $271 \mathrm{f}$.

77 Zu Šayh Yūsuf Hamad̄ān̄, siehe Schimmel, Mystische Dimensionen 514f.; Knysh, Islamic mysticism 271f. İz, Ahmmad Yasawī, in $E I^{2}$, gibt 555/116o als Todesjahr von Yūsuf al-Hamadānī an. Schimmel und Knysh nennen 1140.

78 Aḥmad Yasawī soll gemäss der Darstellung des Wilāyetnāme Ḥāğğ̄i Bektāš nach Anatolien geschickt haben; vgl. dazu unten bei Anm. 114.

79 Zum Orden der Yasawiyya siehe Zarcone, Yasawiyya, in $E I^{2}$; Öztürk, The eye of the heart 49-55 (Abschnitt: The Yesevis).

80 Der Begriff hikmet hat hier die Bedeutung „religiöses Gedicht". DeWeese, The Mashā'ikh-i Turk and the Khojagān 183 (mit Anm. 10), zeigte auf, dass diese Gedichte Yasawī zugeschrieben wurden und nicht authentisch sind.

81 Knysh, Islamic mysticism 272, mit Verweis auf Zarcone, Le Turkestan chinois 270 . verbreiteten seine Lehre in der Gegend des Syr Daryā, an der Wolga und in Hwārazm. Unter ihnen spielten Ḥakìm Ata (gest. 582/1183) ${ }^{82}$ und Sa ${ }^{c} 1 \bar{d}$ Ata (gest. 615/1218) eine wichtige Rolle. D. DeWeese zeigte auf, dass die Verbreitung der Yasawiyya und die Islamisierung der Bevölkerung in der Zentralasiatischen Steppe eng miteinander verknüpft sind. ${ }^{83} \mathrm{Da}$ der Mongolensturm im 13. Jh. weite Teile dieser Gegend in Mitleidenschaft zog, suchten zahlreiche Angehörige der Yasawiyya Zuflucht in Anatolien.

Bereits in Zentralasien und später in Anatolien kam es zu engen Kontakten zwischen der Yasawiyya und der Qalandariyya, in der sich antinomistisch ausgerichtete Derwische lose zusammengeschlossen hatten. Die Yasawiyya näherte sich in Anatolien jenem Zweig der Qalandariyya an, der als Haydariyya bekannt war. Die Yasawiyya verlor ihren Einfluss in Zentralasien selbst ab dem 9./16. Jh. an die Naqšbandiyya. ${ }^{84}$ Der Hauptzweig der Yasawiyya ist unter dem Namen 'Azīziyya bekannt und geht auf Ğamāl ad-Dīn 'Azīzān (gest. 912/1507) zurück. Diese Gruppierung war in der Gegend von Samarkand aktiv und entbehrte einer klaren hierarchischen Struktur. Die Gräber von Vorstehern der Yasawiyya in Zentralasien (u.a. Kasachestan, Dašt-i Qipčak, Turkestan und Shymkent) dienten als wichtige Bezugspunkte dieser Bruderschaft.

Die Grabstätte Ahmad Yasawīs stellt das bedeutendste Heiligtum der Yasawiyya dar. Es liegt in Yasi im Süden Kasachestans (ca. 220 km nordnordwest-

82 Diese Angaben gemäss A. Knysh (vorangehende Anm.); abweichende Angaben bei Zarcone, Ahmmad Yasawī, in $E I^{2}$ : nämlich $582 / 1188$. Alpay, Hakīm Ata, in $E I^{2}$, erwähnt als Todesjahr 582/1186.

83 Knysh, Islamic mysticism 272, weist in diesem Zusammenhang hin auf DeWeese, Islamization.

84 Zur Naqšbandiyya siehe Knysh, Islamic mysticism 218234. Die Naqšbandiyya war ursprünglich ebenso in Zentralasien beheimatet. Sie führt ihre silsila im Gegensatz zu den meisten andern Bruderschaften nicht auf 'Alī sondern auf Abū Bakr zurück. Das Mausoleum des Ordensgründers Bahā' ad-Dīn Naqšband befindet sich in Bukhara und wird von seinen Anhängern als Pilgerort geschätzt (vgl. Knysh, 220); siehe dazu https://archnet .org/sites/2443/ (Stand 29. August 2017). 
lich von Taschkent). Dieses Mausoleum entwickelte sich zu einer wichtigen Pilgerfahrtsstätte für die Turkvölker aus Zentralasien und der Wolgaregion. Dieser heute noch bestehende Schrein wurde auf Anordnung Tīmūrs zwischen 1389 und 1405 errichtet. Die Stätte ist im vorliegenden Zusammenhang von Interesse, da ihre reichen Dekorationen verschiedene Elemente enthalten, die sich ebenso auf bestimmten Dokumenten in Rollenform nachweisen lassen. ${ }^{85}$

\subsection{2 Ğalāl ad-Dìn Rūmì und die Mawlawiyya}

$\mathrm{Zu}$ jenen heiligmässigen Männern, die mit den Migrationsbewegungen im Gefolge des Mongolensturms nach Westen gelangten, zählt im weiteren Sinn auch Ğalāl ad-Dīn Rūmī (gest. 1273). Er ist der Begründer des nach seinem Ehrentitel Mawlānā („unser Herr“) benannten Derwischordens der Mawlawiyya. Diese Bruderschaft vertritt Standpunkte, die sich weniger weit von den Vorstellungen der traditionalistisch orientierten Theologie entfernen, als dies auf die Bektāšiyya zutrifft. ${ }^{86}$ Allerdings war zumindest Ğalāl ad-Dīn selbst von den heterodox ausgerichteten Standpunkten der Qalandariyya geprägt, die sich im 13. Jh. auch in Anatolien verbreitet hatten. ${ }^{87}$

85 Zum Mausoleum Ahmmad Yasawīs und Abbildungsmaterial dazu siehe: http://archnet.org/sites/3057; http://whc .unesco.org/en/list/1103 (Stand 21. Juli 2016). Golombek und Wilber, Timurid architecture I, 145 f., Nr. 53 (284-288), und Bd. II, Abb. 123-129; Hillenbrand, Islamic architecture 297 und 301-305 (mit Skizzen 5.126-127 und Abb. 217219); siehe ausserdem Grundriss (539, Nr. 5.125).

86 Für nähere Angaben zu Ğalāl ad-Dīn Rūmī vgl. Ritter und Bausani, Djalāl al-Dīn Rūmī, in $E I^{2}$; Schimmel, Mystische Dimensionen 438-462; Knysh, Islamic mysticism 156-161. Siehe ausserdem Zarcone, La Mevlevije, confrérie des derviches tourneurs 504-508.

87 Gemäss A. Gölpinarli, anfänglich selbst ein Mitglied dieses Ordens, betrachten die Mawlawīs ihren Orden nicht als Bruderschaft im engeren Sinn. A. Gölpinarli sieht auch Anzeichen dafür, dass die Mawlawiyya mit der Malāmatiyya aus Khorasan in Beziehung steht. H. Ritter meint ebenso, in den Predigten Bahā' ad-Dīn Walads, Ǧalāl ad-Dīn Rūmīs Vater, Anzeichen dafür zu erkennen, dass er der Qalandariyya nahestand. Die Qalandariyya unterhielt wiederum Verbindungen zur Malāmatiyya. Jedenfalls lassen sich in den erwähnten Predig-
Ğalāl ad-Dīn Rūmī soll 6o4/1207 in Balh geboren worden sein und starb 672/1273 in Konya. Seine Familie verliess ihre Heimat in Zentralasien kurz vor dem Einfall der Mongolen in Richtung Westen. Sein Vater war in Balh ein beliebter Sufi-Prediger. Der Wegzug der Familie wird oft mit einer Auseinandersetzung mit dem Huwarazm Šāh 'Alā' adDīn Muhammad und dessen Schützling Fahr adDīn ar-Rāzī (gest. 6o6/1209-1210) ${ }^{88}$ in Zusammenhang gebracht. Vieles spricht allerdings dafür, dass die Familie erst später, wahrscheinlich 614/1217 oder kurz zuvor auswanderte. Aflākī jedenfalls datiert die Ankunft der Familie in Malatya ins Jahr 1217. Bahā' ad-Dīn hielt sich 616/1219 in Sivas auf; er lebte danach etwa vier Jahre in Akşehir in der Nähe von Erzincan. Ab 619/1222 lebte er wohl während sieben Jahren in Laranda. Die Übersiedlung nach Konya soll im Jahr 626/1228 auf Verlangen des Seldschuken-Prinzen 'Alā' ad-Dīn Kayqubād erfolgt sein. Dort starb Bahā' ad-Dīn Walad 628/1231.

Ğalāl ad-Dīn schloss sich in Konya als murīd Sayyid Burhān ad-Dīn Muhaqqiq an. Dieser war ein ehemaliger Schüler Bahā’ ad-Dīns und wollte diesen in Konya besuchen. Burhān ad-Dīn soll seinen neuen Anhänger Ğalāl ad-Dīn darauf aufmerksam gemacht haben, dass sein Vater auch über esoterisches Wissen verfügt habe. Nachdem Burhāan ad-Dīn neun Jahre später (wohl 637/1239-1240) in Kayseri verstorben war, blieb Ǧalāl ad-Dīn während fünf Jahren allein.

Ǧalāl ad-Dīn Rūmīs Leben nahm 642/1244 mit der Ankunft des Wanderderwischs Šams ad-Dīn Muhammad-i Tabrīzī in Konya eine entscheidende Wende. Rūmī verliebte sich in der Art der Derwi-

ten Hinweise auf eine Fröhlichkeit und innere Gelöstheit feststellen, die an die țibat al-qulüb in der Qalandariyya erinnern; vgl. Ritter und Bausani, Djalāl al-Dīn Rūmī, in $E I^{2}$, wo dieser Standpunkt angeführt wird. Siehe ausserdem Ritter, Oriens 8.2 (1955), 359-361: Rezension zu Macārif. Macmūee-i mavāì va suxunān-i Sulțān al'ulamā' Bahā' ud-Dīn; darin 36o. Siehe überdies Ritter, Philologika. XV. Farīduddīn 'Atțār, III.7. „Der Dīwān“, in Oriens 12.1-2 (1959), 1-88; darin 15.

88 Zu Faḩr al-Dīn ar-Rāzī siehe Anawati, Fakhr al-Dīn alRāzī, in $E I^{2}$. 
sche in ihn. Šams lehrte Rūmī die Liebe der Sufis. Er zeigte ihm auch auf, dass Wissen nicht allein aus Büchern erlernt werden kann. Ğalāl ad-Dīn selbst war überdies von den heterodox ausgerichteten Standpunkten der Qalandariyya geprägt, die sich im 13.Jh. in Anatolien verbreitet hatte. Ekstatische Erfahrungen spielten dabei eine bedeutende Rolle. Für Rūmī waren ausserdem Musik und Tanz von grosser Wichtigkeit.

Gemäss Aflākī soll Ǧalāl ad-Dīn Tabrīzī bereits von einem Aufenthalt in Damaskus gekannt haben. Šams-i Tabrīzī galt als unberechenbarer Mann, der sich keinen Deut um die sozialen Konventionen scherte. Šams' Auffassungen provozierten das religiöse establishment in Konya. ${ }^{89}$ Seine Vertreter schimpften ihn einen Weltenbummler und nahmen Anstoss daran, dass er weder Familie noch ein festes Daheim hatte. Šams' ruheloses Umherwandern war typisch für das Derwischwesen jener Zeit. Die Derwische werden gern als „die Reisigen" bezeichnet. ${ }^{90}$ Im Fall von Šams war das Herumziehen derart ausgeprägt, dass es ihm den Übernamen paranda (der Fliegende) eintrug.

Ğalāl ad-Dīn räumte seiner Beziehung zu Šams ein derart grosses Gewicht ein, dass sich seine Jünger übergangen fühlten. Jedenfalls sind Berichte dazu im Umlauf, dass sie Šams ad-Dīn nach dem Leben trachteten. Dies wiederum veranlasste Šams zur Flucht nach Damaskus (643/1246). Auf Rūmīs wiederholte Aufforderungen hin kehrte Šams schliesslich zu Fuss nach Konya zurück. Dies versetzte Rūmīs Anhänger erneut in Aufruhr. Die Angelegenheit spitzte sich zu, als auch die Stadtbewohner an Šams' Eskapaden und seinem verächtlichen Verhalten Anstoss nahmen. Am 5. Šacbān 645/5. Dezember 1247 wurde Šams, wohl unter Beteiligung von Sulțān Walads Bruder 'Alā' ad-Dīn

89 Vgl. Knysh, Islamic mysticism 156 (mit Verweis auf Hodgson, Venture of Islam II, 245).

90 Vgl. Taeschner, Zünfte und Bruderschaften 279. Auch Kissling bezeichnet diese Derwische in einem seiner Aufsätze als „die Reisigen“; die Stelle liess sich leider nicht mehr eruieren; vgl. ebenso Beldiceanu, Abdalan1 Rum, historical, in $E I^{3}$ (darin misafer/musāfir). Siehe auch Wolper, Cities and saints 78a (misāfir). ermordet. Seine Leiche wurde in einen Brunnen geworfen, wo sie Sulțān Walad fand und insgeheim bestattete. Ğalāl ad-Dīn Rūmī selbst erfuhr allerdings nichts von den genauen Umständen von Šams' Verschwinden und machte sich verzweifelt auf die Suche nach ihm. Die geschilderten Vorfälle stürzten Rūmī in eine tiefe Krise.

Es kam zu erneuten Spannungen zwischen Rūmī und seinen Anhängern, als dieser - gewissermassen als Ersatz für den verschwundenen Šams Șalāh ad-Dīn Zarkūb (der Goldschmied) als seinen halīfa (Stellvertreter) einsetzte. Seine Schüler störten sich an dessen niederen Herkunft und geistigen Schwerfälligkeit. Sie hielten Șalāḥ ad-Dīn Zarkūb jedenfalls für ungeeignet, einem Sufiorden vorzustehen. Diesmal war Rūmī gewarnt. Er kam einem Anschlag auf Șalāh ad-Dīn zuvor, indem er seinen Jüngern drohte, er würde Konya für immer verlassen. Jedenfalls war Șalāḥ ad-Dīn bis zu seinem Tod 657/1258 zehn Jahre lang als Rūmīs halīfa aktiv. Auf ihn folgte Ḥusām ad-Dīn Hasan, dem Rūmī seinen Mațnawì widmete. Ḥusām adDīn übte sein Amt bis zu Rūmīs Tod (672/1273) aus und wollte sich dann zugunsten von dessen Sohn Sulțān Walad zurückziehen. Dieser allerdings liess Ḥusām ad-Dīn den Vortritt und übernahm das Amt des halīfa erst nach dessen Tod im Jahr 683/1284. Für die vorliegenden Belange von Interesse ist allenfalls, dass Ḥusām ad-Dīns Familie aus Urūmiya stammte. Husām ad-Dīns Vater war der Vorsteher der Ahis in Konya und war in der Stadt unter dem Namen Ahī Turk bekannt. ${ }^{91}$

Die eigentliche Geschichte des MawlawiyyaOrdens beginnt unter Sulțān Walad, der die Geschicke der Bruderschaft weise lenkte und erste Zweigniederlassungen gründete. Sulțān Walad gab dem Orden klare Strukturen. Er fixierte die Zeremonien und stärkte die Stellung des $\operatorname{sama} \bar{a}^{c}$. Die Mawlawiyya ist im Westen als Orden der Tanzenden Derwische bekannt. ${ }^{92}$ Sulțān Walad rich-

$91 \mathrm{Zu}$ den $A h \bar{\imath}$-Bruderschaften vgl. unten Kapitel 3.2.2.

92 Zu dieser Zeremonie vgl. Ritter, Reigen; siehe ausserdem Meier, Der Derwischtanz 42 und 47. 
tete ausserdem einen effizienten Verwaltungsapparat ein. Er drängte die heterodoxen Elemente im Orden zurück. Die Bruderschaft rekrutierte ihre Mitglieder anfänglich v.a. unter den Handwerkern. ${ }^{93}$ Sie richtete sich allerdings bald auf die Oberschicht aus und stand in Anatolien in hohem Ansehen. Wiederholt wird darauf hingewiesen, dass die Mawlawiyya gemässigte Positionen vertrat. Emotionale Aspekte nahmen in der Bruderschaft einen bedeutenden Platz ein. Sulțān Walad übte die Aufgabe des Ordensvorstehers bis zu seinem Tod aus (712/1312). Die Leitung ging danach an Sulțān Walads Nachkommen über.

Die Mawlawiyya ist einer der wenigen Orden, der eine zentrale Struktur aufbauen konnte, in der der Mutterkonvent in Konya bis heute eine bedeutende Stellung einnimmt. Die Nachfolger Ğalāl ad-Dīns haben den Orden von hier aus kontrolliert, indem sie die Vorsteher der Nebenkonvente ernannten. Die Mawlawiyya teilte sich in zwei Zweige (qul) auf, ohne dass die Einheit des Ordens dadurch gefährdet worden wäre. Es handelt sich einerseits um die Šamsīs (in Anspielung auf Šams ad-Dīn-i Tabrīzī), die stärker heterodox ausgerichtet sind und šarîa-rechtlichen Bestimmungen eine geringere Bedeutung zumessen. Der zweite Zweig hingegen, die Waladīs (in Anspielung auf Sulțān Walad) respektierte die šarīa. Die Mawlawiyya ist grundsätzlich aristokratisch und urban geprägt. ${ }^{94}$ Sie war gegenüber der breiten Bevölkerung eher verschlossen. Am Anfang war der Orden allerdings eng mit der ländlichen Bevölkerung verbunden und unterhielt enge Beziehungen zur Qalandariyya.

Aus politischer Perspektive ist von Bedeutung, dass die Mawlawiyya enge Verbindungen mit dem Herrscherhaus der Osmanen unterhielt. Verschiedene Sultane sollen der Mawlawiyya angehört

$93 \mathrm{Zu}$ den engen Beziehungen zwischen Sufi-Orden und Handwerkern vgl. die Ausführungen zu den Futuwwaund $A h \bar{\imath}$-Bruderschaften und dem Zunftwesen (Kapitel 3.2, bei Anm. 231 und 255-262; Kapitel 3.2.3).

94 Vgl. Zarcone, La Mevlevije, confrérie des derviches tourneurs 505 . haben (Selim III. am Ende des 18. Jh., Meḥmed Reşād v., Anfang 2o.Jh.). Der Vorsteher des Ordens, der Čelebī, hatte ab dem 17. Jh. das Recht, die Schwertgürtung vorzunehmen. Er und seine Nachfolger banden von nun an dem neuen Sultan das Schwert des Ahnherrn der Dynastie, 'Uțān Gāzīs, um. Die Mawlawiyya verbreitete sich auf dem gesamten Gebiet des Osmanischen Reichs, vom Balkan bis nach Arabien. ${ }^{95}$ Neben dem Mutterkonvent in Konya lassen sich bald Zweigkonvente in Karahisar, Kütahya, Amasya, Erzincan, Nigde oder Karaman nachweisen. ${ }^{96}$ Im 16. und 17. Jh. verbreitete sich der Orden ausserdem im arabischen Teil des Reichs (Lattakia, Aleppo, Kairo, Damaskus, Bagdad, Jerusalem, Mossul und Mekka).

\subsection{3 Ḥāğǧği Bektāš, die Bektāšiyya und ihre Bezüge zu den Janitscharen und der Hurūfiyya}

Zu den Hurāsān erenleri gehört auch Ḥāğğḡi Bektāš, der Namensgeber des heterodox geprägten Derwischordens der Bektāšiyya: ${ }^{97}$ Biographische Angaben zu ihm lassen sich in erster Linie Werken hagiographischen Charakters entnehmen. Als Hauptquelle gilt Uzūn Firdawsīs Wilāyet-nāme, das wohl zwischen 886 und 907 (1481 und 1501) in osmanisch-türkischer Prosa verfasst worden ist. Die grosse zeitliche Distanz zwischen Lebenszeit von Ḥāğǧ̃̄ Bektāš (gest. wohl 669/1270-1271) und der Abfassung dieses Werks ist allerdings ein deutlicher Hinweis darauf, dass es nur mit Vorsicht als historische Quelle stricto sensu dienen kann. Zum Zeitpunkt seiner Entstehung hatte sich die Bektāšiyya zu einem Orden entwickelt, in den zahlreiche schiitisch beeinflusste Auffassungen Eingang gefunden hatten, wie sie damals in Anatolien in breiten Kreisen in Schwang waren. Immerhin

95 Vgl. op. cit. 508.

96 Vgl. auch Pfeiffer, Mevlevi-Bektashi rivalries.

97 Zu Hạăğǧì Bektāš siehe Mélikoff, Hadji Bektach: Un mythe et ses avatars. Die folgenden Hinweise stützen sich auf die kürzeren Darstellungen von Algar, Bektāš, Ḥājī, in EIr, und Zarcone, Bektaş Hacı, in $E I^{3}$. 
ist festzuhalten, dass an der historischen Existenz von Ḥāğğ̄̄ Bektāš inzwischen keine Zweifel mehr bestehen. ${ }^{98}$

Gemäss dieser hagiographischen Quelle wurde Hâăğḡī Bektāš in Nayšāpūr geboren. Dies lässt sich allerdings nicht verifizieren. Firdawsīs Text stellt Ḥăğğì Bektāš als Sohn eines Sayyid Muḥammad b. Mūsā vor. Er soll der Grossohn von Mūsā alKāẓim (gest. 183/799), dem 7. Imam der Schiiten, sein. Dies ist selbstredend unmöglich, lebte Hâağğĩ Bektāš doch erst im 13. Jh. Die Quelle stellt Hāăğḡī Bektāš ebenso als Vertreter (halīfa) Aḥmad Yasawīs (gest. 562/1166-1167) vor. ${ }^{99}$ Rein historisch betrachtet ist auch diese Abhängigkeit nicht haltbar. Die Angabe dürfte aber ein Echo davon sein, dass im Lauf der Zeit im schiitisch geprägten Umfeld in Anatolien zahlreiche frühere Anhänger der eigentlich sunnitisch ausgerichteten Yasawiyya Anschluss an die Bektāšiyya gesucht haben. Auch wird angegeben, dass Ḥāğǧ̃̄ Bektāš Schüler des Luqmān-i Paranda, eines Anhängers Aḥmad Yasawīs, gewesen sei.

Ḥăğğĩ Bektāš war unter den Turkmenenstämmen aktiv, die im Zusammenhang mit den Mongoleneinfällen aus Khorasan und Aserbaidschan nach Anatolien flohen. ${ }^{100}$ Hạăğğì Bektāš selbst dürfte über Nağaf und Mekka nach Anatolien gelangt sein, wo er sich Bābā Ilyās Hurāsānī anschloss. Dieser Bābā Ilyās, auch bekannt als Bābā Rasūl, führte einen politisch motivierten Aufstand gegen die Seldschuken an, der allerdings gewaltsam niedergeschlagen wurde. Bābā Ilyās kam dabei ums Leben (638/1240). ${ }^{101}$

Hậ̄ğỹì Bektāš hatte sich Bābā Rasūl in Sivas angeschlossen. Er beteiligte sich militärisch aller-

98 Mélikoff, Hadji Bektach: Un mythe et ses avatars 51. Zur Ergänzung der folgenden Darstellung wird hier in allgemeiner Form auf I. Mélikoffs Ausführungen verwiesen. Sie teilt ihren Bericht über Hāāğǧī Bektāš ein in a. einen historischen Abriss $\left(55^{-58}\right)$, und b. einen Überblick über die Berichte in den Legenden (58-61).

99 Zur Yasawiyya vgl. Kapitel 3.1.1.

100 Vgl. Mélikoff, Hadji Bektach. Un mythe et ses avatars 53; eadem, L'ordre des Bektachis 3.

101 Zum Bābā'î-Aufstand siehe Ocak, Baba İlyas-i Horasani, in $E I^{3}$; ders., La révolte de Baba Resul. dings nie ebenso aktiv an dieser Widerstandsbewegung wie sein Bruder Menteş. Dies erklärt auch, dass Hāāğğī Bektāš bei der Niederschlagung des Aufstands im Gegensatz zu seinem Bruder nicht ums Leben kam. Hạāğǧī Bektāš liess sich danach in Suluca-Karaöyük, einem Dorf in der Nähe von Kırşehir, nieder. Der Ort ist heute unter dem Namen Hacı Bektaş bekannt. Hier verbrachte Ḥâğğḡi Bektāš zusammen mit einer kleinen Schar von Anhängern den Rest seines Lebens. Er verbreitete unter den nomadischen und niedergelassenen Türken in Anatolien weiterhin seine Lehre, die Sufismus, Schiismus und türkischen Volksglauben miteinander verband. ${ }^{102}$

Er verwies jene Anhänger, die direkte spirituelle Unterweisung suchten, an eine Adoptivtochter, die unter dem Namen Huātūn Anā bekannt ist. Es ist umstritten, ob Hạăğǧì Bektāš auch Nachkommen im biologischen Sinn hatte. Gewisse Quellen halten fest, die genannte Qadıncık Anā habe ihm zwei Söhne geschenkt. Sie soll jedoch unter wundersamen Umständen schwanger geworden sein: Sie habe eine Mischung aus dem Blut des Heiligen und dem Wasser getrunken, mit dem er sich die Hände gewaschen habe. Einer seiner beiden Söhne, Huị̂r Lāla Čuwān, soll später die Leitung der zāwiya in Karaöyük übernommen haben. Hāğğḡì Bektāš ist mit grosser Wahrscheinlichkeit 669/1270-1271 gestorben. Sulțān Murād I. (reg. 763796/1362-1389) errichtete das erste Mausoleum für ihn $(769 / 1367-1368)$.

Für die hier relevanten Zusammenhänge ist auch von Bedeutung, dass das Wilāyet-nāme-i Hāci Bektāş-i Welì auf die Futuwwa-Bewegung aufmerksam macht. Der Text weist überdies auf die Verbindungen zwischen Ḥāğğĩ Bektāš und Akhī Evren hin. Dieser Akhī Evren, der Heilige aus Kurşehir, lebte in der zweiten Hälfte des 13. Jh. und war der Schutzherr der Zunft der Gerber. ${ }^{103}$

\footnotetext{
102 Siehe dazu Mélikoff, L'ordre des Bektachis 4. Auch Knysh, Islamic mysticism 277, zur Bektāšiyya allgemein ebenda 277-28o.

103 Die Bektāšiyya wiederum wird oft als eigentliche Erbin des in den Ahī-fityān-Bünden gepflegten Brauchtums bezeichnet. Die synkretistische Ausrichtung der Bektā-
} 
Aus den Menākibu 'l-Kudsiyye lässt sich ableiten, dass Sheykh Ede Bali zu den engen Gefährten des Ḥāğǧ̃̄ Bektāš zählte. Dieser Ede Bali wiederum wurde später 'Uțmān Ġāzīs Schwiegervater. ${ }^{104}$ Es ist weiter bekannt, dass 'Uțmān Ġāzī (gest. 1326), der Begründer der Dynastie der Osmanen, Beziehungen zu den Ahiss unterhielt. Es sind überdies Angaben dazu im Umlauf, dass Hāḡğǧñ Bektāš an 'Uțān Ġāzī die Schwertgürtung vornahm. ${ }^{105}$ Angesichts dieser Abhängigkeiten kann nicht erstaunen, dass das Ritual der Bektāšiyya Elemente aus der Futuwwa und dem Ahïtum aufweist.

Der Derwischorden der Bektāšiyya erlangte seine charakteristische Ausrichtung erst deutlich nach dem Tod von Ḥāğǧìi Bektāš. Der spätere Orden zeichnet sich durch eine grosse Nähe zur volkstümlichen Schia sowie zur Hurūfiyya und durch Offenheit gegenüber dem Christentum aus. ${ }^{106}$ I. Mélikoff betont, dass Ḥāğğḡi Bektāš anfänglich ein Heiliger der Turkmenen war und ihm lokale Bedeutung zukam. Sein Ruf habe nach und nach zugenommen. Mit der Zeit sei er als Nationalheiliger der Turkmenen verehrt worden. ${ }^{107} \mathrm{Th}$. Zarcone wiederum hält fest, dass das Wilāyet-nāme („Buch der Freundschaft [mit Gott]“) die drei folgenden, für die Auffassungen von Hāāğḡī Bektāš charakteristischen Aspekte hervorhebe: a. schiitisch motiviertes Missionieren, b. sufische Ausrichtung und c. schamanistischen Hintergrund:

a. Aufgrund seiner Tätigkeit als schiitisch motivierter Missionierer wird Hạăğḡī Bektāš als sayyid und Nachkomme der schiitischen Imame beschrieben. Er wird auch "Geheimnis 'Alīs" genannt und soll die Liebe zu 'Alì (tawallā) in Ana-

šiyya dürfte die Übernahme von unter den ahī-fityān gepflegten Ritualen und Wertvorstellungen begünstigt haben. Der Vorsteher des Mutterklosters der Bektāšiyya in der Nähe von Kırşehir trägt ausserdem den Titel Ahī Dede. Auch dies unterstreicht die Nähe der Bektāšiyya zum Ahītum; zum Ahītum vgl. ausführlich Kapitel 3.2.2.

Siehe dazu Mélikoff, L' ordre des Bektachis 6 .

Diese Feststellung steht allerdings in Widerspruch zu Angaben beim Historiker Aşikpāşazāde; zitiert bei Mélikoff, Hadji Bektach: Un mythe et ses avatars 61.

Vgl. Algar, Bektāš, Hājīi, in EIr.

Mélikoff, Hadji Bektach: Un mythe et ses avatars 61. tolien überhaupt bekannt gemacht haben. Ausserdem sollen Muhammad und 'Alì ihm auf wundersame Weise den Koran gelehrt haben. Während ihm Muḥammad dessen äusseren Sinn (zāahir) erschlossen habe, habe ihn 'Alī in dessen inneren Bedeutung (bāțin) unterwiesen.

b. Hâăğḡi Bektāš weist auch Bezüge zum Sufismus auf: er zählt zu den Hurāsān erenleri und soll von Aḥmad Yasawī abhängig sein. Zusätzlich kann auf seine Nähe zur Malāmatiyya hingewiesen werden. Die Entstehung dieses Sufiordens geht auf das 3./9. Jh. zurück. Seine Mitglieder missachten soziale Gepflogenheiten bewusst und ziehen die Verachtung (malāma) ihrer Mitmenschen auf sich. Innerlich allerdings zeichnen sie sich durch Aufrichtigkeit aus. Auch soll Ḥāğğ̄̄ Bektāš der Vorsteher der abdāl gewesen sein, bei denen es sich um eine Gruppe antinomistischer Derwische aus Anatolien handelt. ${ }^{108}$ Ḥāğğḡi Bektāš hegte ausserdem Sympathien für die Qalandariyya, in der sich unverheiratete antinomistische Wanderderwische zusammengeschlossen hatten.

Auch Ḥāğğ̄̄ Bektāš zählt zu jenen heiligmässigen Männern, die sich durch das Wirken von Wundern (karāma: Huldwunder) auszeichneten: Er heilte Kranke, verhalf Frauen zur Schwangerschaft, vermehrte die Speisen oder auferweckte Tote. Er ermutigte auch zahlreiche Menschen dazu, sich zum Islam zu bekehren. Er erleichterte ihnen den Übertritt durch seine Offenheit gegenüber althergebrachtem Brauchtum. Die Aufgeschlossenheit der Bektāšiyya gegenüber andern Bekenntnissen fand in der synkretistischen Ausrichtung dieses Ordens ihren Niederschlag. ${ }^{109}$ Hạaǧğī Bektāš pflegte überdies Umgang mit den weltlichen Machthabern oder mass sich mit den Vorstehern rivalisierender Derwischgruppierungen, indem er Wunder wirkte.

\footnotetext{
108 Mélikoff, op. cit. $74 \mathrm{f}$.

109 Zur Bektāšiyya im allgemeinen vgl. Birge, The Bektashi order of dervishes; die früheste bedeutende Studie stammt von Jacob, Die Bektaschijje; siehe auch Öztürk, The eye of the heart 59-83; Zarcone, Bektaşiyye (Bektāshiyya) und Bektaş Hacı, beide in $E I^{3}$; Knysh, Islamic mysticism 277-280.
} 
c. Hạāğǧĩ Bektāš werden letztlich auch Fähigkeiten zugeschrieben, die ebenso aus dem Schamanismus bekannt sind. Er oder seine Anhänger sollen die Gestalt von Tieren und Vögeln angenommen haben (z.B. Hirsch, Falke, Taube, Kranich). Ähnlich den Schamanen waren sie in der Lage, Kranke zu heilen und über die ğinn zu gebieten. Es sind gerade auch Berichte aus dem Wilāyet-nāme, die auf die schamanistischen Fähigkeiten von Ḥāğǧ̃̄ Bektāš hinweisen. Diese Quelle weiss, dass Ḥāğğ̄i Bektāš zur Eroberung der Bewohner von Baldahān aufbrach und die dortige Bevölkerung zum Islam bekehrt habe. ${ }^{110}$ Er habe sie durch seine ausserordentlichen Fähigkeiten für den Islam gewonnen, sei er doch in der Lage gewesen, Naturkatastrophen zu bewirken. Die Rede geht von Überschwemmungen, Dürren, Hungersnöten und dem Verursachen von lang anhaltender Finsternis. Schliesslich habe er auch einen Drachen besiegt.

In diesem Kontext lässt sich ebenso erwähnen, dass Hāāğǧì Bektāš von Aḥmad Yasawī ins Land Rūm geschickt worden ist. ${ }^{111}$ Gemäss dieser Darstellung war Yasawī ein Nachkomme von Muhammad b. al-Ḥanafìyya. ${ }^{112}$ Er sei von 'Alī b. Mūsā arRiḍā, dem 8. Imām, in sein Amt eingesetzt worden, habe sich nach Turkestan begeben und sich dort im Ort Yasi niedergelassen und 99'ooo Anhänger gehabt. Sie hätten in Ahmad Yasawīs Tekke eine Reihe von heiligen Gegenständen entdeckt, nämlich: a. Elifi tac (Kopfbedeckung) ${ }^{113}$; b. hirqa (Flickenrock der Derwische); c. çıră̆ (Kerze); d. sofra (Decke zum Auslegen des Essens); e. 'alam (Standarte); f. sağğāda (Gebetsteppich). Gemäss der Überlieferung hat Allāh diese Gegenstände

110 Vgl. Mélikoff, op. cit. 70; Mélikoff schreibt Baldahchan. 111 Vgl. Mélikoff, op. cit. 70-73.

112 Muhammad b. al-Hanafiyya war ein Sohn 'Alī b. Abī Țālibs; bei der Mutter handelt es sich aber nicht um Fāțīma, sondern um Hawla aus dem Stamm der Banū Hanīfa (vgl. Mélikoff, loc. cit., und Buhl, Muhammad Ibn al-Hanafiyya, in $\left.E I^{2}\right)$.

113 Die Bektāšīs kannten zwei Arten von Kopfbedeckungen. Beim elifi tac handelt es sich um eine konische Mütze aus weissem Filz. Sie diente später als Kopfbedeckung der Janitscharen (vgl. Mélikoff, op. cit. 70, Anm. 65); siehe Kapitel 2, bei Anm. 212-217. dem Propheten Muhammad überreicht, der sie an 'Alī weiter gegeben habe. Sie seien schliesslich über die weiteren Imame an 'Alī b. Mūsā ar-Riḍā gelangt. Dieser habe sie Aḥmad Yasawī übergeben. Seine halīfas hätten ihn gebeten, diese Gegenstände an einen unter ihnen weiterzureichen und ihm so sein Amt zu übertragen. Yasawī habe ihnen allerdings entgegnet, dass jene Person, für die sie bestimmt seien, diese Gegenstände selbst abholen werde.

Hāăǧğī Bektāš erhielt durch Telepathie Kunde von diesem Geschehen, erhob sich in die Luft und sauste in einem Augenblick nach Turkestan, wo ihn Ahmad Yasawī empfing, ihm nach dem Brauch das Haupthaar schnitt und ihm die heiligen Gegenstände übergab. Danach habe er ihn ins Land Rūm geschickt und ihm dort den Ort Soluca Karaöyük zugewiesen. Im Land Rūm würden viele Erleuchtete und Ekstatiker leben, er solle sich rasch zu ihnen begeben. An der Grenze zum Land Rūm habe er sich in eine Taube verwandelt und sich auf einem Felsen bei Soluca Karaöyük niedergelassen. ${ }^{114}$

Als die Derwische in Rūm (Rūm erenleri) von der Ankunft des Ḥāğǧñ Bektāš erfuhren, seien sie über die neue Konkurrenz beunruhigt gewesen. Einer ihrer halîfas, Hāğǧğ Toğrul, habe sich in einen Falken verwandelt und wollte die Taube angreifen. Ḥăğğĩ Bektāš habe sich in diesem Moment allerdings wieder in einen Menschen verwandelt, habe den Falken gepackt und ihm die Kehle zugeschnürt. Haăğğĩ Toğrul habe sich deshalb geschlagen geben müssen. Jedenfalls habe ihm Ḥāğğīi Bektāš zu bedenken gegeben, dass er in friedfertiger Absicht nach Rūm gekommen sei, sei die Taube doch ein sanftes Tier. Schliesslich erwiesen ihm die Derwische aus Rūm die Ehre und akzeptierten die Überlegenheit des ihnen von Ahmad Yasawī geschickten Ḥāğǧī Bektāš.

Diese Angaben lassen erahnen, dass Hậ̄ğǧì Bektāš unkonventionelle Standpunkte vertrat. Die Bektāšiyya steht ebenso wie weitere religiöse Gruppierungen mit einem Bezug zum Städtedrei-

114 Vgl. Mélikoff, op. cit. 71. 
eck Konya, Tabriz und Bagdad für eine Form des Islams, die als $\dot{G} u l a \bar{t}$-Schia bezeichnet wird. ${ }^{115}$ Beim Begriff $\dot{g} u l a \bar{t}$ handelt es sich morphologisch um ein Partizip aktiv (Plural; Singular: $\dot{g} a \overline{l i n}$ ) zur arabischen Wurzel $\dot{g}-l-w$, zu der das Verbalnomen (mașdar) guluww gebildet wird. Die Grundbedeutung des Verbs (I. Stamm) lautet „das Mass, die gebührenden Grenzen überschreiten, zu weit gehen, übertreiben".116 Der Begriff geht auf die schiitischen Häresiographen zurück.

Die bedeutendste Übertreibung der Angehörigen von der $\dot{G} u l a ̈ t-S c h i a$ zuzuordnenden Gruppierungen besteht darin, dass sie den Status der Imame, allen voran jenen 'Alī b. Abī Ṭālibs, des ersten Imams der Schiiten, in ungebührlicher Weise überhöhen und ihnen göttliche Qualitäten zuschreiben. Dies kommt in der Verehrung der Bektāšīs für 'Alī und die weiteren Märtyrer aus seiner Familie zum Ausdruck. Gruppierungen aus dem Umfeld der $\dot{G} u l a ̄ t-S c h i a$ werden deshalb auch als extremistische Schia bezeichnet. Neben der Bektāšiyya selbst sind in diesem Kontext auch die mit ihr eng verwandten Gruppierungen der Alawiten (bzw. Nușayrier), der Qizilbāš, der Ahl-i Haqq oder der 'Alī-Ilāhīs zu erwähnen. ${ }^{117}$ Von Bedeutung ist überdies, dass die Bektāšīs an eine Trinität glauben, die von 'Alī, Muhammad und Allāh gebildet wird. Die Positionen der Bektāšiyya selbst gelten gegenüber jenen anderer heterodoxer Kreise, z. B. jenen der Hurūfiyya, als gemässigt. Sie unterscheiden sich allerdings dennoch deutlich von der Lehre eines traditionalistisch orientierten Islams.

Ḥāğğ̄i Bektāš hat zwar jenem Orden den Namen gegeben, der sich um seine Person herum ab dem 14. Jh. ausbildete. ${ }^{118}$ Allerdings war Bālim Sultān der eigentliche Begründer und Organisa-

\footnotetext{
115 Vgl. für die weiteren Angaben Halm, Ğolāt, in EIr. Siehe ausserdem Hodgson, Ghulāt, in $E I^{2}$.

116 Gemäss Wehr, Wörterbuch, s.v.

117 Man vergleiche dazu u.a. die Untersuchungen von Moosa, Extremist Shiits. Auf diese Zusammenhänge wird später ausführlich zurückzukommen sein.

118 Vgl. Mélikoff, Hadji Bektach: Un mythe et ses avatars 51; siehe ausserdem Zarcone, Bektaşiyye, in $E I^{3}$.
}

tor der Bektāšiyya. ${ }^{119}$ Er ist jener pìr-i țānī (zweiter Meister, Vorsteher), der sich in mystischen Orden oft nachweisen lässt und die Bruderschaften organisatorisch auf feste Beine stellt. ${ }^{120}$ Der osmanische Sulțān Bāyazīd II. hatte Bālim Sulțān 907/1501 zum Vorsteher der Haupttekke der Bektāšiyya ernannt. ${ }^{121}$

Es war auch ungefähr zu jener Zeit, dass sich der Orden in zwei Gruppierungen aufspaltete. Die erste Gruppierung, die Șüfiyān, wurde mit den angeblichen Nachkommen des Hāğğḡì Bektāš, den Čelebīs, in Verbindung gebracht und war in der Haupttekke des Ordens in Hāāı Bektāş beheimatet. Die zweite Gruppierung ist unter dem Namen Bābāgān bekannt. Ihr Vorsteher, der Dede-Bābā, wurde unter den wählbaren ledigen Bektāšì-Predigern ausgesucht. Die Angehörigen dieser zweiten Gruppierung führten ihre Abstammung auf Bālim Sulțān zurück. ${ }^{122}$ Die wiederholten Bemühungen der Osmanen im Lauf des 16. Jh., die Bektāšis als Bruderschaft zu institutionalisieren, zielten auch darauf ab, sie unter die Kontrolle der Regierung zu stellen.

Der osmanische Verwaltungsapparat setzte sich in erster Linie mit der Gruppierung der ȘūfiyānČelebīs auseinander, die die meisten Tekkes des Ordens kontrollierten. ${ }^{123}$ Angaben zu den Bābāgān fehlen in den offiziellen Dokumenten weitgehend. Die Čelebīs waren hauptsächlich in den Provinzen aktiv, gerade auch in Albanien. Die meisten Konvente wurden von lokalen ČelebīFamilien verwaltet, die allerdings ihre Abhängigkeit von der Haupttekke der Bektāšiyya akzeptierten. Diese Funktion war eigentlich erblich, wobei die osmanischen Behörden und der Šayh in der Haupt-Tekke den Nachfolger jeweils im Amt

\footnotetext{
119 Zu Bālim Sulțān vgl. Zarcone, Bektaşiyye, in $E I^{3}$.

120 Zu Bālim Sulțāns Rolle als pīr-i țānı̄ vgl. Ziaee, Kapitel 1: „Sufism in Albania: Bektashism, Qadiri, Rufai, Khalqati, Saadi“ 2.

121 Knysh, Islamic mysticism 277.

122 Vgl. dazu Birge, The Bektashi order of dervishes 5658; Clayer, La Bektachiyya 468-469. Siehe ausserdem Knysh, Islamic mysticism 277-278.

123 Knysh, Islamic mysticism 278.
} 
bestätigen mussten. Diese Kontrolle verhinderte, dass die Bektāšiyya-Konvente von lokalen Gruppierungen mit allzu stark heterodoxen Tendenzen unterwandert wurden. Diese Gefahr drohte gerade von Seiten der Qizilbāš und weiterer $\dot{G} u l a ̄ t-$ Gruppierungen unablässig. Die soeben erwähnten Gruppierungen waren hauptsächlich auf dem Land aktiv.

Die politische Bedeutung der Bektāšiyya ergab sich ausserdem aus ihrer engen Verbindung mit den Janitscharen (Yeniçeri), den osmanischen Elitetruppen. Die Forschung machte wiederholt darauf aufmerksam, dass Angehörige der Bektāšiyya beim Aufstieg der Osmanen eine bedeutende Rolle spielten. ${ }^{124}$ Dieser Orden konnte seinen Einfluss im Osmanischen Reich dank seiner engen Beziehungen zu den Janitscharen aber auch noch deutlich später geltend machen. ${ }^{125}$ Die Janitscharen verehrten Ḥāğǧ̄̄ Bektāš als ihren Schutzheiligen. ${ }^{126}$ Die Angehörigen dieser Eliteeinheiten wurden im Rahmen der Knabenlese (devşirme) in den christlichen Familien v.a. auf dem Balkan rekrutiert. ${ }^{127}$

124 Zarcone, Bektaşiyye, in $E I^{3}$ (Abschnitte 1, 2 und 4).

125 Kissling, Derwischorden $12 \mathrm{f}$.

$126 \mathrm{Zu}$ den Beziehungen zwischen Bektāšiyya und Janitscharen vgl. auch Karamustafa, God's unruly friends $83^{-}$ 84 und 95: „The reason for the success of the Bektāşis was the firm connection with the Ottoman military system: the Janissaries, by long-standing tradition, paid allegiance to Hāāi Bektāş, the patron saint of the Bektāşī group (84)“. Siehe auch 133 (mit Anm. 71) bei A.T. Karamustafa.

$\mathrm{Zu}$ den Beziehungen zwischen der Bektāšiyya und den Janitscharen äussert sich ausserdem Mélikof, Hadji Bektach: Un mythe et ses avatars 101-102, 151-153, und ihr Index s.v. „Janissaires“; Mélikoff, Un ordre de derviches colonisateurs: les Bektaşis 118-123.

Vgl. überdies Feteke, Gül-Baba. L. Feteke hält u.a. fest (2): „Pečevī raconte que les ghazis de Buda ayant rapporté un grand bouc d'une de leurs entreprises militaires, l'ont remis au Gül-Baba-tekke pour être immolé - ce qui prouve que les tekke de Buda tout comme les bektāšì-tekke en général étaient en rapport étroit avec les Janissaires“. 3: „En temps de guerre, [les derviches bektāšĩs] partaient eux aussi en campagne avec les soldats pour stimuler leur zèle guerrier“. Siehe auch 7 f.: Gül Bābā selbst soll an zahlreichen Feldzügen, auch an der Eroberung Budas, teilgenommen haben.

Vgl. Gábor, Janissaries, in $E I^{3}$; zur devşirme siehe Kafa-
Die Janitscharentruppen wurden für die Osmanen jedoch zunehmend zur Hypothek, waren sie doch in zahllose Meutereien und Aufstände verwickelt. Sulțān Maḥmūd II. setzte dieser Plage 1826 ein Ende, indem er diese Einheiten grausam vernichtete. Dabei wurde auch die Bektāšiyya in Mitleidenschaft gezogen. Zahlreiche BektāšiyyaKonvente gingen an andere Bruderschaften über, u.a. an die Naqšbandiyya, die Sa'diyya, die Mawlawiyya, die Šãdiliyyya und die Halwatiyya. ${ }^{128}$ Erst um die Mitte des 19. Jh. kam es unter Sultān 'Abd al-Mağīd zu einer gewissen Erholung. ${ }^{129}$ H.J. Kissling macht auf den innern Widerspruch aufmerksam, dass der Osmanische Staat zumindest seit Selim I. (reg. 1512-1520) klar sunnitisch ausgerichtet war. Zugleich stützte sich dieses Reich aber bis 1826 wesentlich auf eine Kampftruppe, deren spirituellen Betreuer der Bektāšiyya angehörten.

Die in der Bektāšiyya vertretenen Auffassungen können hier nicht in extenso vorgestellt werden. Die einzelnen Forscher rücken stets auch ganz unterschiedliche Aspekte in den Vordergrund. ${ }^{130}$ Zentral ist jedenfalls der synkretistische Charakter dieses Ordens, in dem u.a. christliche Elemente eine Rolle spielen (Verteilen von Wein, Brot und Käse bei der Initiation; Bekennen der Sünden vor dem Šayh). Von Bedeutung sind ausserdem die Abhängigkeiten der Bektāšiyya von der Schia. Auch radikalere Gruppierungen unter den Qizilbāš-Turkmenen, die ihre Vorsteher vergöttlichen, weisen Verbindungen zur Bektāšiyya auf. ${ }^{131}$ Gewiss ist, dass die Bektāšiyya zahlreiche ihrer Auffassungen aus den vorislamischen Riten und dem Brauchtum der Turkmenenstämme übernommen hat. Zum heterodoxen Charakter der Bektāšiyya trug auch bei, dass sie als Sammel-

dar, Yeniçeri-esnaf relations 14-28, und Kreiser, Kleine Geschichte der Türkei 158.
128

129

130

131 
becken für Angehörige noch stärker umstrittener Gruppierungen diente. Dazu zählt v.a. die Hurūufiyya.

Die Hurūfiyya kam am Ende des 14. Jh. auf und geht auf Faḍl-Allāh Astarābādī (geb. 740/1340) zurück. ${ }^{132}$ B.S. Amoretti charakterisiert ihn als sayyid, Mystiker von Kindsbeinen an, Traumdeuter und eifrigen Pilger. Er hielt šarĩa-rechtliche Bestimmungen strikt ein, wozu er sich als Sohn eines $Q \bar{a} d \grave{l} \grave{\imath}$ verpflichtet fühlte. Faḍl-Allāh dachte oft über metaphysische Fragen nach. Er gewann seine ersten Anhänger, indem er ihre Träume deutete und ihre Gedanken las (firāsa).133 Ausserdem verstand Faḍl-Allāh die Vogelsprache, wie dies auch von den Imamen bekannt ist. Faḍl-Allāhs Anhänger unterschieden sich nicht wesentlich von den Gefolgsleuten anderer Derwischgemeinschaften. Sie waren zumeist niederer Herkunft und gingen einer handwerklichen Tätigkeit nach. Sie übten sich in Bescheidenheit und Rechtschaffenheit. Dies sind Merkmale, wie sie auch von andern Gruppierungen, gerade auch von den Futuwwaund Ahì-Bünden, bekannt sind.

Faḍl-Allāh stand bereits in fortgeschrittenem Alter, als er theopathische Erlebnisse hatte (ca.1386). Er erfasste die innere Bedeutung der prophetischen Offenbarung und die Würde des Șạhib $a z-z a m a \bar{n}$. Er schrieb damals auch sein Hauptwerk, das Ğāwidān-nāma-i kabīr. Er war oft zwischen Šìrwān und Isfahan unterwegs und lud die weltlichen Herrscher ein, sich ihm anzuschliessen. Allerdings war ihm gerade der mächtige Timur nicht wohlgesinnt. Es steht jedenfalls fest, dass ihn dessen Sohn Mīrān-Šāh gefangen setzte. Faḍl-Allāh wurde 1401 in Alinğaq grausam umgebracht. 'Alī lA'lā, Faḍl-Allāhs erstem halîfa, erging es nicht besser, als er versuchte, mit Qara Yūsuf in Kontakt zu treten. ${ }^{134}$ 'Alī l-Álā spielte eine bedeutende Rolle

132 Vgl. Amoretti, Religion in the Timurid and Safavid Periods, in $C H I$ VI, 623-625. Beachte zur Hurūfiyya auch Mir-Kasimov, Hurūfiyya, in $E I^{3}$; Bashir, Fazlallah Astarabadi; Mir-Kasimov, Words of power; Knysh, Islamic mysticism 275 .

133 Zur firāsa vgl. Fahd, Firāsa, in $E I^{2}$.

134 Vgl. Bashir, Fazlallah Astarabadi 97-99. bei der Verbreitung der Hurüufi-Lehre unter den Bektāšīs in Anatolien.

Die Ḥurūfiyya schreibt dem Menschen eine zentrale Stellung zu. Gottes Offenbarung in menschlicher Gestalt ist ein wichtiger Bezugspunkt ihrer Lehre. Die Fokussierung der Hurūfiyya auf den Menschen als Ort göttlicher Offenbarung bildet ihre wichtigste Gemeinsamkeit mit der Lehre der Ismāīiliyya. Die Hurūūiyya unterscheidet sich von der Ismã íliyy a allerdings insofern, als sich die göttliche Wirklichkeit (haqīqa) gemäss ihrer Auffassung in den Buchstaben (hurüf, Sg. harf) und nicht in der Person des Imams offenbarte. Diese zentrale Bedeutung der Buchstaben lässt auch einen Einfluss kabbalistischer Auffassungen vermuten. Die Ḥurūfiyya unterscheidet sich von schiitischen Auffassung stricto sensu am deutlichsten durch ihre Behauptung, sie besitze, den Schlüssel zur göttlichen Realität (haqīqa). Dieser Standpunkt erklärt, dass sie keines Imams als Vermittler zwischen Menschen und Gott bedarf.

\subsubsection{Qalandariyya, Hāksār, Haydariyya, Baraq $B \bar{a} b \bar{a}$}

Ins Umfeld dieser Derwischgruppierungen mit heterodoxen und antinomistischen Tendenzen zählen auch die als qalandar ${ }^{135}$ bekannten und oft in Gruppen umherziehenden Wanderderwische. Sie prägten die religiöse Landschaft in Zentralasien und Anatolien bereits im 6.-7./12.-13. Jh. massgeblich. ${ }^{136}$ Sie zeichneten sich durch ihr speziel-

135 Gemäss Baldick, Les Qalenderis 5oo, stammt der Ausdruck qalandar aus dem Perischen, ist aber letztlich unbekannten Ursprungs. Der Begriff ist auch mit dem persischen Wort kalandar in Verbindung gebracht worden, das a. einen „Klopfer aus Holz“ und b. einen „Klotz, einen ungehobelten Mann“ bezeichnet. Gemäss Mélikoff, Hadji Bektach. Un mythe et ses avatars 54, stammt der Begriff qalandar aus dem Persischen und bedeutet a. eine Person, die sich nicht an die Konventionen hält, und b. einen Bettel- bzw. Wanderderwisch. I. Mélikoff entnimmt diese Angaben Redhouse, A Turkish and English Lexicon. Siehe auch Dihhudā, Luġat-nāma, s.v.

136 Vgl. für die weiteren Ausführungen Knysh, Islamic mysticism 272-274; Baldick Les Qalenderis 500-503. Vgl. auch die Überlegungen bei Mélikoff, Hadji Bektach. Un mythe et ses avatars 53-55. 
les Äusseres aus. ${ }^{137}$ Diese Bewegung ist gemeinhin als Qalandariyya bekannt. Sie unterscheidet sich von den weiteren hier vorgestellten Gruppierungen insofern, als sich die Qalandar-Derwische nicht in eigentlichen Orden organisierten. Sie verliessen sich für ihren Lebensunterhalt auf Gottes Fürsorge (tawakkul) $)^{138}$ bzw. lagen der einheimischen Bevölkerung auf der Tasche - letztlich eine Frage der Perspektive. Sie mutierten damit zu einer weitherum gefürchteten Landplage. Sie beachteten eine Reihe von ungeschriebenen Regeln, die sie von den restlichen Sufis unterschieden. Die Qalandar-Derwische verschwanden im 10./16. Jh. in Anatolien. ${ }^{139}$ Sie konnten sich aber in Zentralasien und Ost-Turkestan bis zum Beginn des 20. Jh. halten.

Die Qalandariyya hatte ihren Ursprung zwar im Osten der islamischen Welt und war auch v. a. dort verbreitet. Sie machte sich aber ebenso in zentraleren Teilen des islamischen Kulturraums bemerkbar. Qalandar-Derwische lassen sich am Anfang des 13. Jh. in Damaskus und Damietta (Ägypten) nachweisen. Der Perser Ğamāl ad-Dīn Sāwī (gest. 630/1223) wird oft als Begründer der Bewegung angeführt. Sāwī war anfänglich ein gewöhnlicher Sufi und hielt seine Predigten in einem gut ausgestatteten Konvent im Iraq. ${ }^{140}$ Er wurde dieses Lebens in Wohlstand allerdings überdrüssig und zog zusammen mit vierzig Anhängern umher. Er

137 Mélikoff, Hadji Bektach: Un mythe et ses avatars 54, macht auf das Aussehen dieser Qalandar-Derwische aufmerksam. Sie seien gerade in Zentralasien noch heute unterwegs, trügen Kappen mit Schwanenfedern, Gürtel mit Schellen und amulettwertigen Gegenständen und hätten einen Stock. Für Abbildungen solcher Wanderderwische siehe Öztürk, The eye of the heart, Illustrationen 1(S. 5), 7 (S. 11); Karamustafa, God's unruly friends, Abb. 1-7 (nach S. 49).

138 Zum Tawakkul-Konzept vgl. Reinert, Die Lehre vom tawakkul.

139 In Anatolien waren Ǧamāl ad-Dīn Sāwīs Anhänger als Ğawlaqiyya bekannt. Der Begriff bringt zum Ausdruck, dass die Angehörigen dieser Gruppierung Kleider aus Sacktuch ( ǧiwāliq) trugen.

140 Knysh, Islamic mysticism 273, wo Verweis auf Karamustafa, God's unruly friends 40-44; siehe auch den Index bei Karamustafa, s.v. „Sāvi““. wandte sich in Übereinstimmung mit dem Prophetenwort موتوا قبل ان تموتوا von der Welt ab. ${ }^{141}$ Er gab Besitz und soziale Stellung auf und verliess Frau und Freunde.

Sāwī predigte zwar ein Leben in Zurückgezogenheit und Weltentsagung. Seine Anhänger schlossen sich jedoch zu Gruppen von Wanderderwischen zusammen. Im Lauf der Entwicklung musste die Gemeinschaft Zugeständnisse an die allgemeinen sozialen Gepflogenheiten machen. Sāwī selbst hatte seine Anhänger dazu aufgefordert, sich von Gras und Wildfrüchten zu ernähren, nackt umherzuziehen und nur ihre Lenden zu bedecken. Später gestattete er ihnen allerdings, fromme Gaben anzunehmen und wollene Kleider zu tragen.

Sāwī wurde gegen Ende seines Lebens seiner zahllosen Verehrer überdrüssig und überliess seine Gemeinschaft ihrem Schicksal. Er selbst liess sich auf einem Friedhof bei Damietta nieder, wo zu seinen Ehren später eine zāwiya errichtet wurde. ${ }^{142}$ Sāwīs Lehre wurde hauptsächlich mündlich überliefert. Gelehrtenwissen war ihm zuwider. Auch begegnete er weltlichen und religiösen Autoritäten mit Geringschätzung. Seine Anhänger vermieden Heuchelei und verachteten den Luxus. Sie erfreuten sich aber des Anblicks anmutiger Gesichter und verehrten darin die Manifestation der göttlichen Schönheit.

Auch die Qalandar-Derwische sahen sich angesichts der Bedrohung durch die Mongolen gezwungen, nach Anatolien und Indien auszuwandern. ${ }^{143}$ Sie werden gerade in Anatolien heftig kritisiert, wirft man ihnen doch Unzucht vor. In Indien schlossen sich der Qalandariyya - zumindest vorübergehend - auch einige berühmte SufiPersönlichkeiten und Intellektuelle an und vertraten deren gegen das establishment gerichte-

\footnotetext{
141 Die Übersetzung dieses angeblichen Prophetenworts lautet: „Sterbt, bevor ihr sterbt!“

$142 \mathrm{Zu}$ Ğamāl ad-Dīn Sāwīs zāwiya in Damietta siehe Karamustafa, God's unruly friends $43 \mathrm{f}$. (mit Anm. 19, S. 118).

143 Vgl. Baldick, Les Qalenderis 501.
} 
ten Standpunkte. Dazu gehören Faḩr ad-Dīn 'Irāqī (gest. 686/1287) und Amīr Husaynī (gest. 718/1318).

In Anatolien überwachten die Seldschuken die Qalandar-Derwische überall und zwangen sie zur Mitarbeit auf Feldern, in Weinbergen oder beim Errichten von Festungen. Ab 1240 schliessen sich die Qalandarīs den Rebellionen und den Volksbewegungen an. Die ersten osmanischen Sultane räumen ihnen zwar Privilegien ein, verjagen sie aber doch immer wieder aus ihrem Einflussbereich. Im Jahr 1416 beteiligen sich die Qalandarīs an der Revolte Badr ad-Dīns. ${ }^{144}$ Unter Meḥmed II. (reg. 1444-1446 und 1451-1481) haben die Osmanen für die Qalandarīs Konvente errichtet und konnten sie so besser überwachen. 1492 beging ein QalandarDerwisch ein Attentat auf Bāyazīd II. Der Angreifer beanspruchte, der Mahdī zu sein. Dieses Attentat veranlasste den Sultan dazu, die Qalandarīs aus dem europäischen Teil seines Reichs zu verjagen.

Aus osmanischen und europäischen Quellen geht hervor, dass die Qalandarīs 'Alī b. Abī Ṭālib verehrten. Sie verfluchen jedoch die drei ersten Kalifen, die die Rechte 'Alīs auf die Nachfolge Muhammads missachtet hatten. ${ }^{145}$ Im Jahr 1527 beteiligen sich diese Wanderderwische an der Revolte Qalender Celebis, der über Tausende von Anhängern verfügte. Es sind die QalandarTruppen, die den Osmanen am längsten Widerstand leisten. Im Jahr 1579 verübt ein weiterer Qalandar-Derwisch bei einer Audienz ein Attentat auf den Wesir und verletzt ihn tödlich. Ab dem 17. Jh. gehen die Qalandarīs zunehmend in der Bektāšiyya auf, wie dies auch auf weitere heterodoxe Strömungen zutrifft. Allerdings gibt es in der Türkei weiterhin Wanderderwische. Sie werden erst in der zweiten Hälfte des 19. Jh. gänzlich verdrängt.

Im 20. Jh. lassen sich die Auffassungen der Qalandariyya in der Bruderschaft der Hāāssār beob-

\footnotetext{
144 Vgl. Baldick, Les Qalenderis 501. Zum Aufstand Badr adDīns, vgl. Karatas, Badr al-Dīn b. Qāḍī Samāwnā, in $E I^{3}$; siehe ausserdem: Balivet, Vie du cheikh Bedreddin.

145 Das rituelle Verfluchen der ersten drei Kalifen (sabb wa la'nat) war unter den Safawiden weit verbreitet. Vgl. dazu Calmard, Tabarru', in $E I^{2}$.
}

achten. ${ }^{146}$ Riḍā Šāh (1925-1941) unterdrückte die Hāksār massiv. Die Huāksār-Derwische mussten ihr Wanderleben deshalb aufgeben und sich in ihre Konvente zurückziehen. Sie sind für ihren Opiumgenuss bekannt. In Zentralasien wiederum diente ihnen das Mausoleum Šayh Ṣafās in der Nähe von Samarkand als Zentrum. ${ }^{147}$ Sie zeichnen sich durch Merkmale aus, die sowohl aus dem Derwischtum als auch dem Schamanismus bekannt sind. In Syrien hat die Qalandariyya bis nach $195^{\circ}$ in Aleppo einen Konvent besessen, ist danach aber verschwunden.

Die Haydariyya erlebte ihre Blüte im 9.-10./15.16. Jh. im Osmanischen Reich. Sie vertrat die Auffassungen der Qalandariyya in besonderes extremer Form. Die Mitglieder dieser Bruderschaft kleideten sich in Sacktuch, Filzstoff oder Schafhäute. Sie trugen Eisenringe am Ohr, um den Nacken, die Knöchel und an den Genitalien. ${ }^{148}$ Auch sie begegneten den Positionen der offiziellen Religion mit Verachtung und scherten sich keinen Deut um die Regeln eines korrekten sozialen Verhaltens. Die osmanischen Gelehrten bezichtigten sie deshalb der Pädophilie, des Rauchens von Cannabis und des Alkoholgenusses. ${ }^{149}$

Nach der Machtübernahme durch die Safawiden lassen sich die Haydarīs in Iran weiterhin nachweisen. Regelmässig kommt es in den grossen Städten zu Auseinandersetzungen zwischen den Haydarīs und ihren Rivalen, den Ni'matullāhīs. Die beiden Gruppierungen bewohnen je eigene Stadtteile. Bei diesen gewissermassen ritua-

146 Zu den Hāassār vgl. u.a. Gramlich, Derwischorden Persiens. Erster Teil: Die Affiliationen 70-88 und 92; ders., Dritter Teil: Brauchtum und Riten 17, 19, 44-48; Kapitel: Die Aufnahme bei den Ḩāksār (79-117). Siehe ausserdem Nūr ad-Dīn Mudarrisī Čahārdahī, Hākssar wa ahl-i haqq.

147 Vgl. Zarcone, Islam: The Sufi orders of northern Central Asia. Auch Bennigsen und Enders Wimbush, Mystics and commissars 13 .

148 Vgl. die Abbildungen bei Karamustafa, God's unruly friends Abb. 3 (nach S. 49).

149 Auch Mélikoff, Hadji Bektach: un mythe et ses avatars 54, macht im Zusammenhang mit der Qalandariyya auf derartige Missstände aufmerksam. 
lisierten Kämpfen gibt es regelmässig Verletzte. Die Haydarīs haben bedeutenden Einfluss auf die Handwerker ausgeübt. Dies hat wiederholt die 'ulam $\bar{a}$ ' auf den Plan gerufen, in deren Augen dieser Einfluss der Produktivität der Handwerker abträglich war.

Bereits im 12. und vermehrt im 13. Jh. taten sich unter den Derwischen Einzelpersonen hervor, die sich sowohl durch ihr äusseres Erscheinungsbild als auch durch ihre weltanschaulichen Positionen von den Standpunkten eines traditionalistisch orientierten Islams abhoben. Unter ihnen erlangten drei Männer grössere Bekanntheit. Es handelt sich um Baraq Bābā (auch Barāq Bābā), Qayg̉usuz Abdāl und Sulțān Şücācc ${ }^{150}$ Die weiteren Ausführungen weisen unter ihnen auf Baraq Bābā stellvertretend eingehender hin. ${ }^{151}$

H. Algar nennt Baraq Bābā (655-707/1257-1258 bis 1307-1308) einen krypto-schamanistischen turkmenischen Derwisch aus Anatolien, der über enge Beziehungen zu zwei Îlhāniden-Herrschern verfügt habe. Viele Angaben zu ihm sind nicht gesichert. Er soll in einem Dorf in der Nähe von Tokat in Zentral-Anatolien geboren worden sein. Sein Vater 'Izz ad-Dīn Kaykāūs (gest. 678/1279-128o) diente unter den Rūm-Seldschuken als Militärkommandant. Baraq Bābā soll als Kind getauft worden sein und später eine Ausbildung zum griechisch-orthodoxen Priester in Angriff genommen haben. Er soll allerdings durch Șarı Șalțūq zum Islam zurückgefunden haben. Șarı Șalțūq war ein halblegendärer Krieger-Heiliger, der zur Verbreitung des Islams auf der Krim und in der Dobrudja beigetragen hat. ${ }^{152}$

Baraq Bābā verliess Șarı Șalțūq zu einem unbestimmten Zeitpunkt und begab sich an den Hof der Îlhāniden in Tabriz. Sein šayh hatte zuvor vermutlich einen militärischen Rückschlag erlitten.

\footnotetext{
$15^{\circ}$ Vgl. den Hinweis bei Karamustafa, God's unruly friends 62.

Die weiteren Ausführungen stützen sich auf Karamustafa, God's unruly friends if., $62 \mathrm{f}$., siehe auch seinen Index s.v. Baraḳ Baba; Algar, Barāq Bābā, in EIr; Algar, Baraq Baba, in $E I^{3}$.

152 Vgl. zu ihm Leiser, Sari Salțūk Dede, in $E I^{2}$.
}

Bei seiner Ankunft am Hof Ġāzāns (reg. 1295-1304) in Tabriz soll man seine okkulten Fähigkeiten auf die Probe gestellt haben, indem man einen Tiger (allenfalls einen Löwen) auf ihn loshetzte. Ein kurzer Schrei Baraq Bābās habe allerdings genügt, um das Raubtier zu stoppen. Jedenfalls scheint Baraq Bābā dadurch das Vertrauen Ġāzāns und von dessen Nachfolger Muhammad Hudābanda Ölğäytü (reg.1304-1316) gewonnen zu haben. Verschiedentlich wurden Baraq Bābā diplomatische Missionen bzw. Spionageaufträge anvertraut.

Seine Ankunft in Damaskus im Jahr 706/1306 hat vielfache Beachtung gefunden. Er zog dort mit dem Banner der Īlhāniden und einem Ernennungsschreiben ein. Sein sonderbares Aussehen hat unter den Damaszenern sowohl Belustigung als auch Abscheu hervorgerufen. Er und seine Anhänger - die Rede ist von etwa hundert Derwischen - sollen weitgehend nackt gewesen sein und sich nur mit einem roten Lendenschurz bekleidet haben. Ihr Haar war ungepflegt und filzig. Auch soll Baraq Bābā einen mit Kuhhörnern versehenen Turban getragen haben. Seine Begleiter traten in gleicher Aufmachung auf. Sie machten Musik mit Gebeinen und Schellen, zu der Baraq Bābā tanzte. Da ihm die Einreise nach Ägypten verweigert wurde, zog Baraq Bābā mehrfach zwischen Damaskus und Jerusalem hin und her, bevor er nach Iran zurückkehrte. Im Jahr darauf wurde er nach Gilan gesandt, wo sich die Bevölkerung gegen die Herrschaft der Îlhāniden auflehnte. Er sei allerdings als Šayh der Mongolen und Feind der Muslime beschimpft und umgebracht worden. Baraq Bābā wurde darauf in Sulțāniyya bestattet.

Baraq Bābās Ruhm überdauerte ihn selbst in Sulțāniyya und Anatolien. Ölǧäytü errichtete für seine Anhänger in Sultāniyya einen hānaqāh. Der šayh scheint auch eine kurze Risāla auf Qipčaq-Türkisch verfasst zu haben, zu der ein persischer Kommentar von Quțb ad-Dīn al-'Alawī existiert. Quṭb ad-Dīn interpretiert die ekstatischen Aussagen Baraq Bābās in Übereinstimmung mit der Lehre des klassischen Sufismus in Iran. $\mathrm{H}$. Algar schliesst daraus, dass zu jener Zeit keine klare Trennlinie zwischen Baraq Bābās krypto- 
schamanistischen Auffassungen und den Vorstellungen der Angehörigen des besser etablierten traditionalistisch ausgerichtetem Sufismus bestand. Es kann sein, dass Baraq Bābā Ğalāl ad-Dīn Rūmī getroffen hat. Auch später könnte es zu einem Austausch zwischen Gefolgsleuten Baraq Bābās und Vertretern der Mawlawiyya gekommen sein.

Auch Baraq Bābā soll an die göttliche Natur 'Alīs geglaubt haben. 'Alī seinerseits soll sich in der Person des İlhāniden-Herrschers Muhammad Hudābanda manifestiert haben, der sich zur Schia bekannte. ${ }^{153}$ Wenn dies zutrifft, lässt sich in Baraq Bābā ein früher Vertreter einer Entwicklung erkennen, die die Safawiden zwei Jahrhunderte später an die Macht brachte. Aus den soeben festgehaltenen Beobachtungen geht jedenfalls hervor, dass Baraq Bābā Standpunkte vertrat, in denen sich türkischer Schamanismus, Sufismus und $\dot{G} u l a ̄ t-S c h i a$ miteinander vermischten.

A.T. Karamustafa tritt übrigens der zumeist vertretenen Auffassung entgegen, dass sich nur Ungebildete aus den breiten Massen antinomistischen Gruppierungen anschlossen. Diese übten vielmehr auch auf die literati im weitesten Sinn des Wortes ihre Anziehungskraft aus. Es lassen sich unter ihnen durchaus Dichter, Gelehrte und Schriftsteller feststellen. Der Vorwurf, es schlössen sich vornehmlich des Lesens Unkundige aus den breiten Massen diesen Bewegungen an, dürfte in erster Linie auf die Kritiker an diesen Gruppierungen im religiösen establishment zurückgehen. ${ }^{154}$

\subsubsection{Die Bayramiyya}

Neben der Qalandariyya ist aus dem Osmanischen Reich mit der Bayramiyya bzw. der BayramiyyaMalāmatiyya auch ein weiterer Derwischorden mit antinomistischen Tendenzen bekannt. ${ }^{155}$ Die Bayramiyya wurde im 9./15. Jh. von Ḥăğğì Bay- ram (gest. 833/1429) in Ankara gegründet. ${ }^{156}$ Er gab sich gegenüber seinen Anhängern als geistiger Nachkomme und Erneuerer der MalāmatiyyaBewegung aus Khorasan aus. ${ }^{157}$ Er untersagte seinen Jüngern in Übereinstimmung mit der Lehre der ursprünglichen Malāmatiyya das öffentliche

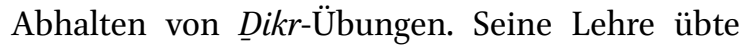
zwar in Zentral-Anatolien durchaus einen gewissen Einfluss aus. Es gelang ihr allerdings nie, auch in der Hauptstadt des Osmanischen Reichs Fuss $\mathrm{zu}$ fassen. H. Sohrweide weist auf die engen Beziehungen zwischen der Șafawiyya und der Bayramiyya hin. ${ }^{158}$ Mawlānā Šayh Ḥāmid b. Mūsā, der Lehrer von Hāăğḡi Bayram, habe die mystische Lehre von Huwāğa 'Alī (1392-1429), dem Grossohn Safī ud-Dīns übernommen.

Nach Hāāğğī Bayrams Tod kam es innerhalb des Ordens zu Spannungen. 'Umar as-Sikkīnī (gest. 880/1476) zeigte sich nicht bereit, Āq Šams adDīn als Hāğğḡì Bayrams Nachfolger anzuerkennen, und gründete seinen eigenen Orden, der als Malāmatiyya-Bayramiyya bekannt wurde. Die Abtrünnigen verzichteten auch auf das Tragen der hergebrachten Kleidung (hirqa, tāğ).

Ansonsten ist wenig über die Hintergründe dieser Abspaltung bekannt, bei der Rivalitäten zwischen zwei Gruppen von Ḥāğğì Bayrams Anhängern eine wichtige Rolle gespielt haben dürften. Die Anhänger Āq Šams ad-Dīns vertraten Standpunkte, wie sie aus der Schia allgemein bekannt sind, und unterstrichen den radikalen Unterschied zwischen Gott und dem Menschen. Die Malāmatiyya hingegen neigte der Auffassung Hallāğs zu, wonach Gott sich in einigen auserwählten Personen manifestieren kann; diese stehen Gott besonders nahe. Bei diesen vollkommenen Personen handelt es sich um die Vorsteher der MalāmatiyyaGemeinschaft. Diese Auffassung wiederum hat die

\footnotetext{
156 Clayer et al. (Hg.), Melâmis-Bayrâmis; Yavuz, The making of a Sufi order; Kissling, Bajrâmijje.

157 Zur ursprünglichen Malāmatiyya in Khorasan siehe Knysh, Islamic mysticism 94-99.

$15^{8}$ Sohrweide, Șafaviden 116 f.; vgl. auch die Überlegungen bei Kissling, Bajrâmijje 196-203 [242-249].
} 
sunnitischen 'ulamā' im Osmanischen Reich alarmiert, die darin einen Angriff auf die šarīa erkannten.

Gewisse Aussagen der Malāmatiyya-Gelehrten lassen auf eine Abhängigkeit von der Hurūfiyya schliessen. Aufgrund ihrer impliziten Nähe zur Ḥurūfiyya wurde auch die Malāmatiyya im Osmanischen Reich Opfer von Verfolgungen. Die Angehörigen dieses Ordens sahen sich deshalb gezwungen, in den Untergrund zu gehen und ihre Auffassungen vor uneingeweihten Kreisen geheimzuhalten.

Bis am Anfang des 10./16. Jh. beschränkte sich die Verbreitung der Malāmatiyya auf Zentralanatolien. Oğlān Šayh allerdings begann, diese Lehre auch in der Osmanischen Hauptstadt unter Soldaten und der Zivil-Bevölkerung zu verbreiten. Die 'ulam $\bar{a}$ überprüften deshalb seine Glaubensauffassungen bei Befragungen und bezichtigten ihn der Häresie. Er wurde gestützt auf eine fatwā des osmanischen Gelehrten und Staatsmanns Kemāl Paşazāde (gest. 940/1545) hingerichtet. Später verbreitete Šayh Ahmad, der Kameltreiber (gest. 952/1543), die Auffassungen der Malāmatiyya auf dem Balkan. Der Orden fasste v.a. in Bosnien Fuss, wo er durch seine regierungskritischen Aktivitäten auffiel. Šayh Ahmmad hinterfragte die Legitimität des herrschenden osmanischen Sultans. Aus dem Balkan stammt mit Šayh Hamza (gest. 968/1561) auch der nächste Märtyrer dieses Ordens. Er hatte ebenso versucht, die Lehre des Ordens in Istanbul zu verbreiten. Hamza genoss grosses Ansehen; die Gruppe seiner Anhänger war als Hamzawiyya bekannt.

Die Anstrengungen der Behörden, die Malāmatiyya in der Hauptstadt und in den Provinzen auszurotten, waren nur bedingt erfolgreich. Im Jahr 1073/1662 wurde der letzte Märtyrer der Malāmatiyya zusammen mit vierzig Gesinnungsgenossen hingerichtet. Zu diesem Zeitpunkt hatte die Malāmatiyya ihre radikaleren Auffassungen aufgegeben und den Primat der šarīa akzeptiert. Aufgrund dieser Mässigung fanden auch Mitglieder der herrschenden Eliten des Osmanischen Reichs Zugang zum Orden. Dies stellte einen wesentli- chen Faktor in der Konsolidierung dieser Bruderschaft dar. Die Malāmatiyya erwachte später unter dem ägyptischen Sufi Muḥammad Nūr al-'Arabì (gest. 1306/1888) zu neuem Leben.

\subsubsection{Die Kubrāwiyya}

Die bisherigen Ausführungen haben ausgewählte Derwischorden vorgestellt, die im Osmanischen Reich eine wichtige Rolle spielten (Mawlawiyya, Yasawiyya, Bektāšiyya, Qalandariyya, BayrāmiyyaMalāmatiyya). Sie lassen sich zumindest indirekt zumeist mit den Wanderungsbewegungen der Turkvölker aus Zentralasien in Richtung Anatolien in Verbindung bringen. Im folgenden soll mit der Kubrāwiyya auf einen weiteren Derwischorden aus Zentralasien aufmerksam gemacht werden. 159

Die Kubrāwiyya war der einflussreichste SufiOrden in Zentralasien und Persien zur Zeit der Mongolen. ${ }^{160}$ Dieser Orden geht auf Nağm adDīn Kubrā (gest. 617/1220) zurück. ${ }^{161}$ Er wurde 1145 (allenfalls 1155) in Hwwārazm geboren. Nağm adDīn befasste sich anfänglich mit Theologie, doch im Alter von ca. 35 Jahren begann er, sich intensiver für spirituelle Fragen zu interessieren. Er reiste jedenfalls viel (Nišāpūr, Hamadan, Isfahan, Mekka, Alexandrien, Kairo, Dezful). Er kehrte 1184 nach Zentralasien zurück. Vieles spricht dafür, dass Rūzbihān Mișrī, 'Ammār Yāsir Bidlīsī und Ismācīl Qașrī zu seinen wichtigsten Lehrern zählten. Gerade Bidlīsī spielte eine bedeutende Rolle für seinen spirituellen Werdegang. Da Nağm ad-Dīn seine wichtigste hirqa von Bidlīsī erhielt, lässt sich auch auf Abhängigkeiten Nağm ad-Dīns von der Suhrawar-

159 Ebenso aus Zentralasien stammt die Naqšbandiyya. Ihre Positionen weisen eine grosse Nähe zum traditionalistisch ausgerichteten sunnitischen Islam auf. Die Naqšbandiyya wird hier nicht näher vorgestellt; vgl. zu ihr Knysh, Islamic mysticism 218-234.

16o Vgl. zu Nağm ad-Dīn Kubrā und der Kubrāwiyya: Algar, Kobrawiyya I. The Eponym, und Kobrawiyya II. The Order, beide in EIr; Knysh, Islamic mysticism 234-239; Nağm ad-Dīn Kubrā, Die Fawāih al-ğamāl wa-fawātị̣ al-ğalāl.

161 Er soll im Rahmen des Einfalls der Mongolen ums Leben gekommen sein. 
diyya schliessen, der Bidlīsī angehörte. In Huwārazm (Kunya Urgench) befindet sich Nağm ad-Dīn Kubrās Mausoleum, das immer wieder von Pilgern aufgesucht wurde. Die zu seiner Ausschmückung eingesetzten Gestaltungsmittel sind auch für die Untersuchung der Dokumente in Rollenform relevant. ${ }^{162}$

\subsubsection{Ausgewählte Sufi-Bruderschaften aus der arabischen Welt: Qādiriyya, Šādiliyya und Suhrawardiyya}

Obwohl Khorasan bei der Ausbildung der SufiOrden eine zentrale Rolle spielte, lässt sich das Phänomen der Tarīqa-Bildung im 6.-7./12.-13. Jh. auch ausserhalb Zentralasiens beobachten. Auf diese Zeit gehen die Anfänge der Qādiriyya (Bagdad), der Šādiliyya (Ägypten) und der Suhrawardiyya (Bagdad) zurück. Die weiteren Ausführungen befassen sich mit diesen Orden, die in weiten Teilen der islamischen Welt eine wichtige Rolle spielen sollten. Sie gehen v.a. auf die Suhrawardiyya ein, da sie - indirekt zumindest - mit der Reform der Futuwwa-Bewegung verbunden ist, die später vorgestellt wird. ${ }^{163}$ Knapper fallen hingegen die Darstellungen zur Qādiriyya und der Šādiliyya aus, die jedoch vorangestellt werden:

Die Qādiriyya zählt zu den bedeutendsten SufiOrden in der islamischen Welt und geht auf 'Abd al-Qādir al-Ǧìlānī (481-561/1088-1166) zurück..164 Auch diese Gemeinschaft entwickelte sich erst nach dem Tod ihres Namensgebers zu einer eigentlichen Bruderschaft. 'Abd al-Qādir al-Ǧīlānī war zu derselben Zeit aktiv wie der ältere Suhrawardī, auf den der Derwischorden der Suhrawardiyya zurückgeht. ${ }^{165}$ Ğìlānī war hanbalitischer Prediger und zog

162 Vgl. http://www.karakalpak.com/ancnajam.html und https://archnet.org/sites/3956 (ohne Abbildungen; Stand beide 31. August 2017).

163 Zur Futuwwa vgl. Kapitel 3.2.1.

164 Zu 'Abd al-Qādir al-Ǧ̄ilānī und der Qādiriyya vgl. Schimmel, Mystische Dimensionen 350-352, und ihren Index s.v. 'Abdul Qādir Gīlānī (gest. 1166; Eigennamen); Knysh, Islamic mysticism 179-183 und 184-192; Öztürk, The eye of the heart 103-106; Chabbi, 'Abd al-Qādir alJīlānī, in $E I^{3}$.

165 Mit dem älteren Suhrawardī ist 'Abd al-Qāhir Abū die Einwohner Bagdads in Scharen in seinen Bann. Er stammt aus der Provinz Gilan am Kaspischen Meer, wie sich aus seiner nisba ableiten lässt. Er kann als volkstümlichster Heiliger in der islamischen Welt betrachtet werden. Sein Ruf gründet in erster Linie auf unzähligen Legenden, während historische Fakten mit grossen Unsicherheiten verbunden sind. Diese Legenden passen nicht zum Bild des ernsten und nüchternen Predigers, der hanbalitisches Recht studiert hatte. Sein Mausoleum zieht heute zahllose Pilger aus dem Indischen Subkontinent an, wo sich die Qādiriyya im 15. Jh. etablierte.

'Abd al-Qādirs Ruf nahm rasch unglaubliche Ausmasse an. Er wird Muhyī d-Dīn genannt, soll er doch den Glauben zu neuem Leben erweckt haben. Dieser Ehrentitel geht auf eine Begebenheit zurück, bei der Ğīlānī einem alten, entkräfteten Mann am Wegrand wieder auf die Beine half. Dieser Mann gab sich gegenüber Ǧīlānī darauf als „Religion des Islams“ zu erkennen. Die Forschung konnte bis anhin die Frage nur bedingt klären, wie sich dieser strenge, in hanbalitischem Recht geschulte Prediger zum Vorbild des volksnahen, in der gesamten islamischen Welt verehrten Heiligen entwickelte. ${ }^{166}$ Der Umstand, dass er nicht weniger

Naǧīb as-Suhrawardī (gest. 1168) gemeint, auf den die Suhrawardiyya letztlich zurückgeht. Noch einflussreicher, auch für den Orden, sollte aber sein Neffe 'Umar as-Suhrawardī (1145-1234) sein, von dem noch die Rede gehen wird; vgl. zu ihm unten nach Anm. 172.

Zu Ğīlānīs Ausbildung siehe Knysh, Islamic mysticism 179f.: Ǧìlānī soll im Alter von 17 Jahren nach Bagdad gekommen sein, um hanbalitisches Recht und Hadīt Wissenschaft zu studieren. Seine eigentliche Hinwendung zum Sufismus fand unter dem strengen Meister Abu l-Huayr ad-Dabbās (gest. 523/1131) statt. Dabbās verpflichtete Ǧīānī zu eiserner Disziplin (nächtliche Gebete, langandauerndes Fasten, zahllose Rezitationen des Korans, Rückzug in die Wüste ohne Vorräte). Im Alter von fünfzig Jahren hatte Ǧīlānī allerdings einen Traum (521/1127). Er fühlte sich jetzt reif genug, in die Gesellschaft zurückzukehren und sein Wissen in seinen Predigten weiterzugeben. Seine Anhänger stammten aus dem gemeinen Volk und dem Königshaus; sie rekrutierten sich ebenso unter den reichen Händlern. Kurz vor seinem Tod hatte der hanbalitische Asket Muharrimī 'Abd al-Qādir ausserdem mit der Leitung 
als vier Frauen und 49 Söhne hatte, unterstreicht allerdings, dass er kein strenger Asket gewesen sein konnte. Sein Erfolg dürfte in erster Linie auf seinem unwiderstehlichen Charisma beruht haben. ${ }^{167}$

Während die Qādiriyya eher aus dem Osten der islamischen Welt stammt, ist die Šādiliyya in erster Linie in Ägypten und in Nordafrika beheimatet. ${ }^{168}$ Der Orden geht auf Abu l-Ḥasan aš-Šādilīi (ca. 593656/ca. 1196-1258) zurück. Seine Person ist uns aufgrund der Berichte seiner Schüler bekannt; sie sind oft spät entstanden und haben hagiographischen Charakter. Diese Darstellungen thematisieren den Archetypen des walī. Šādilī soll um 583 oder auch erst zehn Jahre später geboren worden sein. Er stammt angeblich über die Linie Hasans vom Propheten ab. Er studierte die religiösen Disziplinen in Fes, gab diese Ausbildung aber zugunsten der Mystik auf. 615/1218 brach er in den Iraq auf, wo er bei Abu l-Fatḥ al-Wāsițī (gest. 632/1234), einem halîfa Aḥmad Rifāīis, dem Namensgeber der Rifā‘̄yya, lernte. ${ }^{169}$ Einer seiner Lehrer legte ihm allerdings nahe, in den Maghreb zurückzukehren. Er lebte zuerst bei 'Abd as-Salām b. Mašǐš (gest. 625/1228), zog nach einigen Jahren aber ins Dorf Šādila, das auf halbem Weg zwischen Tunis und Kairouan (Qayrawān) gelegen ist. Von diesem Ort leitet sich auch seine nisba aš-Šādilī ab. Hier zog er die Pilger in Scharen an und soll zahlreiche Wunder gewirkt haben. Seine Lehre weckte allerdings den Widerstand der dortigen 'ulama $\bar{a}$. Er reiste deshalb 1244 oder $125^{2}$ nach Alexandrien weiter, wo er bald eine ebenso zahlreiche Anhängerschaft hatte. Šàdilī schenkte den religiösen Pflichten grosse Auf-

seiner madrasa in Bagdad beauftragt (vgl. Schimmel, Mystische Dimensionen 350). Bald wurde dieser Institution ein Hospiz (ribāt ) hinzugefügt. Sein Erfolg war derart gross, dass in Bagdad ein besonderes Gebäude für die Zusammenkünfte errichtet werden musste. Vgl. Knysh, Islamic mysticism 18of. Mystische Dimensionen 354-36o; Knysh, Islamic mysticism 207-218; Lory, al-Shādhilī (ca. 593-656/ca. 1196$\left.125^{8}\right)$, in $E I^{2}$; Lory, Shādhiliyyya, in $E I^{2}$.

169 Zur Rifāciyya siehe Öztürk, The eye of the heart 110-113; Bosworth, Rifāìyya, in $E I^{2}$. merksamkeit und unternahm mehrfach den haağğ. Er starb 656/1258 (im Jahr der Eroberung Bagdads durch die Mongolen) unterwegs nach Mekka in alḤumaytira (Oberägypten).

Šādilī vertrat in seiner Lehre einen gemässigten Sufismus, der den materiellen Lebensbedingungen seiner Anhänger und den sozialen Aspekten grosse Aufmerksamkeit schenkte. Die Šādiliyya befolgt die Standpunkte der sunnitischen Lehre strikt und ist der šarīa verpflichtet. Zwar ermahnt Šādilī seine Anhänger zur Aufgabe irdischer Ziele und zum Kampf gegen die Triebseele (nafs). Er ermuntert sie aber nicht $\mathrm{zu}$ einem Leben in strenger Askese, sondern zu frommem Wandel in sozialer Verantwortlichkeit. Šādilī legte durchaus Wert darauf, sich elegant zu kleiden. Er verurteilte jedenfalls das Tragen besonderer Derwischkleidung. Er distanzierte sich ausserdem von spektakuläreren Formen von Zusammenkünften, wie sie aus der Rifāiiyya bekannt sind. Berichte über die Rifāciyya wissen von Trancezuständen, in denen die Adepten auch ausserordentliche Handlungen vorgenommen haben (Gehen auf Feuerglut, Durchstechen des Körpers etc.).

Für Šādilī selbst standen vielmehr unablässiges Gottgedenken und Standhaftigkeit gegenüber den zahllosen Versuchungen im Alltag im Vordergrund. Von ihm sind keine Schriften zu Lehrfragen bekannt. Er soll v.a. Gebete (du'a' , Pl. ad'iya) und Litaneien (hizb, Pl. ahzzāb) verfasst haben, die in entsprechenden Sammlungen zusammengestellt sind. Seine Litaneien sind sehr beliebt und weit verbreitet. Dazu zählen der Hizb al-Bahr (der ihm direkt vom Propheten eingegeben worden sein soll) und der Hizb kabìr (auch Hiğāa šarīf genannt). Šādilī werden ausserdem die folgenden Litaneien zugeschrieben: Hizb al-Barr, Hizb an-Nūr, Hizb al-Fath und der Hizb aš-Šayh Abi lHasan. ${ }^{170}$ Es sei bereits bei dieser Gelegenheit festgehalten, dass sich einzelne der soeben erwähn-

\footnotetext{
170 Diese Texte sind enthalten in 'A. H. Maḥmūd, alMadrasa aš-šādiliyya al-hadīta wa-imāmu-hā Abu lHasan aš-Šâdilī. Sie gehen zurück auf Ibn aṣ-Ṣabbāg und Ibn 'Iyād.
} 
ten Texte auf den hier untersuchten Dokumenten in Rollenform nachweisen lassen. ${ }^{171}$ Oft lässt sich nur unklar unterscheiden zwischen der Rezitation dieser Gebete im Rahmen der Liturgie und ihrer magischen und talismanischen Verwendung durch Šādilīs Anhänger. Šādilī selbst ist aber nicht für diese Entwicklungen im Rahmen des Heiligenkults verantwortlich. Er distanzierte sich jedenfalls deutlich von jeglicher Form der Götzenverehrung.

Šādilī dürfte zwar nie die Gründung einer Bruderschaft (tarīqa) beabsichtigt haben. Seine Lehre ordnet sich allerdings klar in die Entwicklung des Sufismus in eine in Bruderschaften organisierte Institution ein. Zwei seiner unmittelbaren Nachfolger, Abu l-'Abbās al-Mursī (gest. 686/1287) aus Murcia in Andalusien und der Ägypter Ibn 'Ațā' Allāh (gest. 709/1309), trugen später massgeblich zur Verbreitung von Šādilīs Lehre bei. Sie kodifizierten das Dikr-Ritual und gründeten Konvente (hānaqāh). Auf die Entwicklung des ŠādiliyyaOrdens selbst soll an dieser Stelle nicht näher eingegangen werden. Es sei aber festgehalten, dass er sich gerade in Ägypten, Ifrīqiya, Marokko, Syrien und im Hiğāz verbreitete.

$\mathrm{Zu}$ den drei wichtigen Orden, die um 1200 in der arabischen Welt entstanden, zählt auch die Suhrawardiyya. ${ }^{172}$ Sie hat sich aus dem Zirkel der Anhänger von Šihāb ad-Dīn Abū Hafṣ 'Umar asSuhrawardī heraus gebildet, der von 539-632/11451234 lebte. Er darf nicht mit andern Personen mit derselben nisba verwechselt werden, insbesondere nicht mit seinem Zeitgenossen Šihāb ad-Dīn Yahyyā as-Suhrawardī al-Maqtūl, der 587/1191 in Aleppo wegen seiner häretischen Auffassungen und politischen Einstellungen hingerichtet wurde.

Unser Suhrawardī gilt als einer der bedeutendsten Sufis. Er wurde 539/1145 in Suhraward geboren, das etwas westlich von Sulțāniyya (Iran) liegt und später von den Mongolen zerstört wurde.

171 Der Hizb al-Bahr ist enthalten auf Is 1626 (Chester Beatty Library, Dublin). Siehe dazu Kapitel 4.9 , bei Anm. 509.

172 Vgl. für die weiteren Ausführungen Knysh, Islamic mysticism 191-207: Hartmann, al-Suhrawardī, in $E I^{2}$; Sobieroj, Suhrawardiyya, in $E I^{2}$.
Abū Hafṣ 'Umar kam bereits in seiner Jugend nach Bagdad, wo ihn sein Onkel Abu n-Nağîb mit den Grundlagen der religiösen Wissenschaften vertraut machte und ihn im Predigen unterwies. Abu n-Naǧīb selbst war ebenso ein berühmter Sufi. Der zweite bedeutende Lehrer Abū Hafṣ 'Umars war 'Abd al-Qādir al-Ǧīlānī (470 oder 481-561/1077 oder 1088-1166), von dem die bereits erwähnte Qādiriyya abstammt. ${ }^{173}$ Die enge Beziehung zwischen dem noch jungen Schüler und dem in fortgeschrittenem Alter stehenden šayh sollte Suhrawardī gerade in religionsdogmatischen Fragen prägen. 'Abd al-Qādir schien dem jungen Suhrawardī von einer vertieften Beschäftigung mit der KalāmWissenschaft abgeraten zu haben.

Nach dem Tod seines Onkels Abu n-Nağīb (563/1168) folgte auch Abū Hafṣ 'Umar as-Suhrawardī selbst dem Pfad der Zurückgezogenheit. Er betätigte sich als Prediger und leitete mystische Zusammenkünfte im ribāt seines Onkels. Sein Ruf als begnadeter Prediger verbreitete sich in der abbasidischen Hauptstadt Bagdad rasch. Bei seinen Veranstaltungen geriet das Publikum regelmässig in Ekstase.

Suhrawardī unterhielt freundschaftliche Beziehungen zu Mu'īn ad-Dīn al-Čištī (gest. 633/1236), dem Begründer der Čištiyya, die sich später hauptsächlich in Indien verbreitete. ${ }^{174}$ Die Čištiyya orientierte sich in ihrer frühen Phase stark an Suhrawardīs Hauptwerk 'Awārif al-máārif. ${ }^{175}$ Suhrawardī fühlte sich überdies Nağm ad-Dīn arRāzī, genannt ad-Dāya (573-654/1177-1256), einem Schüler des Nağm ad-Dīn al-Kubrā, verbunden. ${ }^{176}$ Er traf Dāya 618/1221 in Malatya (Ost-Anatolien), als dieser auf dem Weg von Hwwārazm nach Kleinasien war. Dāya legte Suhrawardī sein Werk Mirșād al-ibād vor, das dieser wohlwollend aufnahm. Suhrawardī verfasste für Dāya ein Empfehlungs-

\footnotetext{
173 Zu 'Abd al-Qādir al-Ǧīlānī und der Qādiriyya vgl. Kapitel 3.1.7, bei Anm. 164-167.

174 Zur Čištiyya vgl. Auer, Chishtiyya, in $E I^{3}$; Arya, Chishtiyya, in Encyclopaedia Islamica.

175 Das Werk wurde übersetzt von Gramlich: Suhrawardī, Die Gaben der Erkenntnisse.

176 Vgl. zu ihm Algar, Nadjm al-Dīn Rāzī Dāya, in $E I^{2}$.
} 
schreiben zuhanden des Rūm-Seldschuken 'Alā' ad-Dīn Kayqubād I. in Konya.

Suhrawardī folgte in seiner Lehre zwar den Standpunkten der frommen Vorgänger (as-salaf wa-l-halaf). Er ging allerdings gerade in der Mystik darüber hinaus und äusserte deutliche Sympathien für Hallāğs Aussage „Anā l-ḥaqq“. Suhrawardīs Offenheit ging jedoch nie derart weit, dass er sich weiteren „Freidenkern“ aus seiner Zeit anschloss. Er richtete sich jedenfalls klar gegen den von Ibn al-'Arabī (gest. 1240) vertretenen Pantheismus und kritisierte v.a. dessen Verbindung von mystischen Vorstellungen mit Auffassungen aus der griechischen Philosophie. Es soll in Bagdad angeblich auch zu einem Treffen zwischen Suhrawardī und dem um etwa zwanzig Jahre älteren Mystiker aus Andalusien gekommen sein. Die Berichte darüber enthalten allerdings zahlreiche legendenhafte Elemente. ${ }^{177}$ Auch Darstellungen zu einer Zusammenkunft mit Rūzbihān al-Baqlī entbehren realer Grundlagen. Gesichert ist hingegen, dass Suhrawardī bei seiner letzten Pilgerfahrt (628/1231) den arabischen Mystiker und Dichter Ibn al-Fāriḍ (gest. 632/1235) ) $^{178}$ im Heiligen Bezirk in Mekka traf.

Für die vorliegenden Belange von besonderem Interesse sind die engen Beziehungen zwischen Suhrawardī und dem Abbasiden-Kalifen an-Nāṣir li-Dīn Allāh. ${ }^{179}$ Der Abbasiden-Herrscher interessierte sich zunehmend für Suhrawardīs Zusammenkünfte und begegnete ihm mit grossem Wohlwollen. Der Kalif unterstützte u.a. die Gründung des Ribāt al-Marzubāniyya massgeblich, das ebenso unter dem Namen Ribāṭ al-Mustağadd bekannt war (599/1202-1203). Dies geschah zu einem Zeitpunkt, da an-Nāṣir li-Dīn Allāh begonnen hatte, die mystisch geprägte Ausrichtung der Futuwwa zu fördern und sie in den Dienst des Kalifats zu stellen. Diese Futuwwa-Bünde werden uns sogleich näher beschäftigen. Vorläufig ist

177 Vgl. dazu Addas, Red Sulphur 240-241.

178 Zu Ibn al-Fāriḍ vgl. Nicholson [Pedersen], Ibn al-Fārị̣, in $E I^{2}$; Homerin, Ibn al-Fāriḍ, in $E I^{3}$.

179 Zu an-Nāṣir li-Dīn Allāh vgl. die ausführliche Studie von Hartmann, An-Nāṣir li-Dīn Allāh. festzuhalten, dass an-Nāșir darum bemüht war, eine neue, dem Abbasiden-Kalifat verpflichtete Futuwwa zu etablieren. Dieses Anliegen lag auch Suhrawardī am Herzen. Der Kalif war darum bemüht, die Futuwwa zu einer Organisation zu entwickeln, die seine politische Handlungsfähigkeit stärkte.

Suhrawardī wies in seinen Werken auf die enge Abhängigkeiten zwischen Futuwwa und Sufismus hin. Er entwickelte eine Lehre, die die zentralen Aspekte von futuwwa, tașawwuf und hiläfa in aufsteigender Reihenfolge miteinander in Beziehung setzte. Suhrawardī hält in seinem Werk $I d \bar{a}$ lat al-i'yān 'alā l-burhān fest, ${ }^{180}$ dass das Kalifat ein Buch (daftar) darstelle, in dem der tașawwuf einen Abschnitt bilde. Die Lehre des tașawwuf sei ihrerseits ein Buch (daftar); darin sei dann die futuwwa enthalten. Die zitierte Stelle charakterisiert die Futuwwa sodann als die reinen Moralvorstellungen (al-ahlāq az-zakiya). Der taṣawwuf wiederum beinhalte die frommen Handlungen und Übungen (awrād). Und das Kalifat als oberste Instanz baue auf den mystischen Zuständen, den frommen Handlungen und den reinen Moralvorstellungen auf. Die soeben vorgestellte Hierarchisierung von futuwwa-tașawwuf-hiläfa erinnert an die Dreiteilung von šarìa-țarīqa-haqìqa.

Die gegenseitige Abhängigkeit, die gemäss Suhrawardī zwischen Sufismus und Kalifat besteht, erklärt letztlich auch, weshalb an-Nāṣir li-Dīn Allāh den šayh mehrfach als seinen Vertreter an die Höfe der benachbarten Herrscher sandte. Am besten bekannt ist Suhrawardīs diplomatische Mission an den Hof der Ayyubiden. Nāșir hatte sich selbst als qibla für alle Angehörigen der FutuwwaBewegung ( fityān) vorgestellt. Er hatte nun Suhrawardī mit der Aufgabe betraut, die AyyubidenHerrscher in Aleppo (al-Malik az-Zāăhir) und Kairo (al-Malik al-Kāmil) auf seine Futuwwwa zu verpflichten. Nach seiner Rückkehr in den Iraq wurde

180 Hartmann, al-Suhrawardī, in $E I^{2}$; das Werk Idālat ali'yān ist nur als Handschrift erhalten; vgl. Nr. 3 in der Aufzählung bei A. Hartmann $\left(E I^{2}\right)$; ebenso erwähnt bei Hartmann, an-Nāṣir li-Dīn Allāh 326 (Nr. 26). 
Suhrawardī anfänglich mit grosser Ehre empfangen. Nāșir nahm allerdings zunehmend Anstoss daran, dass Suhrawardī das bescheidene Auftreten eines Sufis abgelegt hatte. Er entzog ihm deshalb die Oberaufsicht über seinen ribāt und untersagte ihm das Predigen. Suhrawardīs aufrichtige Reue liess ihn in der Gunst des Kalifen aber bald wieder aufsteigen.

Nāṣir sandte Suhrawardī 614/1217-1218 nach Hamad̄ān, als der Huwārazm Šāh 'Alā' ad-Dīn Muhammad II. die Stellung des Abbasiden-Kalifats hinterfragte. Der Huwārazm Šāh marschierte damals gegen Bagdad und empfing Suhrawardī ausgesprochen kühl. Der Hुwārazm Šāh war nicht willens, an-Nāṣir als Kalifen zu akzeptieren. Er warf ihm insbesondere vor, Mitglieder des Herrscherhauses ungebührlich zu behandeln und seine eigene Macht zu mehren. Konkret ging es darum, dass an-Nāṣir seinen eigenen Sohn und dessen Familie gefangen gesetzt hatte. Der Huwārazm Šāh berief sich in seinem Widerstand auf ein Prophetenwort, wonach es unzulässig sei, die Nachkommen von al-Abbās b. 'Abd al-Mutțalib unehrenhaft zu behandeln. Suhrawardī konnte bei dieser Mission keine Einigung herbeiführen.

Er hatte aber 618/1221 deutlich mehr Erfolg, als er in an-Nāṣir li-Dīn Allāhs Auftrag an den Hof des Rūm-Seldschuken 'Alā'-al-Dīn Kayqubād reiste. Suhrawardī überreichte ihm die Insignien eines Sultans und installierte ihn als Herrscher über die islamischen Gebiete Kleinasiens. Es gelang Suhrawardī bei dieser Mission ausserdem, zahlreiche Mitglieder für die Futuwwa des Kalifen zu gewinnen. Auch Kayqubād selbst und zahlreiche Beamte und Gelehrte schlossen sich in Konya der Futuwwa des Kalifen an. Suhrawardī leitete dabei die Initiationszeremonien. Ibn Bībī beschreibt in seiner Chronik der Seldschuken die freundliche Atmosphäre bei diesen Riten.

Seine häufigen Reisen im Auftrag des Kalifen zur Verbreitung der Futuwwa in ihrer erneuerten Form gestatteten es Suhrawardī zugleich, seine eigenen mystischen Auffassungen und seine theologische Weltsicht zu verbreiten. Er vertrat die Meinung, dass seine Lehre in Übereinstimmung mit der Weisheit des Propheten stehe. Gerade in Suhrawardīs späten Schriften finden sich allerdings Hinweise darauf, dass sich herkömmliche Auffassungen aus dem Sufismus mit heterogenen Elementen aus gnostischen und neoplatonischen Kontexten vermischen.

Es steht jedenfalls fest, dass Suhrawardī zahlreiche Anhänger hatte, die seine Lehre in Syrien, Kleinasien, Persien und Nordindien verbreiteten. Es waren denn auch seine Schüler, die den nach ihm benannten Suhrwardiyya-Orden gründeten. ${ }^{181}$ Die Suhrawardiyya sollte später neben der Čištiyya, der Qalandariyya und der Naqšbandiyya in Indien eine wichtige Rolle spielen. Es waren v. a. Suhrawardīs Schüler 'Alī b. Buzgūš (gest. 678/1279-128o in Shiraz), ${ }^{182}$ Bahā' ad-Dīn Zakariyyā (aktiv in Sind und Pandjab) ${ }^{183}$ und Ğalāl adDīn Tabrīzì (gest. vielleicht 642/1244, aktiv in Bengalen $)^{184}$, die zur Verbreitung von Suhrawardīs Vorstellungen beitrugen.

Suhrawardī selbst starb 632/1234 im Alter von 90 Jahren in Bagdad, wo sein Grab ab dem 8./14. Jh. verehrt wurde. Nach der Eroberung Bagdads durch die Osmanen wurde Suhrawardīs Grab ebenso wie die Gräber Abū Ḥanīfas und 'Abd al-Qādir alĞīlānīs erneuert. Die Verbreitung der Suhrawardiyya in Iran erklärt, dass auch von dort Konvente dieses Ordens bekannt sind. Erst im Vorbeigehen sei hier auf eine bekannte Anlage der Suhrawardiyya in Natanz, nämlich auf das Mausoleum 'Abd aș-Ṣamads, hingewiesen, das von Sh. Blair in ihrer Dissertation untersucht worden ist. Dieser Komplex wurde ganz am Anfang des 14. Jh. errichtet und wird uns später eingehender beschäftigen. ${ }^{185}$

Die vorangehenden Angaben haben auf unterschiedliche Sufiorden und Derwischbruderschaf-

181 Zum Orden der Suhrawardiyya vgl. Sobieroj, Suhrawardiyya, in $E I^{2}$; Knysh, Islamic mysticism 192-195 und 203207.

182 Vgl. zu ihm Shams, Buzghush Shīrāzī, in Encyclopaedia Islamica.

183 Vgl. Nizami, Bahā' al-Dīn Zakariyyā, in $E I^{2}$.

184 Vgl. Sobieroj, Tabrīzì, Djalāl al-Dīn, in $E I^{2}$.

185 Blair, Natanz; vgl. dazu ausführlicher Kapitel 3.4 bei Anm. 408-410. 
ten aufmerksam gemacht, die ab dem 12. Jh. entstanden sind. Die Vielzahl dieser Bünde untersagt es, hier eine vollständige Übersicht einzufügen. Für unsere vorliegenden Belange ist insbesondere relevant, dass diese Derwischbruderschaften eine grosse Nähe zu weiteren Männerbünden aufweisen, die unter dem Oberbegriff Futuwwa bekannt sind. Auf diese Zusammenhänge ist soeben kurz hingewiesen worden. Diese Futuwwa-Bünde sollen im folgenden eingehender vorgestellt werden. Die in der Futuwwa vertretenen Auffassungen fanden verschiedentlich ein Echo auf den in dieser Studie untersuchten Dokumenten in Rollenform.

\subsection{Das Bundeswesen im Islam}

Die vorangehenden Hinweise zu den Derwischorden machten auch auf die Suhrawardiyya aufmerksam. ${ }^{186}$ Diese Gemeinschaft geht auf 'Abd alQāhir Abū Naǧīb as-Suhrawardī (gest. 1168), einen Schüler Aḥmad Ġazzālīs (gest. 1126), zurück. ${ }^{187}$ Der soeben erwähnte Suhrawardī ist der Verfasser eines bekannten Handbuchs über mystische Tugenden (Ādāb al-murìdīn). Sein Neffe, Abū Ḥaf̣s 'Umar as-Suhrawardī (1145-1234), beeinflusste die weitere Entwicklung dieses Ordens allerdings noch stärker. Er hat die Hauptaspekte der mystischen Lehre in einem Traktat mit dem Titel 'Awārif al-ma'ārif zusammengefasst. ${ }^{188}$ Dieser Text gilt als Standardwerk der Mystik und wurde gerade in Indien vielfach gelehrt.

Abū Ḥafș 'Umar war auch politisch aktiv. Unter dem Kalifen an-Nāṣir li-Dīn Allāh (gest. 1225) war er Šayh aš-šuyūh in Bagdad und somit der offizielle Sufimeister in der Hauptstadt des AbbasidenReichs. Die Abbasiden hatten um 1200 ihren früheren Glanz längstens eingebüsst. An-Nāșir liDīn Allāh gilt allerdings als letzter Vertreter dieser Dynastie, der über einen gewissen politischen

186 Vgl. Kapitel 3.1.7, bei Anm. 174-185.

187 Vgl. Schimmel, Mystische Dimensionen 347-350.

188 Vgl. die Übersetzung von Gramlich, Die Gaben der Erkenntnisse ('Awārif al-ma'ārif).
Handlungsspielraum verfügte. Er verfolgte das Ziel, das darbende geistige Leben in seinem Reich zu erneuern. Ausserdem war ihm bewusst, dass der islamischen Welt Gefahr durch die Mongolen drohte. Er versuchte deshalb, die muslimischen Herrscher für die gemeinsame Sache im Kampf gegen die Eindringlinge zu gewinnen.

Der Kalif schickte Abū Hafș 'Umar as-Suhrawardī in diesem Sinn als Gesandten an die Höfe der Ayyubiden in Ägypten und Syrien. Suhrawardī reiste ausserdem nach Konya, wo die RūmSeldschuken gerade auf dem Höhepunkt ihrer Macht standen. Konya entwickelte sich nur wenige Jahre nach Suhrawardīs Besuch überdies zu einem bedeutenden Zentrum der islamischen Mystik. Die engen Beziehungen Suhrawardīs zu den weltlichen Machthabern charakterisierten auch die Einstellung seines Ordens gegenüber der herrschenden Klasse in den folgenden Jahrhunderten gerade in Indien. Die Suhrawardiyya zeigte gegenüber der Teilnahme am politischen Geschehen eine grössere Offenheit als dies auf andere Orden zutrifft.

Dieser Abū Hafṣ 'Umar as-Suhrawardī spielte auch eine bedeutende Rolle bei an-Nāșir li-Dīn Allāhs Vorhaben, die Futuwwa-Bewegung zu reformieren. Die Futuwwa geht in ihrem Kern auf den frühen Sufismus zurück. Im 13. und am Anfang des 14. Jh. hatten diese Bewegung und ihre Nachfolgeorganisationen (Ahītum; Handwerksgilden: șinf) einen Charakter angenommen, der sie kaum mehr von jenem anderer mystisch ausgerichteter Männerbünde unterschied. Vereinfacht ausgedrückt lässt sich die Futuwwa als angewandte Form der Mystik, als Mystik für die breiten Massen, bezeichnen. Eine klare Strukturierung der geistigen Übungen zielte darauf ab, spirituelles Erleben auch für das Gros der Gläubigen zu öffnen und es nicht allein einer geistigen Elite vorzubehalten.

Bereits F. Taeschner zeigte auf, dass der Sufismus einen wichtigen Beitrag zur Ausbildung des Futuwwa-Ideals leistete. ${ }^{189}$ Y.N. Öztürk machte ebenso auf die engen Beziehungen zwischen Sufi-

189 Taeschner, Der Anteil des Sufismus an der Formung des Futuwwaideals. 
Bruderschaften und Futuwwa-Bünden aufmerksam. ${ }^{190}$ E.S. Wolper wiederum geht so weit, die Begriffe Sufi, Derwisch und fatā (Pl. fityān, Angehöriger der Futuwwa-Bewegung) bzw. aȟ $\bar{\imath}^{191}$ als Synonyme $\mathrm{zu}$ verwenden (14. Jh.). ${ }^{192}$ Bei den soeben aufgeführten Organisationen handelt es sich grundsätzlich um Männerbünde. Der weiteren Darstellung sei die Bemerkung vorausgeschickt, dass in der Futuwwa zentrale Vorstellungen und Werte zum Teil auf den hier im Vordergrund stehenden Dokumenten in Rollenform ein Echo gefunden haben. ${ }^{193}$

\subsubsection{Die Futuwwa-Bünde}

F. Taeschner, weiterhin die Autorität in der $\mathrm{Fu}$ tuwwa-Forschung, macht darauf aufmerksam, dass das Bundeswesen im Mittelalter gerade in Vorderasien weit verbreitet war. Es ist mit dem Schlagwort futuwwa verbunden. Die Grundbedeutung dieses arabischen Begriffs lautet "Jugend, Jungmanntum, Burschentum“. Er bezeichnet auch die

190 Öztürk, The eye of the heart 56 : „Every study of the tariqats of Anatolia and the Balkans should include a discussion of futuwwat and akhi brotherhoods, as these associations, like the tariqats, were institutional embodiments of ideas and values developed by sufis. The akhi brotherhoods preceded the tariqats in Anatolia and the Balkans, and played an important role in the social, economic, and spiritual lives of the Turks living there."

Von den Ahi-Bewegung als Nachfolgerin der Futuwwa gerade in Ost-Anatolien wird sogleich die Rede sein (Kapitel 3.2.2).
Wolper, Cities and saints $77 \mathrm{f}$.

Es bestehen inzwischen zwar jüngere Studien zur Entwicklung der Futuwwa. Dennoch stützen sich die weiteren Ausführungen in erster Linie auf ältere Arbeiten, nämlich: Taeschner, Gemeinschaftsbildende Idee, und Breebaart, Development. Wichtig ist ausserdem Taeschner, Zünfte und Bruderschaften.

Für jüngere Darstellungen beachte u.a.: Ridgeon, Morals and mysticism; British Journal of Middle Eastern Studies 44.1 (2013): Spezialband zur Futuwwa (Hg. L. Ridgeon); Gevorgyan, Full list: http://futuww a.blogspot.ch/2012/11/full-list-of-literature-on-futuwwa .html (Stand 4. September 2017, enthält am Schluss eine Zusammenstellung aller Arbeiten F. Taeschners zum Thema); Mahğūb, Ā'īn-i ğawānmardī; ders., Spiritual chivalry; ders., Ǧawānmardī wa ā'̄̄n-i ān.
"Jugendblüte“ oder den ,jugendlichen Leichtsinn“. Dieses Abstraktum leitet sich vom Ausdruck fatā (Pl. fityān; „Bursche, Jungmann“) ab. Futuwwa entspricht dabei dem lateinischen iuventus. Der iuvenis ist der bereits erwachsene junge Mann, der vom adolescens zu unterscheiden ist. Diese Grundbedeutung des Begriffs hat vielfache Erweiterungen erfahren, wobei für F. Taeschner dessen ethische und soziale Implikationen im Vordergrund stehen. ${ }^{194}$

Aus der ethischen Perspektive ist die futuwwa mit den Idealen Edelmut, Grossmut, Ritterlichkeit verbunden. Diese Qualitäten zeichnen den wahren fatā aus. Die soziale Dimension der Futuwwa wiederum äussert sich darin, dass sich diese jungen Männer ( fityān) zu Bünden zusammenschlossen, die sich der Pflege der soeben angeführten Tugenden verschrieben. In diesem Sinn bezeichnet der Begriff Futuwwa den Burschenbund, die Korporation. ${ }^{195}$

F. Taeschner unterscheidet in Übereinstimmung mit den ethischen und den sozialen Implikationen der Futuwwa zwischen geistes- und sozialgeschichtlichen Aspekten in dieser Entwicklung. Diese beiden Linien laufen in der vom AbbasidenKalifen an-Nāṣir li-Dīn Allāh (reg. 118o-1225) angestrengten Reform des Bundeswesens zusammen und lassen sich danach nicht mehr voneinander trennen. Für unsere vorliegenden Belange sind gerade die Veränderungen im 13. und 14. Jh. relevant. Dennoch soll hier zuerst auf die Eckpunkte der Entwicklungen davor hingewiesen werden.

Jene Qualitäten, die den wahren fatā auszeichnen, lassen sich mit einem Blick auf die Verwendung des Begriffs in frühen arabischen Textzeugnissen, also im Koran und in der altarabischen Dichtung, erschliessen. In den soeben angeführten Quellen fehlt allerdings das Abstraktum futuwwa. Die folgende Darstellung stützt sich des-

\footnotetext{
194 Taeschner, Gemeinschaftsbildende Idee 123.

195 Die vorliegenden Ausführungen schreiben Futuwwa, wenn der Begriff die Bewegung als Institution bezeichnet. Wenn hingegen von der futuwwa als Charaktereigenschaft die Rede ist, wird Kleinschreibung verwendet. Die Abgrenzung ist allerdings nicht immer klar.
} 
halb auf die Verwendung des Ausdrucks fatā (bzw. Pl. fityān). Der Begriff bezeichnet im Koran eigentlich ausschliesslich einen Jüngling. So werden u.a. Ibrāhīm (Q 21:6o), die Siebenschläfer (Așhāb al-kahf; Q 18:10 und 18:13), ${ }^{196}$ aber auch Yūsuf (Q 12:30) fatā bzw. fityān genannt. Auch Moses' im Koran namenloser Gehilfe wird als fatā bezeichnet (Q 18:6o und 62). ${ }^{197}$ Die angeführten Stellen äussern sich alle zu Personen, die ethisch positiv gewertet werden. Mitglieder der Futuwwa-Bewegung haben diese Koranverse später aufgegriffen. Sie haben darin Belege dafür gesehen, dass Ibrāhīm, die Siebenschläfer, Yūsuf oder Moses' Gehilfe auch aus koranischer Perspektive Träger der futuwwa im Sinn der späteren Institution waren.

196 Gemäss Ibn Ğacdawayhī (aktiv im 11. Jh.) nannte Gott die Siebenschläfer wegen fünf Eigenschaften fatā: 1. der wahre fatā gibt dem Freund gegenüber dem Feind den Vorzug; 2. er meidet den Feind zugunsten des Freunds; 3. er bleibt seinem Bund mit dem Freund treu; 4. er verlässt sein Haus, um sich zum Freund zu begeben; 5. er enthält sich jeglicher Handlung, die dem Freund schaden könnte (vgl. Mir'āt al-muruwwa, verfasst für Nizāam al-Mulk, 456-485/1062-1092); Darstellung hier nach Breebaart, Development 12-16.

Ibn Ğāıdawayhī erkennt im Erlebnis der Siebenschläfer die soeben angeführten Grundsätze: Die Siebenschläfer haben sich vom heidnischen König Dākiyānūs (dem römischen Kaiser Decius, reg. 249-251) abgewandt, hatten sie doch mit dem einen Gott einen Bund geschlossen. Da sie ihrer Freundschaft mit dem einen Gott treu blieben, verliessen sie ihr Zuhause. Sie enthielten sich aller Handlungen, die ihrem göttlichen Freund hätten schaden können. Ibn Ğa'dawayhī erkennt in dieser Einstellung das wahre Wesen der futuwwa.

In dieser Interpretation hat die futuwwa eindeutig mystische Qualitäten. Während die futuwwa zuvor einen moralischen Kodex darstellt und die Beziehungen unter den Menschen regelt, kommt ihr im Fall der Așhāb al-kahf (Siebenschläfer) eine neue Dimension $\mathrm{zu}$, beschreibt sie doch das ideale Verhalten zwischen dem Menschen und Gott. Aus Ibn Ğacdawayhīs Ausführungen lässt sich auch ableiten, dass sich der wahre fatā durch unbedingten Gehorsam gegenüber Gott auszeichnet.

197 Für eine umfassendere Zusammenstellung siehe Breebaart, Development $5 \mathrm{f}$.
Gemäss F. Taeschner bezeichnet der Begriff fat $\bar{a}$ in der altarabischen Dichtung in erster Linie den edlen Vollmenschen, der den Arabern als Ideal vorschwebt. ${ }^{198}$ Der fatā zeichnet sich gemäss diesen frühen Auffassungen einerseits durch seine Gastfreundschaft und Freigebigkeit, anderseits durch seine Tapferkeit aus. Auch in der eigentlichen Futuwwa-Bewegung stellten diese beiden Qualitäten die Haupttugenden des wahren fatā dar. Der richtige fatā nimmt in seiner Gastfreundschaft und Freigebigkeit keinerlei Rücksicht auf seine wirtschaftlichen Möglichkeiten. Diese Einstellung kann unter Umständen zu seinem finanziellen Ruin führen. Der altarabische Fürst Hātim aț-Tầì gilt wegen seiner ebenso sprichwörtlichen wie grenzenlosen Gastfreundschaft als Prototyp der Freigebigkeit. 199

Während Hātim aṭ-Ṭāī für Gastfreundschaft und Freigebigkeit steht, hat die spätere Futuwwa in 'Alī b. Abī Ṭālib (gest. 4o/661), Muḥammads Cousin und Schwiegersohn, dem vierten Kalifen der Muslime und ersten Imam der Schiiten, ihr eigentliches Vorbild gefunden. 'Alī nimmt in der Futuwwa eine zentrale Stellung ein. Er soll sein Leben mehrfach für den Propheten aufs Spiel gesetzt haben. Gemäss der Überlieferung hat die Stimme eines unsichtbaren Rufers (hätif $)^{200}$ 'Alī als wahren fatā gepriesen und festgehalten, dass es kein anderes Schwert als das Dū l-faqār-Schwert und keinen andern Jungmann ausser 'Alī gebe („Lā fatā illā 'Alī, wa-lā sayfa illā D̄ū l-faqār.“). ${ }^{201}$ Diese Aussage kann als Leitspruch der Futuwwa bezeichnet werden und lässt sich auf den hier untersuchten Dokumenten in Rollenform wiederholt nachweisen.

\footnotetext{
198 Taeschner, Gemeinschaftsbildende Idee 125.

199 Vgl. auch van Arendonk, Hātim al-Ṭā'̄̄, in $E I^{2}$.

200 Zum Hātif-Konzept vgl. Nünlist, Dämonenglaube 326334.

201 Vgl. zu diesem Prophetenwort u.a. Farès, L'honneur 26 ff.; Calmard, Dū 'l-Faqār, in EIr, weist diese Aussage nach bei Ṭabarī, I.3 (S. 1359, 1402); Bal'amī (Ausgabe Rowšan) III, 169 (genaue Stellenangaben in EIr); siehe auch Dihhudā, Lugat-nāma, s.v. Dū l-faqār; Dozy, Supplément II, s.v. faqara. Siehe neu auch Bellino, Dhū lFaqār, in $E I^{3}$.
} 
Futuwwa drückt sich ausserdem durch Nachsicht und Toleranz gegenüber den Schwächen der Mitmenschen aus. Ibn Ğa'dawayhī (11. Jh.) illustriert diesen Aspekt, indem er eine Aussage 'Alī b. Abī Tālibs aufgreift. Demnach zeichnet sich der wahre fatā durch folgende Qualitäten aus: a. er ist demütig im Erfolg; b. vergibt, wenn er an der Macht ist bzw. Rache üben könnte; c. übt sich in Grosszügigkeit, ohne eine Gegenleistung zu erwarten; d. gibt selbst an jene gute Ratschläge, die ihm feindselig gesinnt sind; e. zeigt sich grosszügig, auch wenn er selbst Unterstützung bräuchte. ${ }^{202}$

Mit dem Futuwwa-Konzept eng verbunden ist die muruwwa. Dieser Begriff steht sachlich und etymologisch mit mar', imra' (Mann) in Verbindung. Die Vorstellung der muruwwa deckt sich weitgehend mit dem Begriff virtus im Lateinischen. Im Altarabischen beinhaltet die muruwwa jene Pflichten, die sich aus dem Schutz des Familienverbands und der Gastfreundschaft ergeben. Auch das Ausüben der Blutrache gehört letztlich hierhin. Die muruwwa kann als allgemeines Konzept verstanden werden, das die Ideale der futuwwa in sich schliesst, dem aber deren Bezüge zum Kriegsheldentum abgehen.

F. Taeschner vertritt die Auffassung, dass das altarabische Ideal des Edelmanns ( fatā) mit den arabischen Eroberungen Eingang in die frisch für den Islam gewonnenen Gebiete, v.a. nach Khorasan, fand. ${ }^{203}$ Es ist bekannt, dass sich die iranischen Adelskreise rasch an die Gepflogenheiten der Eroberer anpassten und unter den Abbasiden ihre früheren Privilegien und ihre Macht de facto zurückgewannen. In iranischen Kreisen waren dabei Vorstellungen bekannt, die sich von den soeben geschilderten Idealen der alten Araber nicht allzu stark unterschieden. ${ }^{204}$ Während die Qualitäten des fatā im Arabischen unter dem Begriff futuwwa zusammengefasst werden, kennt das Persische dafür die Lehnübersetzung ğawān-

202 Vgl. Breebaart, Development 12-16.

203 Taeschner, Gemeinschaftsbildende Idee $126 \mathrm{f}$.

204 Baldick stellt die Auffassung zur Diskussion, dass es sich bei der Futuwwa um ein ursprünglich iranisches Konzept handelt: „The Iranian origin of the futuwwa“. mardī, „Jungmanntum“. Der Ausdruck lässt sich bereits in der Fürstenspiegel-Literatur aus dem 10. und 11. Jh. nachweisen. ${ }^{205}$

Es sind anfänglich die arabischen Glaubenskämpfer, die das Fatā-Ideal pflegten. Von ihnen haben es darauf die Sufis übernommen, passte ihre Mentalität doch gut zum Radikalismus der Futuwwa-Bewegung. Die Bedeutung und Tragweite der Futuwwa-Ideale veränderten sich im sufischen Umfeld allerdings. Die Sufis überhöhten diese Ideale und füllten sie ebenso wie die Vorstellung vom ğihād mit modifizierten Inhalten. ${ }^{206}$

F. Taeschner macht auf die Darstellung in einer anonymen Futuwwa-Schrift aus Istanbul aufmerksam, wonach „die Futuwwa in allen ihren Tatäusserungen eine gewisse Gemeinsamkeit mit dem Sufismus" aufweise. ${ }^{207}$ Allerdings unterscheide sich der Endzweck von Sufismus und Futuwwa. Das Ziel der noch nicht mystisch beeinflussten fityān bestehe darin, Lob von Seiten der Menschen auf sich zu ziehen. Der Sufi hingegen wolle Lob von Gott erfahren. Es ist wichtig, die Sufis gerade von niederen fityān zu unterscheiden. $^{208} \mathrm{~F}$. Taeschner hält gestützt auf die ange-

205 Vgl. dazu Kaykāwūs b. Iskandar b. Qābūs, Qābūs-nāma. Der Text wurde 1082 verfasst. Das 44. und letzte Kapitel darin handelt von der ğawān-mardī. Vgl. dazu auch Breebaart, Development 9 .

206 Zum Ǧihād-Konzept unter den Mystikern bzw. zum Kampf gegen die nafs (Triebseele) vgl. Schimmel, Mystische Dimensionen 166-172 und 272-274 und ihren Index s.v. „nafs“ (S. 716); Cook, Islam in Iran, XI. Jihad in Islam, in EIr (v.a. am Schluss des Artikels); Heck, Jihad revisited, darin v.a. $99 \mathrm{f}$.

207 Taeschner, Gemeinschaftsbildende Idee 128 (mit Anm. 2), der aus Istanbul MS AS 2049, fol. 207 ${ }^{\text {r }}$ Z. 16 ff., zitiert. Auf diesen Text macht in Anschluss an F. Taeschner auch Breebaart, Development, aufmerksam (S. 27). Demnach hätten die Sufis das Futuwwa-Konzept übernommen, da die futuwwa in all ihren Aspekten Gemeinsamkeiten mit dem Sufismus aufweise. Allerdings bestehe ein Unterschied in Bezug auf das eigentliche Ziel: Der fatā ziele letztlich auf das Lob durch seine Mitmenschen ab, während der Sufi auf Anerkennung von Gott aus sei.

208 Die Futuwwa-Bewegung ist ausgesprochen vielschichtig. Die Abbasiden sahen sich verschiedentlich mit in Banden organisierten fityān konfrontiert, die ihre poli- 
führte Handschrift fest, dass wahre futuwwa weder Lasterhaftigkeit noch Ausschweifung bedeute. Die Futuwwa-Tugend bestehe vielmehr darin, dem Mitmenschen eine Mahlzeit vorzusetzen, eine Gabe zu spenden und ihm mit einem freundlichen Antlitz zu begegnen. Überhaupt zeichne sich futuwwa durch Zurückhaltung und Scheu aus. Man solle sich davor hüten, seinem Mitmenschen Leid zuzufügen. ${ }^{209}$

Die Sufis modifizierten die Futuwwa-Tugenden dahingehend, dass sie einer altruistischen Grundhaltung ( $\bar{t} \underline{t} \bar{a} r)$ einen zentralen Platz zuwiesen. Diese Einstellung (ītâr $)$ besteht darin, dass der fatā seinen Mitmenschen in jeder Hinsicht in den Vordergrund rückt. Grundsätzlich ist der fatā jener, der stets gibt, aber nie nimmt. Er ist auch jener, der sogar noch seinem Feind gegenüber sich selbst den Vorzug gibt. ${ }^{210}$ Innerhalb des Sufismus hat die Malāmatiyya das Futuwwa-Konzept des itâar auf die Spitze getrieben. Sie geht davon aus, dass es zur ethischen Vollkommenheit gehört, durch sozial geächtetes Verhalten den Tadel seiner Mitmenschen auf sich zu ziehen. Die Sufis haben den malāmatī vielfach als das Modell des wahren fatā bezeichnet.

Das in der islamischen Mystik entwickelte Ideal der futuwwa geht jedenfalls weit über jene Tugenden hinaus, die in altarabischer Zeit den wahren fatā auszeichneten. F. Taeschner erkennt in der futuwwa sogar eine Art Zentralbegriff der

tische Autorität ernsthaft in Frage stellten. Sie marodierten gerade auch in Bagdad bandenmässig und stellten ein ernsthaftes Sicherheitsproblem dar. Grundsätzlich lässt sich festhalten, dass Futuwwa-Bünde erstarken, wenn die Zentralmacht schwach ist. Vgl. zu dieser Problematik auch unten bei Anm. 218-219.

209 Vgl. Taeschner, Gemeinschaftsbildende Idee 128 (mit Anm. 3), der die Aussage auch bei Sulamī, Futuwwa §95, nachweist. Sulamī schreibt diese Aussage Ğa'far aș-Ṣādiq (gest. 148/765) zu. Vgl. ähnlich auch Sulamī, Futuwah: traité de chevalerie soufie 57 (bei Anm. 34). Qušayrī, Risāla 122.30 (al-Qāhira, 1318) bzw. 103, Z. 4 v.u. (al-Qāhira 1367/1949), macht auf eine Aussage von alḤārit al-Muḥāsibī aufmerksam, wonach die futuwwa darin bestehe, „dass Du Gerechtigkeit gibst, aber keine beanspruchst, - dass du gibst, aber nicht nimmst." Hier zitiert gemäss Taeschner, loc. cit. 128 (Anm. 4). sufischen Ethik. Im Vordergrund dieses auf den Mitmenschen ausgerichteten Zweigs des Sufismus stünden die Qualitäten Altruismus, Selbstverleugnung und praktische Nächstenliebe. Diese könne bis zur Selbstentäusserung gehen.

Angesichts der zentralen Bedeutung der $\mathrm{Fu}$ tuwwa-Tugenden im Sufismus erstaunt nicht, dass sich verschiedene als Verfasser mystischer Werke bekannte Autoren auch dazu äussern. $\mathrm{Zu}$ ihnen zählt Sulamī (gest. 412/1021), der das Thema in einem selbständigen Werk mit dem Titel Kitāb al-Futuwwa behandelt. ${ }^{211}$ Qušayrī (gest. 465/1073), sein Schüler, wiederum befasst sich in einem besonderen Kapitel seiner Risāla mit diesem Konzept. ${ }^{212}$ Später geht auch Ibn 'Arabī (gest.

211 Vgl. Taeschner, As-Sulamì's Kitāb al-Futuwwa. Für Übersetzungen des Texts beachte: Sulamī, Futuwah: traité de chevalerie soufie; Sulamī, The book of Sufi chivalry; Sulamī, Der Sufi-Weg.

Auch D.A. Breebaart weist auf Sulamīs Auffassungen zur Futuwwa hin (Development 16-21). Für Sulamī sind die folgenden Aspekte der futuwwa relevant: a. 14 Aussagen heben die Grosszügigkeit des fatā hervor; b. 8 Aussagen betonen seine Gastfreundschaft; c. 25 unterstreichen die Bedeutung von Freundschaft und Kameradschaft; d. 44 Belege äussern sich in allgemeiner Form zum Verhalten gegenüber Mitmenschen; e. 4 Aussagen heben die Wichtigkeit der Aufrichtigkeit in der Rede hervor; f. und 5 befassen sich mit der Aufrichtigkeit im Herzen. In Sulamīs Futuwwa-Verständnis kommt dem Altruismus (ītār $r$ grosse Bedeutung zu. Wichtig ist D.A. Breebaarts Hinweis, dass verschiedene Aussagen kaum auf jene Personen zurückgehen, denen sie von Sulamī in den Mund gelegt werden. Die jeweiligen Zuschreibungen zielen - ähnlich wie im Fall von Prophetenworten - vielmehr darauf ab, Autorität herzustellen.

212 Vgl. dazu Breebaart, Development 21-26: Auch Qušayrī macht auf den Propheten Ibrāhīm aufmerksam, der im Koran fatā genannt wird. Seine futuwwa habe darin bestanden, dass er die Götzenbilder zerstörte (vgl. Q 21:6o). Ibrāhīm spielt auch in einer Anekdote eine zentrale Rolle, wonach ein Magier bei ihm vorbeigekommen sei und um seine Gastfreundschaft gebeten habe. Ibrāhīm allerdings schickte den Magier weg. Er war in seinen Augen ein Ungläubiger, der zuerst Reue zeigen und den wahren Glauben annehmen sollte. Erst dann sei er seiner Gastfreundschaft würdig. Nachdem der Magier weggegangen war, wies Gott allerdings Ibrāhīm zurecht. Dieser holte den Magier ein und ent- 
638/1240) in den al-Futūhātal-makkiyya darauf ein und bezeichnet die futuwwa als einen maqām, eine Station. Diese Autoren setzen sich in erster Linie aus einer ethischen Perspektive mit der

schuldigte sich für sein Fehlverhalten. Nachdem Ibrāhīm dem Magier vom Eingreifen Gottes erzählt hatte, bekehrte sich dieser zum Islam; vgl. diese Anekdote bei Breebaart, op. cit., $22 \mathrm{f}$.

Auch die Anekdote zu jenem Mann, der nach der Heirat entdeckt, dass das Gesicht seiner Frau durch Pockennarben entstellt ist und Blindheit simuliert, illustriert die in der futuwwa dominierende Grundhaltung. Nachdem seine Frau zwanzig Jahre später starb, öffnet er seine Augen wieder. Er erklärt seinen Freunden, er habe Blindheit vorgetäuscht, um seine Frau beim Anblick ihres entstellten Gesichts nicht zu verletzen (bei Breebaart 23f.).

Der wahre fatā zeichnet sich ausserdem durch Keuschheit aus, wie eine Anekdote über Nūḥ al-'Ayyār aus Nayšāpūr illustriert. Demnach wollte jemand Nūḥs Enthaltsamkeit auf die Probe stellen. Die fragliche Person verkaufte ihm eine Sklavin mit hellem Teint, die aber Männerkleider trug. Nūh al-Ayyār erstand sie im Glauben, es handle sich um einen Knaben. Einige Monate später wurde die Sklavin gefragt, ob ihr Besitzer inzwischen bemerkt habe, dass sie weiblichen Geschlechts sei. Sie verneinte jedoch; Nūh al-'Ayyār habe sie noch nie berührt (bei Breebaart 24).

Auch die folgende Anekdote illustriert die Grundhaltung der futuwwa: Ein Mann hatte einige fityān zu sich nach Hause zum Essen eingeladen. Der Gastgeber bat seinen Diener, alles für die Bewirtung der Gäste vorzubereiten. Der Diener allerdings liess seinen Herrn über Gebühr warten. Als er zur Rede gestellt wurde, wies er ihn darauf hin, dass einige Ameisen über das für die Bewirtung der Gäste vorgesehene Tuch gekrochen seien. Es wäre seiner Auffassung nach mit der futuwwa unvereinbar gewesen, die Tiere einfach vom Tuch zu wischen. So habe er eben gewartet, bis die Ameisen weggegangen seien (bei Breebaart 25).

Vielfach wird in der Futuwwa-Literatur, und vorliegend auch bei Qušayrī, auf eine Anekdote hingewiesen, in der Ğacfar aș-Ṣādiq (6. Imam der Schiiten, gest. 765 ) eine zentrale Rolle spielt. Demnach war Ğaffar aṣṢādiq in den Strassen Medinas unterwegs, als ein Mann auf ihn zukam und ihn beschuldigte, seinen Geldbeutel gestohlen zu haben. Der Imam wies zwar jegliche Schuld von sich, erkundigte sich aber dennoch nach dem Betrag, der dem aufgebrachten Mann angeblich gestohlen worden war. Nachdem der Mann angegeben hatte, es handle sich um tausend Dinar, begaben sich die beiden zu Ğafar nach Hause. Der Imam übergab dem Mann dort die genannte Summe. Als der vermeint-
Futuwwa auseinander und befassen sich nicht mit den sozialen Implikationen dieser Organisationen. Für unsere vorliegenden Belange sind aber gerade diese zuletzt genannten Aspekte relevant.

Diese sozialen Implikationen des FutuwwaKonzepts spielen v.a. in Gruppierungen eine Rolle, die als Männerbünde organisiert waren und sich in erster Linie in Städten feststellen lassen. ${ }^{213}$ Das Phänomen lässt sich auch im iranischen Kulturraum feststellen. ${ }^{214}$ In den Städten schlossen sich junge Männer in der Absicht zusammen, das altarabische Futuwwa-Ideal aufleben zu lassen. Allerdings schenkten diese fityān der Ausrichtung ihres Handelns zugunsten ihrer Mitmenschen vorerst nur geringe Beachtung und legten besonderen Wert auf ihr eigenes Wohlleben. Dazu gehörten gutes Essen und eine eher lockere Moral mit freizügiger Sexualität. Ausserdem beschränkte sich die Unterstützung gegenüber andern Menschen auf die Mitglieder des eigenen Bundes. Auch zeigte man seine Manneskraft primär, um mit seiner Körperstärke zu prahlen und seinen eigenen Ruhm zu steigern. Der selbstlose Held hat damit zum Raufbold oder - moderner formuliert - zum rauflustigen hooligan mutiert. Oft sicherten sich Mitglieder derartiger Organisationen den Lebensun-

lich Bestohlene wieder in seine Wohnung zurückgekehrt war, entdeckte er seinen Geldbeutel doch wieder. Er kehrte darauf zu Ğaffar zurück und wollte ihm die tausend Dinar zurückgeben. Ğa far aṣ-Ṣādiq aber nahm das Geld nicht zurück. Was er einmal gegeben habe, nehme er nicht mehr an sich (bei Breebaart 25f.).

Qušayrī erläutert seine Vorstellung der Futuwwa anhand von derartigen Anekdoten und fügt nur einige wenige Definitionen ein. Vieles spricht dafür, dass es sich bei den fityān in seinem Text nicht um Sufis handelt. Allerdings reden seine Handlungsträger einem ethisch vorbildlichen Verhalten das Wort. Dennoch lässt sich auch bei Qušayrī beobachten, wie sufische Vorstellungen Aufnahme in das Umfeld der Futuwwa finden.

213 Taeschner, Gemeinschaftsbildende Idee 130.

214 Taeschner, Gemeinschaftsbildende Idee 130. Es ist überdies aus dem grundsätzlich christlichen Armenien bekannt; vgl. Anm. 301. 
terhalt auch durch Wegelagerei. ${ }^{215}$ In gehobeneren Zirkeln wiederum war der fatā zum feinen Herrn geworden, der das Leben genoss und seine männliche Kampfkraft in sportlichen Aktivitäten (z.B. Bogenschiessen) demonstrierte. Ein derartiges Futuwwa-Verständnis hatte natürlich nichts mehr mit den im Sufitum vorherrschenden Idealen zu tun. ${ }^{216}$

Unter den Abbasiden haben sich diese fityān wiederholt zu eigentlichen Kampfgruppen zusammengeschlossen, die politische oder religiöse Forderungen durchzusetzen versuchten. Sie verschrieben sich dem Kampf ( $\breve{g} i h \bar{a} d)$ für die Sache Gottes ( $f \grave{\imath}$ sabìl Allāh). Gerade in Khorasan, aber auch in Transoxanien, lassen sich Kampfgruppen nachweisen, deren Anführer ra's̄s al-fityān genannt wurde. Auch in dieser Hinsicht lassen sich gegenseitige Beeinflussungen der Vorstellungen der Glaubenskämpfer und der Werte der Sufis erkennen. Jedenfalls kamen die Glaubenskämpfer gerade in den ribāt, den militärischen Stützpunkten des Glaubenskampfs entlang der Grenzen der muslimischen Welt, mit den Derwischorden in Kontakt. Dies führte dazu, dass sufische

215 Vgl. zu diesen Aspekten auch Irwin, 'Futuwwa': Chivalry and gangsterism.

216 Es gibt Hinweise darauf, dass sportliche Aktivitäten in der Futuwwa einen gewichtigen Platz einnahmen. Der Kalif an-Nāṣir li-Dīn Allāh soll das Kugelschiessen mit der Armbrust (ramy al-bunduq) und das Züchten von Brieftauben (tuyūral-manāsib) mit der Futuwwa in Verbindung gesetzt haben. Wer diese Sportarten betrieb, war verpflichtet, sich auf den Kalifen zu beziehen, der als bester Armbrustschütze seiner Zeit galt. Man gibt auch an, dass der Kalif sämtliche alten Brieftauben habe umbringen und junge Tiere habe verteilen lassen. Diese Massnahme habe sichergestellt, dass der gesamte Nachwuchs an Brieftauben aus der Hand des Kalifen stammte. F. Taeschner äussert die Vermutung, Nāșir habe Sport und Futuwwa miteinander verbunden, um so weitere Fürsten zum Eintritt in die Futuwwa zu bewegen. Vgl. dazu Taeschner, Gemeinschaftsbildende Idee $141 \mathrm{f} . ;$ ders., Zünfte und Bruderschaften, Index s.v. „Brieftauben“ (658). Zum Züchten von Brieftauben im Umfeld der Futuwwa siehe auch Breebaart, Development 53. Beachte ausserdem Frembgen und Rollier, Wrestlers 49-9o; Hartmann, an-Nāṣir li-Dīn Allāh 9698, 103, 210.
Vorstellungen unter den fityān zu einem Zeitpunkt an Bedeutung gewannen, als auch die ersten mystischen Orden entstanden (5.-6./11.-12. Jh.). Im 6./13. Jh. weitet sich der Sufi-Einfluss eigentlich auf alle Futuwwa-Gruppierungen aus, wie sich anhand der Futuwwa-Literatur aus dem 12.-14. Jh. aufzeigen lässt. Die Futuwwa-Gruppierungen hatten also bereits vor an-Nāșir li-Dīn Allāhs Reformbestrebungen zahlreiche Vorstellungen der Sufis aufgegriffen. Vieles spricht auch dafür, dass die Futuwwa-Bruderschaften gewisse aus den SufiOrden bekannte Strukturen übernommen hatten. Es lässt sich überdies aufzeigen, dass die Vorsteher von Derwischbünden oft zugleich in Futuwwa-Gruppierungen aktiv waren und gern auch deren Leitung übernahmen. ${ }^{217}$ Überhaupt lässt sich beobachten, dass viele Personen mehreren Gruppierungen angehörten oder ihnen zumindest als Sympathisanten nahestanden. Jedenfalls lassen sich multiple Zugehörigkeiten im Umfeld dieser Männerbünde häufig beobachten.

Während diese Grenzkämpfer, die in erster Linie am Rand der islamischen Welt lebten und dort ihre Heimat verteidigten, stark von sufischem Gedankengut beeinflusst waren, verfolgte eine zweite Gruppe das Ziel, in den grossen Städten der islamischen Welt ohne Rücksicht auf die herrschende Ordnung wieder Gleichheit und Gerechtigkeit herzustellen. Sie achteten auf eine gleichmässige Verteilung des Besitzes und waren auch bereit, die staatliche Ordnung auszuhebeln. Ihre Einstellung trug ihnen scharfe Kritik von Seiten der 'ulamă' ein. Wegen ihrer Geringschätzung der tatsächlichen Machtverhältnisse wurden sie 'ayyār, „Räuber, Vagabunden“ geschimpft. Dieser Ausdruck wird oft weitgehend synonym für fityān gebraucht. ${ }^{218}$

Gerade aus der Zeit von der Mitte des 9. bis ins 12. Jh. liegen Berichte über die Aktivitäten von derartigen Fityān-Verbünden in den Städten vor, wobei die Quellenlage zur Situation in Bag-

217 Taeschner, Gemeinschaftsbildende Idee $135 \mathrm{f}$.

218 Mit Quellenverweisen bei Taeschner, Gemeinschaftsbildende Idee 132 (Anm. 29). 
dad besonders reich ist. Die 'ayyār konnten die Macht damals an sich reissen, da die Staatsmacht geschwächt war. Diese Männerbünde griffen oft auf terroristische Mittel zurück und schüchterten die Bevölkerung ein. Bei Ibn al-Atīir finden sich Hinweise, dass die 'Ayyār-Verbände in Bagdad in der Zeit von 1135-1145 ein Terrorregime ausübten. Die Quellen schweigen allerdings darüber, ob und gegebenenfalls welche politischen (anti-abbasidischen oder pro-fatimidischen) Zielsetzungen die Ayyār-Gruppierungen verfolgten. Es bleibt auch festzuhalten, dass sich heute kaum mehr beurteilen lässt, ob die Quellenberichte dazu glaubwürdig sind. Grundsätzlich lässt sich aber feststellen, dass Futuwwa-Bewegungen erstarken, wenn die Staatsmacht schwächelt. ${ }^{219}$

F. Taeschner macht auch darauf aufmerksam, dass wohl zumeist des Lesens und Schreibens unkundige Leute der bündischen Futuwwa angehörten. Dies erklärt für ihn auch, dass ihre Vorstellungen und ihr Brauchtum vor 1200 zumeist im Halbdunkeln verharren. Erst mit den von Nāșir eingeleiteten Reformmassnahmen zeichnet sich ein klareres Bild dieser Vereinigungen ab. Unter ihm verbinden sich die geistes- und sozialgeschichtlichen Dimensionen der Futuwwa. Es kommt unter diesem Kalifen sozusagen zu einem Neubeginn.

Die von an-Nāṣir li-Dīn Allāh (1158-1225; reg. 575-622/118o-1225) geförderte Organisation der Futuwwa ist als höfische Futuwwa bekannt. ${ }^{220}$ Verschiedene Quellen wissen, dass sich Nāșir kurz nach seinem Regierungsantritt durch den SufiScheich ‘Abd al-Ğabbār b. Yūsuf b. Șāliḥ al-Bag̉dādī (gest. 583/1187) in die Futuwwa aufnehmen liess (578/1182-1183). Dieser sei zugleich der Vorsteher der Futuwwa (šayh al-futuwwa wa-ra'šsu-hā $)^{221}$ in Bagdad gewesen. ${ }^{222}$ Ibn al-Atīr (gest. 63o/1234),

\footnotetext{
219 Op. cit. 135.

220 Op. cit.136-141.

221 Dieser Hinweis aus ad-Dahabī, Ta'rīh al-Islām (Paris BNF, Ms. ar. 1582, fol. $11^{\mathrm{r}}$ ), zitiert bei Cahen, Futuwwa d' an-Nāṣir, Hinweis S. 18. Vgl. auch F. Taeschner, folgende Anm.

222 Taeschner, Gemeinschaftsbildende Idee 137.
}

die Hauptquelle für die Entwicklungen unter den späten Abbasidenkalifen, hält fest, dass Nāṣir die Futuwwa-Bünde im allgemeinen abgeschafft habe. Er habe nur noch jene Gruppierungen toleriert, die sich ihm selbst angeschlossen hätten. Wer sich zur Futuwwa bekannte, musste sich zwangsläufig dem Kalifen unterordnen. Nāṣir versuchte, die auf ihn selbst ausgerichtete Futuwwa auch in andern Regionen der islamischen Welt durchzusetzen. Zahlreiche Fürsten im Einflussbereich des Abbasidenkalifats sahen sich gezwungen, von Nāșir die „Hosen der Futuwwa“ (sarāwìl al-futuwwa) anzunehmen und ihm zu Ehren aus dem Becher ( $k a$ 's) der Futuwwa zu trinken. Es ist davon auszugehen, dass sich zusammen mit ihrem Vorsteher jeweils auch die ganze Anhängerschaft der lokalen Machthaber Nāșirs Futuwwwa anschloss.

Während die Verbindungen zwischen FutuwwaBünden und dem Sufismus bzw. dessen organisierte Ausbildung in den Derwischorden bis anhin eher am Rand existierten, verstärkte sich der sufische Einfluss auf die Futuwwa-Bruderschaften mit Nāṣirs Reformmassnahmen. Dieser verstärkte Einfluss kommt auch darin zum Ausdruck, dass ausgerechnet ein Sufi-Šayh Nāṣir in die Futuwwwa aufnahm. Überdies spielte mit Šihāb ad-Dīn Abū Hafṣ 'Umar as-Suhrawardī ein weiterer bedeutender Sufi aus jener Zeit im Rahmen der von an-Nāṣir liDīn Allāh eingeleiteten Reformbestrebungen eine massgebliche Rolle. ${ }^{223}$ Suhrawardī war gewissermassen Nāṣirs Hoftheologe. ${ }^{224}$

Für die Entwicklung der Futuwwa von besonderer Bedeutung ist ein vom 9. Șafar 6o4/4. September 1207 datierender Erlass des Kalifen anNāṣir, der im Wortlaut erhalten geblieben ist. ${ }^{225}$

223 Taeschner, op. cit. 142. Vgl. zu Suhrawardī und seinen Ausführungen zur Futuwwa auch Taeschner, Zünfte und Bruderschaften 229-236 und 242-262 (ebenso sein Index s.v. Suhrawardī, Šihāb ad-Dīn). Von Suhrawardī (539-632/1145-1234) war bereits zuvor im Zusammenhang mit dem Derwischorden der Suhrawardiyya die Rede; vgl. Kapitel 3.1.7, bei Anm. 174-185.

225 Vgl. zu diesem Erlass auch Taeschner, Zünfte und Bruderschaften 73-78. Der Bagdader Geschichtsschreiber Ibn as-Sācīi, al-Ğāmi al-muhtașar IX, $221 \mathrm{ff}$., hat diesen 
Da es zwischen den Mitgliedern verschiedener Futuwwa-Gruppierungen (hizb, Pl. ahzāab) zu blutigen Auseinandersetzungen gekommen war, sah sich der Kalif zum Eingreifen gezwungen. Er setzte in seiner Funktion als Grossmeister der Futuwwa scharfe Massnahmen um, um derartige Konflikte in Zukunft zu verhindern.

Die von an-Nāșir wiederbelebte Futuwwa ist als ordensartige Gemeinschaft organisiert. Sie umfasst verschiedene Zweige und lässt sich in unterschiedlichen Regionen der islamischen Welt nachweisen. Auch gehören ihr Mitglieder aus vielfältigen sozialen Umfeldern an. Dazu zählen abenteuerlustige Landstreicher, mächtige Fürsten, fromme Mystiker im Dienst ihrer Mitmenschen oder auch geckenhafte Lebemänner. Über ihnen allen jedoch steht der Kalif als Grossmeister. Die soeben erwähnten Mitglieder ordnen sich ihm unter und berufen sich auf ihn. F. Taeschner vermutet, dass Nāșirs Ziel im Rahmen der FutuwwaReform darin bestand, ein Machtmittel in der Hand zu haben, um seine Autorität in den Ländern des Islams durchzusetzen. Seine Bestrebungen zielten zugleich darauf ab, sich die lokalen weltlichen Machthaber unterzuordnen.

Zumindest im Iraq dürfte die höfische Futuwwa den Einfall der Mongolen nicht überdauert haben. ${ }^{226}$ Allerdings scheint die Futuwwa in Ägypten eine Zeit lang überlebt zu haben. Unter dem Mamluken-Sulțān Baybars (reg. 658-676/126o-

Erlass im Wortlaut festgehalten; vgl. dazu die Quellenangaben bei Taeschner, Gemeinschaftsbildende Idee 139 (Anm. 3).

226 Zwar zog der Mongoleneinfall auch die FutuwwaBünde in Mitleidenschaft. Dennoch sind Werke erhalten geblieben, die noch zur Zeit an-Nāșir li-Dīn Allāhs verfasst worden sind und einen Eindruck vom Bundeswesen in der ersten Hälfte des 13. Jh. vermitteln. Es handelt sich einerseits um Ibn al-Mi'mārs (gest. 642/1244) Kitāb al-Futuwwa, das eigentlich im Geist eines islamischen Rechtsbuchs abgefasst ist (vgl. Taeschner, Zünfte und Bruderschaften 79-83 und 89-187). Anderseits hatte Ahmmad b. Ilyās an-Naqqāš al-Hartabirtī ein Werk namens Tuhfat al-wașāya verfasst und darin die Beziehungen zwischen den Futuwwa-Bünden und dem Sufismus hervorgehoben (vgl. Taeschner, Zünfte und Bruderschaften $84-87$ und 189-216).
1277) war das Abbasidenkalifat nach Ägypten übertragen worden. Baybars und einige seiner Nachfolger sollen Mamluken-Fürsten und andere Emire mit dem Gewand der Futuwwa bekleidet und somit geehrt haben. Es sieht jedoch danach aus, dass die höfische Futuwwa in Ägypten im 14., spätestens jedoch im 15. Jh., erloschen ist. ${ }^{227}$ Es ist jedenfalls bekannt, dass der hanbalitische Rechtsgelehrte Ibn Taymiyya (gest. 728/1328) Schriften gegen die Futuwwa verfasst hat. ${ }^{228}$ Die Futuwwa musste somit zu Ibn Taymiyyas Lebzeiten noch existiert haben.

Wenn auch die höfische Futuwwa in den Wirren im Nachgang des Mongolensturms wesentlich an Bedeutung eingebüsst hat, gingen die in den Futuwwa-Bünden vertretenen Wertvorstellungen von Tapferkeit, Grosszügigkeit und Aufrichtigkeit im Glauben damals doch nicht verloren. Die Futuwwa-Ideale wurden allerdings in einem andern Rahmen weitergepflegt. Wir sind darüber u. a. dank der Berichte des maghrebinischen Weltreisenden Ibn Batțūṭa (gest. 1368 oder 1377) über seinen Aufenthalt in Anatolien gut informiert, auf die sich die weiteren Ausführungen zum Ahītum teilweise stützen. ${ }^{229}$

\subsubsection{Das Ahìtum}

Die Futuwwa-Bünde verbanden sich im Nachgang des Mongolensturms mit dem Handwerkertum. ${ }^{230}$ Im seldschukischen Anatolien entwickelte sich dabei eine interessante Sonderform der FutuwwaBewegung; sie lässt sich unter der gewerbetreibenden Bevölkerung in den Städten nachweisen. Die Angehörigen dieser Bewegung werden als $a h \bar{\imath}$ bezeichnet. Es hat sich eingebürgert, diese Organi-

227 Taeschner, Gemeinschaftsbildende Idee $143 \mathrm{f}$.

228 Für Ibn Taymiyyas Äusserungen gegen die Futuwwa vgl. Taeschner, Zünfte und Bruderschaften 225, mit den Quellenangaben in Anm. 12 (S. 613); ders., Die islamischen Futuwwabünde 40; Irwin, 'Futuwwa': Chivalry and gangsterism 165. Siehe auch Goshgarian, Beyond the social and spiritual 91.

229 Zu Ibn Baț̣ūța und seinen Darstellungen vgl. unten bei Anm. 255-262.

230 Vgl. für die weiteren Ausführungen Taeschner, Gemeinschaftsbildende Idee $144-151$. 
sation in Anatolien als Ahītum zu bezeichnen. ${ }^{231}$ Der Ausdruck wurde wiederholt mit dem arabischen $a h \bar{\imath}$ („,mein Bruder“) in Verbindung gebracht. Dies ist zwar auf den ersten Blick naheliegend, letztlich aber nicht haltbar. Bereits der Turkologe J. Deny konnte aufzeigen, dass der Begriff auf den alttürkischen Ausdruck aqı̌ („Freigebigkeit, Edelmut“) zurückgeht. ${ }^{232} \mathrm{~F}$. Taeschner zieht die Möglichkeit in Betracht, dass sich das Ahìtum noch vor Anatolien in Iran nachweisen liess. Er verweist auf Ahī Farağ Zinğānī (gest. 457/1065), der in Iran verehrt wurde. ${ }^{233}$ Wahrscheinlicher scheint allerdings, dass es sich bei ihm um einen Sufi-Šayh handelte, der sich durch seine Freigebigkeit und Gastfreundschaft auszeichnete.

Es ist der Geschichtsschreiber Ibn Bībī, dem wir präzisere Angaben dazu verdanken, unter welchen Umständen bereits die höfische Futuwwa in Anatolien Fuss fassen konnte. ${ }^{234}$ Gemäss seiner Darstellung hatte Sulțān Kaykāwūs I. von den Rūm-Seldschuken den Kalifen an-Nāṣir li-Dīn Allāh im Jahr 612/1215-1216 darum gebeten, ihm das Gewand der Futuwwa (libās al-futuwwa) zu schicken. Unter seinem Nachfolger 'Alā' ad-Dīn Kayqubād I. (regierte 616-634/1219-1236) reiste Abū Ḥaș ‘ 'Umar as-Suhrawardī, der uns bereits bekannte Hoftheologe Nāṣirs, als dessen Gesandter an den Hof in Konya. Bei diesem Empfang gaben auch die Qāḍīs, die Vornehmen sowie die Ahīs und fityān aus Konya dem Gesandten des Kalifen die Ehre. ${ }^{235}$

231 Für neue Übersichten zum Ahītum mit weiteren Quellenangaben vgl. Ocak, Ahi, in $E I^{3}$; Dianat, Akhī, in Encyclopaedia Islamica.

232 Siehe Breebaart, Development 109 (mit Anm. 1), wo Verweis auf Deny, Futuvvet-nāme 182. Siehe ebenso Taeschner, Gemeinschaftsbildende Idee 145 .

233 Siehe zu ihm Taeschner, Zünfte und Bruderschaften 233; ders., Gemeinschaftsbildende Idee 145.

234 Vgl. zu den weiteren Ausführungen Taeschner, Gemeinschaftsbildende Idee $145 \mathrm{f}$; siehe zum Ahïtum ebenso Breebaart, Development 109-144. Suhrawardīs Breebaart, Development 109. Mit Verweis auf Ibn Bībī, Salğuq-nāma, übersetzt von Duda, Die Seltschukengeschichte des Ibn Bībī 102.

Bereits Ibn Bībīs soeben angeführter Bericht weist darauf hin, dass bei Suhrawardīs Empfang in Konya auch ahīs anwesend waren. Gemäss F. Taeschner legen weitere Darstellungen aus der Seldschukenzeit nahe, dass die ahis genannten Persönlichkeiten jeweils einer Gruppe junger Männer vorstanden, die als rindān bezeichnet wurden. ${ }^{236}$ Diese Schar gestattete es ihrem Anführer auch, bei Bedarf die politischen Auseinandersetzungen in seiner Stadt zu seinen Gunsten zu beeinflussen. Es spricht Verschiedenes dafür, dass es sich bei diesen Gruppierungen um Parallelorganisationen zur Futuwwa in der arabischen Welt, gerade auch zu den 'ayyār in Bagdad, handelte. ${ }^{237}$

Aflākī ${ }^{238}$ erwähnt in seinem Werk Manāqib al'Ārifin mehrere Ahīs im engsten Umfeld Ǧalāl adDīn Rūmīs (6o4-672/1207-1273), der bekanntlich in Konya lebte. Einige Ahīs standen in direktem Kontakt mit Rūmī selbst. Dazu zählt Ahī Husām ad-Dīn, der Ǧalāl ad-Dīn als Vorsteher der Mawlawiyya in Konya nachfolgte. ${ }^{239} \mathrm{Im}$ Rahmen dieser Nachfolgeregelung war es allerdings zu Auseinandersetzungen unter den Anhängern Rūmīs gekommen. Ein gewisser Ahī Aḥmad und seine Gefolgsleute lehnten sich gegen Ahī Ḥusām ad-Dīn auf. Fragen rund um den $\operatorname{sama}^{c}$ standen im Vordergrund dieser Auseinandersetzungen. Es gelang Aḩ̄ Ahmad jedenfalls, eine Anzahl von lokalen rind $(\mathrm{Pl} \text {. runūd })^{240}$ hinter sich zu scharen und seinem

236 Zum Ausdruck rind vgl. de Bruijn, Rind, in $E I^{2}$.

237 F. Taeschner gibt auf die genaue Funktion dieser frühen Ahī-Bünde in Anatolien keine Antworten und verweist stattdessen auf Cahen, Sur les traces des premiers Akhis.

238 Šams ad-Dīn Aḥmad Aflākī 'Ārifī (gest. 761/136o) war ein persischer Sufi-Schriftsteller und Verfasser des Werks Manāqib al-'ārifin (Feste der Gotteskenner). Dieses Werk stellt die Vorsteher der Mawlawiyya vor, darunter auch Ğalāl ad-Dīn Rūmī. Vgl. zu Aflākī Losensky, Aflākī, 'Ārifī, in $E I^{3}$; Mohammadi, Aflākī, in Encyclopaedia Islamica. Vgl. Kapitel 3.1.2.

240 Der persische Ausdruck rind bezeichnet einen gerissenen, furchtlosen, mit allen Wassern gewaschenen Kerl. Es kann sich auch um einen débauché handeln. Gemäss H.W. Duda gehörten die rind zu den niederen Händlern und Handwerkern in den Städten. Es liegt nahe, sie mit 
Protest gegen Ḥusām ad-Dīn als neuen Čelebī des Ordens der Mawlawiyya Nachdruck zu verleihen. Ahī Ḥusām ad-Dīn konnte sich allerdings schliesslich dank der Unterstützung durch andere Ahīs durchsetzen.

Im Umfeld der Mawlawiyya stand auch Ahī Ahmad-Šāh in hohem Ansehen. Gemäss Aflākī hatte er Tausende von rind um sich scharen können und wurde „König der fityān" genannt. Dieser Ah̄ì Aḥmad-Šāh gehörte zu den wohlhabenden Bewohnern Konyas und war durch Seidenhandel zu Vermögen gekommen. Er zeigte sich gegenüber Sulțān Walad, Ğalāl ad-Dīns Sohn und Nachfolger, ausgesprochen loyal. Dies trug ihm unter den Mawlawiyya-Angehörigen grossen Respekt ein. Aflākī preist ihn, da sein mutiges Vorgehen massgeblich zur Rettung Konyas vor dem mongolischen Prinzen Gayhātū beigetragen hatte. ${ }^{241}$

Sowohl Ahī Aḥmad als auch Ahī Aḥmad-Šāh spielten eine wichtige Rolle in den inneren Angelegenheiten Konyas. ${ }^{242}$ Sie organisierten den Widerstand der rind ( $\mathrm{Pl}$. runūd) und der fityān gegen die mongolischen Machthaber, wenn diese die lokale Bevölkerung drangsalierten. Ausserdem verteidigten sie die Stadt später gegen die Qaramaniden. ${ }^{243}$ Das grosse Ansehen, das Ahī Aḥmad-Šāh in Konya genoss, kommt überdies darin zum Ausdruck, dass 15'ooo Bewohner der Stadt im Jahr 697/1297-1298 an seinem Begräbnis teilnahmen und die Läden während vierzig Tagen geschlossen blieben. ${ }^{244}$

Gegen das Ende der Herrschaft der RūmSeldschuken in Anatolien, d.h. um etwa 1300, ${ }^{245}$ lassen sich klare Verbindungen zwischen Ahìtum und Futuwwa feststellen. Aus dieser Zeit stammen auch Handbücher, die von Ahis für ihre Mitbrü-

den aus Bagdad bekannten 'ayyārūn-fityān zu vergleichen; siehe Duda, Die Seltschukengeschicke 241 (mit Anm. a, S. 242). Vgl. dazu Aflākī, Manāqib al-ĀÂrifin, übersetzt von Huart, Les Saints des derviches tourneurs II, 238.

Breebaart, Development 111.

Vgl. Cahen, Sur les traces des premiers Akhīs 87 . Vgl. dazu Cahen, op. cit. 89 .

$\mathrm{Zu}$ den Rūm-Seldschuken vgl. Bosworth, New Islamic dynasties 213f. (Nr. 107). derverfasst worden sind. Diese Werke sind zumeist unter dem Begriff Futuwwat-nāma bekannt. Sie stellen die Gedankenwelt der Futuwwa in jener Form dar, wie sie ihre vom Sufismus beeinflussten Autoren herausgearbeitet haben. Sie beschreiben auch das zuweilen seltsame Brauchtum, das auf die fityān zurückgeht. F. Taeschner verweist bei dieser Gelegenheit einerseits auf das Futuwwatnāma des anatolischen Dichters Nāșirī (beendet 689/129o); es handelt sich um ein MatnawiGedicht mit 800 persischen Doppelversen. ${ }^{246}$ Etwas später, um die Mitte des 8./14. Jh., entstand Yahyā b. Halīl al-Burgaāzīs Futuvvet-nāme in osmanischer Prosa. ${ }^{247}$ Die beiden Werke dürften auf eine gemeinsame Vorlage zurückgehen, die sich bis anhin allerdings nicht identifizieren liess. Da Burḡāzīs Text auch Abschnitte aus den im Umfeld des Kalifen an-Nāșir li-Dīn Allāh entstandenen Schrifttum enthält, liegen auch aus diesem Grund Verbindungen zwischen Ahìtum und Futuwwa nahe. ${ }^{248}$

Diese Schriften über das Ahītum zeigen auf, dass sich dieses in verschiedener Hinsicht von der höfischen Futuwwa unterscheidet. Dies kommt am deutlichsten in der zentralen Stellung des $a h \bar{\imath}$ als Vorsteher einer Schar junger, unverheirateter Männer zum Ausdruck. Die Ahi-Futuwwa umfasst drei Grade, nämlich jene des yiğit, des ahī und des šayh. ${ }^{249}$ Beim yiğit handelt es sich um den Novizen, der noch in Ausbildung steht. Die angeführten Texte äussern sich aber in erster Linie zur Stellung des $a h \bar{\imath}$, bei dem es sich um den Vorsteher des örtlichen $A h \bar{\imath}$-Bunds handelt und der sich um die Ausbildung der jungen Bundesmitglieder kümmert. Die Ausführungen zur Stellung des šayh legen sodann nahe, dass er nicht wirklich zum Kreis der aktiven Bruderschaft gehört. Es

246 Vgl. Taeschner, Der anatolische Dichter Nāșirī; siehe ausserdem Taeschner, Zünfte und Bruderschaften 307313 und 394-401.

247 Siehe Taeschner, Zünfte und Bruderschaften 302-307, 309-311, 319-393.

248 Vgl. zu diesem Schrifttum aus dem Umfeld des Kalifen an-Nāșir li-Dīn Allāh Anm. 226.

249 Taeschner, Gemeinschaftsbildende Idee 147. 
dürfte sich bei ihm vielmehr um einen bedeutenden Derwisch handeln, dem sich der jeweilige $A h \bar{i}-$ Verbund angeschlossen hatte. Dem ahi steht ein Zeremonienmeister, füke genannt, ${ }^{250}$ zur Seite. Er übernimmt jene Aufgabe, für die in der höfischen Futuwwa der naqīb verantwortlich ist.

Die Quellen enthalten zugleich Hinweise darauf, dass die Mitglieder von Ahī-Bünden in zwei Klassen eingeteilt werden, nämlich in die qawliss und die sayfıs. ${ }^{251}$ Bei den sayfıs dürfte es sich um Vollmitglieder der Gemeinschaft handeln. Der Ausdruck leitet sich vom arabischen Begriff sayf, „Schwert“, ab und bezeichnet sozusagen die Schwertbrüder. Die qawlīs hingegen, von arabisch qawl, „Wort, Rede“, legen gewissermassen nur ein Lippenbekenntnis ab. Sie bilden den äusseren Kreis, der diesen Gruppierungen, ähnlich wie bei den Derwischen die muhibb, als Sympathisanten verbunden ist. Eigentlich liegt die Vermutung nahe, dass die sayfis, die Schwertbrüder, eine Art Kampfgemeinschaft bildeten und in den heiligen Krieg, den ǧihād, zogen. Allerdings fehlen in den Quellen Angaben, die diese Vermutung explizit bestätigen.

Bei dieser Gelegenheit soll ausserdem auf ein persisches Futuwwat-nāma von Nağm ad-Dīn Zarkūb-i Tabrizī (14.Jh. $)^{252}$ hingewiesen werden. Diese Schrift ist wohl im Umfeld der Ahī-Bünde entstanden. ${ }^{253}$ Der Text fügt zwischen den sayfis und den qawlīs mit den šurbīs (von arabisch šariba, Verbalnomen šurb, „trinken“) eine dritte Klasse von Mitgliedern ein. Es handelt sich bei ihnen um jene Bundesgenossen, die den Initiationstrunk aus dem Becher der Futuwwa (ka's al-futuwwa) zu sich genommen haben. Die Klasse der šurbīs übrigens

250 Der Ausdruck könnte sich gemäss F. Taeschner von arabisch faqīh ableiten (vgl. vorangehende Anm.).

251 Taeschner, Gemeinschaftsbildende Idee 147.

252 Die nisba Tabrīzī weist darauf hin, dass dieser Verfasser aus Tabriz und damit aus dem Städtedreieck stammt, auf das hier bereits mehrfach hingewiesen worden ist.

253 Zu Nağm ad-Dīn Zarkūb-i Tabrīzì und seinem Werk siehe jetzt auch Ohlander, The Futuwwat-nāma of Najm al-Dīn Zarkūb of Tabriz. ist auch von den Zünften (șinf, Pl. aṣnāf) bekannt, von denen später noch die Rede gehen wird. ${ }^{254}$

Die $A h \bar{\imath}$-Bünde in Anatolien sind auch dank den Darstellungen in Ibn Bațtūțas (703-770 oder 779/1304-1368 oder 1377) Reiseberichten gut bekannt. ${ }^{255}$ Dieser Weltreisende aus dem Maghreb hat Anatolien von Aleppo her kommend nach 730/1330 durchquert. Er lobt in seiner Darstellung die gastfreundliche Aufnahme in den höchsten Tönen, die er bei den ahīs gefunden hatte. Diese Bünde hatten es sich zur Pflicht gemacht, Fremde zu empfangen. Auch Ibn Bațtūțas Ausführungen lässt sich entnehmen, dass sich in diesen Gruppierungen junge, unverheiratete Männer aus dem Handwerkstand zusammenschlossen. Die Vorsteher dieser Gruppierungen wurden ahī genannt und übten lokal oft bedeutenden Einfluss aus.

Ibn Bațūtạa charakterisiert die aȟss als edel gesinnt, selbstlos, mitleidvoll und einfühlsam. Er ist u.a. in Antalya, Konya, Niğde, Akseray, Sivas und Bursa in ihre zāwiyas eingeladen worden. In der Stadt Ladik kam es zwischen zwei $A h \bar{\imath}-$ Gruppierungen, nämlich jener des Ahī Sinān und jener des Ahī Ṭūmān sogar zu Auseinandersetzungen darüber, wer den berühmten Reisenden zuerst bewirten und beherbergen dürfe. ${ }^{256}$ In Konya wiederum kam Ibn Bațțūta in der zāwiya des örtlichen $q \bar{a} d \hat{\imath} \bar{\imath}$ unter, der als ahı̄ bezeichnet wird und eine grosse Zahl von Anhängern hatte. Auch Ibn Bațtutụa macht darauf aufmerksam, dass die ahīs in gewissen Städten politische Macht ausübten. ${ }^{257}$ Da in Akseray und Niğde kein Îlhāniden-Prinz vor Ort

\footnotetext{
254 Zu den Zünften vgl. Kapitel 3.2.3.

$255 \mathrm{Zu}$ Ibn Bațțūta vgl. Waines, Ibn Batțūța, in $E I^{3}$. Vgl. zu den weiteren Ausführungen auch Breebaart, Development $111 \mathrm{f}$.

Taeschner, Zünfte und Bruderschaften 289-298, stellt die relevanten Passagen zusammen. Siehe auch Ibn Bațtūța, Rihla 285-322 (= The travels of Ibn Battuța; Bayrūt, Dār Bayrūt, 198o); französische Übersetzung mit arabischem Text: Defrémery und Sanguinetti, Voyages d'Ibn Batoutah II, 254-354, englische Übersetzung von Gibb, Ibn Battuta 123-141.

256 Vgl. Defrémery und Sanguinetti, Voyages d'Ibn Battūtah II, 273.

257 Breebaart, Development 112.
} 
war, kümmerten sich die ah̄is um die Verwaltung der lokalen Angelegenheiten und die Aufrechterhaltung eines geordneten Alltags. Gemäss Ibn Batțūṭa verwaltete ein gewisser Ahī Ǧārūq die Stadt Niğde. ${ }^{258}$

Der maghrebinische Weltreisende beschreibt ausserdem, dass die ahis in Anatolien jeweils einer Gruppe von Handwerkern und jungen, ledigen Männern vorstanden. Sie gingen bis zur Zeit des Nachmittagsgebets ihrem Tagwerk nach. Sie versammelten sich danach in ihrer zāwiya, wo sie ihre Tageseinkünfte ihrem $a h \bar{\imath}$ übergaben. ${ }^{259}$ Mit diesem Betrag wurden Lebensmittel gekauft und das gemeinsame Essen der $A h \bar{\imath}$-Gruppierung zubereitet. Ibn Battūta hatte mehrfach die Gelegenheit, an diesen Mahlzeiten teilzunehmen. Nach dem Essen machten die ahīs Musik, diskutierten miteinander oder praktizierten den sama $\bar{a}^{c}$. Das Zusammensein zog sich oft bis weit in die Nacht hinein. ${ }^{260}$

Aus den schriftlichen Quellen geht überdies hervor, dass diese zāwiyas häufig mit Matten und Teppichen ausgelegt waren. Auch waren Öllampen zur Beleuchtung aufgestellt, um die sich besondere Diener kümmerten. Die ahì-fityān trugen gemäss Ibn Battūta lange Kleidung und Stiefel. An ihrem

$25^{8}$ Vgl. Defrémery und Sanguinetti, Voyages d'Ibn Battūtah II, 287 .

259 Die Futuwwa- und Ahī-Gruppierungen legen grossen Wert darauf, dass ihre Mitglieder ihren Lebensunterhalt aus eigenen Anstrengungen bestreiten. Diese Bestimmung richtet sich implizit gegen die Angehörigen von Derwischbünden, die im Vertrauen auf Gott (tawakkul 'alā $[A] l l a ̄ h)$ durch die islamischen Lande zogen. Diese Wanderderwische stellten eine Landplage dar, sassen sie doch einfach der arbeitenden Bevölkerung auf der Tasche. Vgl. Breebaart, Development 167; Taeschner, Zünfte und Bruderschaften 288 (bei Ibn Batțūța; auch bei Defrémery und Sanguinetti, Voyages d'Ibn Battūtah II, 261); Taeschner, Zünfte und Bruderschaften 46o-463, v.a. 46o (Abschnitt aus 'Alä' ud-Dīn ar-Raḍawīs Miftāh ad-daqā’iq: „5. Abschnitt. Berufsmoral des Handwerkers und Kaufmanns“; 46o: „Geschichten über die Verdienstlichkeit des Lebenserwerbs aus dem Erlös von Arbeit der eigenen Hände“).

26o Vgl. Defrémery und Sanguinetti, Voyages d'Ibn Battūtah II, $261 \mathrm{f}$.
Gurt hing ein Schwert oder ein grosses Messer. Ibn Batțūta beschreibt auch ihre Kopfbedeckung, qalansuwa genannt. Sie trugen Futuwwa-Kleidung (libās al-futuwwa), wie Ibn Bațțūta festhält. ${ }^{261}$

Diese Beobachtungen Ibn Bațțūtas werden durch die umfangreiche Literatur bestätigt, die im 7.-8./13.-14. Jh. im Umfeld der Ahi-fityān entstand. Ibn Battūtas Darstellung bedarf insofern einer Korrektur, als nur ein Teil der ahis auch wirklich ledig war. Die Quellen enthalten vielfach Hinweise auf eigentliche $A h \bar{\imath}$-Familien, deren Angehörige über mehrere Generationen in die libās alfutuwwa, die Futuwwa-Kleidung, eingekleidet worden waren. Die ahīs übten nicht ein bestimmtes Gewerbe oder eine bestimmte Handelstätigkeit aus. Qāḍ̄s, reiche Händler, Handwerker ebenso wie Emire, Madrasa-Lehrer und Mystiker waren in $A h \bar{\imath}$-Bünden häufig vertreten. Sie sind die Vorsteher (muqaddam) der lokalen fityān, die sich zu einem grossen Teil unter den Handwerkern und den Kleinhändlern rekrutierten. ${ }^{262}$

Aus Ankara sind Beispiele von vornehmen $A h \bar{\imath}-$ Familien bekannt, die in diesen Männerbünden über mehrere Generationen eine führende Stellung innehatten. Anhand von Waqf-Dokumenten und Inschriften an Gebäuden und auf Gräbern lässt sich belegen, dass in Ankara unter den vornehmen Ahìs die Familie des Ahī Ḥusām ad-Dīn (gest. 695/1296) eine bedeutende Rolle spielte. Die ortsansässigen ahis hatten auch in Konya, Sivas, Tokat, Kayseri etc. eine wichtige Stellung als Stifter von Schulen (madrasa), Moscheen, Waisenhäuser und Spitälern inne. ${ }^{263}$

Ankara war am Anfang des 14. Jh. zwar formell Teil des Îlhāniden-Reichs. Dies wird auch durch eine Inschrift bestätigt, die der Î̄hāan Abū Sa'̄ìd 1333 an der Burg von Ankara hatte anbringen lassen.

261 Vgl. Taeschner, Zünfte und Bruderschaften 29o (Stellen bei Ibn Batțūța: vgl. Defrémery und Sanguinetti, Voyages d'Ibn Battūtah II, 263-265).

262 Breebaart, Development 114.

263 Vgl. Taeschner, Beiträge zur Geschichte der Akhīs in Anatolien 37. Siehe ausserdem Breebaart, Development 114. 
Nach Abū Saīds Tod (1335) ${ }^{264}$ ging Ankara zwar de iure an die Sultane von Sivas über. De facto aber war Ankara eigenständig. Eine Ahī-Familie dürfte $\mathrm{zu}$ jener Zeit eine bedeutende Rolle im gesellschaftlichen Leben der Stadt gespielt und sozusagen eine fürstliche Stellung eingenommen haben. Diese Ahis von Ankara bezeichneten sich selbst als Gross-Ahīs (ahī mu'azzam). Sie liessen in der Stadt u. a. die Arslanhane-Moschee errichten, wie sich anhand von Inschriften belegen lässt. Sie untermauerten dadurch ihre Stellung als reiche Herren in der Stadt.

Der osmanische Sulțān Murād I. (gest. 791/1389) nahm Ankara nach seinem Sieg im Jahr 1361 aus den Händen der Ahìs entgegen. F. Taeschner ging überdies Berichten nach, wonach sich Murād I. nach der Eroberung der Stadt von einem ahī gürten liess. Eine Stiftungsurkunde aus dem Jahr 767/1366 legt sogar nahe, dass Murād I. nach der Eroberung Ankaras selbst Mitglied des dortigen Ahì-Bunds geworden ist. ${ }^{265}$ Murād soll danach seinerseits die Gürtung an Ahī Mūsā vollzogen und dabei jenen Gürtel benutzt haben, der bei seiner eigenen Aufnahme in den $A h \bar{\imath}$-Bund verwendet worden war. ${ }^{266}$

Unter Bāyazid Yildirim (gest. 8o4/1403) waren die Ahīs in Ankara mit den lokalen osmanischen Machthabern derart unzufrieden, dass sie einen zwanzigtägigen Generalstreik organisierten und die Bevölkerung aufforderten, zu den Waffen zu greifen. Im Jahr 826/1423 wiederum rückte Muṣțafā, der Sohn von Sulțān Meḥmed, gegen seinen Bruder Murād II. vor, der sich in Bursa aufhielt. Die Bevölkerung der Stadt sandte zwei Ahīs, nämlich Ahī Ya'qūb und Ahī Qādim, zu Verhandlungen mit dem heranziehenden Muṣtafā aus, um die drohende Belagerung der Stadt abzuwenden. Diese Bemühungen stellen allerdings das letzte Beispiel

\footnotetext{
264 Abū Sa'īd war der letzte Îlhuāniden-Herrscher.

265 Siehe auch Taeschner, Murad I.

266 Vgl. dazu Taeschner, Murād I. 23-28. Es gibt allerdings Hinweise, die die Authentizität der entsprechenden Dokumente in Frage stellen; siehe dazu Taeschner, Zünfte und Bruderschaften 405 mit Anm. 3 (S. 632). Siehe auch Breebaart, Development 115 .
}

dar, anhand dem sich der Einfluss der Ahīs auf das politische Geschehen illustrieren lässt. ${ }^{267}$

Ähnliche Entwicklungen lassen sich auch in Iran aufzeigen. ${ }^{268} \mathrm{~F}$. Taeschner jedenfalls macht auf einen Mann aufmerksam, der einfach Ahığūq („Achilein“) geheissen wurde. Er konnte in Tabriz und in Aserbaidschan drei Jahre lang (75876o/1357-1359) die Herrschaft ausüben. Damals waren die Îlhāniden in der Region nur noch nominell an der Macht und hatten eine effiziente Kontrolle über das Gebiet nach Abū Sa'īds Tod (1335) eingebüsst. Als der Ğalāyiride Uways die Macht übernahm, büsste dieser Ahığūq allerdings jeglichen Einfluss wieder ein. ${ }^{269}$ Ahis hielten sich damals ausserdem in Ardabil auf, wo der Derwischorden der Șafawiyya im Aufstieg begriffen war. $^{270}$

Das Ahìtum konnte sich in Anatolien gut entwickeln, solange das Reich der Rūm-Seldschuken in Konya vor sich hinserbelte. Als aber die Osmanen an Macht gewannen und die einstigen BeylikStaaten in Kleinasien in ihr Reich integrierten, verloren die Ahis ihren Einfluss zunehmend. ${ }^{271}$ Danach lassen sich nur noch vereinzelt Belege für eine wichtige Rolle der Ahis in Anatolien feststellen. Die Hintergründe für diesen Bedeutungsschwund sind nicht restlos geklärt. Vieles spricht aber dafür, dass im aufsteigenden Osmanenstaat mit seinem starken Verwaltungsapparat kaum noch Platz für männerbündlerisch organisierte Gruppierungen war, die immer wieder eigene Machtansprüche geltend machten.

267 Breebaart, Development 115 .

268 Die folgenden Ausführungen stützen sich auf Taeschner, Gemeinschaftsbildende Idee 151. Zur Ergänzung sei darauf hingewiesen, dass sich auch J. Pfeiffer in jüngeren Untersuchungen mit derartigen Entwicklungen in Ost-Anatolien und Tabriz befasste; vgl. Pfeiffer, Confessional ambiguity vs. confessional polarization.

269 F. Taeschner behandelt diesen Ahīğūq ausführlicher in seinem Aufsatz: Der Achidschuk von Tebriz; vgl. auch Taeschner, Zünfte und Bruderschaften 234.

270 Zur Präsenz von Ahīs in Ardabil vgl. Gronke, Derwische 9of.

271 Siehe dazu Taeschner, Gemeinschaftsbildende Idee $148 f$. 
Die Futuwwa- und Ahì-Bewegungen und ihre Vorstellungen waren lange nur aufgrund der Berichte Ibn Battūțas bekannt. Inzwischen ist dazu eine deutlich breitere Literatur greifbar, die hier jedoch nicht in extenso vorgestellt werden kann. ${ }^{272}$ Diese Werke beschreiben die im Umfeld der $a h \bar{i}-$ fityān in Anatolien gepflegten Rituale und Glaubensvorstellungen. ${ }^{273}$

Es kann einerseits auf ein mystisch-didaktisches Gedicht des Gülşehrī in osmanischer Sprache hingewiesen werden, das 717/1317 beendet wurde und in einem Kapitel auf die Futuwwa eingeht. ${ }^{274}$ Die beiden bedeutendsten Werke zur $A h \bar{\imath}-$ Futuwwwa sind jedoch erstens Yahyā b. Halīl Çobans, auch Burḡāzī genannt, Futuvvet-nāme. ${ }^{275}$ Beim zweiten wichtigen Text handelt es sich um Nāṣinīs Futuvvet-nāme, das 689/129o beendet wurde und in Ostanatolien entstanden sein dürfte. ${ }^{276}$

Nāṣirīs Futuvvet-nāme ist sufischen Wertvorstellungen verpflichtet. ${ }^{277}$ Nāṣirī betrachtet die šarĩa als Grundlage der futuwwa. Von der šarĩa aus führen zwei Wege zum Thron Gottes, nämlich die țarīqa und die haqīqa. Šarīa, țarīqa und haqīqa stellen drei Etappen auf dem Weg zur Vereinigung mit Gott dar. In Nāșirīs Aufzählung fehlt mit der márifa das vierte Element, das üblicherweise die soeben aufgezählte Dreiheit ergänzt. Die šarî̃a stellt jene Stufe dar, auf der der murìd zum strikten Einhalten der rituellen und šarīa-rechtlichen Pflichten aufgefordert ist. Auf der Tarīqa-Stufe betritt der murìd den mystischen Pfad im eigentlichen Sinn. Er gibt äussere zugunsten innerer Fröm-

272 Zur Sekundärliteratur über die Futuwwa- und AhīBünde vgl. bereits Anm. 193.

273 Breebaart, Development 116.

274 Siehe zu diesem Text Taeschner, Das Futuvvetkapitel in Gülšehris altosmanischer Bearbeitung von 'Atțārs Manțiq ut-țayr. Siehe dazu auch Taeschner, Zünfte und Bruderschaften 286f., 313-318, 402.

$275 \mathrm{Zu}$ Autor und Text vgl. Taeschner, Zünfte und Bruderschaften 302-307, 309-311, 319-393. Siehe ausserdem Breebaart, Development 116 (Anm. 19).

276 Zu Autor und Text vgl. Taeschner, Zünfte und Bruderschaften 307-313 und 394-401. Siehe ausserdem Breebaart, Development 116 (Anm. 20).

277 Breebaart, Development 117. migkeit auf und erreicht die Stufe der ma'rifa. Auf dieser höchsten Stufen der márifa (Gnosis) nimmt der Sufi Gott in allen erschaffenen Dingen wahr.

Nāṣirī integriert die futuwwa in die soeben aufgezählten Stufen von šarīa, țarīqa, haqìqa und márifa, indem er sie als Teil der tarīqa versteht. ${ }^{278}$ Seine Sichtweise ist letztlich ein Echo von Suhrawardīs Risālat al-Futuwwa. ${ }^{279}$ Auch gemäss Suhrawardīs Perspektive ist die futuwwa Teil der tarīqa. ${ }^{280}$ Als Teil der țarīqa steht die futuwwa zwischen šarīa und haqìqa. Die futuwwa stellt damit in Sufi-Kreisen ein Stadium dar, das auch für jene zugänglich ist, die für das Erreichen des eigentlichen Ziels, nämlich der mystischen Vereinigung mit Gott, zu schwach sind.

Neben organisatorischen Fragen gehen Nāṣirī und Burḡāzì auf jene ethischen Grundregeln ein, die die Angehörigen eines $A h \bar{\imath}$-Bunds zu befolgen haben. ${ }^{281}$ Sie erwähnen, dass die ahis sechs Gebote einhalten. Sie bestehen darin, drei Dinge zu schliessen und drei zu öffnen. Der $a h i ̄$ ist verpflichtet, sein Gesicht zu öffnen (als Zeichen für Freundlichkeit), seine Tür offen zu halten (Gastfreundschaft) und sein Tischtuch auszubreiten (Grosszügigkeit). Anderseits muss der ahī drei Dinge geschlossen halten. Es sind dies a. seine Augen, damit er nichts Unerlaubtes sieht; b. seine Zunge, damit er niemanden beleidigt oder betrügt; und c. den Gürtel seiner Hosen ( $\check{s} a$ lwār $)$, damit er sich unmoralischer Handlungen enthält und keusch bleibt. Die soeben aufgezählten sechs Gebote werden in den meisten Futuwwa-Werken aufgezählt. Suhrawardī führt in seiner Risālat al-Futuwwa eine modifizierte Liste an, die sechs innere (bātin) und sechs äussere (zāahir) Prinzipien umfasst. ${ }^{282}$

\footnotetext{
278 Breebaart, Development 118.

279 Vgl. zu Abū Hafș 'Umar as-Suhrawardī bei Anm. 223f. und 235 und Kapitel 3.1.7, bei Anm. 174-185.

280 Breebaart, Development 118; Taeschner, Zünfte und Bruderschaften $245 \mathrm{f}$.

281 Breebaart, Development 120.

282 Vgl. die Übersicht bei Breebaart, Development $120 \mathrm{f}$.: a. bei den sechs innern Prinzipien handelt es sich um Grosszügigkeit, Demut, Grossherzigkeit, Bereitschaft zum Verzeihen, Widerstehen vor den sinnlichen Gelüsten und Erwachen aus der Trunkenheit der Illusionen.
} 
Nāṣirī weist in seiner Aufzählung der Qualitäten der ahīs auf die Bedeutung von Grosszügigkeit, Keuschheit, Kameradschaft und Zurückhaltung hin. Von besonderer Wichtigkeit ist, dass Nāṣirī die Angehörigen von Ahī-Bünden auch verpflichtet, für ihren eigenen Lebensunterhalt aufzukommen und einem Broterwerb nachzugehen. ${ }^{283}$ Burgāāì unterstreicht diese Verpflichtung ebenso. Er ergänzt sie um den Hinweis, dass ein $a h \bar{\imath}$ nie mehr als achtzehn Dirham für sich selbst zurückbehalten darf. Er ist gehalten, den übersteigenden Betrag zugunsten von Bedürftigen auszugeben. Die ahis traten in der Tat als Wohltäter in ihrer Stadt in Erscheinung. Dies kam nicht zuletzt darin zum Ausdruck, dass sie zahlreiche gemeinnützige Stiftungen (waqf) errichteten. ${ }^{284}$

Die Verpflichtung des $a h \bar{i}$, einem Broterwerb nachzugehen, dürfte eine indirekte Reaktion auf die zu jener Zeit im Vertrauen auf Gott (tawakkul 'alā Allāh) in grosser Zahl umherziehenden Wanderderwische sein. ${ }^{285}$ Sie bringt eine Einstellung zum Ausdruck, die sich auch am Beispiel der Propheten orientiert. David verdiente seinen Lebensunterhalt als Waffenschmied. Sein Sohn Salomon wiederum war als Korbflechter tätig. ${ }^{286}$ Aus dieser Verpflichtung ergibt sich ebenso, dass nicht Mitglied eines $A$ hì-Bunds werden kann, wer kei-

Bei den sechs äussern Prinzipien handelt es sich um sechs Dinge, die verschlossen sein sollen, nämlich: die Hosen (šalwār, als Zeichen der Keuschheit), der Bauch (Enthaltsamkeit von verbotenem Essen), die Zunge, die Hände und Füsse (um niemanden zu schlagen oder zu verletzen) und schliesslich das Tor des Geizes und weltlicher Ziele.

Vgl. für weitere Ausführungen Taeschner, Gülschehris Methnevī auf Achi Evran 73; siehe ebenso Breebaart, Development 121.

283 Breebaart, Development 122.

284 Vgl. zur Institution des waqf: Meier, Wakf, in $E I^{2}$.

285 Vgl. bereits Anm. 259 und Kapitel 3.1.4 (bei Anm. 138). Zum tawakkul vgl. Lewisohn, Tawakkul, in $E I^{2}$; Reinert, Die Lehre vom tawakkul.

286 David und Salomon gelten im Islam als Propheten. Zur Tätigkeit Salomons als Korbflechter vgl. Nünlist, Dämonenglaube 433. Siehe auch Nāṣirī, Futuvvet-nāme 321322, in Iktisat Fakültesi Mecmuası, Istanbul University, 11 (1949-1950). nen Beruf ausübt. Auch sind nicht alle Tätigkeiten akzeptiert. Grundsätzlich sind die Ungläubigen (kāfir) und die Heuchler (munāfiq) aus der Futuwwa-țariqa ausgeschlossen. ${ }^{287}$ Auch Wahrsager (kāhin), Säufer, Badangestellte, Marktschreier, Weber, Metzger, Chirurgen, Jäger, Steuereintreiber und Lebensmittel-Spekulanten sind nicht zur Aufnahme in die Gemeinschaft der ahis zugelassen. ${ }^{288}$ Bei der Einordnung von Nāṣirīs Darstellung ist dem Umstand Rechnung zu tragen, dass er ein Idealbild der $A h \bar{\imath}$-Bünde entwirft. Es kann somit nicht ausgeschlossen werden, dass die gelebte Realität anders aussah. Allerdings fehlen dazu bis anhin verlässliche Angaben. Aus Nāṣirīs Ausführungen lässt sich aber ableiten, dass die futuwwa im Fall eines ernsthaften Verstosses gegen die islamische Moral (Diebstahl, Ehebruch, Sodomie, Weintrinken etc.) verwirkt ist. Ein Ausschlussgrund besteht auch, wenn jemand gegen die erwähnten sechs Futuwwa-Pflichten verstösst. ${ }^{289}$

Die vorangehenden Ausführungen zeigten auf, dass das Ahītum in Anatolien gerade im 14. Jh. seine Blüte erlebte. In Iran lassen sich zu derselben Zeit ähnliche Entwicklungen beobachten, wie F. Taeschner mit Verweis auf den persischen Sufi-Šayh und Heiligen Amīr Sayyid 'Alī b. Šihāb ud-Dīn Hamadānī (714-786/1314-1384) aufzeigte, der eine Risāla-i futūwatiyya verfasst hat und auch

287 Für die folgende Zusammenstellung der Ausschlussgründe vgl. Breebaart, Development 122. Siehe auch Nāṣirī, Futuvvet-nāme 316-317.

288 Ungläubige, Heuchler, Wahrsager und Säufer werden ausgeschlossen, da sie gegen fundamentale Bestimmungen des Islams verstossen. Badangestellte sind der Aufnahme in Futuwwa-Bünde unwürdig, da der hammām grundsätzlich als schmutzig gilt. Herolde wiederum wurden als nicht vertrauenswürdig angesehen. Metzger, Quacksalber und Jäger kamen bei ihrer Tätigkeit mit unreinem Blut in Kontakt und galten überhaupt als grausam. Zumindest Nāșirī schliesst die Weber von der futuwwa aus und wirft ihnen Betrug vor. Weber hatten im Orient allgemein einen schlechten Ruf. Allerdings gibt es auch Beispiele dafür, dass Weber in die Ahī-Bünde Aufnahme finden konnten; vgl. Breebaart, Development 123 (mit Anm. 29).

Vgl. oben bei Anm. 281-282. 
einfach 'Alī II. ('Alī-i duwwum) genannt wird.290 Die Schrift ist wichtig, da sie futuwwa und tașawwuf miteinander gleichsetzt und den futuwwatdār, den „Inhaber von futuwwa“, als ahı̄ bezeichnet. Für die geographische Einordnung dieses Heiligen ist von Bedeutung, dass er angibt, Ahī Ṭūṭi 'Alīšāhī al-Huuttalānī sei sein Lehrmeister in der Futuwwa gewesen. Aufgrund seiner nisba lässt sich dieser ahı̄ mit der Region Huttalān am oberen Amū Daryā in Verbindung bringen, die im äussersten Nordosten des persischen Sprachgebiets liegt. Dies war 'Alī Hamadānīs Wahlheimat, wo er auch starb.

Burgaāzì ergänzt Nāṣirīs Angaben, indem er den idealen fatā als grosszügigen und bescheidenen Mann beschreibt, der von seinem eigenen Erwerbseinkommen lebt. Er hält seine rituellen Pflichten ein und unterstützt die Armen, Schwachen und Bedürftigen. Es sind die Qualitäten Frömmigkeit, reine Gesinnung, Bescheidenheit und Treue, die den ahī auszeichnen. Burgāzì warnt den ahū auch davor, bei den mächtigen Herrschern vorzusprechen. Diese würden sich den Lebensfreuden hingeben und seien innerlich verdorben. ${ }^{291}$ Burḡāzī erwähnt ausserdem zahllose Anstandsregeln ( $a d a b$, Pl. $\bar{a} d \bar{a} b)$, die der ahì einhalten muss und sein soziales und sittliches Verhalten bestimmen. Diese a $\bar{a} \bar{a} b$ können sich z.B. auf das Essen beziehen und stellen eine Erweiterung der šarīa-rechtlichen Bestimmungen dar. ${ }^{292}$ Man darf während des Essens weder spucken noch sich schneuzen. Niemand darf sich erheben, während andere noch am Essen sind. Auch ist es verpönt, zugleich zu essen und zu trinken. Das Essen selbst ist mit Respekt zu behandeln. Nach der Mahlzeit wiederum soll man seine Hände waschen. Dabei wird auch bestimmt, wie man den gereichten Wasserkrug zu halten hat. Ausserdem

290 Siehe dazu Taeschner, Gemeinschaftsbildende Idee $148 f$.

291 Breebaart, Development $132 \mathrm{f}$.

292 Gemäss der šarīa muss die Nahrung rein sein. Auch verlangt die sunna das Aussprechen der Formel bismillāh vor und al-hamdu li-llāh nach dem Essen. Die sunna bestimmt zusätzlich, dass man nicht aus der Mitte der Schüssel, sondern vom Rand essen soll. sind gemäss Burgaāzī die Fātiha und Gebete auf 'Alī b. Abī Ṭālib, Ḥasan, Ḥusayn, Abū Muslim, ${ }^{293}$ den pādišāh und weitere Personen ${ }^{294}$ zu rezitieren. ${ }^{295}$

Ebenso wie fürs Essen bestehen auch für zahlreiche weitere Alltagssituationen Verhaltensregeln $(\bar{a} d \bar{a} b){ }^{296}$ Sie beziehen sich z.B. aufs Reden. Es darf nicht zu laut sein, man soll nicht herumschauen, nicht gestikulieren und immer die Höflichkeitsform verwenden. Auch das Gehen auf der Strasse, das Betreten eines Hauses, der Handel im Bazar, das Ausziehen der Schuhe oder der Besuch von Kranken: all diese Tätigkeiten werden, oft bis ins kleinste Detail, durch Adab-Regeln vorgegeben. Gemäss Burgāāì gibt es insgesamt 124 Adab-Regeln. Diese Zahl lehnt sich an die 124'ooo Propheten an. Der ahi hat diese Bestimmungen strikt einzuhalten. Allerdings bestehen für den šayh noch zusätzliche Regeln, insgesamt 740. Burgaāzī präzisiert sie allerdings nicht.

Die vorangehenden Ausführungen haben die grundlegenden Werte der $A h \bar{\imath}$-Bünde anhand der Standpunkte Nāṣirīs und Burgāāīs vorgestellt. Bei dieser Gelegenheit soll darauf hingewiesen werden, dass F. Taeschner auch weitere Texte aus dem Umfeld der Futuwwa- und Ahi-Bünde in deutscher Sprache zugänglich gemacht hat. ${ }^{297}$ Es

293 Für die zunehmende Bedeutung der Verehrung von Respektspersonen aus der Schia im Umfeld von $\mathrm{Fu}$ tuwwa- und Ahi-Bünden siehe Yildirim, Shicitization; siehe zur Frage auch Kapitel 3.3 „Alid loyalty“. Breebaart, op. cit. 135 (Anm. 42), hält allerdings fest, dass es sich bei Burgāāzīs Futuvvet-nāme um einen Text handle, der noch klar sunnitisch ausgerichtet sei.

294 Breebaart, Development 135.

295 Die Futuwwa-Werke enthalten zumeist Angaben, die auch das korrekte Verhalten in weiteren Alltagssituationen regeln, wie ein Blick in die Inhaltsverzeichnisse dieser Texte aufzeigt; vgl. Kāšifì, Futuwwat-nāma-i Sulțāni 205-272: Bāb-i panğum: Dar ādāb-i ahl-i țarīqat.

296 Vgl. Breebaart, Development ${ }^{135^{-137}}$, die sich auf Burgāāī stützt.

297 Taeschner, Zünfte und Bruderschaften. 
sei hier aufmerksam gemacht auf Ḥusayn Wāciz Kāšifìs (gest. 1504) Futuwwat-nāma-i sulțān̄ in persischer Sprache. Kāšifì hatte am Ende der Timuridenzeit in Herat gelebt. ${ }^{298} \mathrm{H}$. Corbin und M. Sarraf haben zusätzliche Futuwwa-Texte in persischer Sprache erschlossen. ${ }^{299}$ Ausserdem hat sich M.Ğ. Mahğūb wiederholt mit der FutuwwaBewegung, gerade auch in iranischen Kontexten, befasst. ${ }^{300}$ R. Goshgarian macht sodann darauf aufmerksam, dass Männerbünde von der Art der Futuwwa- und Ahi-Bewegung im 14. und 15. Jh. ebenso im grundsätzlich christlichen Armenien bezeugt sind. ${ }^{301}$

Die $A h \bar{\imath}$-Bünde büssten ihren Einfluss in Anatolien mit dem Aufstieg der zunehmend zentralistisch ausgerichteten Staatsgebilde der Osmanen und Safawiden ein. ${ }^{302}$ Dies bedeutet allerdings nicht, dass ihre Wertvorstellungen sang- und klanglos verschwanden. Es kann an dieser Stelle auf Šāh Ismā̄îl I. hingewiesen werden, mit dem die Dynastie der Safawiden in Tabriz auch die weltliche Macht übernahm. Er hat unter dem tahallus Hațā̄i einen Dīwān in azeri-türkischer Sprache verfasst. ${ }^{303}$ Šāh Ismāīîl nennt darin wiederholt die ahīs, die $\dot{g} \bar{a} z \bar{\imath} s$ und die abdāls seine Parteigänger. ${ }^{304}$ Es ist zwar nicht restlos geklärt, wer mit den soeben angeführten Personenkreisen genau gemeint ist. Gewiss ist aber, dass unter den Qizilbāš - auf sie konnten sich die Safawiden bei ihrer Übernahme der weltlichen Macht im wesent-

298 Vgl. Subtelny, Kāšefî, Kamāl-al-Dīn Hosayn Wāeez, in EIr; Ridgeon, Morals and mysticism 92-122. Kāšifīs Futuwwa-Text wurde ins Englische übersetzt: Kāšifî, The royal book of spiritual chivalry = Futūwat nāmah-yi sulțānì.

299 Șarrāf, Rasā̉il-i ğawānmardān: muštamil bar haft Futuwwat-nāma.

300 Mahğūb, Ā'̄̄n-i ğawānmardī, yā Futuwwat; ders., Spiritual chivalry and early Persian Sufism; ders. Ğawānmardī wa ā’yīn-i ān; bereits zitiert in Anm. 193. Vgl. dazu Goshgarian, Futuwwa in thirteenth century Rūm and Armenia.

Siehe dazu Taeschner, Gemeinschaftsbildende Idee 151. Zu Šāh Ismāc̄ils bzw. Hațāīs Dīwān vgl. Savory und Karamustafa, Esmāīl I Șafawī, II. His poetry, in EIr. So gemäss Taeschner, Gemeinschaftsbildende Idee 151. lichen stützen - ähnliche Wertvorstellungen in Schwang waren wie in den Futuwwa- und AhīBünden.

Das Ahìtum verliert in Anatolien ab dem späten 14. Jh. an Bedeutung. ${ }^{305}$ Dabei spielten die vier folgenden Faktoren eine wichtige Rolle ${ }^{306}$ :

a. Es lassen sich zunehmend Fälle nachweisen, in denen der $A h \bar{\imath}$-Titel vom Vater an den Sohn vererbt wird. Der Neuling hat sich also nicht durch besondere Verdienste auszuweisen. Burğāzī lehnt diese Vererbbarkeit des $A h \bar{\imath}-$ Rangs ab. Wenn der Ahi-Rang erblich ist, wird persönliches Bestreben hinfällig. Dies läuft grundlegenden Prinzipien jeglichen FutuwwaVerständnisses entgegen.

b. Führende ahīs waren im Lauf der Zeit zu Vermögen gekommen. Dies war nicht mit der asketischen Grundeinstellung der Ahī-Bünde vereinbar. Die Anzahl der wirklich reichen ahis lässt sich allerdings kaum abschätzen. Nur im Fall von Ankara, Konya und Sivas lässt sich ihr Einfluss auf die Politik belegen.

c. Vieles spricht dafür, dass die $A h \bar{\imath}$-Bünde mit dem Erstarken der osmanischen Verwaltung an Bedeutung verloren. Zugleich ist allerdings festzuhalten, dass die Osmanen die lokalen Körperschaften zumeist anerkannten und kaum in ihre innern Angelegenheiten eingriffen. ${ }^{307}$

d. Letztlich könnte auch der zunehmende Einfluss der Derwischorden, allen voran der Mawlawiyya und der Bektāšiyya, den Bedeutungsschwund der Ahī-Bünde in Anatolien beschleunigt haben.

305 Vgl. Breebaart, Development $141 \mathrm{f}$.

306 Die folgende Zusammenstellung stützt sich auf Breebaart, Development 142 f. D.A. Breebaart hält allerdings fest, dass sie nur auf Faktoren aufmerksam machen kann, die in diesem Prozess möglicherweise eine Rolle spielten. Zur Klärung der eigentlichen Zusammenhänge wären weitere Studien erforderlich. 


\subsubsection{Das Zunftwesen}

Die $A h \bar{\imath}$-Bewegung verschwindet um die Mitte des 15. Jh. aus nicht wirklich geklärten Gründen. ${ }^{308}$ Die ahiss suchten vor dem Hintergrund der geänderten sozio-politischen Konstellationen einerseits Anschluss an Derwischgruppierungen, gerade auch an den Bektāšiyya-Orden. Ihre Tradition lebte anderseits im Zunftwesen weiter, das unter dem Begriff șinf ( $\mathrm{Pl}$. așnāf) bekannt ist. ${ }^{309}$ Gerade die Zunft der Gerber pflegte das Brauchtum der ahis in modifizierter Form weiter. ${ }^{310}$ In dieser Zunft spielte Ahī Nāṣir ed-Dīn Evran aus Kırşehir eine wichtige Rolle, wie sich anhand eines Lobgedichts Gülšehrīs aufzeigen lässt. ${ }^{311} \mathrm{Um}$ diesen Ahī Evran ranken sich zahlreiche Legenden.

Das Hauptwerk der türkischen Gilden hält den Stellenwert des $A h \bar{\imath}$-Brauchtums in den späteren Vereinigungen von Handwerkern fest. Es handelt sich um Seyyid Mehemmed b. Seyyid 'Alä' adDīn al-Husaynī r-Raḍawīs Futuvvet-nāme-i kabīr (verfasst 1524). ${ }^{312}$ Die weiteren Entwicklungen des Gildenwesens im Osmanischen Reich während des 16. und 17. Jh. werden hier nicht im Einzelnen untersucht. Für die vorliegenden Belange genügt eine Darstellung der Ausgangssituation. ${ }^{313}$

308 Vgl. Breebaart, Development 143; Taeschner, Zünfte und Bruderschaften 405-423, v. a. 405f.

309 Zum Zunftwesen im islamischen Orient besteht inzwischen eine umfassende Literatur, auf die im Lauf der weiteren Ausführungen noch einzugehen ist. Die folgende Darstellung stützt sich im wesentlichen aber erneut auf Taeschner, Gemeinschaftsbildende Idee 151156. Man beachte zusätzlich Breebaart, The Fütüvvetnāme-i kebīr. A manual on Turkish guilds; Kafadar, Yeniçeri-esnaf relations; Yi, Guild dynamics; Floor, Așnāf, in EIr.

310 Yildirim, Shī'itisation 57, mit weiteren Quellenhinweisen in Anm. 25.

311 Zu Ahī Evran siehe Taeschner, Gülschehris Mesnevi auf Akhi Evran. Siehe auch die weiteren Literaturhinweise bei Taeschner, Gemeinschaftsbildende Idee 150 (Anm. 1). Taeschner, Zünfte und Bruderschaften 407-417 und 424-549.
Für weiterführende Literatur zur Bedeutung der Handwerksgilden im Osmanischen Reich siehe Breebaart, Development, Kapitel 6: „The organisation, ritual and ethical ideals of the Turkish futūwah guilds“, $145^{-224}$.
Vieles spricht dafür, dass das Gewerbe im islamischen Orient anders organisiert war als im christlichen Abendland. In orientalischen Städten hatten sich einzelne Gewerbezweige in der Regel in einem bestimmten Viertel oder entlang einer Gasse niedergelassen, während sich diese örtliche Konzentration im Westen derart ausgeprägt kaum beobachten lässt. Es fehlen zwar Quellenangaben, die klare Hinweise auf die Organisation der Zünfte z.B. in Anatolien in der Vormoderne und ihren allfälligen Bezug zu den Futuwwa-Bünden enthalten. Erst verhältnismässig spät lassen sich eigentliche Zunftschriften nachweisen (frühestens im 9./15. Jh.). Zu jener Zeit entwickelte sich das Osmanische Reich von einer Grossmacht zur Weltmacht. Gildenartige Organisationsformen des Gewerbes und des Handwerks sind zwar auch aus andern Gebieten des islamischen Kulturraums, z.B. aus Iran oder Ägypten, bekannt. Da das Zunftwesen im Osmanischen Reich aber dank F. Taeschners Untersuchungen am besten erschlossen ist, stellen es die weiteren Ausführungen in erster Linie anhand von osmanisch-türkischen Quellen vor.

Trotz der soeben formulierten Vorbehalte lässt sich feststellen, dass es sich beim Zunftschrifttum letztlich um Futuwwa-Literatur handelt. Diese Schriften enthalten kaum Angaben zur ökonomischen Situation der einzelnen Gewerbezweige, sondern äussern sich im wesentlichen zu deren Funktionieren als Männerbünde. Diese Texte sind vielfach als Katechismen aufgebaut und stellen jene Fragen zusammen, die dem Lehrling bei seiner Aufnahme in eine bestimmte Handwerksgilde vorgelegt werden. Diese Kataloge drehen sich um das in der jeweiligen Gilde relevante Brauchtum. Es ist bereits bekannt, dass sich hauptsächlich Handwerker in den $A h \bar{\imath}$-Bünden organisiert hatten. Daraus lässt sich ableiten, dass auch in den Zünften Gedankengut und Brauchtum aus der Futuwwa - in oft modifizierter Form - überlebt hatte. Allerdings dürften unterschiedliche weitere Aspekte auf die Ausbildung der im Zunftwesen gepflegten Moralvorstellungen eingewirkt haben.

F. Taeschner betrachtet das Grosse Futuvvetnāme von Seyyid Mehemmed b. Seyyid 'Alā' ad- 
Dīn als zentrale Schrift des Zunftwesens. Der Text ist 931/1524 entstanden; sein genauer Titel lautet Miftāh ad-daqāì fì bayān al-futuwwa wa-lhaqā’iq. ${ }^{314}$ Seyyid Mehemmed beschreibt darin die Futuwwa-Vorstellungen der Zünfte bis ins Detail. Ihre Futuwwa-Tradition unterscheidet sich von jener der $A h \bar{\imath}$-Bünde insofern, als diese jüngeren Gruppierungen jetzt nicht mehr bloss drei (Ahi Bünde), sondern neun Grade kennen: Bei den ersten drei Graden handelt es sich um jene des nāzil, des nìm-țarīq und des meyān-beste. Es dürfte sich um die bei den Handwerkern bekannte Einteilung in Lehrling (terbiye oder čiraq), Geselle (kalfa) und Meister (usta) handeln, wobei diese Nomenklatur im Futuvvet-nāme fehlt. Bei den Graden 46 handelt es sich um jene, die im Ahītum jenen des naqīb (Zeremonienmeister) entsprechen, in den Zünften aber auf drei Untergrade verteilt sind (Grade 4-6: 4. bǐšrevǐs: Gehilfe des naqīb; 5. naqīb; 6. Ober-Naqīb: naqīb un-nuqabä). Die Grade 7-9 wiederum entsprechen jenem des Šayh bei den $a h i ̄ s$. Es lässt sich die folgende Unterteilung feststellen: 7. Stellvertreter (halīfa) des šayh (auch ahī genannt); 8. šayh und 9. Ober-Šayh (šayh aššuyūh). Das Futuvvet-nāme nimmt zugleich eine Einteilung in drei Klassen vor und unterscheidet sich damit vom Ahītum, das bloss zwei Klassen kennt. Es handelt sich um die Aufteilung in qawli, šürbi und seyf $\iota .315$

Aus den Schriften zur Zunft-Futuwwa geht überdies hervor, dass der Novize, hier jeweils nāzil genannt, nicht nur einen Meister, einen Wegvater (yol atası), wählt. Ihm stehen bei den wichtigen Etappen des Eintritts in den Bund vielmehr auch zwei Wegbrüder (yol kardeşleri) zur Seite, bei denen es sich um fortgeschrittene Lehrlinge handelt.

Bei der Durchsicht des Grossen Futuvvet-nāme fällt ausserdem auf, dass es häufig einen zwölferschiitischen Hintergrund aufweist. Da das Werk

314 Siehe Taeschner, Gemeinschaftsbildende Idee $15^{2} \mathrm{f}$. (mit präziseren Angaben in Anm. 1); siehe ausserdem Taeschner, Zünfte und Bruderschaften 407-417 und 424-55o (Zusammenfassung).

$315 \mathrm{Zu}$ dieser Dreiteilung vgl. bereits oben bei Anm. 253254. am Anfang des 16. Jh. entstanden ist, ist dies nicht weiter erstaunlich. Zu jener Zeit war die Zwölferschia gerade in Iran erstarkt und daran, unter den Safawiden zur Staatsreligion zu werden. Diese imamitischen Vorstellungen haben vor den Reichsgrenzen nicht Halt gemacht, sondern sind auch auf osmanisches Gebiet übergesprungen. Die als Qizilbāš bekannt gewordenen turkmenischen Anhänger der Safawiden hatten Šāh Ismāīls Auffassungen mit grosser Begeisterung aufgenommen und ihrem Vorsteher göttliche Verehrung entgegengebracht. Nachdem Selim I. Šāh Ismā̄îl I. 1514 in der Schlacht von Čāldirān eine schwere Niederlage zugefügt hatte, wurden die Qizilbāš auf osmanischem Gebiet zwar heftig verfolgt. Sie waren aber in Anatolien dennoch weiterhin aktiv. ${ }^{316}$

F. Taeschner weist zur Kontextualisierung der damaligen Entwicklungen ausserdem darauf hin, dass Bālim Sulțān dem Orden der Bektāšiyya am Anfang des 16. Jh. eine straffere Organisationsform verpasste. Die Bektāšiyya ist für ihre schia-nahen Vorstellungen bekannt. ${ }^{317} \mathrm{~F}$. Taeschner glaubt in Seyyid Mehemmeds Grossem Futuvvet-nāme Berührungspunkte mit der Bektāšiyya feststellen zu können.Jedenfalls finden sich unterschiedliche, terğümān genannte und bei den Feierlichkeiten der Zünfte rezitierten Sprüche einerseits bei Seyyid Mehemmed verzeichnet. Sie lassen sich anderseits zugleich im Kitāb Mir'āt ul-maqāṣid fì def' ilmefāsid nachweisen, das von Seyyid Ahmed Rif'at verfasst worden ist und Zeremonien der Bektāšiyya beschreibt. ${ }^{318}$ Aus diesen Beobachtungen lassen sich Berührungspunkte zwischen der ZunftFutuwwa und der Bektāšiyya ableiten.

316 Čāldiran liegt heute in der Provinz Van (Ost-Anatolien, Türkei). Zu dieser Schlacht siehe Kapitel 2.5 (bei Anm. 240 und 243f.). Gerade R. Yildirim würdigt diese Entwicklungen aber auch im Zusammenhang mit einer weitherum zu beobachtenden Loyalität gegenüber 'Alī und den Seinen; vgl. Kapitel 3.3: „Alid Loyalty“. Siehe zur Reorganisation des Derwischordens der Bektāšiyya unter Bālim Sulțān ausführlicher Mélikoff, Hadji Bektach. Un mythe et ses avatars 154-161.

318 Diese Hinweise aus Taeschner, Gemeinschaftsbildende Idee 153. Zu Seyyid Ahmed Rif'at und seinem Werk siehe auch Taeschner, Zünfte und Bruderschaften 414. 
Seyyid Mehemmeds Grosses Futuvvet-nāme ist nur in wenigen Handschriften erhalten geblieben. ${ }^{319}$ Allerdings lassen sich in zahllosen Bibliotheken kleinere Schriften nachweisen, die im Umfeld der Zünfte entstanden sind und bei denen es sich zumeist um Auszüge aus dem Grosssen Futuvvet-nāme handelt. Es lässt sich daraus schliessen, dass viele Zünfte anhand des Grossen Futuvvetnāme für sie selbst verbindliche Schriften zusammengestellt haben. Der schiitische Charakter der Vorlage tritt in diesen kleineren Traktaten allerdings oft in den Hintergrund. Dies lässt sich damit erklären, dass die Sunna nach Selims I. Sieg in Čāldirān im Osmanischen Reich die Oberhand über die Schia gewann. Diese Feststellung trifft zumindest auf die offizielle Religionspolitik zu. Die arabischen Futuwwa-Traktate, die H. Thorning seinen frühen Untersuchungen dieser Literatur zugrunde gelegt hatte, greifen ebenso auf Seyyid Mehemmeds Grosses Futuvvet-nāme zurück und sind zumeist als arabische Übersetzungen von Auszügen daraus aufgebaut. ${ }^{320}$

Seyyid Mehemmeds Grosses Futuvvet-nāme hält die meisten Aspekte des in den Zünften gepflegten Brauchtums fest. Es gibt im Umfeld der Zünfte allerdings auch Traditionen, die direkt auf das Ahītum zurückgehen. Diese Feststellung trifft auf die Zunft der Gerber und andere lederverarbeitende Berufsgattungen, z.B. die Sattler und Schuhmacher, zu. Sie brachten dem bereits zuvor erwähnten Ahī Evran, dem Ortsheiligen von Kırşehir in Anatolien, grosse Verehrung entgegen. Er soll selbst Gerber gewesen und danach als Vorsteher ( $p \bar{i} r$ ) der Gerberzunft verehrt worden sein. Die Zunft der Gerber stützt sich nicht auf Seyyid Mehemmeds Grosses Futuvvet-nāme, sondern greift auf Yahyyā b. Halīl al-Burgāāīs Futuvvet-nāme

319 Taeschner, Gemeinschaftsbildende Idee 154; siehe ausserdem Taeschner, Zünfte und Bruderschaften 407-417 und 424-549.

H. Thorning leistete einen wesentlichen Beitrag zur Erforschung der Futuwwa. Die Ergebnisse seiner Auseinandersetzungen sind veröffentlicht in Thorning, Beiträge zur Kenntnis des islamischen Vereinswesens: auf Grund von Bast Madad et-Taufiq. zurück, das bereits den Ahīs als Bundesschrift gedient hatte. ${ }^{321}$ Die meisten Handschriften dieses Texts aus dem Umfeld der Gerberzünfte sind allerdings um einen Nachtrag erweitert, der auf die neueren, jetzt aus Seyyid Mehemmeds Grossem Futuvvet-nāme bekannten, termini aufmerksam macht. F. Taeschner leitet aus dieser Beobachtung ab, dass die Übertragung der Vorstellungen aus Seyyid Mehemmeds Futuvvet-nāme auf das Ahī-Brauchtum im Umfeld der Gerber stattgefunden hat. Die Ahī-Tradition der Gerber beeinflusste aber zugleich auch andere Zünfte.

Diese Beeinflussung wurde durch die Organisation der Gerber begünstigt. Diese Zunft verfügte am Grab ihres Vorstehers Ahī Evran in Kurşehir über ein klares Zentrum. Hier befand sich auch eine Tekke, deren Vorsteher Ahī Bābā genannt wurde. ${ }^{322}$ Er wurde als Nachkomme Ahī Evrans angesehen und als Vorstand der Gerberzünfte im gesamten Osmanischen Reich verehrt. ${ }^{323}$ Diese Feststellung trifft jedenfalls auf den türkischen Teil des Reichs (Anatolien, Rumelien, Bosnien und die Krim) zu. Der Einfluss dieses Ahī Bābā reichte jedoch nicht bis in die arabischen Provinzen.

Für unsere Belange von Interesse ist, dass sich dieser Ahī Bābā oder einer seiner Vertreter auf den Weg in die Provinzen machte und dort die Lehrlinge durch ein Gürtungsritual (kuşak kuşatmasi: Gürtung mit einem Gürtel) in die Zunft aufnahm. Da die Kandidaten für dieses Ritual auch Gebühren entrichten mussten, kam gerade die Zunft der Gerber zu einem gewissen Vermögen. Es gelang den Ahī Bābās sogar, sich zusätzlich das Privileg der Gürtung in anderen Zünften zu sichern. Damit stieg natürlich auch ihre Machtstellung unter den Handwerkern im Osmanischen Reich. Diese Ent-

\footnotetext{
321 Taeschner, Gemeinschaftsbildende Idee 154.

322 Zur Tekke der Gerberzunft in Kırşehir siehe den knappen Hinweis bei Taeschner, Legendenbildung um Achi Evran; beachte darin S. 61 (Anm. 2), wo Verweis auf Gordlevskij, Les derviches tourneurs de l'ordre d'Akhi Evran; französisches Referat dazu von Vajda, Les corps de métiers en Turquie; Taeschner, Gülschehris Mesnevi auf Achi Evran 1. 
wicklung führte dazu, dass Ahī Evran zum pīr des gesamten osmanischen Zunftwesens aufstieg.

Unter diesen weiteren Zünften ist vielleicht auf jene der Barbiere besonders hinzuweisen, bei deren Vorsteher es sich um Salmān al-Fārisī (gest. angeblich $35 / 655$ oder $36 / 656$ ) handelt. ${ }^{324}$ Dieser Salmān-i Fārisī, ebenso als Salmān-i Pāk bekannt, nimmt neben 'Alī b. Abī Ṭālib einen zentralen Platz in den Zünften ein. Er zählte zu den persönlichen Freunden des Propheten und war sein Barbier. Auf diesen Salmān gehen die meisten Gewährsketten (silsila) der Futuwwa-Leute zurück. Seine Grabstätte liegt bei Ktesiphon (al-Madāin) und wird von den Schiiten gern besucht. ${ }^{325}$

Salmān al-Fārisī soll die Gürtung an 55 Zunftpatronen vorgenommen haben. ${ }^{326}$ Diese Gürtungen (šadd) durch Salmān haben allerdings eine längere Vorgeschichte. Demnach soll der Erzengel Gabriel Muhammad bei dessen Himmelfahrt (mi'rāğ) gegürtet haben. Als Muhammad später seine Abschiedswallfahrt unternahm, soll er seinerseits beim Ort Gadīr Humm die Gürtung an 'Alī b. Abī Ṭālib vorgenommen haben. Er soll dabei denselben Gürtel benutzt haben, mit dem er anlässlich seiner Himmelfahrt von Gabriel gegürtet worden ist. Alī band darauf die Lenden von insgesamt 17 Zunfpatronen, die bei F. Taeschner zusammen mit ihren Tätigkeiten namentlich erwähnt werden. ${ }^{327}$ 'Alī band als erstes die Lenden Salmān al-Fārisīs. 'Alī forderte Salmān darauf auf,

324 Vgl. zu ihm Levi Della Vida, Salmān al-Fārisī, in $E I^{2}$.

325 Salmān ist ausserdem eine wichtige Gewährsperson in den silsilas vieler Sufi-Orden. In der Gulät-Schia nimmt er in der Abfolge der göttlichen Emanationen den zweiten Platz direkt hinter 'Alī ein. Bei den Nuṣayriern gilt er als drittes Glied jener Trinität, die durch die Buchstabenfolge 'ayn-mim-sin dargestellt wird ('ayn für 'Alī; mìm für Muhammad; sinn für Salmān); Salmān stellt in dieser Trinität das Tor $(b \bar{a} b)$ dar. Salmān soll ausserordentlich alt geworden sein (200, 300, 350 oder sogar 553 Jahre; vgl. vorangehende Anm.).

Die folgenden Ausführungen stützen sich auf Taeschner, Zünfte und Bruderschaften 432-444, der sich seinerseits auf 'Alā' ud-Dīns (auch Seyyid Meḥemmed b. es-Seyyid 'Alā' ad-Dīn al-Ḥuseynī r-Raḍawīs) Grosses Futuvvet-nāme beruft. seinerseits 55 Zunftpatrone zu gürten. F. Taeschner stellte auch die Namen dieser 55 Zunftpatrone und ihre Tätigkeiten zusammen. ${ }^{328}$

Die Zünfte waren für die osmanischen Sultane ausserdem von Bedeutung, da sie sie für Versorgungsaufgaben im Kriegsfall heranzogen. ${ }^{329}$ Die Zünfte waren verpflichtet, dem Heer einerseits die benötigten Waren zu liefern. Sie wurden anderseits auch zur Rekrutierung zusätzlicher Soldaten herangezogen. Es gab überdies Zünfte, die direkt zur Heeresfolge verpflichtet waren. Das Zunftwesen stellte in der frühen Zeit für das Osmanische Reich auch die einzige Möglichkeit dar, das Bürgertum zu erfassen. ${ }^{330}$ Bei Evliyā Čelebī finden sich Beschreibungen von gelegentlichen Aufzügen der Zünfte unter Murād IV. im Jahr $1048 / 1638 .^{331}$

Es versteht sich von selbst, dass sich die 'ulamä' wiederholt an diesen Verhältnissen im Umfeld der Zünfte störten. Sie nahmen einerseits Anstoss an den schiitischen Vorstellungen, die gerade in Seyyid Mehemmeds Grossem Futuvvet-nāme zum Ausdruck kamen. Ausserdem war ihnen der Kult ein Dorn im Auge, der sich unter den Gerbern um die Person von Ahī Evran entwickelt hatte. Es ist u. a. Münīrī (Ibrāhīm b. Iskender) Belg̀rādī, der dieses Missbehagen der traditionalistisch orientierten Gelehrten in einem Werk mit dem Titel Nișāb ul-intisāb wa-ādāb ul-iktisāb thematisierte. Er beleuchtet in dieser Schrift das Handwerker-

\footnotetext{
328 Taeschner, op. cit. 441-445.

329 Vgl. zu dieser Funktion der Zünfte bzw. Gilden Kafadar, Yeniçeri Esnaf relations 65: „In a practice that can be dated as far back as the fourteenth century, and that was interestingly discontinued after the destruction of the Yeniçeris in 1826, the government required a number of guilds to send their members to military campaigns." Beachte auch Yi, Guild dynamics 132-16o und 192, auch über die engen Beziehungen der Gilden zu den Janitscharen. Verdeutlichungen bei Taeschner, Gemeinschaftsbildende Idee 157.

Taeschner, Gemeinschaftsbildende Idee 155 (Anm. 3), macht aufmerksam auf Evliyā Čelebi, Seyāhatnāme I, $506 \mathrm{ff}$. (Istanbul 1314 h.q.) und die Übersetzung dazu von Hammer-Purgstall, Narrative of travels I.2, $104 \mathrm{ff}$.
} 
tum aus einer in seinen Augen korrekten sunnitischen Perspektive. ${ }^{332}$ Es ist allerdings mehr als fraglich, ob seine Kritik ihre Adressaten überhaupt erreichte. Gewiss ist jedenfalls, dass sie kaum fruchtete.

Für unsere Belange ist die Feststellung relevant, dass das Zunftwesen auch in den europäischen Provinzen des Osmanischen Reichs, u.a. in Bosnien, an den soeben skizzierten Entwicklungen teilhatte. ${ }^{333}$ Seyyid Mehemmeds Grosses Futuvvet-nāme war aber, wie bereits angetönt, auch im arabischen Teil des Osmanenstaats als massgebliche Grundschrift der Zünfte bekannt. Auch die dortigen Handwerksgilden stellten sich anhand dieses Texts Auszüge zusammen, die auf ihre jeweiligen Bedürfnisse abgestimmt waren. H. Thorning hat sich in seiner Darstellung des islamischen Vereinswesens auf dieses Textmaterial gestützt. ${ }^{334}$

Vielfach wird in der Literatur auch auf eine Darstellung des Zunftwesens in Damaskus verwiesen, die 1883 von Elia Qoudsi vorgelegt worden ist. ${ }^{335}$ Gemäss F. Taeschners Einschätzung stimmte das Zunftwesen in Damaskus damals noch weitgehend mit den Darstellungen in den früheren osmanischen Quellen überein. ${ }^{336}$ Es zeigt sich allerdings, dass es im islamischen Orient im Lauf des 19. Jh. an Bedeutung verliert. Es leidet unter dem Import industriell produzierter Güter aus Europa und wird sozusagen von innen ausgehöhlt. Das Zunftwesen wurde im Osmanischen Reich unter dem Einfluss der Jungtürken abgeschafft (Gesetz

332 Zu Münīrī vgl. die kurze Bemerkung bei Taeschner, Zünfte und Bruderschafte $417 \mathrm{f}$.

333 Taeschner, Gemeinschaftsbildende Idee 156 (mit zusätzlichen Literaturangaben in Anm. 2).

334 Thorning, Beiträge zur Kenntnis des islamischen Vereinswesens.

335 Taeschner, Gemeinschaftsbildende Idee ${ }_{15} 6$ (mit Anm. 4); Notice sur les corporations de Damas; ders., Zünfte und Bruderschaften 557-59o. Deutsche Übersetzung von O. Rescher als Anhang II („Über die Zünfte in Damaskus“), in Die „Nawādir“ 280-309.

336 Taeschner, Gemeinschaftsbildende Idee 156. Siehe ausserdem Taeschner, Zünfte und Bruderschaften 557-59o. vom 13. Februar 1325/26. Februar 1910). Im Jahr 1943 wurden in der Türkei die Handelskammern eingeführt. ${ }^{337}$

\subsection{Alid loyalty oder die Schiitisierung der Futuwwa-Bewegung}

Die Forschung hat wiederholt darauf hingewiesen, dass die 'Alī-Verehrung in der islamischen Welt im 14. und 15. Jh. an Gewicht gewann. Diese Entwicklung war mit einer Stärkung schiitischer Positionen verbunden. Gerade im 14. Jh. kam es in diesem Kontext zu einem Schulterschluss zwischen Sunniten und Schiiten. Dieser äussert sich wiederholt in einer gleichzeitigen Verehrung von Personen, die grundsätzlich der Sunna bzw. der Schia zuzuordnen sind. M.G.S. Hodgson machte darauf aufmerksam, dass das 14. und 15. Jh. durch ein auffälliges Erstarken der Verehrung 'Alīs und der Seinen (ahl al-bayt) auch ausserhalb der Schia selbst verpflichteter Kreise gekennzeichnet waren. Er spricht von einer bemerkenswerten Verbreitung einer 'Alid loyalty. Sie lasse sich gerade auch in Derwischorden feststellen. ${ }^{338}$

Dieses Nebeneinander ist aber auch ein Charakteristikum von Futuwwa- und Ahī-Bünden. Es lässt sich auf ausgewählten Dokumenten in Rollenform beobachten; dies trifft gerade auf Is 1624 aus der Chester Beatty Library zu (datiert 1362 und 1366; vgl. Kapitel 4.6). Auf weiteren Belegstücken wird 'Alī speziell hervorgehoben (vgl. Kapitel 4.8: Rolle aus Basel). Die weiteren Ausführungen machen gestützt auf einen Aufsatz R. Yildirims auf diese Entwicklungen im Umfeld der Futuwwa-Bünde aufmerksam und tragen indirekt zur Einordnung einzelner Dokumente in Rollenform bei. ${ }^{339}$ Wiederholungen von bereits bekann-

\footnotetext{
337 Taeschner, Gemeinschaftsbildende Idee $157 \mathrm{f}$.

338 Hodgson, Venture of Islam II, 186, 203-204, 214-216, 463 $465,466,470$.

339

Yildirim, Shı̄'itisation. Es wird auch auf die beiden folgenden Untersuchungen R. Yildirims hingewiesen: 1. Turkomans between two Empires; 2. Anadolu'da İslâmiyet.
} 
ten Elementen liessen sich in der folgenden Darstellung nicht vermeiden. Die weiteren Ausführungen beleuchten die bereits bekannten Zusammenhänge allerdings aus einem andern Blickwinkel.

Bei den in der Sunna besonders verehrten Personen handelt es sich neben dem Propheten Muhammad um die drei ersten rechtgeleiteten Kalifen Abū Bakr, 'Umar und 'Uțmān. Für die Schia wiederum sind die drei ersten Imame ('Alī b. Abī Ṭālib ${ }^{340}$, Hasan, Ḥusayn) und oft auch der 6. Imam, Ǧa'far aṣ-Ṣādiq, von besonderer Bedeutung. Die Schiiten waren am Anfang des Islams nichts anderes als die Parteigänger 'Alīs (vgl. šî́at 'Alī: die Partei 'Alīs). Die Sunniten hingegen übergingen nach dem unerwarteten Tod des Propheten die Ansprüche der Schiiten und brachten nacheinander Abū Bakr, 'Umar und 'Uțmān an die Macht. 'Alī wurde erst nach 'Uțmāns Tod (656) vierter Kalif (reg. 656$661)$.

Dieser gerade im 14. Jh. zu beobachtende Schulterschluss lässt sich als Versuch verstehen, die Muslime wieder zu einen. Er stellte implizit auch die einzige Möglichkeit dar, die islamische Welt nach dem Einfall der Mongolen und dem Fall Bagdads (1258) im Kampf gegen den gemeinsamen äusseren Feind zu verteidigen. Es stellt ein anderes Problem dar, dass diese Verteidigung nicht immer erfolgreich war. L. Ridgeon zeigte auf, dass 'Alī b. Abī Țālibs Stellung unter der Herrschaft der Mongolen (Īlhāniden) an Bedeutung gewann. Denn mit dem Untergang der sunnitisch ausgerichteten Dynastie der Abbasiden fand auch die Unterdrückung der Schiiten durch die Sunniten ein Ende. ${ }^{341}$

R. Yildirim ist der 'Alī-Verehrung in FutuwwaKreisen nachgegangen. Er bemängelt, dass die bisherige Forschung zu den Futuwwa-Bünden ihren

340 'Alī b. Abī Ṭālib kommt eine Doppelstellung zu: Er ist aus schiitischer Perspektive erster Imam. Die Sunniten verehren ihn dagegen als vierten rechtgeleiteten Kalifen.

341 Ridgeon, Morals and mysticism 75f.; vgl. den Hinweis bei Yildirim, Shīitisation 57 (mit Anm. 24). oft stark schiitisch geprägten Auffassungen nicht die gebührende Aufmerksamkeit geschenkt habe. Er beobachtet eine zunehmende Schiitisierung (shīitisation) der Futuwwa zwischen dem 11. und dem frühen 16. Jh. Sie erreiche im 15. Jh. einen Höhepunkt. Die bisherige Forschung habe die Futuwwa-Bewegungen dem sunnitischen Islam zugewiesen, jeweils aber schiitische Einschläge anerkannt. Diese Sichtweise schenke jedoch den Entwicklungen im 15. und 16. Jh. mit ihrer klar schiitisch geprägten Futuwwa-Literatur zu wenig Aufmerksamkeit und tue sie vorschnell als Resultat safawidischer Propaganda ab. R. Yildirim versteht die Schiitisierung der Futuwwa-Tradition im 15. Jh. nicht als Resultat safawidischer Propaganda, sondern erkennt darin den Ausdruck einer breiteren Entwicklung in der islamischen Welt („Islamdom") jener Zeit.

R.Yildirim akzeptiert die grundsätzlich religiöse Ausrichtung der Futuwwa-Bewegung. Er spricht sich aber für ihre Situierung in der innerislamischen Entwicklung aus. Er fasst den Forschungsstand dahingehend zusammen, dass die Initiationslinie der Futuwwwa auf 'Alī b. Abī Ṭālib zurückgehe. Diese Linie dominiere auch die mythologisch geprägten Berichte und Erzählungen, die in den Futuwwa-Gruppierungen im Umlauf seien. Diese philo-'alidische Haltung gehe allerdings nicht über jene Auffassungen hinaus, die in der Sunna noch allgemein akzeptiert würden. Zugleich liessen sich aber historisch abgestützte Berichte über Gruppierungen von fityān mit klar schiitischer Haltung belegen. Die Grundüberzeugungen der Futuwwa liessen sich jedoch weder ausschliesslich der Sunna noch der Schia zuordnen. ${ }^{342}$ Dies treffe sowohl auf Nāṣirs höfische Futuwwa als auch auf die Ahi-Futuwwa zu. Die im späten 15. und frühen 16. Jh. entstandenen Futuwwat-nāmas würden allerdings einen klar schiitischen Charakter aufweisen. Für R. Yildirim sind F. Taeschners oder Cl. Cahens Versuche nicht

342 Yildirim, Shī'itisation 53 f., mit umfassenden Literaturhinweisen in Anm. 2. 
überzeugend, dies mit der safawidischen Propaganda und als vorübergehende Abweichung zu erklären.

F. Taeschner zeigt diese schiitische Ausrichtung der Futuwwa-Ideologie anhand von 'Alā' ad-Dīn arRaḍawīs Futuvvet-nāme-i kebìr aus dem Jahr 1524 auf. ${ }^{343}$ Er macht zugleich auf Balim Sulțān aufmerksam, der die Bektāšiyya am Anfang des 16. Jh. straffer organisierte. F. Taeschner ordnet die Bektāšiyya deshalb der Schia zu, was R. Yildirim mit Blick auf unseren bescheidenen Kenntnisstand kritisiert. Wir wüssten schlicht zu wenig über allfällige Bezüge der Bektāšiyya zur QizilbāšBewegung und deren schiitische Ausrichtung im frühen 16. Jh. Gemäss F. Taeschner hat die Futuwwa im frühen 16. Jh. zwischen der Sunna (Osmanen) und der Schia (Safawiden) laviert. Nach dem Sieg der Osmanen (Čāldirān, 1514) sei die Futuwwa im Osmanischen Reich allerdings zu ihren sunnitischen Wurzeln zurückgekehrt. ${ }^{344}$

R. Yildirim gesteht zwar ein, dass F. Taeschner die soeben vorgestellten Aussagen bloss im Vorbeigehen gemacht habe. Für ihn sind diese Einschätzungen oder jene A. Gölpınarlıs und L. Ridgeons aber doch vorschnell. R. Yildirim betont, dass innerhalb der Futuwwa im Lauf der Zeit divergierende Standpunkte vertreten wurden. Das 15. Jh. stelle eine Zeit des Umbruchs dar, der mit einer klaren Schiitisierung verbunden gewesen sei. Er verdeutlicht seinen Standpunkt, indem er auf die Ausrichtung der Futuwwa unter a. an-Nāșir (höfische Futuwwa) einerseits und b. der Ahì-Futuwwa anderseits eingeht:

a. Unsere Kenntnisse der religiös-dogmatischen Ausrichtung der Futuwwa vor Nāṣirs (reg. 118o1225) Reform sind bescheiden. Erst mit den Reformbestrebungen des Kalifen wird die FutuwwaBewegung historisch klar greifbar. Nāṣir reformierte die Futuwwa mit dem Ziel, den sozialen

343 Vgl. Taeschner, Zünfte und Bruderschaften 407-417 und 424-549; siehe zu diesem Text bereits oben Kapitel 3.2 bei Anm. 312 f. und $319 f$.

344 Vgl. Yildirim, op. cit. 54, der ausserdem auf Auffassungen A. Gölpınarlıs und L. Ridgeons zu ähnlichen Fragestellungen aufmerksam macht.
Zusammenhalt in der islamischen Welt zu stärken. ${ }^{345}$ Nāșirs Aufnahme in die Futuwwa und seine Rolle als deren Vorsteher stellen eine radikale Neuorientierung dieser Organisation dar. Sie war damit verbunden, dass Nāṣir eine neue, auf 'Alī b. Abī Ṭālib zurückgehende Initiationslinie propagierte. ${ }^{346}$

Das bekannte Reform-Edikt des Kalifen aus dem Jahr 604/1207 betont die zentrale Stellung 'Alīs. ${ }^{347}$ Es hält bereits am Anfang fest, dass 'Alī b. Abī Tālib das Wesen, den Ursprung und die Quelle der futuwwa darstelle. 'Alī habe die Regeln der futuwwa festgelegt. Wer in die Futuwwa aufgenommen werde, verpflichte sich letztlich gegenüber ihm. 'Alī habe die Futuwwa-Tugenden in ihrer reinsten Form vorgelebt. Jeder fatā ist somit verpflichtet, seinem Beispiel nachzueifern. Es bestehen allerdings Hinweise, dass 'Alī bereits zuvor eine wichtige Rolle in der Futuwwa spielte. Entsprechende Angaben finden sich bei Maybudī, der den Korankommentar Kašf ul-asrār wa 'uddat ul$a b r a \bar{r}$ verfasst hatte (beendet 520/1126). Auch in Qāni'î Țūsīs Kalīla wa Dimna (verfasst Mitte 12. Jh.) finden sich Hinweise, dass 'Alī als Schutzherr der Futuwwa verehrt wurde. ${ }^{348}$ M.J. Mahjub ist überdies auf Hinweise gestossen, dass einzelne Futuwwa-Vorsteher Propaganda zugunsten der Fatimiden betrieben. ${ }^{349}$ Allerdings lässt sich ebenso feststellen, dass in den Futuwwa-Schriften

345 Cahen, The formation of Turkey 117; zitiert bei Yildirim, Shīitisation 55 (Anm. 9).

346 Vgl. Ohlander, Sufism in an age of transition 272; mit Hinweis bei Yildirim, Shī'itisation 55 (Anm. 10).

347 Zu Nāșirs Edikt zur Reform der Futuwwwa aus dem Jahr 1207 siehe Taeschner, Zünfte und Bruderschaften 73-78.

348 Vgl. die Hinweise bei Yildirim, Shī'itisation 55 (Anm. 12), auf Mahjub, Chivalry 554-556.

349 Mahjub, Chivalry $578 \mathrm{f}$. Es gab auch sunnitisch ausgerichtete Kämpfergruppen, wie sich Ibn Ğubayrs (gest. 614/1217) Reisebericht entnehmen lässt. Demnach soll eine Futuwwa-Korporation in Damaskus gegen ismailitische Kämpfer vorgegangen sein. Die Mitglieder dieses Bundes hätten sich selbst der sunna zugeordnet; vgl. Taeschner, Gemeinschaftsbildende Idee 132 (mit Anm. 1), wo Verweis auf Ibn Jubayr, The travels of Ibn Jubayr 280.10 ff. (1907). 
Sulamīs und Qušayrīs Hinweise auf eine besondere Stellung 'Alīs noch fehlen. ${ }^{350}$

Nāṣir li-Dīn Allāh verfolgte in seiner Reform der Futuwwa-Bewegung in erster Linie imperiale Ziele. Er stärkte einerseits seine Autorität als Kalif. Er unterstützte anderseits aber auch ökumenische Bestrebungen. Diese zielten darauf $a b$, die Spannungen zwischen Sunna und Schia zu entschärfen, die sich über mehrere Jahrhunderte sowohl auf dogmatischer als auch politischer Ebene bemerkbar gemacht hatten. Nāṣir war bestrebt, die 'abbasidischen und 'alidischen Ambitionen in seiner Person zu vereinen. ${ }^{351}$ Er zeigte sich deshalb gegenüber moderaten Positionen der Zwölfer-Schia offen. Die spezifischen Zielsetzungen Nāṣirs sind zwar nicht bis ins letzte Detail geklärt. Allerdings gewinnt 'Alī b. Abī Țālib durch seine Massnahmen in der Futuwwa an Bedeutung. Trotz dieser schiitischen Einschläge kann Nāșirs Futuwwa aber nicht als schiitisch taxiert werden. Die deutlich wahrnehmbare schiitische Ausrichtung der Futuwwa bot schiitischen Kreisen jedoch ein sicheres Umfeld, um ihre Auffassungen innerhalb eines eigentlich sunnitischen Umfelds geltend zu machen. ${ }^{352}$

Die von Nāșir geschaffene höfische Futuwwa verlor ihre Bedeutung im Nachgang des Mongolensturms und dem Untergang der Abbasiden rasch. Jetzt beginnt die nächste Phase der FutuwwaBewegung, die von nun an vor allem in Anatolien und den angrenzenden Regionen vertreten war. Die Futuwwa-Tradition wird hier in den $A h \bar{l}-$ Bünden weitergepflegt, in denen sich Handwerker und Gewerbetreibende zusammenschlossen. Diese neue Struktur der Anhängerschaft zeigt, dass die Futuwwa-Bewegung ihren höfischen Hintergrund und ihre Ausrichtung auf die Person des Kalifen eingebüsst hatte. Die $A h \bar{\imath}$-Bünde sind letzt-

$35^{\circ}$ Yildirim, Shīititisation 56 (Anm. 16); Suhrawardī allerdings betont die Vorrangstellung 'Alīs in der Futuwwa.

351 Yildirim, Shı̄'itisation 56, mit Verdeutlichungen und weiteren Quellenhinweisen in Anm. 19.

$35^{2}$ Yildirim, Shı̄itisation 56, mit Verdeutlichungen und weiteren Quellenhinweisen in Anm. 20-22. lich halb-religiöse Vereinigungen, die sich ähnlich wie Derwischorden organisiert hatten.

b. Die Informationen über die Ahi-Futuwwa lassen sich einigen wichtigen Quellen entnehmen, die teilweise schon vorgestellt worden sind. Dazu gehört einerseits Nāṣirīs 689/129o auf Persisch verfasstes Futuwwat-nāma, anderseits das türkische Futuvvet-nāme des Yahyā b. Halīl al-Burgàāzī. 353 Zusätzlich ist auf die Darstellungen des maghrebinischen Weltreisenden Ibn Bațtūṭa (703-770 oder 779/1304-1368 oder 1377) zu verweisen. R. Yildirim erkennt in den iğāzat-nāmas weitere wichtige Quellen; sie bestätigen ihrem Inhaber die Vollmitgliedschaft im Ahī-Bund. ${ }^{354}$ Erwähnung verdienen ausserdem die $A h \bar{\imath}$-Stammbäume (šă̌ara). ${ }^{355}$

R. Yildirim befragt die angeführten Quellen auf Hinweise auf eine besondere Stellung 'Alīs und der Seinen. Die erwähnten Zeugnisse lassen es in seinen Augen nicht zu, die Ahī-Bünde der Schia zuzuordnen. Die Verehrung 'Alīs gibt diesen Bünden zwar ein schiitisches Gepräge. Allerdings betrachten sich die ahīs selbst als Sunniten. Ibn Bațțūta nennt die Ahīs Hanafiten. Sie sind somit Sunniten. ${ }^{356}$ Auch weitere Quellen gestatten es nicht, die Ahī-Bünde der Schia zuzuordnen. ${ }^{357}$

Die beiden Futuwwa-Bücher Nāṣirīs und Burğāzīs lassen sich gut mit Ibn Bațūțas Beschreibungen in Übereinstimmung bringen. Nāṣirīs Futuwwatnāma jedenfalls weist sozusagen keine schiitischen Einflüsse auf, weder solche aus dem Umfeld der moderaten Zwölferschia noch solche aus der Rāfidiiyya. ${ }^{358}$ Auch Nāṣinī hält wiederholt fest, dass

353 Quellenangaben bei Yildirim, Shīitisation 57 (Anm. 26-28). Zu Nāșirī vgl. Taeschner, Der anatolische Dichter Nāṣirī 1-4 und 5-80, mit Textausgabe; ders., Zünfte und Bruderschaften 307-313 und 394-401. Zu Burgāāī siehe Taeschner, Zünfte und Bruderschaften 302-307 und 319-393.

Eine iǧ $\bar{a} z a$ berechtigt ihren Inhaber, selbst neue Mitglieder auszubilden und in den Bund aufzunehmen. Yildirim, Shīitisation 57.

356 Yildirim, Shīitisation 57, verweist auf Ibn Bațțūta, Riḥla 283-284 (Ausgabe: Bayrūt, 140o/198o); auch II, 256 (Ausgabe Defrémery und Sanguinetti).

357 Vgl. für die Einzelheiten Yildirim, Shīitisation $57 \mathrm{f}$.

$35^{8}$ Zum Begriff rāfị̂a siehe Kohlberg, The term 'Rāfiḍa'. 
'Alī der ideale fatā sei und stellt ihn als Vorsteher der Futuwwa-Bewegung vor. Die FutuwwaQualitäten wurden über die vorislamischen Propheten an Muhammad und von diesem an 'Alī übermittelt. Nāṣirī betont die engen Bande zwischen Muhammad und 'Alī. Sie kommen auch darin zum Ausdruck, dass Muhammad seine Lieblingstochter Fāțima 'Alī zur Frau gab. Es ist für Futuwwa-Werke allerdings bezeichnend, dass sie trotz dieser philo-'alidischen Einstellung auch Abū Bakr, 'Umar und 'Utmān in einem positiven Licht darstellen. Diese Auffassungen lassen sich ebenso bei Nāșirī feststellen. ${ }^{359}$

Burgāāì vertritt im Futuvvet-nāme (entstanden um die Mitte des 8./14. Jh.) weitgehend dieselben Standpunkte wie Nāṣirī. ${ }^{360}$ Auch Burgāāī hebt die Bedeutung der 'Alī-Verehrung hervor. Bei ihm lässt sich aber auch eine besondere Wertschätzung für Abū Bakr nachweisen. Burğāzī geht so weit, im spirituellen Stammbaum zwischen Muhammad und 'Alī die drei rechtgeleiteten Kalifen Abū Bakr, 'Umar und 'Uțmān einzufügen. ${ }^{361}$ Diese zuletzt

359 Yildirim, Shīitisation 58, mit Quellenverweisen in Anm. 35-38.

36o Burgāāīs Text enthält verschiedentlich Stellen, die eine Verehrung von 'Alī b. Abī Tālib zum Ausdruck bringen. Der Verfasser hält den ahī dazu an, nach dem Essen Gebete auf 'Alī, Hasan und Husayn, also die drei ersten schiitischen Imāme, zu rezitieren. Sowohl F. Taeschner als auch A. Gölpinarli weisen allerdings darauf hin, dass Burḡāzī ebenso die Namen der drei ersten rechtgeleiteten Kalifen, also von Abū Bakr, 'Umar und 'Utmān, aufführt und dem yiğit empfiehlt, deren Beispiel zu folgen. Burgāāì hält ausserdem fest, dass Muḥammad die futuwwa an Abū Bakr und nicht etwa an 'Alī b. Abī Țālib weitergegeben habe. Auch Breebaart, Development 135 (Anm. 42), kommt bei der Gegenüberstellung von Burgāāzīs Text mit Seyyid Mehemmeds klar schiitischen Vorstellungen verpflichtetem Futuvvet-nāme- $i$ kebìr zum Schluss, dass Burgāāīs Text in einem grundsätzlich sunnitischen Umfeld entstanden sein muss. Vgl. Taeschner, Zünfte und Bruderschaften 409: „So ist es nicht verwunderlich, wenn das Grosse Fütüvvetnāme des [Seyyid Mehemmed] Ibn 'Alā' ud-Dīn [...] unzweideutig schiitische Einstellung zeigt."

$3^{61}$ Yildirim, Shīitisation $5^{8}$ (Anm. 43), mit Hinweis auf Burgāzī, Futuvvet-nāme 147, herausgegeben von Gölpınarlı, Burgâzî ve 'Fütüvvet-Nâme'si', in İstanbul Üni- angeführten Berichte dürften durch Burgaāzī selbst eingeführte Neuerungen darstellen. Jedenfalls lassen sich in der früheren Futuwwa-Literatur keine Parallelen dazu feststellen. Es könnte allerdings auch sein, dass diese stark sunnitisch geprägten Zusätze von einem Kopisten eingefügt worden sind. Das älteste bekannte Manuskript von Burgāzīs Text datiert aus dem Jahr 913/1507-1508 und stammt somit aus einer Zeit, als die schiitischen Safawiden die sunnitischen Osmanen ernsthaft bedrohten. ${ }^{362}$ Wichtig ist auch, dass sich Burgāzī auffällig häufig für 'Alīs Nachkommen interessiert. ${ }^{363}$ Der Text erwähnt die beiden Söhne 'Alīs, Hasan und Husayn, ebenso wie Zayn al-Ābidīn, Husayns Sohn, wiederholt als prominente Mitglieder der Futuwwa-Bewegung. ${ }^{364}$

Auch weitere Quellen aus dieser Zeit betonen die Bedeutung, die der Verehrung der Familie des Propheten (ahl al-bayt) im Rahmen von Initiationszeremonien zukommt. Dazu gehört einerseits Nağm ad-Dīn Zarkūbs Futuwwat-nāma, das wohl im 14. Jh. verfasst worden ist. ${ }^{365}$ In dieselbe Richtung weist anderseits ein anonymes Futuwwatnāma aus der zweiten Hälfte des 13. Jh. Allerdings lässt sich anhand dieser Texte allein keine Schiitisierung der Futuwwa-Bewegung im 13. Jh. belegen. Denn bereits Ibn al-Mi'mārs früher entstandenes Futuwwat-nāma greift Überlieferungen auf, die auf Ğaffar aṣ-Ṣādiq (6. Imām, gest. 765) und Zayn al'Ābidīn (4. Imām, gest. 94/712 oder 95/713) zurückgehen. ${ }^{366}$

R. Yildirim hebt hervor, dass sich dieser allgemeine Trend der Verehrung der Ahl al-bayt auch anhand von bis anhin wenig benutzten weiteren

versitesi İktisat Fakültesi Mecmuası 15.1-4 (Ekim 1953Temmuz 1954) 76-151.

362 Yildirim, Shī'itisation 58 (unten).

363 Für die weiteren Ausführungen vgl. Yildirim, Shīcitisation 59 .

364 Yildirim, Shī'itisation 59, verweist auf Burḡāzī, Futuvvet nāme 143 (Anm. 44).

365 Zu Nağm ad-Dīn Zarkūb und seinem Futuwwat-nāma vgl. Ohlander, The Futuwwat-nāma of Najm al-Dīn Zarkūb of Tabriz.

366 Yildirim, Shīitisation 59 (mit Anm. 46), mit Verweis auf Taeschner, Zünfte und Bruderschaften, 106 und 169. 
Quellengattungen aus dem Umfeld der Ah̆i-Bünde aufzeigen lässt. Es sind dies die bereits erwähnten Šă̌ara-Dokumente und die iğāzat-nāmas. In dieselbe Richtung weisen überdies die hier zu untersuchenden Dokumente der Andacht in Rollenform. Die Ahl al-bayt und die zwölf Imame gewinnen im Umfeld der Ahi-Bünde an Gewicht. In dieser Hinsicht lässt sich eine deutliche Veränderung gegenüber der Situation in Nāșirs höfischer Futuwwa feststellen. ${ }^{367}$

Aus der šağara des Ahī Šaraf ad-Dīn aus Ankara (gest. 1351) spricht gemäss R. Yildirim eine philo'alidische Grundhaltung. Das Dokument erwähne am Anfang zwar die Namen der drei ersten rechtgeleiteten Kalifen, weise danach aber auch 'Alī einen wichtigen Platz zu. Ausserdem preise es die zwölf Imame. Die Angehörigen von Ahī Šaraf ad-Dīns Familie würden sich aber dennoch nicht als Schiiten verstehen. ${ }^{368}$ Das Dokument ist auch insofern interessant, als sich darin spirituelle und genealogische Abstammung, silsila und nasab, vereinigen. Ahī Šaraf ad-Dīn soll seine spirituelle Qualitäten von 'Alī geerbt haben (silsila). Diese spirituelle Abhängigkeit geht einher mit einer genealogischen Abstammung von 'Alī b. Mūsā ar-Riḍā (8. Imam).

Ein weiteres iǧăzat-nāma aus dem Jahr 876/1471 im Museum von Kırşehir enthält vergleichbare Elemente. Es hält einerseits die genealogische Abstammung eines gewissen Sayyid Mușțafā fest, die über Mūsā al-Kāẓim (7. Imam) auf 'Alī b. Abī Ṭālib zurückgeht. Es führt am Anfang die Namen der Frauen des Propheten, seiner Töchter, von zehn prominenten Prophetengenossen ebenso wie jene der zwölf Imame auf. 'Alī wird darin als Vorsteher der futuwwa bezeichnet. Es führt 'Alīs walāya ${ }^{369}$ und die Prophetschaft (nubuwwa) Muhammads als Pfeiler des Glaubens an. Das Dokument betont überdies, dass die Genealogie des šayh in seiner

367 Yildirim, Shīitisation 59 (mit Anm. 47), wo Belege für weitere Einzelheiten.

368 Yildirim, Shīitisation 59 (mit Anm. 51).

369 Yildirim, Shī'itisation 6o, versteht walāya als „Heiligkeit“ („sainthood“).
Funktion als Nachfolger 'Alīs auf die Familie des Propheten (ahl al-bayt) zurückzugehen habe.

Die soeben angeführten Belege unterstreichen, dass die Verehrung der ahl al-bayt und der Kult der zwölf Imame unter den Ahīs in Anatolien von grösserer Bedeutung war, als dies noch in der höfischen Futuwwa unter Nāșir der Fall gewesen war. In der Ahi-Futuwwa gewinnen ausserdem die Erinnerungen an Karbalā’ und die Person Abū Muslims ${ }^{370}$ an Bedeutung. Burgàazī erwähnt Abū Muslim zusammen mit 'Alī, Hasan, Husayn und Hamza; dies stellt eine bedeutende Neuerung dar. ${ }^{371}$ Diese Beobachtungen deuten darauf hin, dass im 14. Jh. unter den Muslimen in Anatolien ${ }^{372}$ Vorstellungen lebendig waren, die um Husayns Martyrium in Karbalā’ kreisen. ${ }^{373}$ Auch F. Köprülü macht darauf aufmerksam, dass im kollektiven Gedächtnis der Muslime Anatoliens Geschichten über 'Alīs legendenhafte Feldzüge und über Husayns Märtyrertod in Karbalā' im 13. und 14. Jh. weit verbreitet waren. Dieselbe Feststellung trifft auf die Volksepen über Abū Muslim, Battāl Ġāzī, Dānišmend Ġāzī und Sarı Saltuk zu. Auch das Epos Maqtal al-Husayn stammt aus dieser Zeit. ${ }^{374}$

Diese Epen wurden zumeist mündlich überliefert. Sie unterscheiden zwischen zwei Gruppierun-

370 Vgl. dazu auch unten nach Anm. 377. Siehe zu Abū Muslim am ausführlichsten Mélikoff, Abū Muslim; Babayan, Mystics, monarchs, and messiahs 121-16o („5. Abu Muslim: Victim of the waning of the Qizilbash"). Yildirim, Shīitisation 6o (mit Anm. 56), wo Verweis auf Burḡāzī 147 (vgl. Anm. 361). Wozu auch die muslimische Bevölkerung in Thrakien und auf dem Balkan zu zählen ist.

373 Auch der Reisebericht Ibn Bațtutụas betont die Bedeutung der Erinnerung an Karablā' im Umfeld der ahiss. Als sich Ibn Battūța 1332 in Bursa aufhielt, war er in der zāwiya eines gewissen Ahī Šams ad-Dīn untergekommen. Hier wurde er am 10. Muharram Zeuge von Feierlichkeiten in Gedenken an Husayns Martyrium. Die Zeremonie war begleitet von Koranrezitationen, Predigten und rituellem Tanz $\left(s a m \bar{a}^{c}\right)$. Die Derwische wehklagten ekstatisch; einige fielen sogar tot zu Boden. Vgl. Ibn Bațtūṭa, Riḥla II, 318f. (Ausgabe Defrémery und Sanguinetti; Ausgabe Bayrūt 140o/1980: S. 307). Yildirim, Shīitisation 6o (mit Anm. 57), wo Verweis auf Köprülü, Türkler, Edebiyat, in IA Xıı.2, 536 . 
gen: Es gibt einerseits diejenigen, die die Familie des Propheten (ahl al-bayt) lieben, wobei 'Alī eine besonders wichtige Rolle spielt. Anderseits gibt es jene, die der Familie des Propheten feindlich gesinnt sind und negativ wahrgenommen werden. Die der Familie des Propheten gegenüber positiv eingestellten Kreise werden als muhibb ahl al-bayt, 'Alawì und Turābì bezeichnet. ${ }^{375}$

I. Mélikoff hat sich eingehend mit der Figur Abū Muslims und der Maqtal-Literatur befasst. Sie konnte aufzeigen, dass die ahīs in Abū Muslim den idealen fatā erkannten. ${ }^{376}$ Die Epen über Abū Muslim seien in den Ahì-Zentren oft rezitiert worden. ${ }^{377}$ Diese Literatur stellt Abū Muslims Aufstand gegen die Omeyyaden in Khorasan weitgehend als $A h \bar{\imath}$-Unternehmung dar. Abū Muslims Parteigänger werden darin als die „Ahīs aus Marw“ vorgestellt. I. Mélikoff geht davon aus, dass es ein enges Netzwerk zwischen den zuvor aufgeführten Epen des Abū Muslim-Zyklus gebe, die mündlich überliefert wurden. ${ }^{378}$

R. Yildirim fasst seine Beobachtungen dahingehend zusammen, dass sich die in der $A h \bar{\imath}-$ Futuwwa vertretenen Überzeugungen nicht grundlegend von jenen Auffassungen unterscheiden, die in Futuwwa-Kreisen bereits zuvor im Vordergrund standen. ${ }^{379}$ Die Ahi-Futuwwa betont zwar in erster Linie die Bedeutung der Liebe für die Ahl al-bayt, wozu hier auch die zwölf Imame zu zählen sind. Auch Husayns Schicksal hat besondere Bedeutung erhalten. 'Alī selbst nimmt zwar immer noch einen bedeutenden Platz ein, ist aber etwas in den Hintergrund getreten. Während sich Nāṣirs Futuwwa

375 Die Begriffe bedeuten a. "Jene, die die ahl al-bayt lieben“, b. ,jene, die zu 'Alī gehören“; c. ,jene, die sich zu Turāb (= Beiname 'Alīs) bekennen“.

376 So auch Taeschner, Futuwwa: Post-Mongol period, in $E I^{2}$.

377 Mélikoff, Abū Muslim 68-69.

378 Besonders eng sind die Verbindungen zwischen $A b \bar{u}$ Muslim-nāma und Maqtal al-Husayn, die wohl auf denselben Verfasser, nämlich Šādī, zurückgehen (vgl. dazu Mélikoff, Le drame de Kerbela 134f.). Auch die Epen über Battāl Ġāzī, Dānišmend Ġāzī und Sarı Saltuk sind in diesem Umfeld entstanden.

Yildirim, Shī'itisation 62. in erster Linie an die herrschenden Kreise gerichtet hatte, verbreitete sich jetzt die Basis der potentiellen Mitglieder. Zunehmend schlossen sich auch gewöhnliche Stadtbewohner den $A h \bar{\imath}$-Bünden an. Mit dieser Verbreiterung der Basis ging die Fokussierung auf die Person 'Alīs zurück. Die ritterliche Futuwwa nahm eine taríqa-artige Struktur an, die in hāanaqāhs (zāwiyas) organisiert war und unter der Leitung eines spirituellen Vorstehers stand. ${ }^{380}$ Es ist kaum möglich, die Ahī-Zāwiyas bezüglich Funktion und Struktur von den Süfi-Zāwiyas zu unterscheiden, die im 14. Jh. in Anatolien ebenso verbreitet waren. ${ }^{381}$

Ebenso wie die höfische Futuwwa Nāṣirs zuvor verlor im Lauf des 15. Jh. auch die Ahì-Futuwwa an Bedeutung. ${ }^{382}$ Diese Feststellung trifft allerdings nicht auf die Gilde der Gerber zu, in der gewisse Elemente aus der Ahī-Futuwwa weiter gepflegt wurden. Die Futuwwa-Bewegung kann in diesem Umfeld ein weiteres Jahrhundert oder sogar länger überleben. Allgemein lässt sich feststellen, dass sich die Futuwwa-Ideale des Ahitums trotz seines Niedergangs in den Handwerksgruppierungen halten konnten. Die Forschung redet in diesem Zusammenhang von einer Gilden-Futuwwa. ${ }^{383}$

R. Yildirim warnt allerdings davor, die Post- $A$ h $\vec{\imath}$ Futuwwa als Ganzes dem Gildenwesen zuzuweisen, hätten sich gewisse dieser Bünde im 16. Jh. doch noch weiter entwickelt. ${ }^{384}$ Er bezeichnet das 15. Jh. als wichtige Übergangszeit. Diese Bünde hätten sich damals verstärkt an schiitischen Vorstellungen orientiert. Damals sind auch die drei folgenden Futuwwa-Schriften entstanden: 1. Ibn Ġaybīs (aktiv unter Sulțān Meḥmed II., reg. 1451-1481)

380 Ohlander, Sufism in an age of transition 271-291, weist Suhrawardī eine massgebliche Rolle bei diesen Veränderungen zu.

381 Vgl. Yildirim, Shīcitisation 62 (mit Anm. 69). Wolper, Cities and saints 77 f., vertritt denselben Standpunkt in einem etwas andern Kontext.

382 Yildirim, Shīitisation 62-67.

383 Yildirim, Shīitisation 63; siehe auch Taeschner, Futuwwa: Post-Mongol period, in $E I^{2}$; Breebaart, Development $145^{-224}$.

384 Yildirim, Shī'itisation 63 (mit Anm. 72), wo Quellenverweise. 
Futuvvet-nāme: Es ist das früheste Futuvvet-nāme mit klar schiitischem Einschlag und diente als Vorlage für spätere Futuvvet-nāmes in türkischer Sprache. ${ }^{385}$ 2. Hierhin gehört auch 'Alā' ad-Dīn ar-Radawīs Futuvvet-nāme. Es ist eine FutuwwaSchrift par excellence und baut auf Ibn Gaybīs Werk auf. ${ }^{386} 3$. Beim dritten wichtigen Text handelt es sich um Husayn Wāciz Kāšifīs Futuwwat-nāma-i sulțāni. Es ist zeitlich zwischen die Werke Ibn Gaybīs und Raḍawīs einzuordnen und in Herat in spättimuridischer Zeit entstanden. ${ }^{387}$ Gemäss R. Yildirim stellt Ibn Gaybīs Schrift einen Wendepunkt in der Entwicklung der Futuwwa-Idee dar.

1. R. Yildirim hebt hervor, dass sich Ibn Gaybīs Text zwar klar in die frühere Futuwwa-Literatur einfügt. Allerdings lassen sich in diesem Werk auch deutliche Abweichungen davon feststellen. Dazu zählen klare Hinweise auf eine neue Organisationsstruktur der Futuwwa-Bünde. Ausserdem zeichnen eindeutig schiitische Elemente diesen Text aus, der die folgenden Aspekte betont: a. 'Alīs walāya und wașāya; b. die Vorrangstellung der zwölf Imame in der Theologie; c. den Ġadīr Humm-Vorfall ${ }^{388}$. Ibn Gaybī beginnt sein Werk in Übereinstimmung mit weiteren Futuwwa-Schriften mit einem Bericht über den Ursprung die-

385 Ibn Ġaybīs Text dürfte zwischen 1451 und 1481 entstanden sein; er wurde von A. Gölpınarlı veröffentlicht: „Seyyid Gaybî oğlu Seyyid Hüseyin'in Fütüvvetnâmesi“, in İstanbul Üniversitesi İktisat Fakültesi Mecmuası 17.14 (1955-1956) 27-126. Siehe Yildirim, Shīitisation 63 (Anm. 74); Taeschner, Zünfte und Bruderschaften $407 \mathrm{f}$. und $449 f$.

386 Muḥammad b. Ḥusayn ar-Raḍawī verfasste dieses Futuvvet-nāme 931/1524 in Bursa. Siehe dazu Yildirim, Shīitisation 63 (Anm. 73), und Taeschner, Zünfte und Bruderschaften 407-417 und 424-549; vgl. auch Kapitel 3.2.3 bei Anm. $312 \mathrm{f}$.

387 Husayn Wā'iz Kāšifì verfasste seinen Text kurz vor 1503 in Herat. Textausgabe: M.Ğ. Maḥ̆ūb, Tihrān, 135o/1972; Übersetzung: J.R. Crook, The Royal book of spiritual chivalry. Siehe zum Werk ausserdem Ridgeon, Morals and mysticism, darin Kapitel 4: „Timurid futuwwat: the case of Ḥusayn Wāciz Kāshifï“, 92-122.

388 Zum Ġadīr Humm-Vorfall siehe Amir-Moëzzi, Ghadīr Khumm, in $E I^{3}$. In früheren Futuwwa-Texten fehlen Hinweise auf dieses Ereignis gänzlich; bei Ibn Ġaybī aber handelt es sich sogar um ein Schlüsselelement. ser Idee. In Anlehnung an die Tradition stellt er den Propheten Ādam als ersten fatā vor und äussert sich zu seiner Gürtung (šadd). Von Ādam gelangte die futuwwa danach zu weiteren Propheten. Ibn Ġaybī schenkt Noah, Abraham und Joseph besondere Beachtung. Zuletzt wurde Muhammad während seiner nächtlichen Himmelfahrt (mi'rāğ) vom Erzengel Gabriel gegürtet. ${ }^{389}$

Ibn Gaybīs Darstellung stimmt soweit mit der traditionellen Sichtweise überein. Sein Bericht unterscheidet sich davon allerdings bei der Beschreibung, wie Muhammad 'Alī in die futuwwa einführte. Gemäss Ibn Gaybī fand die Gürtung (šadd) 'Alīs bei der Rückkehr Muhammads von der Abschiedswallfahrt in Gadīr Humm statt und stellt das zentrale Element der dortigen Ereignisse dar. Die Futuwwa-Rituale lassen sich als Reinszenierung dieses halb-mythischen Geschehens verstehen.

Ibn Gaybīs Bericht lehnt sich eng an die schiitische Sichtweise an, gemäss der Muhammad 'Alī in Ġadīr Humm als seinen wași und walı̄ einsetzte. Muhammad übertrug 'Alī damals zugleich die Aufgaben eines Kalifen und Imams. ${ }^{390}$ Muhammad betont gegenüber 'Alī auch, dass sie beide aus ein und derselben göttlichen Substanz erschaffen worden seien, und hebt dadurch die enge Beziehung zwischen ihnen beiden hervor. Wer Muhammad als mawlā anerkenne, müsse auch 'Alī als seinen mawlā akzeptieren. 'Alīs Gürtung symbolisiert, dass Muhammad ihn mit den Qualitäten der wașāya und imāma betraut. Muhammad hält nach der Gürtung fest, dass die Zeit der Prophetschaft zu Ende sei und soeben die Ära von walāya und imāma begonnen habe. Ebenso wie er, Muhammad, der beste Prophet sei, sei 'Alī der hervorragendste walī. Der Prophet fordert 'Alī auf, seinerseits seine Vertreter bzw. Nachfolger zu gürten und derart in die futuwwa aufzunehmen. 'Alī nimmt darauf die Gürtung von drei Personen vor: 'Amr

\footnotetext{
389 Vgl. Ibn Ġaybī, Futuvvet-nāme 75-79; Hinweis bei Yildirim, Shīitisation 64 (Anm. 78).

390 Ibn Ġaybī verwendet in seinem Bericht beide Begriffe; vgl. Yildirim, op. cit. 64.
} 
b. 'Umayya, Bilāl al-Ḥabašì und Salmān al-Fārisī. Von grosser Bedeutung ist, dass Salmān al-Fārisī danach seinerseits die Gürtung an siebzehn weiteren Personen vornimmt.

Ibn Gaybīs Futuwwa-Schrift zeichnet sich ausserdem dadurch aus, dass sie den zwölf schiitischen Imamen grosse Bedeutung zuschreibt. Sie stellen einen wesentlichen Bestandteil des Glaubens dar. Nur indem er ihrem Licht folgt, kann der Gläubige Erlösung finden. Zwar akzeptiert Ibn Gaybī die wichtige Stellung der Prophetengenossen, hebt aber die Bedeutung 'Alīs und seiner Nachfolger besonders hervor. Sie werden als sündlos ( $m a$ ș̣um $)$ charakterisiert. Sie zeichnen sich ausserdem dadurch aus, dass sie in religiösen Angelegenheiten eigentlich über ebenso vollkommenes Wissen verfügen wie die Propheten.

Ibn Gaybī stellt den von Muhammad-'Alī vorgegebenen Pfad als Kern von Islam und Futuwwa dar. Die Liebe für die Angehörigen der Ahl al-bayt bildet einen zentralen Bestandteil der FutuwwaBewegung. Diese Grundeinstellung wird auch bei der Initiation thematisiert. Der Initiand bringt bei dieser Zeremonie a. seinen Glauben an 'Alīs walāya und wașāya zum Ausdruck und macht b. seine Liebe für die Angehörigen des Hauses des Propheten (tawallā) und c. seinen Hass auf deren Feinde (tabarrā) deutlich. ${ }^{391}$ Die Initiationszeremonie wird durch eine hutba und das Anrufen der Namen der zwölf Imame abgeschlossen. Auch fällt auf, wie oft Ibn Ġaybīs Text die Aussage wiederholt, wonach 'Alī Allāhs wal̄ sei (" „Alī walī Allāh“). 392

Ibn Ġaybīs Text vertritt zwar dezidiert zwölferschiitische Positionen. Allerdings erhebt der Autor keinen Anspruch auf eine Führerschaft der Imame auf der politischen Ebene. Er bringt ebenso seinen Respekt gegenüber den Prophetengenossen zum Ausdruck. Wenn er sie auch nicht namentlich aufführt, begegnet doch auch er den vier rechtgeleiteten Kalifen mit Wertschätzung und nennt sie die

$391 \mathrm{Zu}$ den beiden Prinzipien tawallā und tabarrā vgl. Calmard, Tabarru', in $E I^{2}$.

392 Yildirim, Shī'itisation 65 (mit Anm. 84). čahār yār-i guzīn. ${ }^{393}$ In Ibn Ġaybīs Text fehlt ausserdem noch jeglicher Hinweis auf die aus der politischen Schia (rafaḍ, rāfị̂) ${ }^{394}$ bekannten Position, dass die drei ersten Kalifen das eigentlich 'Alī zustehende Recht auf die Nachfolge des Propheten usurpiert hätten. Sein Text unterstreicht vielmehr die Überlegenheit 'Alīs und seiner Nachkommen in Glaubensfragen. Aus diesen Auffassungen lässt sich schliessen, dass Ibn Ġaybī der Schia näher steht als der Sunna.

2. 'Alä' ad-Dīn ar-Radawīs Grosses Futuvvetnāme (auch bekannt als Miftāh ad-daqāiq fí bayān al-futuwwa wa-l-haqā̄iq) lehnt sich in weiten Teilen an Ibn Gaybīs Text an. Raḍawī fügt allerdings in drei Punkten wesentliche Ergänzungen hinzu: a. formelhafte Sätze und kurze Geschichten unterstreichen, dass für Radawī die Futuwwa-Tradition noch stärker auf die Organisationsform der tarīqa ausgerichtet ist als dies bei Ibn Gaybī der Fall war; b. lange Passagen sind den Ritualen in bestimmten Handwerksgilden gewidmet; c. ausserdem wird dieses Brauchtum noch präziser als bei Ibn Ġaybī geschildert. Wenn auch sowohl Ibn Gaybī als auch Raḍawī 'Alī grosse Wertschätzung entgegenbringen, fällt doch auf, dass das bekannte Prophetenwort bei ihnen beiden noch fehlt, wonach es keinen andern fatā gebe ausser 'Alī und kein anderes Schwert als das $D \bar{u}$ l-faqār-Schwert. ${ }^{395}$

3. Diese Aussage lässt sich allerdings in Husayn Wāciz Kāšifīs (gest. 910/1504) persischem Futuwwat-nāma-i sultān̄i feststellen. Diese FutuwwaSchrift dürfte von Ibn Gaybī weitgehend unabhängig sein, wurde sie doch in einem andern politischen und kulturellen Umfeld, nämlich in Herat am Ende der Timuridenzeit, verfasst. Ausserdem weicht ihr Aufbau stark von klassischen Futuwwa-Texten ab. Bei Kāšifiss Werk handelt es sich ebenso sehr um eine Futuwwa-Schrift als auch um einen Sufi-Text. Kāšifí betont die Nähe zwi-
393

394

395
Yildirim, Shīitisation 65 (mit Anm. 85), wo Verweis auf Ibn Gaybī, Futuvvet-nāme 97. Ibn Ġaybī erwähnt ausserdem den Kalifen 'Umar mit Respekt (115).

Vgl. Anm. $35^{8}$.

Vgl. zu diesem Prophetenwort Bellino, Dhū l-Faqār, in $E I^{3}$. 
schen Futuwwa und Sufismus jedenfalls vielfach. Er äussert sich überdies eingehend zu den Verhaltensregeln ( $a d a b, \mathrm{Pl} . \bar{a} d \bar{a} b$ ) in unterschiedlichen Berufsgruppen. Er unterstreicht damit, dass sich Futuwwa und Handwerksgruppierungen zunehmend miteinander vermischen. Der Stil von Kāšifīs Text bringt überdies zum Ausdruck, dass es sich um die Schrift eines gebildeten Autors handelt. Kāšifī dürfte sich bei ihrer Abfassung auf eine ganze Reihe von Quellen gestützt haben. Auch Ibn Gaybīs Text könnte dazu gehört haben. Dies lässt sich allerdings nicht mit Sicherheit feststellen.

Es fällt aber auf, dass Kāšifĩ in seinem Text klar schiitische Positionen vertritt, wie dies bereits Ibn Ġaybī und Raḍawī taten. ${ }^{396}$ Auch Kāšifĩ beschreibt 'Alī als walı̄ Gottes und wașī Muhammads. Seine Schrift stellt 'Alī einerseits als Schutzheiligen der Futuwwa dar, erkennt in ihm anderseits zugleich den Vorsteher einer țarīqa. Kāšifì hielt sich allerdings mit einer allzu starken Verehrung 'Alīs doch auch wieder zurück. Gleichzeitig erfahren in seinem Text auch die weiteren schiitischen Imame grosse Wertschätzung. Kāšifīs Werk greift auffällig oft Aussagen der Imame, gerade von Ğaffar aș-Ṣādiq (6. Imam, gest. 765) auf. Er führt überdies die Namen aller zwölf Imame in jenem Gebet auf, das während der Gürtungszeremonie rezitiert wird. Auch Kāšifĩ liegt die Verehrung der Ahl albayt und der Nachkommen 'Alīs am Herzen; sie stellt einen Kernpunkt seiner Futuwwa-Idee dar. Er bringt jedoch zugleich seinen Respekt gegenüber den drei ersten rechtgeleiteten Kalifen zum Ausdruck und steht damit in Einklang mit Ibn Gaybī und Raḍawī. Erwähnung verdient bei dieser Gelegenheit, dass Kāšifĩ zugleich der Verfasser der Rawdat aš-šuhadā' ist. Dieser Text beklagt das Schicksal Husayns und der Seinen in Karbalā'. ${ }^{397}$

396 Vgl. für die weiteren Ausführungen Yildirim, Shīitisation $66 \mathrm{f}$., mit Verweisen auf Kāšifì, Futuwwat-nāma, und Ridgeon, Morals and mysticism, in den Anmerkungen.

397 Zu Kāšifīs Rawḍat aš-šuhadā’ und der Einordnung dieses Texts siehe Jacobs, Sunni and Shii perceptions.
R. Yildirim leitet aus seinen soeben stark gekürzt wiedergegebenen Beobachtungen ab, dass im Lauf des 15. Jh. entscheidende Entwicklungen stattgefunden hatten, die zu einer Schiitisierung der Futuwwa-Tradition führten. ${ }^{398}$ Diese Schiitisierung komme in den beiden voneinander wohl weitgehend unabhängigen Futuwwa-Schriften Ibn Ġaybīs und Kāšifīs besonders deutlich zum Ausdruck. Ibn Ġaybīs Standpunkt dürfe dabei nicht als Randerscheinung aufgefasst werden, sondern stelle eine allgemein zu beobachtende Entwicklung der Futuwwa dar. Sie müsse zwischen 1451 und 1481 stattgefunden haben, habe Ibn Ġaybī seinen Text doch um diese Zeit verfasst.

R. Yildirim ${ }^{399}$ kommt darauf auf seine Kritik an der Erklärung der Schiitisierung der Futuwwa im 15. Jh. aus der safawidischen Propaganda heraus zurück; sie lasse sich aus historischer Perspektive nicht beweisen. Jedenfalls lassen sich in den Futuwwa-Schriften Ibn Ġaybīs, Raḍawīs und Kāšifîs keinerlei Hinweise auf eine Verbindung zwischen den Safawiden und den Angehörigen der Futuwwa-Bünde feststellen. Die drei Texte verwenden auch das Wort šāh nicht, das unter den Qizilbāš damals weit verbreitet war. Diese Qizilbāš waren massgeblich für die militärischen Erfolge der Safawiden unter Šāh Ismā̄ill verantwortlich Auch fehlen weitere Quellen, die auf einen Einfluss der Safawiden auf die Futuwwa vor dem 16. Jh. schliessen lassen.

Gemäss R. Yildirim kann ein derartiger Einfluss nicht einmal erwartet werden. Die Forschung geht im allgemeinen davon aus, dass die Schiitisierung des anfänglich sunnitischen Derwischordens der Șafawiyya unter Šayh Ğunayd um die Mitte des 15. Jh abgeschlossen war. Allerdings ist zu betonen, dass die schiitische Ausrichtung der Safawiden vor Šāh Ismāīil I. trotzdem noch nicht voll ausgebildet war. Es fällt jedenfalls auf, dass Faḍlullāh b. Rūzbihān Hunğ̄̄, die früheste Quelle zur religiösen Hal-

\footnotetext{
398 Yildirim, Shīitisation 68-70.

399 Taeschner, İslam ortaçağında Fütüvva teşkilatı 21; Breebaart, The Fütüvvet-nāme-i kebīr 205; siehe auch Yildirim, Shī'itisation 68 (mit Anm. 111).
} 
tung der Qizilbāš unter Ǧunayd und Ḥaydar, diese nicht des Schiismus bezichtigt, sondern sie wegen ihrer ausgesprochen heterodoxen Haltungen kritisiert, ihnen also Gulāt-Gesinnung vorwirft. ${ }^{400}$

Selbst wenn der Safawiden-Orden unter Šayh Ğunayd schon klar schiitische Tendenzen aufwies, ist sodann zu bedenken, dass sich der militante schiitisch ausgerichtete Sufismus Šayh Ğunayds vor der Machtübernahme durch Šāh Ismāōil im Jahr 1501 in den städtischen Zentren nicht hatte durchsetzen können. Somit ist auch nur schwer vorstellbar, dass die Mitglieder der primär in den Städten ansässigen Futuwwa-Bünde ein Publikum darstellten, das gegenüber der safawidischen Propaganda offen gewesen wäre. Der safawidisch geprägte Sufismus vertrat überdies zunehmend militante und messianische Positionen, die unter den tribal organisierten Turkmenen ein grösseres Echo fanden als unter den Mitgliedern der in den Städten verankerten Futuwwa-Bünde. So dürfte Ibn Gaybī kaum von Auffassungen der Safawiden beeinflusst worden sein, deren Propaganda sich primär an die nomadisierenden Turkmenenstämme richtete.

R. Yildirim schätzt auch die Wahrscheinlichkeit als gering ein, dass Kāšifĩ (gest. 908/1504) von der safawidischer Propaganda beeinflusst worden war. $^{401}$ Gegen diese Möglichkeit spricht insbesondere, dass er die letzten Jahrzehnte seines Lebens unter Husayn Bayqarā in Herat verbrachte, wo die Dynastie der Timuriden kurz vor ihrem Ende stand. Es ist nicht klar, zu welchem Zeitpunkt Kāšifī sein Futuwwat-nāma verfasste. Es ist aber gewiss, dass er vor der Einnahme Herats durch Šāh Ismāî̀ im Jahr 1510 starb. Es ist damit so gut wie ausgeschlossen, dass es zu direkten Kontakten zwischen Kāšifĩ und Šāh Ismā̄ill kam. Auch war Herat am Anfang des 16. Jh. gegenüber Tabriz kulturell weit überlegen. Dass Kāšifī nicht von der safawidischen Propaganda beeinflusst worden war, kommt ausserdem darin zum Ausdruck, dass die Safawiden im Futuwwat-nāma-i sulțān̄ gar nicht

400 So gemäss Yildirim, Shī itisation 68.

401 Yildirim, op. cit. 69. erwähnt werden. Überdies fehlt im Abschnitt über die Kopfbedeckungen ein Hinweis auf die roten Kappen der Qizilbāš, die damals in Anatolien in aller Munde waren.

R. Yildirim schliesst aufgrund seiner Beobachtungen aus, dass die safawidische Propaganda zur Schiitisierung der Futuwwa-Ideologie beigetragen hat. ${ }^{402}$ Auch er kann allerdings erst vage Vermutungen dazu äussern, welche Einflüsse bei diesem Prozess ausschlaggebend gewesen sein könnten. Er stellt fest, dass die Schia im 15. Jh. in breiten Teilen der islamischen Welt an Gewicht gewann. Auch hatte der Sunnismus seine frühere Hegemoniestellung schon während des Mongolensturms eingebüsst. Der zuvor lange unterdrückte schiitische Islam fand damit Entwicklungsmöglichkeiten, von denen er auch profitierte. Ausserdem zeigten sich die İlhāniden in Religionsangelegenheiten sehr offen. Dies trug zur Abschwächung der zuvor oft heftig geführten Auseinandersetzungen zwischen Sunniten und Schiiten bei. Die früher scharfen Abgrenzungen zwischen Sunna und Schia verwischten sich dadurch. Diese Entwicklungen begünstigten, dass unterschiedliche schiitische Vorstellungen in die sunnitische Ideologie eindringen konnten. Dies wiederum führte dazu, dass die anfänglich eigentlich sunnitischen Derwischorden zunehmend schiitisch beeinflusst wurden. ${ }^{403}$

Nach dem Mongolensturm fehlte vorerst auch ein staatliches Gebilde, das dogmatisch klar sunnitisch oder schiitisch ausgerichtet war. Die Auseinandersetzung zwischen den beiden Auffassungen verlor damit ihre politische Dimension. Dies trug zur beidseitigen Mässigung bei und erleichterte die Koexistenz von Schia und Sunna. Das allgemeine politische Klima begünstigte bis ins 15 . Jh. eine Vermischung der beiden Auffassungen. Im Umfeld des Sufismus verlor der Gegensatz zwischen Sunna und Schia sogar seine Bedeutung. ${ }^{404}$

\footnotetext{
402 Yildirim, op. cit. $69 \mathrm{f}$.

403 Vgl. zu diesen allgemeinen Entwicklungen Amoretti, Religion in the Timurid and Safavid period, $\mathrm{CHI}$ VI, 634; Bausani, Religion under the Mongols, $\mathrm{CHIV}, 546$. 
R. Yildirim hebt hervor, dass das türkischmongolisch orientierte Gemeinwesen im Lauf des 15. Jh. zunehmend an Gewicht verlor. An seine Stelle trat das iranisch-islamisch geprägte Gemeinwesen, in dem Religion und Ideologie als Instrumente der Machtausübung einen bedeutend wichtigeren Stellenwert einnehmen. Zugleich verschlechterten sich die Bedingungen, die eine Koexistenz von Sunna und Schia begünstigten. Gemäss R. Yildirim neigte in diesem Umfeld auch die Futuwwa-Bewegung zunehmend der Schia zu.

R. Yildirim gesteht allerdings ein, dass er einstweilen nicht in der Lage sei, diese allgemein formulierte These umfassend zu belegen. Er hält im Sinn einer vorläufigen Schlussfolgerung jedoch fest, dass die Schiitisierung der Futuwwa-Bewegung in der zweiten Hälfte des 15. Jh. nicht auf die safawidische Propaganda zurückzuführen sei. Diese Beeinflussung habe eher in umgekehrter Richtung von der Futuwwa auf die Qizilbāš-Bewegung im Umfeld der Safawiden stattgefunden. Die Schiitisierung der Futuwwa-Bewegung, des Safawidenordens und weiterer Derwischbruderschaften im 14. und gerade im 15. Jh. sei deshalb in breitere Entwicklungen einzuordnen, die die islamische Welt damals prägten.

\subsection{Ausgewählte Aspekte des Brauchtums im Umfeld von Männerbünden}

Die vorangehenden Ausführungen haben im Vorbeigehen wiederholt auf den Reichtum des in den Männerbünden gepflegten Brauchtums hingewiesen. Die weitere Darstellung macht als Überleitung zur Auseinandersetzung mit den Dokumenten in Rollenform selbst auf drei ausgewählte Aspekte dieses Brauchtums aufmerksam.

1. Pilgerfahrten sind v.a. im Umfeld von Derwischorden relevant (3.4.1): Diese Praxis bringt einerseits die im Volk tief verwurzelte Frömmigkeit zum Ausdruck, die sich auch in der Verehrung heiligmässiger Männer äussert. Sie verdient anderseits Beachtung, da die in den einzelnen Pilgerfahrtszentren angebrachten textlichen und ornamenta- len Elemente wiederholt ein Echo auf den untersuchten Rollen gefunden haben. Auf der visuellen Ebene lässt sich eine bemerkenswerte Affinität zwischen der Ausschmückung von Pilgerfahrtszentren und gewissen Zierelementen auf den Rollen feststellen.

2. Spirituelle Übungen und Techniken, die in den Männerbünden gepflegt werden (3.4.2): Die Angehörigen von Derwischorden ziehen sich zur Klausur (halwa) gern während 40 Tagen zurück (arbaīniyya, čilla). Anderseits versammeln sich die Angehörigen von Männerbünden zusätzlich zum Ritualgebet (șalāt) zu gemeinsamen Andachtsübungen (dikr, samāc) und Rezitationen von freien Gebeten (wird, hizb, hiǧāb). Diese Übungen vergegenwärtigen den Teilnehmenden die Glaubensinhalte auf auditiver Ebene. Die dabei rezitierten Textelemente lassen sich auffällig häufig auf den untersuchten Dokumenten in Rollenform nachweisen.

3. Initiationszeremonien haben in den Männerbünden einen zentralen Platz (3.4.3): Auch im Verlauf dieser Riten werden Gebetstexte rezitiert. Diese Zeremonien finden in einem besonders feierlichen Rahmen statt. Sie stellen in diesem Sinn eine Erweiterung der gewöhnlichen Zusammenkünfte der Angehörigen dieser Männerbünde dar. Spezielle Erwähnung verdient, dass im Rahmen dieser Riten am Novizen die Gürtung (šadd) vorgenommen wird. Dieser Brauch hat mutmasslich die Gestaltung ausgewählter Belegstücke in Rollenform aus dem 14. und 15. Jh. beeinflusst.

\subsubsection{Schreinbauten als Pilgerfahrtszentren}

Die Darstellungen der historischen Entwicklungen zwischen 125 o und 1500 haben dem Aufstieg der Safawiden grosse Aufmerksamkeit geschenkt. Diese Dynastie hat sich aus einem anfänglich sunnitisch orientierten Derwischorden heraus entwickelt, dessen Zentrum in Ardabil in NordwestIran lag (Aserbaidschan). Aus dem Osten der islamischen Welt sind auch weitere religiöse Zentren bekannt, die im 13.-15. Jh. errichtet wurden. Sie weisen jeweils einen engen Bezug zu einem bestimmten Derwischorden oder zu damit ver- 
wandten weiteren Männerbünden auf. Derartige Zentren entwickelten sich um einen Konvent oder die Grabstätte eines wichtigen Ordensmitglieds. Diese Konvente sind im iranischen Kulturraum unter dem Begriff hāanaqāh bekannt.

Der Ausdruck hānaqāh lässt sich ebenso in der arabischen Welt nachweisen. In Kairo wurden unter den Mamluken eine Reihe von hānaqāhs errichtet. Es handelt sich in diesem Fall um staatlich geförderte Institutionen zur Unterbringung von Sufis, die gerade im 14. Jh. in grosser Zahl aus dem Osten (Zentralasien, Iran, Ostanatolien) nach Ägypten gelangten. Die Verwendung des persischen Begriffs lässt Rückschlüsse auf die Herkunft dieser Institution selbst zu. ${ }^{405}$

Der spezifisch arabische Ausdruck zur Bezeichnung derartiger Zentren lautet aber zāwiya. Diese Bezeichnung charakterisiert später gerade in Nordafrika die Wirkstätte eines einzelnen jener im Volk verehrten heiligmässigen Männer. Dieses Phänomen ist im Maghreb als Marabutismus bekannt. Im Osten allerdings bezeichnet der arabische Begriff zāwiya in erster Linie Bauten, deren Funktionen mit jenen des hānaqāh weitgehend identisch sind. Das Türkische nennt vergleichbare Institutionen tekke. Zumeist finanzierten die weltlichen Machthaber oder die mit ihnen eng zusammenarbeitenden weiteren Angehörigen der administrativen, politischen und militärischen Eliten Errichtung und Unterhalt dieser Bauten. Diese Stätten der Volksfrömmigkeit sind in der Regel als fromme Stiftung (waqf) konstituiert. ${ }^{406}$

Die folgenden Ausführungen machen in einem ersten Schritt auf ausgewählte Zentren und die Finanzierung durch ihre jeweiligen Stifter aufmerksam. Sie stellen anschliessend die Anlage in Ardabil eingehender vor. Diese Schreinbauten werden hier besonders erwähnt, da die bei ihrer Ausschmückung eingesetzten visuellen und textlichen Mittel zumeist eine grosse Nähe zum ent-

405 Vgl. u.a. Fernandes, Khanqah; Little, Khānqāhs, ribāts, and zāwiyas; Hofer, ,Chief sufi; ders., Popularisation, darin v.a. „Part One: State-sponsored sufism: The sufis of the khānqāh Sa'īd as-Su'adā'“, 1-102.

406 Zum waqf vgl. Meier, Wakf, in $E I^{2}$. sprechenden Vokabular auf den Dokumenten in Rollenform aufweisen. Die folgenden Ausführungen verweisen zur Illustration dieser gegenseitigen Abhängigkeiten in den Anmerkungen auf Abbildungsmaterial zu den einzelnen Heiligtümern.

In Yasi befindet sich das Heiligtum, das Timur zwischen 1389 und 1405 in Turkistan (Süd-Kasachestan) zu Ehren des Sufi-Heiligen Aḥmad Yasawī (starb im frühen 13. Jh.) hatte errichten lassen. ${ }^{407}$ In Natanz (zwischen Isfahan und Kashan) wiederum steht das Heiligtum, das für den Suhrawardiyya-Šayh 'Abd aṣ-Ṣamad errichtet worden ist und aus der Īlhāniden-Zeit datiert. Sh. Blair hat sich in ihrer Dissertation eingehend mit dieser Anlage befasst. ${ }^{408}$ Sie konnte aufzeigen, dass Zayn ad-Dīn Halīfa b. Husayn b. 'Alī al-Mastarī die für die Errichtung dieses Derwischkonvents erforderlichen finanziellen Mittel zur Verfügung stellte. ${ }^{409}$ Dieser Zayn ad-Dīn al-Mastarī war Statthalter $(n \bar{a} i b)$ des Îlhāniden-Wesirs Sa'd ad-Dīn Sīwağī. Sacd ad-Dīn fiel allerdings bei den Îlhāniden in Ungnade. Er wurde zusammen mit fünf seiner engsten Vertrauten am 10. Šawwāl 711/19. Februar 1312 in der Nähe von Bagdad enthauptet. Auch Zayn ad-Dīn al-Mastarī, der Stifter der Anlage in Natanz, wurde in diesem Zusammenhang hingerichtet. ${ }^{410}$ In Gazurgāh (bei Herat, Afghanistan) befindet sich sodann der Schrein Hwāğa 'Abdullāh Anșārīs (gest. 1089). Auch dieses Heiligtum war von den Timuriden gefördert worden. ${ }^{411}$ In weiten Kreisen ist ausserdem der Schrein Ni'amatullāh Walīs in Māhān (östlich von Kerman, Iran) bekannt. ${ }^{412}$ Šāh Ni`matullāh Walī ist der Begründer

407 Vgl. dazu https://archnet.org/sites/3057 (Stand 4. Juni 2017).

408 Blair, Natanz; und https://archnet.org/sites/1645 (Stand 6. September 2017); siehe auch Wilber, Architecture 133 f. (mit Abb. 52-57 und Plan 23).
409

410

411

412 Blair, op. cit. 6-12. Op. cit. 7 .

Rizvi, Shrine 3 (mit Anm. 3, S. 211). Siehe ausserdem: https://archnet.org/sites/3936 und https://archnet.org/ sites/6410 (Stand 6. September 2017). https://archnet.org/sites/1637 (Stand 6. September 2017). 
des noch heute in Iran aktiven schiitischen Derwischordens der Ni'matullāhiyya.

E.S. Wolper hat sich mit ähnlichen Bauten in Sivas, Tokat und Amasya in Ost-Anatolien befasst. ${ }^{413}$ Ihre Errichtung wurde zumeist ebenso aus Mitteln der lokalen Eliten finanziert. Sie dienten den Angehörigen von Derwischorden und weiteren Männerbünden als Versammlungsstätten. Auch die osmanischen Sultane haben immer wieder Derwischschreine unterstützt. ${ }^{414}$ Sultan Selīm I. (gest. 1520) z. B. hatte einen Konvent für den Hulwatiyya-Šayh Ibrāhīm Gülşenī (gest. 1534) errichten lassen. ${ }^{415}$ Auch aus Indien sind bedeutende Zentren von Derwischbewegungen bekannt. Es kann u.a. auf den Schrein des Mu īn ad-Dīn Čištī (gest. 1230) in Ajmer hingewiesen werden.416

Es ist bekannt, dass die weltlichen Machthaber diesen Schreinen regelmässig Unterstützungsleistungen zukommen liessen. So förderte die Moghul-Dynastie den soeben erwähnten Schrein in Ajmer. ${ }^{417}$ Im Fall des Heiligtums der Șafawiyya in Ardabil ist belegt, dass Timur dieses Zentrum wiederholt unterstützte. ${ }^{418}$ Auch die in Bursa im Aufstieg begriffenen Osmanen haben der Șafawiyya in Ardabil regelmässig Geschenke zukommen lassen. ${ }^{419}$ Die Angehörigen der weltlichen Eliten unterstützen diese Derwischorden und ihre Schreinbauten zumeist nicht ausschliesslich aus Frömmigkeit. Sie suchen die Nähe zu den Vorstehern dieser Männerbünde in der Regel aus viel pragmatischeren machtpolitischen Überlegungen heraus. Es lässt sich jedenfalls feststellen, dass

413 Wolper, Cities and saints 42-72 („Part II: Dervish lodges and urban spaces: Sivas, Tokat, and Amasya“).

414 Rizvi, op. cit. 7 (mit Anm. 16, S. 212), wo Verweis auf Necipoğlu, The age of Sinan 6 of.

415 Die Gülşeniyya ist aus der Halwatiyya hervorgegangen; vgl. Knysh, Islamic mysticism 265; Yazici, Gulshānī [türkisch; Gülshenī], in $E I^{2}$.

416 Zu den Sufi-Schreinen in Indien vgl. Troll (Hg.), Muslim shrines in India.

417 Rizvi, op. cit. 7 (mit Anm. 15, S. 212), wo Verweis auf Tirmizi, Mughal documents relating to the Dargah of Khwaja Mu'īn al-Din Chishti.

418 Vgl. Kapitel 2, vor Anm. 162.

419 Vgl. die Hinweise bei Hinz, Aufstieg 14. die Vorsteher von auf den ersten Blick religiös ausgerichteten Gruppierungen über bedeutende Macht verfügten. Sie konnten die ihnen oft blindlings ergebenen Anhänger für ihre eigenen Zwecke mobilisieren und ihren Ansprüchen dadurch Nachdruck verschaffen. Derartige Männerbünde stellten damit einen ernstzunehmenden Machtfaktor dar. Sie waren in der Lage, weltliche Machthaber in arge Bedrängnis zu bringen oder sogar zu stürzen. Die Stifter hatten damit - neben ihrer allfälligen Frömmigkeit - noch ganz handfestere Interessen, sich die Gunst der Derwisch-Šayhs zu sichern.

Die Macht dieser Vorsteher von Männerbünden erklärt sich nicht zuletzt aus ihrer baraka. Es handelt sich um eine Kombination aus ihrem persönlichen Charisma und ihrer Gottesnähe (walāya). Die Anhänger eines bestimmten Derwischordens suchen ihren Šayh gern auch persönlich auf, erstatten ihm einen Besuch (ziyāra). Sie tun dies in der Hoffnung, direkt an seiner baraka teilzuhaben. Verschiedene Zentren von Derwischorden haben ihre Anhänger magnetisch angezogen und sind zum Ziel von eigentlichen Wallfahrten geworden. Diese Stätten haben wegen ihrer leichteren Erreichbarkeit oft eine Bedeutung erlangt, die jene des fernen Mekkas überstieg.

Unter diesen Zentren der Derwischorden wird der hānaqāh der Șafawiyya in Ardabil im folgenden näher vorgestellt. ${ }^{420}$ Bereits Šayh Șafī ud-Dīn, der Ordensgründer, zog durch seinen frommen Lebenswandel zahllose Pilger an. Sie liessen sich in Ardabil in der Lehre des Ordens unterweisen, von der allerdings wenig bekannt ist. ${ }^{421}$ Verschiedene Angaben beziffern die Zahl der Pilger aus Iraq und Anatolien bereits zu Lebzeiten Șafĩ ud-Dīns in nur drei Monaten auf 13'ooo Personen. ${ }^{422}$ Etwas später

420 Hinz, Aufstieg 19-21. Zum Heiligtum in Ardabil vgl. jetzt insbesondere Rizvi, Shrine. Siehe auch die älteren Arbeiten von Morton, Ardabil shrine; Sarre, Ardabil. Man beachte auch http://whc.unesco.org/en/list/1345 und http://whc.unesco.org/uploads/nominations/1345 .pdf (Stand 6. September 2017).

421 Hinz, Aufstieg $16 \mathrm{f}$.

422 Hinz, Aufstieg 14, mit Quellenangaben in Anm. 3. 
liessen sich Anhänger der Șafawiyya auch in den Städten Balkh und Bukhara weiter im Osten nachweisen.

Auch um die Grabmoschee von Šayh Șafĩ udDīn in Ardabil hat sich im Lauf der Jahrhunderte ein Heiligtum entwickelt, das Ziel von Wallfahrten wurde. Hier strömten die Angehörigen des Ordens zusammen, um dem von ihnen verehrten aktuellen Šayh und dessen Vorfahren, allen voran Șafī ud-Dīn, zu huldigen. ${ }^{423}$ Ab der zweiten Hälfte des 15. Jh. wurde Ardabil zu einem wichtigen Bezugspunkt der Qizilbāš. Die Anlage in Ardabil wurde im Lauf der Jahrhunderte mehrfach ausgebaut. Diese Erweiterungen wurden durch die Erfordernisse diktiert, die sich aus dem wachsenden Strom von Anhängern ergaben, die die von ihnen verehrten Šayhs in Ardabil aufsuchten. Es galt, Strukturen zu schaffen, um diese frommen Besucher zu empfangen, $\mathrm{zu}$ verpflegen und ihnen allenfalls auch Unterkunft anzubieten.

Es ist bekannt, dass in Ardabil bereits zur Zeit von Šayh Șafī ud-Dīn Armenspeisungen stattfanden. ${ }^{424}$ Ein Sayyid namens Ğamāl ud-Dīn aus Isfahan soll damals für diese Speisungen verantwortlich gewesen sein. Er habe an einem einzigen Tag dafür tausend Schafe benötigt. Derartige Speisungen fanden in Ardabil auch noch statt, als die Safawiden in Iran seit langem die politische Macht übernommen hatten. W. Hinz jedenfalls weist auf die immensen Mengen an Lebensmitteln hin, die die Küchen am Anfang des 17. Jh. unter 'Abbās I. (reg. 1587-1629) zur Verköstigung der Besucher benötigten. Gemäss seinen Berechnungen handelt es sich u.a. um 142'50okg Reis, 57'oookg Fleisch und $855 \mathrm{o} \mathrm{kg} \mathrm{Salz.} .25$

423 Für die folgenden Ausführungen vgl. den Plan der Anlage bei Hinz, Aufstieg, zwischen S. 18 und 19 eingefügt; siehe ausserdem die Pläne bei Rizvi, op. cit. Fig. 1 (S. 29) und Fig. 7 (S. 47).

424 Hinz, Aufstieg 19 mit Anm. 1, wo Verweis auf Šayh Ḥusayn b. Šayh Abdāl Pīrzāda Zāhidī, Silsilat un-nasab-i Safawiyya 36-38.

425 Hinz, Aufstieg 18 mit Anm. 3, wo Verweis auf Šayh Ḥusayn b. Šayh Abdāl Pīrzāda Zāhidī, Silsilat un-nasab-i Şafawiyya 111.
Das Heiligtum in Ardabil ist in den letzten Jahrzehnten zunehmend besser erfasst worden. ${ }^{426}$ Auch Forscher aus dem Westen haben sich wiederholt damit auseinandergesetzt. F. Sarre hat die Bauten im Jahr 1897 photographisch dokumentiert und vermittelt einen ausgezeichneten Einblick in den Zustand der Anlage zu jener Zeit.427 Von Jacques de Morgan stammt weiteres Abbildungsmaterial. Es zeigt das Heiligtum vor den um die Mitte des 20. Jh. unternommenen Renovationsarbeiten. ${ }^{428}$ In jüngerer Vergangenheit haben sich A.H. Morton ${ }^{429}$ und K. Rizvi mit der Anlage befasst. ${ }^{430}$ Diese Vorarbeiten erleichtern die Auseinandersetzung mit den textlichen und gestalterischen Mitteln, die bei der Ausschmückung dieses Schreins eingesetzt worden sind. ${ }^{431}$ Zwar sind viele dieser Verzierungen und Inschriften im Lauf der Zeit repariert oder ersetzt worden. Dennoch bleibt eine beachtliche Anzahl von Stellen übrig, die auf die Zeit der Errichtung der jeweiligen Gebäude selbst zurückgeht. ${ }^{432}$

Den weiteren Ausführungen ist die Bemerkung vorauszuschicken, dass Schreine zwar durchaus als Zentren eines traditionalistisch orientierten Islams dienen konnten. Sie fungierten aber in erster Linie als Orientierungspunkte für Kreise, deren Glaubensauffassungen sich von der normativen Lehre unterscheiden. Dazu zählen die Anhänger

426 Rizvi, op. cit. 16 (mit Anm. 36, S. 213). Erneute Aufmerksamkeit hat der Schrein seitens der iranischen Behörden bei der Vorbereitung von dessen Aufnahme ins Unesco-Weltkulturerbe erfahren (siehe Anm. 420).

Die Resultate dieser Erfassungen wurde 1910 und 1924 publiziert. Sie enthalten wichtiges Abbildungsmaterial, das den Zustand des Heiligtums am Ende des 19. Jh. dokumentiert; vgl. die Quellenangaben in Anm. 420. de Morgan, Mission scientifique I, 338-345 (und Index, s. v. „Ardébil“, S. 406); Tafeln LI-LIV. Rizvi, op. cit.

Rizvi, op. cit. 16 (mit Anm. 37, S. 214, mit Literaturangaben). Für das Entziffern der im Innern und auf den Fassaden des Heiligtums ausgeführten Inschriften kann ausserdem auf die Veröffentlichungen von Sayyid Ğamāl Turābī-Ṭabtabā’ī hingewiesen werden (Quellenangaben bei Rizvi, loc. cit.). 
von Derwischorden. Bei den der Propagierung des normativen Islams dienenden Stätten handelt es sich vornehmlich um Moscheen und Madrasen. Sie sind mit dem Studium der islamischen Theologie in Verbindung zu bringen.

K. Rizvi vertritt die Auffassung, dass die Architektur in derartigen Zentren zwar den Zielen ihres aus der Elite stammenden Stifters verpflichtet ist. ${ }^{433}$ Es zeigt sich aber auch, dass die in diesen Stätten von den breiten Massen praktizierten Rituale mit den Glaubensvorstellungen des normativen Islams in mehrfacher Hinsicht in Widerspruch standen. Es lassen sich in derartigen Konventen immer wieder Gegensätze zwischen der formellen und informellen Inszenierung des Glaubens feststellen. K. Rizvi spricht von der Spannung zwischen doxis und praxis, zwischen institutionalisiertem Glauben und dessen öffentlichen Inszenierung. Bei der formellen Inszenierung kann es sich z.B. um den Widmungstext handeln, der im Bauwerk angebracht worden ist. Im Heiligtum selbst können aber durchaus auch antinomistische Rituale praktiziert werden. ${ }^{434}$

In Ardabil fallen die folgenden Bauten besonders auf: Noch aus Ṣafī ud-Dīns Lebzeit stammt das als Haram-ḩāna bekannte Grab Muhiyy udDīns, des ältesten, vorverstorbenen Sohns von Šayh Șafī ud-Dīn. ${ }^{435}$ Vieles spricht dafür, dass der Šayh selbst diesen Bau ganz am Anfang des 14. Jh. veranlasst hat. ${ }^{436} \mathrm{Im}$ Innern läuft ein Schriftband mit Q 57:26-27 und Angaben zum hier bestatteten Muhiyy ud-Dīn der Basis der Kuppel entlang. ${ }^{437}$ Muhiyy ud-Dīns Grab selbst befindet sich heute nicht mehr in dieser Anlage. Neben weiteren Gräbern sollen sich aber in diesem Bau anfäng-

433 Op. cit. 6.

434 Op. cit. 6 (mit Anm. 12, S. 212), wo Verweis auf Karamustafa, God's unruly friends. Auch Bashir, Shah Isma'il and the Qizilbash cannibalism. Rizvi, op. cit. 42-46 (mit Fig. 4-6).

436 Einzelne Verzierungen an diesem Grabturm lassen sich mit solchen im Schrein von Nūr ad-Dīn 'Abd aṣ-Ṣamad in Natanz vergleichen; siehe bei Anm. 408-410.

437 Rizvi, op. cit. 42-46 (mit Anm. 68), wo Verweis auf Morton, Ardabil shrine. lich noch jene von Bībī Fāṭima, der Ehefrau des Šayhs, und von ihrer gemeinsamen Tochter befunden haben.

Es war Șadr ud-Dīn (Ordensvorsteher: 13341392), der die Errichtung des Grabturms zu Ehren seines verstorbenen Vaters in dessen Konvent selbst in Auftrag gegeben hatte. ${ }^{438}$ Šayh Șadr ordnete auch die Erweiterung des Schreins an und gab die Biographie seines Vaters in Auftrag. Sie wurde von Ibn al-Bazzāz im Jahr 1358 beendet und ist unter dem Titel Șafwat uṣ-Ṣafä bekannt. 439 Ṣafĩ ud-Dīn hatte zwar andere Wünsche bezüglich seiner Grabstätte geäussert. Șadr ud-Dīn entschloss sich nach Rücksprache mit Geistlichen und den Ordensältesten aber dazu, seinen Vater in dessen ehemaligem Halwat-hāna zu bestatten. Es war bereits zu Lebzeiten des Ordensgründers der Fokus des Heiligtums und blieb dies trotz seiner modifizierten Funktion auch nach seinem Tod.

Der Beschreibung bei Ibn al-Bazzāz lässt sich entnehmen, dass das Grab mit einer Kuppel versehen war. Gemäss einer späten Quelle aus dem 18. Jh. soll Șadr ud-Dīn das Grab zwischen 1335 und 1345 errichtet haben. ${ }^{440}$ Überdies soll sich Șadr ud-Dīn um die Beleuchtung im Heiligtum gekümmert und das Halwat-hāna neu errichtet haben. Er habe Koranrezitatoren angestellt, die auch für das Abhalten der täglichen Gebete im Heiligtum verantwortlich waren. Șadr ud-Dīn stellte überdies Diener an, die sich um den Unterhalt des Schreins kümmerten.

Auf der südwestlichen Seite wird Šayh Șafī udDīns Grabturm durch einen Nebentrakt ${ }^{441}$ mit der Dār ul-huffāz verbunden. Grabturm und Haramhâna werden von einem grossen Friedhof umgeben, der unter dem Namen Šahìdgāh bekannt ist.

438 Rizvi, op. cit. 46, und Fig. 7: mit Übersicht über das Heiligtum um 135 .

439 Zu Ibn al-Bazzāz' Șafwat uṣ-Ṣafā siehe Savory, Ebn Bazzāz, in EIr.

440 Rizvi, op. cit. 46 (mit Anm. 72), wo Verweis auf Šayh Ḥusayn b. Šayh Abdāl Pīrzāda Zāhidī, Silsilat un-nasab-i Safawiyya 39 .

441 Dieser Trakt ist heute als Šāhniš̄nn (königliche loggia) bekannt; vgl. Rizvi, op. cit. 46. 
Der Grabturm wurde aus Backsteinen errichtet und erreicht eine Höhe von $17.5 \mathrm{~m} .{ }^{442}$ Der Turm ist mit neutralen und türkisfarbenen Backsteinen belegt, die in geometrisierendem Kūfĩ in grosser Schrift den Namen Allāh bilden. Der Ausdruck Allāh ist jeweils ca. $1 \mathrm{~m}$ lang und konnte auch aus der Ferne erkannt werden. ${ }^{443}$ Er wurde am Turm insgesamt $132 \mathrm{Mal}$ angebracht. ${ }^{444}$

Zusätzlich lassen sich am Bau weitere Textstellen erkennen. Unterhalb des Übergangs des zylindrischen Körpers des Turms zur Kuppel befindet sich ein breites Band mit einer Inschrift in weissem Tulut auf einem Hintergrund mit einem Rankenmuster. ${ }^{445}$ Ein schmales Band aus blauen, weissen und braunen Fliesen fasst das Qibla-Tor des Grabturms ein. ${ }^{446}$ In diesen Rahmen sind eine Reihe von sechseckigen Zierelementen mit Text eingepasst. Am Qibla-Tor fällt zusätzlich das Schriftband auf, das den Eingang mit grossem, weissem Text in Tulut (innen) und schmalem Kūfî (aussen) einfasst. Diese Textbänder enthalten Verse aus dem Koran, die die Grundaspekte des islamischen Glaubens thematisieren. Es handelt sich um Hinweise auf die Einheit und Einzigartigkeit Gottes und die Vergänglichkeit des Lebens im Diesseits. ${ }^{447}$

Auch im Innern des Grabturms lassen sich Textstellen nachweisen. Zuerst ist allerdings auf den achteckigen Grundriss dieses Baus hinzuweisen. ${ }^{448}$ An der Basis des Übergangs zur Kup-

442 Siehe https://archnet.org/sites/1595/media_contents/4 o811 (Stand 6. September 2017).

Für eine Abbildung vgl. Rizvi, Shrine 47 (Fig. 8), S. 198. Gemäss einem Medaillon auf der Aussenwand des Turms wurde der Bau von 'Iwad b. Muhammad alMarāgī errichtet (K. Rizvi liest 'Awḍ anstelle von 'Iwaḍ).

Anhang B, 198-209. Siehe auch Safavi, Hermeneutic approach 6. Bei den Stellen in weissem Tulut handelt es sich um Q 6, Verse 79 und 162-163, sowie Q 17:8o. In blauem Küf $\imath$ wurde die folgende Stelle kopiert: Q 4:95 (vgl. Abb. 6 bei H. Safavi).

448 Dieser Gebetsraum war ursprünglich mit einer Kup- pel befindet sich im Innern ein Schriftband, auf dem die ganze Sure 48 (Sürat al-Fath, „Der Sieg“) in Schachbrettkufi kopiert worden ist. ${ }^{449}$ Zuoberst in der Kuppel wurde ein Strahlenmedaillon wohl direkt auf weissem Grund angebracht. Šayh Ṣafĩ ud-Dīns Sarg befand sich früher zusammen mit zwei weiteren Särgen im Innern des Turms. ${ }^{450}$

Der Besuch von Șafî ud-Dīns Grab stellte den Höhepunkt jeder Pilgerfahrt nach Ardabil dar und wurde als ritueller Akt verstanden. Der Anblick des Gebäudes veranlasste die Besucher unwillkürlich, Šayh Șafì ud-Dīns zu gedenken und ihre innere Kraft auf ihn auszurichten. Sowohl das Errichten als auch das Besuchen einer Stätte, wo einer heiligmässigen Person gedacht wird, stellten einen Akt der Frömmigkeit dar. Schreine wichtiger heiligmässiger Personen wie jener von Šayh Ṣafī udDīn wurden gern mit der Ka ba in Mekka gleichgesetzt. Die Pilgerfahrt dorthin, im vorliegenden Fall also nach Ardabil, galt als rituelle Pflicht. ${ }^{451}$ Die Pilger konnten hier das Grab des ȘafawiyyaŠayhs umschreiten (tawāf), wie ihnen das auch im Fall des haǧğ in Mekka vorgeschrieben war. ${ }^{452}$

pel versehen. Neben der Kanzel dieser Moschee war eine angeblich von der Prophetentochter Fāțima angefertigte Fahne zur Schau gestellt worden, die Sadr udDīn um 1380 aus Medina zurückgebracht hatte. Teil der Anlage ist sodann eine mit einer Kuppel versehene Grabstätte, die als Gunbad-i haram bekannt ist. Hier ist Bībī Fāțima, die Gattin Šayh Șafĩ ud-Dīns und Tochter von dessen Lehrer Šayh Zāhid-i Gīlānī, bestattet. Sie war 1324, also zehn Jahre vor Šayh Șafī ud-Dīn selbst, gestorben. Direkt neben den beiden Grabtürmen des Ordensgründers Šayh Șafī ud-Dīn und seiner Gattin Bībī Fāțima wurde später auch der Grabturm des 1524 verstorbenen Šāh Ismāīil errichtet. So gemäss Sarre, Ardabil 16. Rizvi, op. cit. 48, mit Tafel 5 und Anhang B, 199. Loc. cit. 48 (mit Fig. 9-10). Op. cit. $5^{1}$ (mit Anm. 78, S. 219), wo Verweis auf ein Gedicht Qāḍī Ahmmads, der den Schrein Ṣafĩ ud-Dīns als Ka'ba und Ort des tawāf bezeichnet (Кт 617). Rizvi, op. cit. 48. Hinweise auf den Besuch (ziyāra) von Heiligengräbern finden sich bei Taylor, In the vicinity of the righteous 72-79 (Chapter 2: „The ziyāra“), und Ernst, Sufi shrine pilgrimage 43-67 (ganzer Artikel). 
C.H. Imber macht darauf aufmerksam, dass Ardabil als qibla der Safawiden galt. ${ }^{453}$

In unmittelbarer Nachbarschaft von Șafī udDīns Grab steht die Dār ul-huffāz, das Haus der Koranrezitatoren. Eine Stelle in Ibn al-Bazzāz' Șafwat uṣ-Ṣafā legt nahe, dass Ṣadr ud-Dīn dieses Gebäude einige Jahre nach dem Grabturm für seinen Vater errichtet und so zusätzlichen Platz für Koranrezitatoren und Pilger geschaffen hat. ${ }^{454}$ Auch dieses Gebäude ist reich mit Inschriften versehen. ${ }^{455}$ Die hier kopierten Textstellen weisen u.a. auf die Funktion des Gebäudes hin, das in Übereinstimmung mit seiner Bezeichnung als Ort für Koranrezitationen diente. ${ }^{456}$ Der Saal in der Dār ul-huffäz diente als Vorraum zum Grab Šayh Șafì ud-Dīns. Seine Architektur und aufwendige Gestaltung beeindruckten die Pilger bei ihrem Zugang zum Grabturm. Zitate einiger Inschriften sollen einen Eindruck vom frommen Inhalt der kopierten Stellen vermitteln: ${ }^{457}$

[The Dār ul-ḥuffāz] was set up as meeting place (majlis) for his exaltation, the saint, and planted as a tree of goodness whose roots are firm and its branches [reach] in the sky. It is for the recitation of the Qur'an and is surrounded by God's angels.

Oh Lord! Revive us by the Qur'an and perish us by the Qur'an, and resurrect us by the Qur'an and permit us [on] the path by the Qur'an and [allow] our entrance into Paradise by the Qur'an and [let there be] no separation between us and between the Qur'an. Oh Lord! Bless our recitations from your book toward the spirit of our fathers and our mothers and toward the

453 Imber, Persecution 247; siehe auch Eberhard, Osmanische Polemik 101-104.

454 Zur Dār ul-ḥuffāz vgl. Rizvi, op. cit. 52-55 (mit Fig. 1112); siehe auch Anm. 81 (S. 219), wo Verweis auf Ibn alBazzāz' Safwat us-Safā 989 .

Vgl. Rizvi, op. cit., Anhang B, 200-203, hat die Übersetzungen dieser Inschriften zusammengestellt. Neben frommen Aussagen finden sich darunter auch zahlreiche Koranstellen.

456 Rizvi, op. cit. 53 und Tafel 6.

457 Op. cit. 53. spirits of the inhabitants of the graves, [by the] intervention of the Prophet of God.

Die weiteren auf dem Gebäude angebrachten Textstellen sind ebenso frommen Inhalts. Es wird hier ausführlicher auf diese Inschriften hingewiesen, da die Dokumente in Rollenform zahlreiche ähnliche Texte enthalten. In diesem Zusammenhang wird daran erinnert, dass Dikr- und Sama $\bar{a}^{c}$ Übungen in Sufi-Orden eine wichtige Rolle spielen; darauf ist sogleich näher einzugehen. Zusammenkünfte, bei denen Texte des soeben angeführten oder ähnlichen Inhalts rezitiert werden, prägen das spirituelle und intellektuelle Leben der Sufis. ${ }^{458}$

Der Vollständigkeit halber und mehr im Vorbeigehen sei hier noch festgehalten, dass der bedeutendste Ausbau des Ardabiler Heiligtums erst relativ spät, unter Šāh Ṭahmāsp (reg. 1524-1566), stattfand. Šāh Ṭahmāsp errichtete im rechten Winkel zur Dār ul-huffāz zwei weitere Gebäude, nämlich eine Dār ul-hadīt und den Ğannat-Sarā (Paradiespalast). Da man das Čilla-hāna mit Šayh Ṣafī ud-Dīn selbst in Verbindung brachte, wurde es von späteren Bauherren stets respektiert. Aus textlichen Quellen ist bekannt, dass um den Schrein herum selbst auch Küchen, Bäckereien, eine madrasa errichtet und öffentliche Gärten angelegt wurden. Diese Nebengebäude sind allerdings nicht erhalten geblieben. Bereits damals lag der ganze Komplex inmitten von Wohnvierteln im Herzen der Stadt Ardabil.459

\subsubsection{Spirituelle Übungen und Techniken}

In diesen Männerbünden wurden während der Zusammenkünfte oft spezifische Techniken und spirituelle Übungen gepflegt. Sie zielten darauf ab, den Adepten das Erfahren mystischer Erlebnisse zu erleichtern. Diese Praktiken können hier nicht in extenso vorgestellt werden; dies geschieht in den Handbüchern der einzelnen Orden. Es ist hingegen angezeigt, in allgemeiner Form auf drei

458 Rizvi, op. cit. 53; siehe zur Frage auch Kapitel 3.4.2.

459 Rizvi, op. cit. 13. 
Methoden sufischer Selbstdisziplin ausführlicher einzugehen, nämlich auf a. die halwa, b. den $\underline{d i k r}$ und c. den samāc.

a. Beim Ausdruck halwa handelt es sich um einen terminus technicus. ${ }^{460}$ Er leitet sich vom Verb halā, „allein sein“, ab und bedeutet „Rückzug, Zurückgezogenheit“. Er bezeichnet den Rückzug in eine Zelle, wo der Mystiker spirituelle Übungen ausführt. Dieser Rückzug stellt ein wesentliches Element der Askese (zuhd) dar und ist unter den Sufis weitherum bekannt. Bei der Entwicklung dieser Technik spielten möglicherweise ähnliche Erfahrungen aus dem Christentum eine Rolle. Gewiss ist jedenfalls, dass bereits frühe Mystiker, darunter D̄ū n-Nūn al-Mișrī (gest. 245/86o), die Vorzüge der halwa erkannt hatten. Auch der Sufi Abū Bakr aš-Šiblī (gest. 334/945) äussert sich positiv dazu. Berichte bei Qušayrī (Risāla) lassen allerdings darauf schliessen, dass bereits frühe Sufis der Pflege der Gemeinschaft neben einem Leben in Zurückgezogenheit ('uzla) ebenso grosse Bedeutung zuschrieben. Vieles spricht jedenfalls dafür, dass der Rückzug vorübergehend war und in der Realität keine ständige Isolation geübt wurde. Überhaupt scheint das Leben in der Gemeinschaft mit der Zeit für die grosse Mehrzahl der Mystiker an Bedeutung gewonnen zu haben.

Im nachklassischen Sufismus ist die Situation weitgehend dieselbe, wie sich anhand der Darstellung in Abū Hafṣ 'Umar as-Suhrawardīs (gest. 632/1234) 'Awārif al-ma'ārif aufzeigen lässt. ${ }^{461}$ Demnach soll das Leben in der Gemeinschaft den Sufi vom Asketen unterscheiden. Das Leben in Gemeinschaft sei vorzuziehen, laufe man aufgrund der Beobachtung durch die Mitbrüder doch weniger Gefahr, allfälligen Versuchungen zu erliegen. Allerdings rät Suhrawardī den Sufis auch in der Gemeinschaft dazu, sich im Konvent (ribāț) in Zurückgezogenheit zu üben. Dabei diente dem

46o Vgl. Landolt, Khalwa, in $E I^{2}$; siehe ausserdem Knysh, Islamic mysticism $314-317$, der sich weitgehend auf H. Landolt stützt.

461 Es handelt sich um das Hauptwerk des soeben vorgestellten Suhrawardī, auf den die Suhrawardiyya letztlich zurückgeht.
Sufi sein Gebetsteppich als Rückzugsort. In den Konventen existierten aber auch Zellen für den individuellen Rückzug. Suhrawardī beschreibt dies in den 'Awārif al-ma'ārif in drei Kapiteln. Neben der Suhrawardiyya weisen auch weitere Sufiorden der halwā einen hohen Stellenwert zu. Dazu zählen die Kubrāwiyya, die Šādiliyya, die Qādiriyya und die Halwatiyya, die ihren Namen von dieser Technik ableitet.

Bei der halwa übt sich der Mystiker im Grossen Heiligen Krieg (ğihād kabīr). Er bleibt nachts wach, fastet lange und verrichtet Dikr-Übungen. Beim Betreten der halwa soll man rituell rein sein. Auch erinnere das Betreten der halwa an das Eingehen ins Grab. Die Zelle soll dunkel sein, damit man seine inneren Sinne aktiviere und sich von den äusseren Wahrnehmungen zurückziehe. Allerdings wird wiederholt auch davor gewarnt, diesen inneren Wahrnehmungen einen zu hohen Stellenwert zuzuweisen. Das eigentliche Ziel der halwa bestehe im Erleben des dikr der göttlichen Wesenheit im Rahmen einer konsubstantiellen Erfahrung. 462

Die institutionalisierte Form dieses Rückzugs ist als arbaīniyya (arabisch) bzw. čilla (von čihil, persisch) bekannt und dauert vierzig Tage. Die halwa soll jeweils nur für das gemeinsame Ritualgebet unterbrochen und alljährlich wiederholt werden. Sie erinnert den Mystiker an die Erfahrung des Propheten Muhammad, der sich in einer Höhle auf dem Berg Hirā’ bei Mekka zurückgezogen hatte, bevor ihm die ersten Teile des Korans offenbart wurden.

b. Während seines Rückzugs übt sich der Mystiker gern in der Praxis des $\underline{d} i k r$. Der Ausdruck dikr ${ }^{463}$ bedeutet grundsätzlich „Erwähnung“, wobei damit die Erwähnung des Namens bzw. der Beinamen Gottes ${ }^{464}$ gemeint ist. Die Teilnehmer füh-

462 Vgl. dazu die Übersetzung bei Gramlich, Die Gaben der Erkenntnisse 193-210; arabische Ausgabe Beirut 1966: 207-227.

463 Vgl. Meier, Der Derwischtanz; During, Musique et rite: le samâ'; Lewisohn, The sacred music of Islam.

464 Sie sind als die Schönsten Namen Gottes (al-asmā alhusnā) bekannt; siehe zu diesem Konzept Anawati, Le 
ren diese Übungen in der Form von Litaneien aus und tun dies oft bis zu einem Zustand der Erschöpfung oder Verzückung.

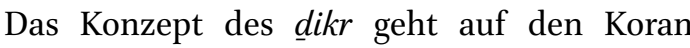
zurück. ${ }^{465}$ In der späteren Sufitradition stellten Dikr-Rezitationen einen rituellen Akt dar. Er zielte darauf ab, den Menschen an Gottes Gegenwart in dieser Welt zu erinnern. Oft praktizierten die Mystiker den $\underline{d}$ ikr für sich allein. Es ist aber auch bekannt, dass eigentliche Dikr-Veranstaltungen (mağlis ad- $\underline{d}$ ikr) organisiert wurden. Gerade im zweiten Fall nahmen diese Rezitationen die Form von Litaneien an, die im Rahmen von speziellen Riten und verbunden mit bestimmten Körperbewegungen gesungen wurden. Diese Riten konnten auch tanzähnlichen Charakter haben (vgl. Mawlawiyya). Die Forschung hat wiederholt auf ähnliche Übungen in andern religiösen Bekenntnissen aufmerksam gemacht. ${ }^{466}$

Die technischen Einzelheiten dieser DikrÜbungen unterscheiden sich von Orden zu Orden. Muhammad as-Sanūsī, der Begründer der Sanūsiyya (gest. 1276/1859), stellte in seinem Werk asSalsabïl al-muìn fì t-țarāiq al-arbaīn die wesentlichen Aspekte der Dikr-Übungen von vierzig verschiedenen Bruderschaften zusammen. ${ }^{467}$ Er gibt an, dass die Sanūsiyya die Nachfolgerin all dieser vierzig früheren Orden sei und die zentralen Elemente aus deren jeweiligem $\underline{d i k r}$ in ihre eigenen Übungen integriert habe.

nom suprême de Dieu. Zu den Schönen Namen Gottes siehe auch Canaan, Decipherment $135^{-136}$; Bain, The late Ottoman En'am-ı Şerif 59-61. Die Schönen Namen Gottes spielen auch bei Būnī (gest. 1225 oder 1232) eine wichtige Rolle; vgl. el-Gawhary, Die Gottesnamen.

465 Vgl. Q 18:24 und Q 33:41. Zur Bedeutung des dikr in der islamischen Mystik siehe ausserdem Anawati und Gardet, Mystique musulmane 187-194. Beachte für die folgenden Ausführungen v.a. auch Knysh, Islamic mysticism 317-322.

466 Knysh, Islamic mysticism 317 f., macht im Vorbeigehen aufmerksam auf das Jesus-Gebet der Mönche im SinaiKloster und auf dem Berg Athos. Ähnliche Rituale sind aus Indien ( japa-yoga) und Japan (nembutsu) bekannt.

467 Anawati und Gardet, Mystique musulmane $202 \mathrm{f}$.
Grundsätzlich lässt sich zwischen dem lauten $\underline{d i k r}(\underline{d} i k r \breve{g} a l \bar{\imath})$ und dem leisen $\underline{d i k r}(\underline{d} i k r$ hafì) unterscheiden. Der laute $\underline{d} i k r$ wurde in der Regel gemeinsam ausgeübt. Der leise $\underline{d} i k r$ hingegen wurde hauptsächlich vom einzelnen Mystiker im Rahmen seiner Übungen und zur Selbstdisziplinierung praktiziert. Verschiedene Bruderschaften betonen die Bedeutung des leisen $\underline{d} i k r$ (z. B. die Šādililiyya, Halwatiyya und die Darqāwiyya); dies sei die Dikr-Form der Eliten (dikr al-hawāṣss).

Kollektive Dikr-Veranstaltungen haben oft einen ritualisierten, liturgie-ähnlichen Charakter. Am Anfang von derartigen Zusammenkünften werden zumeist Koranverse oder Gebete rezitiert, die der Ordensgründer verfasst hatte. Solche Rezitationen werden in der Regel hizb (Pl. $a h z \bar{a} b)$ oder wird (Pl. awrād) genannt. Zu den allgemeinen Voraussetzungen für das Abhalten des $\underline{d} i k r$ gehört, dass man der Welt entsagt und sich für einen asketischen Lebensstil entschieden hat. Dies ist wiederum an die Bedingung geknüpft, dass man zuvor seine aufrichtige Absicht (niyya) formuliert hat. Beim Ausüben des individuellen $\underline{\text { dikr }}$ ist der Sufi gehalten, sich gänzlich von seiner Umgebung zu lösen und sich das Bild seines šayhs vor seinem inneren Auge zu vergegenwärtigen.

Die beim $\underline{d i k r}$ rezitierten Formeln unterscheiden sich nicht nur von Orden zu Orden. Sie sind ebenso vom individuellen Stadium abhängig, das der einzelne Sufi erreicht hat. Der $\underline{d} i k r$ beginnt zumeist mit einem Bekenntnis der Einheit und Einzigartigkeit Gottes (erster Teil der šahāda: $L \bar{a}$ ilāha illā Allāh). Die Šādiliyya empfiehlt, die Rezitation auf der linken Seite der Brust zu beginnen. Diese Körperseite wird als jene Nische beschrieben, in der sich die Lampe des Herzens und das geistige Licht befinden. Der Adept soll die Formel beim Rezitieren aus dem unteren Teil der Brust nach oben ziehen und sie danach zur Ausgangsstellung zurückführen. Die Dikr-Formel beschreibt also einen Kreis in der Brust des Adepten.

Die Dikr-Übung baut gern auf dem Begriff Allāh auf. ${ }^{468}$ Dies ist eigentlich die häufigste Dikr-

468 Gardet und Anawati, Mystique musulmane 200-203. 
Formel. Das Aussprechen des Namen Gottes wird von zwei Bewegungen begleitet. Beim Aussprechen soll man zuerst das Kinn auf die Brust senken. Danach soll man den Namen Allāh in zwei Teilen aussprechen, also zuerst die Silbe $a$ (bzw. das hamza). Darauf soll man den zweiten Teil des Namens (llāh) aussprechen. Der Adept ist gehalten, den Kopf bis zum Nabel zu senken und wieder hochzuheben. Seine Bewegungen sollen einem Rhythmus folgen.

Verbreitet ist sodann jene Form des $\underline{d i k r}$, die auf Hallāğ und seine Anhänger zurückgeht. Sie besteht darin, das al in Allāh wegzulassen, was den Dikr-Ruf auf lāha, lāhi, lāhu reduziert. Sanūsī allerdings rät zu Zurückhaltung beim Rezitieren dieser Spielart. Man müsse sich allfälliger negativer Konsequenzen dieses dikr bewusst sein. Viele Dikr-Formeln bauen auch auf einem der Schönen Namen Gottes (al-asmā'al-husnā) auf, z.B. al-Haqq, al-Hayy, al-Qayyūm, al-Qahhār, oder einfach auf dem Ausdruck huwa.

Die Dauer der Dikr-Übung kann vom šayh bestimmt werden, der die Veranstaltung leitet. Beim individuellen dikr obliegt es dem einzelnen Sufi, die Dauer festzulegen; er kann beim Rezitieren einen Rosenkranz (subha) benutzen. Die Anzahl der Wiederholungen der Dikr-Formel variiert; es kann sich um 300, 3'ooo, 6'ooo, 12'ooo oder sogar 7o'ooo Wiederholungen handeln. Wenn der Adept die Übersicht über die bereits rezitierten Einheiten verliert, redet man von einem endlosen oder auch spontanen dikr.

Ibn 'Ațā' Allāh, der dritte bedeutende ŠādiliyyaMeister (gest. 709/1309 in Kairo), ${ }^{469}$ geht in seinem Werk Miftāḥ al-falăḥ auf die bedeutenden Aspekte des individuellen dikr ein, indem er sich auf Aussagen früherer Mystiker beruft. ${ }^{470}$ Gemäss Ibn 'Ațā' Allāhs Ausführungen unterscheiden die meisten Mystiker beim $\underline{\text { dikr }}$ drei Phasen. Beim ersten Stadium handelt es sich um den dikr der Zunge,

469 Makdisi, Ibn 'Ațā' Allāh, in $E I^{2}$.

470 Vgl. für die weiteren Ausführungen Knysh, Islamic mysticism 32of.; Anawati und Gardet, Mystique musulmane $195 \mathrm{f}$. der mit aufrichtiger Gesinnung rezitiert werden soll. Während dieser Phase bemüht sich der Adept darum, dem Einen, also Gott, einen Sitz in seinem Herzen zu geben. Er respektiert jene Vorgaben, die ihm sein šayh auferlegt hat. Im Idealfall geht die Rezitation in ein spontanes und anhaltendes Rezitieren über. Während dieser Phase lassen sich allerdings immer noch drei Aspekte unterscheiden. Es handelt sich einerseits um den rezitierenden Adepten ( $\underline{d} \bar{a} k i r)$, der sich seines individuellen Handelns bewusst ist. Anderseits bildet der Akt des Rezitierens ( $\underline{d} i k r)$ Teil der Erfahrung. Und drittens lässt sich der Eine unterscheiden, der bei der Übung erwähnt wird ( $m a d k u \bar{r} r)$.

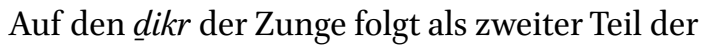
dikr des Herzens. Gemäss Ġazzālī hat der Mystiker in dieser zweiten Phase einen Punkt erreicht, an dem nicht mehr die Zunge, sondern das Herz die $\underline{D} i k r$-Formel rezitiert. Dieses Stadium lässt sich seinerseits in zwei Unterabschnitte einteilen. Der Adept muss anfänglich noch viel Aufmerksamkeit auf das Aussprechen der Formel verwenden. Er kann in seinem Herzen auch einen physischen Schmerz wahrnehmen. Die Rezitation sollte jedoch bald ohne Anstrengung gelingen, nachdem die Formel Teil des natürlichen Herzschlags geworden ist. Der Name Gottes pulsiert jetzt im Einklang mit dem Herzschlag und dem Fliessen des Blutes durch den Körper. Er lässt sich weder als Wort noch innerlich wahrnehmen.

Dieser Zustand stellt zugleich den Ausgangspunkt für den dritten Abschnitt der Dikr-Rezitation dar. Er ist als dikr as-sirr, als dikr des innersten Herzens, bekannt. In dieser Verfassung erreicht der Mystiker den Zustand der direkten Schau Gottes und erlebt die Vereinigung (tawhìd) mit Gott. Dabei wird jegliche Dualität überwunden.

Die Sufi-Autoren weisen dem Ausüben des dikr unterschiedliche Bedeutungen zu. Hallāğ (gest. 309/922) und Kalābādīī (gest. 38o/99o oder 384/994) verstehen den $\underline{\text { dikr }}$ in erster Linie als Methode, bei der sich der Adept an Gott erinnert und sich auf ein Leben in Gottes Gegenwart ausrichtet. Für Ġazzālī (gest. 505/1111) wiederum öffnet der $\underline{d i k r}$ den Sufi für das Empfangen von Got- 
tes Barmherzigkeit. Ibn 'Ațā' Allāh (gest. 709/1309) seinerseits erkennt im dikr nicht einfach eine Vorstufe auf dem mystischen Pfad. Er betrachtet den dikr vielmehr als Technik, die direkten Zugang zum Bereich der göttlichen Geheimnisse (lāhüt) verschafft. Spätere Autoren befassen sich in erster Linie mit technischen Aspekten des dikr. Sie äussern sich u.a. zur Stimmlage, zu Atemtechniken oder den Körperstellungen.

Psychologisch betrachtet zielt das Ausüben des dikr darauf ab, dass der Praktizierende seine gesamte Konzentration und seine Absichten auf das Objekt der Erinnerung ausrichtet. ${ }^{471}$ Der Suchende kann auf diese Art eine direkte Begegnung mit Gott verwirklichen und erkennt die Geheimnisse des Daseins. Randgruppierungen haben gelegentlich Drogen benutzt, um derartige Zustände herbeizuführen. Solche Praktiken trugen der Sufibewegung Kritik ein. Sie stammte gerade aus dem Lager der traditionalistisch ausgerichteten Theologen. ${ }^{472}$

c. Erwähnung verdient mit dem samāc ausserdem eine weitere Technik, die den Adepten ebenso wie der $\underline{d i k r}$ für eine Begegnung mit dem Göttlichen öffnet. ${ }^{473}$ Beim Ausdruck sama $\bar{a}^{\varsigma}$ handelt es sich morphologisch um ein Verbalnomen (mașdar) zum Verb samica. Der Ausdruck bedeutet „das Hören“, kann sekundär aber auch „das Gehörte“, z. B. Musik, bezeichnen.

F. Meier unterscheidet zwar $\operatorname{dikr}$ und $\operatorname{sama} \bar{a}^{c}-$ zumindest theoretisch - voneinander. ${ }^{474}$ Gemäss seiner Darstellung ruft der Ausübende beim dikr seine eigenen Kräfte auf. Beim samā hingegen erwarte er den Anstoss zum Erlebnis von aussen.

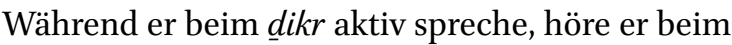
samā einfach zu. Das Ausüben des dikr ist zu jeder Tages- und Nachtzeit erlaubt. Gerade als Konzentrationsformel bildet es in der Klausur einen zen-

471 Knysh, Islamic mysticism 322.

472 Man beachte zum dikr ausserdem Meier, Derwischtanz.

Für die weiteren Ausführungen vgl. During, Samā', in $E I^{2}$; ders., Musique et rite: le samâ'; Meier, Derwischtanz; siehe auch Knysh, Islamic mysticism, 322-325. tralen Baustein im Lehrgang des Sufis. Der samāc dagegen sei beinahe immer einfach eine Ermächtigung ( ruhșa) gewesen und habe oft Unterhaltungscharakter gehabt. Allerdings lassen sich auch Konvergenzen zwischen den beiden Übungen feststellen, zielen sie doch beide auf die Befreiung von der Last des Körpers ab. Jedenfalls lassen sich bei beiden Methoden unter den Beteiligten ekstaseähnliche Zustände beobachten.

F. Meier gesteht allerdings ein, dass die beiden Elemente $\underline{\text { dikr }}$ und sama $\bar{a}^{\mathrm{c}}$ beim Derwischtanz unter diesem Oberbegriff behandelt er die beiden Praktiken - gegebenenfalls miteinander verbunden werden. ${ }^{475}$ Er unterscheidet dabei einen ersten Typ, bei dem der dikr (Gottgedenken), dem samā' (Musikhören), ein- oder vorgebaut, jedenfalls aber untergeordnet ist. Beim zweiten Typ jedoch ist der sama $\bar{a}^{c}$ dem dikr ein- und untergeordnet.

F. Meier verdeutlicht die erste Spielform, ${ }^{476}$ indem er auf Aussagen Aḥmad Ġazzālīs (gest. 520/1126) hinweist. Demnach seien SamācVeranstaltungen häufig in Anschluss an das rituelle Gebet abgehalten worden. Man habe aber ohne weiteres auch Koran- und Dikr-Rezitationen einschieben dürfen. Der sama $\bar{a}^{c}$ habe nach $\mathrm{Ab}$ schluss dieser zusätzlichen Andachtsübungen begonnen. Aḥmad Ġazzālī hält fest, dass die Rezitation des dikr und von Koranstellen den Abschluss des Ritualgebets darstellten. Sie waren jedenfalls nicht als Einleitung zum samā $\bar{c}^{c}$ gedacht. Um 1100 dürfte noch klar zwischen $\operatorname{dik} \mathrm{u}$ und $\operatorname{sam} \bar{a}^{c}$ unterschieden worden sein.

Vieles spricht dafür, dass sich in dieser Hinsicht im 13. Jh. Veränderungen ergaben. F. Meier macht auf Auszüge aus einer Abhandlung des Yahyā b. Sayf ud-Dīn al-Bāharzī (gest. 126o in Bukhara) aufmerksam. Gemäss dieser Darstellung wollte sich bei einer Sam $\bar{a}$-Veranstaltung bei niemandem ein Dawq-Erlebnis einstellen. Bāḩarzī habe zur Steigerung der Emotionen unter den Beteiligten zum

\footnotetext{
475 Op. cit. 128-132.

476 Meier, op. cit. 128-130, verdeutlicht diese Kombination von dikr und samāc.
} 
Einfügen einer gemeinsamen $\underline{D} i k r$-Übung geraten. Zwar sind $\underline{\text { dikr }}$ und sama $\bar{a}^{c}$ auch in diesem Beispiel voneinander getrennt. Und die Verbindung ist hier nur für den einen konkreten Fall belegt. Dennoch ist damit der Grundstein dafür gelegt, dass die beiden Methoden miteinander verknüpft werden. Jedenfalls wird die Dikr-Rezitation in diesem Beispiel in den Dienst des Samā'-Erlebnisses gestellt. Bāharzī fügt erläuternd hinzu, dass die Dikr-Übung innere Blockaden lösen könne, die dem Eintreten der Ekstase im Weg stehen.

In einem weiteren Stadium der Entwicklung wird das Gottgedenken (dikr) sozusagen selbstverständlich dem sama $\bar{a}^{c}$ vorangestellt. Ibn Batțūta berichtet jedenfalls von der Kombination dieser beiden Elemente im Rahmen einer RifāciyyaVeranstaltung, an der er während seines Aufenthalts in Wāsit (Mesopotamien) teilgenommen habe.

Beim zweiten Typ jedoch ist der samác $\bar{a}^{c} \operatorname{dem} \underline{d i k r}$ ein- und untergeordnet. ${ }^{477} \mathrm{~F}$. Meier bezeichnet diesen Typ als $\underline{d i k r}$, nicht als samāc . Er stellt diese Spielform dar, indem er auf eine von F. Köprülü beschriebene Dikr-Veranstaltung der Yasawiyya aus dem 16. Jh. zurückgreift. Demnach hocken die Angehörigen des Ordens beisammen und halten bis um Mitternacht mit grosser Ehrfurcht Dikr-Übungen ab. Diese Übungen werden durch das Singen von als hikmet ("Weisheit") bekannten geistlichen Liedern unterbrochen. Diese SamācTeile sollen die Derwische anregen und ihnen ein mystisches Erlebnis ermöglichen. Damit wird also der $s a m \bar{a}^{c}$ Mittel zur Steigerung der Wirkung des dikr.

Die Sama $\bar{c}$-Partien sind hier zu Ruhepausen geworden, bei denen sich die Teilnehmenden erholen. Danach folgen erneute Rezitationen von Dikr-Formeln. Sie bilden die Grundierung, sozusagen den basso ostinato. Später schliessen sich weitere $S a m \bar{a}^{c}$-Teile an. Bei dieser Form allerdings hat der sama $\bar{a}^{c}$ das Tanzelement eingebüsst und ist zu einem eigentlichen Zuhören reduziert worden. Der $\underline{d i k r}$ selbst hat jedoch an Intensität gewonnen

477 Meier, op. cit. 130-132. und ist um Bewegungselemente erweitert worden. F. Meier illustriert diese Spielform des $\underline{d i k} r$, indem er eine Veranstaltung der Dayfis in Alexandrien beschreibt, die er 1948 beobachten konnte. ${ }^{478}$

F. Meier unterscheidet in seinen Überlegungen zum Derwischtanz zusammenfassend die folgenden Spielformen: ${ }^{479}$

1. den reinen dikr (das Gottgedenken im grossen Rahmen einer Veranstaltung in der Gemeinschaft)

2. den $\operatorname{sama}^{c}$ (das Musikhören mit Tanz) und

3. die Mischformen von $\underline{d i k r}$ und samā mit den beiden folgenden Spielarten: a. der dikr ist dem sama $\bar{a}^{c}$ untergeordnet und b. der $s a m \bar{a}{ }^{c}$ ist dem $\underline{d i k r}$ untergeordnet.

Gemäss F. Meier ist der samā $\bar{a}^{c}$ als solcher auch aus dem profanen Leben bekannt. ${ }^{480}$ Auch beim mystischen sam $\bar{a}^{c}$ hörte man Lieder, die von einem Sänger vorgetragen wurden und von Instrumenten begleitet werden konnten. Die theoretischen Abhandlungen der Sufis enthalten klare Angaben dazu, welche Instrumente zugelassen sind, welchen Anforderungen die Sänger genügen müssen und welche Art von Gesängen im Rahmen eines mystischen $s a m \bar{a}^{c}$ überhaupt vorgetragen werden durften. Diese Bestimmungen stellten sicher, dass sich der mystische vom profanen sama $\bar{a}^{c}$ abgrenzen liess. Sie garantierten anderseits auch, dass Sama $\bar{a}^{\mathrm{c}}$-Veranstaltungen die šarí $a$-rechtlichen Bestimmungen respektierten. ${ }^{481}$

F. Meier bezeichnet den $s a m \bar{a}^{\varsigma}$ als künstliche, domestizierte Form des Hinhörens. Sie ziele auch

478 Bei den Dayfís handelt es sich um einen Zweig der Halwatiyya; vgl. die Beschreibung bei Meier, Derwischtanz $132 \mathrm{f}$.

479 Meier, op. cit. 135. Die Übersicht führt jene Form des dikr nicht auf, die der einzelne Sufi in der Klausur praktiziert.

$480 \quad$ Op. cit. 122.

481 Traditionalistisch orientierte Gelehrte haben die Sama $\bar{a}$-Veranstaltungen dennoch vielfach kritisiert. Auf diese Debatten soll hier nicht im Detail eingegangen werden. Für zusätzliche Informationen dazu wird auf die Literaturangaben in Anm. 465 verwiesen. 
darauf ab, Emotionen zu wecken, und lenke sie in bestimmte Bahnen. Die Entzückungen der Ausübenden werden häufig im Tanz aufgefangen. Es ist dies auch der Grund dafür, dass F. Meier den samā $\bar{a}^{c}$ als Derwischtanz bezeichnet. Das bekannteste Beispiel dafür stellen zweifellos die Tänze der Mawlawiyya dar. ${ }^{482}$ Es ist allerdings festzuhalten, dass auch die Angehörigen der aus Nordafrika und Ägypten bekannten 'Īsāwiyya letztlich tanzende Derwische sind. Auch bei ihnen zielt der Tanz darauf ab, die Ekstase zu erzeugen. ${ }^{483}$

Die theoretischen Schriften legen den Beteiligten allerdings nahe, sich solange als möglich gegen diese Bewegungen zu sperren. Man soll dem inneren Drang erst nachgeben, wenn er einen einfach überkomme. Der Tanz ist damit also Folge des Verlusts der Selbstkontrolle. Es zeigt sich auch, dass die Beteiligten die Selbstkontrolle zu ganz unterschiedlichen Zeitpunkten und in unterschiedlichem Ausmass verlieren. Dies kann zu einem ungeordneten Aufstehen und Sich-Hinsetzen der Adepten führen. F. Meier macht auf die Aussage eines Mystikers aus Bagdad aufmerksam, der die Sufis beim sam $\bar{a}^{c}$ mit einer Herde von Schafen vergleicht, in die soeben ein Wolf eingefallen sei. Der Tanz wurde vielfach auch von lautmalerischen

482 Meier, op. cit. 127, macht darauf aufmerksam, dass dem Tanz in der Mawlawiyya das unmittelbare Moment fehle. Er entwickelte sich hier vielmehr zum obligaten Mittel, um die Ekstase zu erzeugen. Damit veränderte sich auch der Charakter des Tanzes, der zu einem eingeübten Reigen mutiert. Bei dieser Form des Tanzes sind die Körperbewegungen und die Gesten klar vorgeschrieben. Die Musik bestimmt Anfang und Ende. In diesem Fall ist die Ekstase nicht mehr die Ursache, sondern der Zweck des Tanzes. Auch Ritter, Der Reigen 38-40, nennt das Herbeiführen der Ekstase als den eigentlichen Zweck des Tanzes. Der Tanz dürfte im Mawlawiyya-Orden auf die Anfänge der Bruderschaft zurückgehen und wohl von Sulțān Walad (Ordensvorsteher von 1284-1312) eingeführt worden sein.

483 Meier, op. cit. 131 (Anm. 63), warnt vor der Annahme, dass der Derwischtanz von schamanistischen Türken oder allenfalls unter ihrem Einfluss in den Sufismus eingeführt worden sei. Auch allfällige morphologische Abhängigkeiten könnten nicht über diesen Befund hinwegtäuschen.
Ausrufen (' $\bar{a} w$, 'cuy) begleitet. ${ }^{484} \operatorname{Im}$ Lauf der soeben erwähnten Übungen erreichen die Teilnehmenden idealiter einen Zustand der Entrückung, in dem sie eine grosse Nähe zu Gott erfahren.

\subsubsection{Initiationszeremonien}

In den hier vorgestellten Männerbünden werden zumeist auch Initiationszeremonien praktiziert. Dies trifft sowohl auf die Derwischorden als auch auf die Futuwwa- und Ahi-Bünde zu. Derartige Riten sind ebenso aus den Handwerksgilden bekannt. Sie spielen in modifizierter Form auch in den meisten Gruppierungen aus dem Umfeld der Gulāt-Schia eine Rolle. Diese Zeremonien stellen einen Höhepunkt im Leben des Adepten dar. Da dabei auch geheimes Wissen weitergegeben wird, ist der genaue Ablauf dieser Veranstaltungen oft nicht gesichert. Die weiteren Ausführungen vermitteln einen Eindruck von diesen Riten, wie sie wohl in Futuwwa- und Ahi-Kreisen praktiziert worden sind. Sie stützen sich in einem ersten Schritt auf Darstellungen bei Nāṣirī. ${ }^{485}$ Diese Initiationsriten und die dabei rezitierten Texte sind für die Untersuchung der Dokumente in Rollenform unmittelbar relevant.

Nāṣirī teilt die Angehörigen der Futuwwa-Tarīqa in zwei Gruppen ein, nämlich in Novizen (terbiye) und Vollmitglieder (ahī). Es ist die Aufgabe des $a h \bar{\imath}$, den Novizen in die Regeln, das Brauchtum und die Pflichten der fityān einzuführen. ${ }^{486}$ Der ahi figuriert also als Mentor und leitet den Novizen zu moralischer und ethischer Vollkommenheit an. Der Novize ist seinem Mentor absoluten Gehorsam schuldig. Auch ist er gehalten, die šarīa-rechtlichen Bestimmungen einzuhalten. Von besonderer Bedeutung ist, dass der Novize zu Dienstbereitschaft angehalten ist. Er soll sich seinem Mitmenschen gegenüber unabhängig von dessen sozialer Stellung dienstbereit zeigen. Dies stellt eine Grundvoraussetzung der futuwwa dar.

\footnotetext{
484 Meier, Derwischtanz 125.

485 Breebaart, Development $124 \mathrm{f}$.

486 Loc. cit. 125.
} 
Wer in einen solchen Bund aufgenommen werden will, muss diese Regeln kennen und einhalten. ${ }^{487}$

Sowohl Nāṣirī als auch Burgaāzī kennen unterschiedliche Grade der Zugehörigkeit zum Futuwwa-bzw. Ahì-Bund. Demnach gibt es die qawlīfityān und die sayfi-fityān. ${ }^{488}$ Die Bedeutung dieser Einteilung ist nicht restlos geklärt. Es ist anzunehmen, dass sich die qawli-fityān (von arabisch qawl: Rede) mündlich zur futuwwa und ihren Regeln bekennen. Letztlich aber handelt es sich bei ihnen um Mitglieder ohne eigentliche Initiation. Sie leisten wohl einen Eid und bringen damit ihre Zugehörigkeit zum Ausdruck, gelten aber nicht als Vollmitglieder des Bundes. Die sayfi-fityān (von arabisch sayf: Schwert) haben sich jedoch zum Einhalten aller Futuwwa-Regeln verpflichtet und sind im Rahmen einer Initiationszeremonie als Vollmitglieder in den Bund aufgenommen worden. ${ }^{489}$

D.A. Breebaart betrachtet die sayfi-fityān als die aktiven Mitglieder der Futuwwa-Bünde. ${ }^{490}$ Diese Klasse geht möglicherweise auf die als $\dot{g} \bar{a} z \bar{s} s$ bekannten Glaubenskämpfer zurück, die sich noch den altarabischen Futuwwa-Idealen von Kampfmut und Galanterie verpflichtet fühlten. Es kann auch sein, dass die sayfi-fityān sozusagen ein Echo der aus Bagdad und andern Städten des Abbasidenreichs bekannten 'ayyārūn-fityān sind. Hier wurde jeweils unterschieden zwischen den in eine eigentliche Frontorganisation eingebundenen Kämpfern und der grossen Zahl von Sympathisanten, die sich ihnen bei Bedarf anschlossen. Von Bedeutung ist sodann, dass Nāsirī im Futuvvet-nāme die sayfi-fityān als jene bezeichnet, die sich im Heiligen Krieg ( ist zwar typisch sufischem Gedankengut verpflich-

487 Loc. cit. 125; mit Verweis auf Nāṣirī, Futuvvet-nāme 319, in Iktisat Fakültesi Mecmuası, Istanbul University, 11 (1949-1950).

488 Vgl. bereits oben Kapitel 3.2 bei Anm. 251.

489 Gelegentlich findet sich ein Hinweis auf eine dritte Gruppierung, nämlich die šurbīs (von šariba, Verbalnomen šurb: Trinken). Sie dürften einfach das Salzwasser getrunken haben, das bei Initiationsriten den Anwesenden allgemein gereicht wird; vgl. dazu oben Kapitel 3.2 bei Anm. 253-254 und 315.

Breebaart, Development 126. tet und unterscheidet sogleich zwischen innerem (grossem) und äusserem (kleinem) ǧihād. Während sich der innere ğihād gegen die Triebseele (nafs) richtet und für den Mystiker im Vordergrund steht, richtet sich der äussere, also kleine, ğihād gegen die Ungläubigen an den Grenzen der islamischen Welt (dār al-islām). ${ }^{491}$

Aus Nāṣirīs Futuvvet-nāme geht hervor, ${ }^{492}$ dass die Initiation der sayfi-fityān acht Stufen umfasst:493 a. Nachdem der naqīb als Sprecher des terbiye, dessen Wunsch formuliert hat, in den AhiBund aufgenommen zu werden, bringt der terbiye seine Bereitschaft zum Ausdruck, sich mit Körper und Seele dem ahī zu unterwerfen; b. Der terbiye steht darauf während einer geschlagenen Stunde kerzengerade vor der Versammlung (qiyām). Er bringt dadurch seine Dienstbarkeit und seinen Respekt gegenüber dem ahī zum Ausdruck; c. Darauf schliesst sich das Trinken des Salzwassers an; ${ }^{494}$ d. Es folgt als zentrales Element der Zeremonie die Gürtung (šadd) des terbiye durch den $a h \bar{\imath}$ oder den naqīb. ${ }^{495}$ Der Akt der Gürtung bindet den Novizen an seinen $a h \bar{\imath}$ wie einen Sklaven an seinen Meister. ${ }^{496}$ Nach Ablauf einer Probezeit (e.), deren Länge nicht fixiert ist, f. löst der $a h \bar{\imath}$ oder der naqīb den Gürtel des Novizen

491 Loc. cit., 126; mit Verweis auf Nāṣirī, Futuvvet-nāme 333, in Iktisat Fakültesi Mecmuası, Istanbul University, 11 (1949-1950).

492 Die folgende Darstellung stützt sich auf Breebaart, op. cit. 127 f. Vgl. aber auch Taeschner, Zünfte und Bruderschaften $395 \mathrm{f}$.

493 Für die qawlī-fityān werden keine derartigen Riten abgehalten. Sie müssten sich allenfalls für die Aufnahme als Vollmitglied des Bundes entschliessen. Dann würden auch sie unter die sayfi-fityān aufgenommen.

494 Breebaart, Development 127; mit Verweis auf Nāșirī, Futuvvet-nāme 333, in Iktisat Fakültesi Mecmuası, Istanbul University, 11 (1949-1950).

495 Gemäss Nāșirī bringt die Gürtung (šadd, šedd) die Läuterung des Novizen von allen vergangenen Fehlern und Sünden zum Ausdruck. Ausserdem steht die Gürtung auch für Dienstbereitschaft, Edelmut und ausgezeichnete Qualitäten.

496 Bei Nāṣirī fehlt die Erwähnung von Schwert oder Messer, das dem Novizen gemäss Ibn Bațțūtas Beobachtungen bei diesen Zeremonien umgelegt wird; vgl. Kapitel 3.2 vor Anm. 261. 
wieder; g. Der Novize erhält jetzt auch die iǧāza bzw. den dastūr. Dieses Schriftstück legitimiert ihn, von nun an selbst Schüler anzunehmen; ${ }^{497} \mathrm{~h}$. Zuletzt bekleidet der naqüb den Initianden mit der libās al-futuwwa (Futuwwa-Kleidung). Sie besteht aus Hosen, die als šalwār bzw. sarāwīl al-futuwwa bekannt sind. Auch Ibn al-Mi'mār beschreibt diesen letzten Teil der Zeremonie. Demnach zieht der kabīr, wie Ibn al-Mi'mār den naqīb nennt, die Hosen zuerst selbst an und übergibt sie danach dem neuen Mitglied. ${ }^{498}$

Neben Nāṣirīs soeben vorgestelltem Futuvvetnāme sind weitere Futuwwa-Schriften bekannt, die jeweils andere Aspekte der Zeremonien in den Vordergrund rücken, jedoch kein gänzlich anderes Bild von den $A h \bar{\imath}$-Bünden und dem in diesen Gruppierungen gepflegten Brauchtum entwerfen. Ergänzend sei vielleicht darauf hingewiesen, dass im Rahmen des Initiationsrituals die Haare des Novizen geschoren wurden (tirāš), was z. B. aus dem persischen Sufismus bekannt ist. Ausserdem wurde dem Novizen bei dieser Zeremonie die charakteristische Mütze aufgesetzt. ${ }^{499}$ Die Gürtung ( $\check{s} a d d)$ ist insofern von besonderem Interesse, als das Layout gerade früher Dokumente in Rollenform (14. Jh.) als Anspielung auf diese Zeremonie verstanden werden könnte. Auf diesen frühen Dokumenten dominieren Medaillons bzw. Knoten, die als Reminiszenz an diese Gürtungszeremonien gedeutet werden können. ${ }^{500}$

497 Für eine solche iğāza aus der Rifāiyya vgl. Berlin, Staatsbibliothek, Ms. or. fol. 1622 (Dokument in Rollenform).

498 Vgl. zur Darstellung dieser Zeremonie bei Ibn alMi'mār: Taeschner, Zünfte und Bruderschaften 137 (!), auch 139, 142 und 156.

499 Zur Bedeutung der Kopfbedeckung für die Zugehörigkeit zu einem Derwischorden vgl. bereits Kapitel 2 (mit Anm. 213), mit Verweisen auf Th. Menzel, J.W. Frembgen und Müstaḳimzāde, Traktat über die Derwischmützen.

500 Vgl. ausführlicher Nünlist, Devotion and protection: Amuletic scrolls dating from the 14th century 507-512. 